\title{
A STUDY OF BARRIERS TO ONLINE LEARNING IN DISTANCE EDUCATION IN CHINA
}

WANG QIFU, BSc, MEd

Thesis submitted to the University of Nottingham for the Degree of Ed.D in Lifelong Education 


\section{ABSTRACT}

China's 'Modern Distance Education' is a government-led initiative prompted by the need to widen access to higher education and by the opportunities offered by the development of a widespread infrastructure of information and communications technologies. Distance education using television, radio and other technologies has a long history in China, but the advent of computer communications opened new possibilities for promoting educational development and the policy goal of modernisation.

Distance education in China now involves online learning, to various degrees. However, the effectiveness of online courses depends on learners accessing them and using the resources provided. Does this happen? How well do learners manage their online learning? What barriers do they encounter? This thesis examines these questions through a study of adult distance learners based on analysis of a survey of 2931 learners and in-depth interviews with 21 learners and distance education experts in several locations. I find that:

(1) The barriers to online learning faced by the sample learners are of seven types: communication and interaction; teaching and courses; learning resources; learning support services; external support and economic burdens; computer and network operation skills; and conditions for accessing the Internet.

(2) Among the seven types of barrier, the 'communication and interaction' barrier is not only acting as the most important one faced by these learners, but also exists as a markedly independent one.

(3) Improvements in 'communication and interaction' are the most effective in overcoming the other barriers and also contribute to increasing 
the learners' learning efficiency. This lead to the perception that working on 'communication and interaction' is very likely to be the best starting point for tackling barriers to online learning.

According to these findings, I believe that if the situation of 'communication and interaction' in online learning can be improved for online learners to meet their desire for 'sociability', and once they can thus establish their own 'learning communities' and form relatively stable 'student-to-student' relationships, and 'student-to-teacher' relationships, other learning barriers will be reduced as well. Hence, I argue that we should always pay attention to making 'communication and interaction' occur effectively for online learners in the learning process. We should consider the matter of 'interaction' not only in the delivery process of teaching and tutoring as well as in learning activities, but also in the production of teaching materials and in the provision of learning materials, as well as in the building of learning environments. In a word, it is necessary to put the whole matter of 'interaction' at the core of the instructional system design for online learning.

Key words:

learning barriers, online learning, distance education, adult learners, interaction 


\section{ACKNOWLEDGEMENTS}

Today, as I am finishing the final draft of my thesis and preparing to submit it, I feel as though a great weight has been lifted from me. Frankly speaking, it was very hard work for me pursuing the EdD study in an English university on a part-time basis, while I had heavy commitments as a top manager in my organisation and as the father of my daughter and the husband of my wife, as well as the son (son-in-law) of my parents. I felt it was almost an impossible mission for me to do my research while I was involved in endless jobs and business travels. I nearly had to give up my EdD study in the years of 2005-2006 when I was suffering from fatigue and hypertension because of staying up late frequently. Fortunately, after suspending my studies for 2 years, encouraged by my supervisor and my family, I made a fresh start.

Today, when I look back on my EdD study, I fill my mind with a myriad of thoughts and ideas. I am particularly grateful to my sponsors, supervisors, family, friends and colleagues. I could never have finished my research and thesis without their support. Here, I would like to express my deep gratitude to:

(2) The Sino-British Fellowship Trust, which kindly sponsored the whole tuition fee of my EdD study. The unconditional financial support made me realise that my obligation should be 'hold on to the end' as well as 'never give up'!

(-) Mrs. Anne Elizabeth Ely, Chairman and Honorary Director, Sino-British Fellowship Trust, who kindly facilitated my application for grants approved and kept on paying attention to my EdD study. Her expectation 
and encouragement to me was a powerful driving force to my study.

(2) Professor John Morgan, my supervisor at the University of Nottingham, who introduced me into the EdD programme, communicated my study progress with Mrs. Anne Ely, guided me in undertaking my research, encouraged and pushed me to keep going. Especially, after 2 years of suspension of my studies because of my health, it was he who encouraged and instructed me to make a fresh start to carry on my study. Otherwise, I should have dropped out of the programme.

(4) Professor Chris Atkin in Faculty of Education, Liverpool Hope University, who was my co-supervisor when he worked in the University of Nottingham, guided me in ascertaining my research topic and questions, and instructed me on research methods.

- Professor Bernadette Robinson, who carefully read my thesis twice and gave me very detailed comments and advice, which helped me improve my thesis significantly.

- Professor Bob Fryer, former Director of Widening Participation in Learning in the Department of Health, my friend in UK, who proofread my thesis very carefully and did his best to correct my English. His efforts helped me to polish my thesis.

(2) Dr. LI Fengliang, Associate Professor in Tsinghua University, my friend in China, instructed me in the statistical analysis of my research data. His Insights inspired me to seek for more research findings.

- Danqing Huang, my friend and colleague in the Open University of China, gave me much advice on my research work and encouraged me when I was enmeshed in difficulties.

Bing Zhang, my wife, who always supported and pushed me to study, 
cheerfully took on most of the household duties and took care of our daughter and parents, despite her busy work as a HR manager. Especially, she always encouraged me with 'hold on to the end' as well as 'never give up'!

(-) Sophia G.F. Wang, my lovely eight years old daughter, whose growing up accompanied with my busy work and hard study but lacked of fun time with Dad, joined the 'supporting team' with Mum and grand-parents to encourage me with 'hold on to the end' as well as 'never give up'!

(). The O Institute, which provided me with the research environment and conditions, and enabled me to carry out such a large sample research.

With my heartfelt thanks to everybody!

September 30, 2011 



\section{TABLE OF CONTENTS}

ABSTRACT

CHAPTER 1: INTRODUCTION

1 Research Context 13

1.1 Brief Introduction to the Development of Modern Distance Education in China............13

1.2 Problems in the Development of Modern Distance Education in China. 16

2 Research Motivation 20

3 Research Aims 24

4 The Framework of the Thesis.

CHAPTER 2: A LITERATURE REVIEW: FROM LEARNER CHARACTERISTICS TO BARRIERS TO ONLINE LEARNING

1 A Review of Foreign Literature on Learners' Characteristics ................... 35

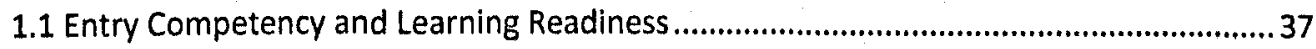

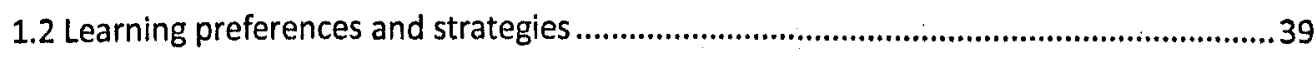

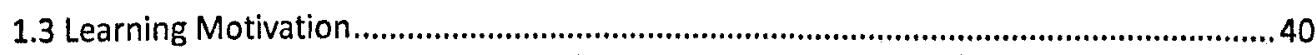

2. A Review of Domestic Literature on Learners' Characteristics................. 41

2.1 Most learners are adults in employment..................................................................4 41

2.2 Marked Difference in Demographic Characteristics .......................................................4

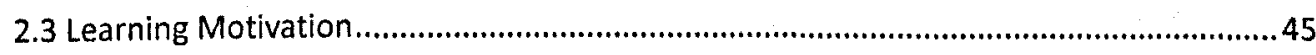

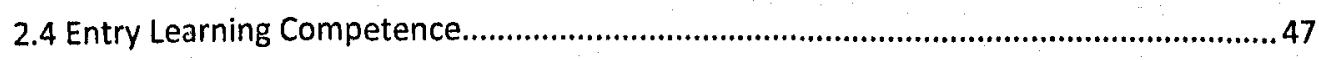

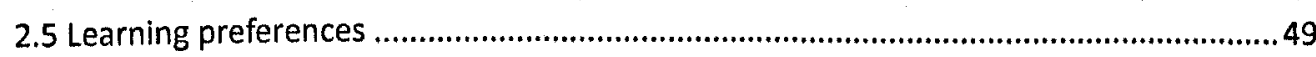

3 A Review of Foreign Literature on Barriers to Learning ................ 51

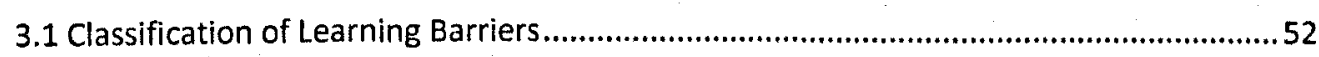

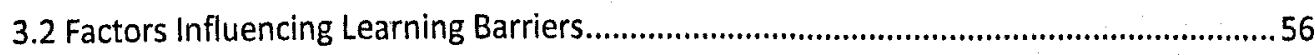

3.3 Suggestions for Overcoming Learning Barriers .......................................................... 58

4 A Review of Domestic Literature on Learning Barriers ................. 62

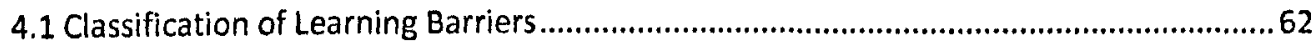

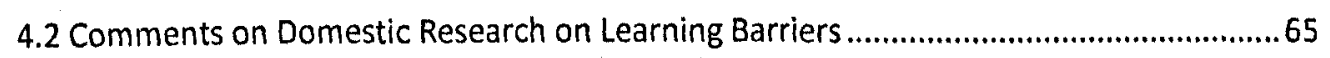

5 An Initial Conceptual 'Framework' of Learning Barriers facing Online Learners .............................................................6 66 


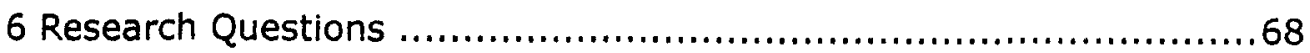

7 Research Hypothesis in Need of Empirical Test ............................69

8 Summary: From Leamer Characteristics to Leamer Barriers .......................70

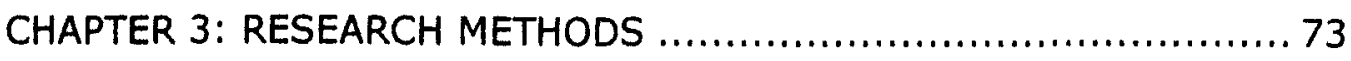

1 Choice of Research Methods................................................. 73

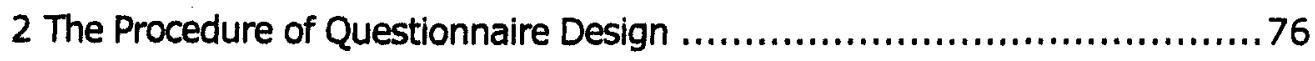

2.1 Establishing an Analytical Framework......................................................................76

2.2 Preliminary Study: Developing a Draft Questionnaire ...............................................77

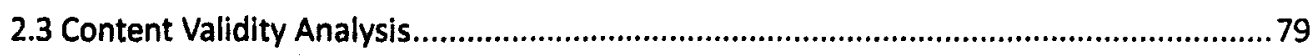

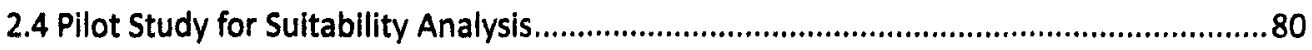

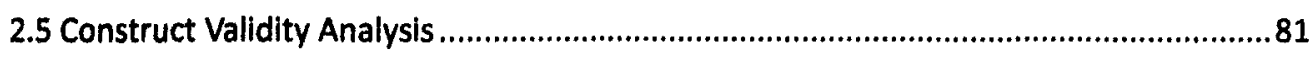

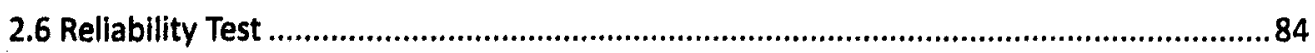

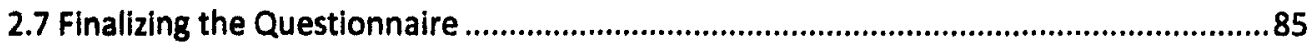

3 Sampling and Conducting of the Questionnaire Survey ...................87

3.1 Random Sampling and the Questionnaires' Collection...............................................8.87

3.2 Eliminating the Invalid Questionnaires ..............................................................89

4 Developing the Interview Outline and Conducting Interviews .............90

4.1 Developing the interview Outline ........................................................................90

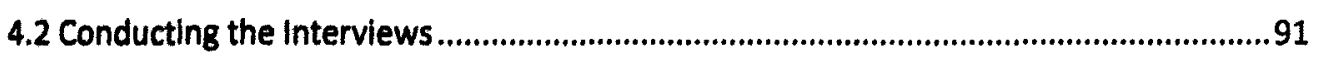

4.3 Principles in Using the Interview Materials.........................................................93

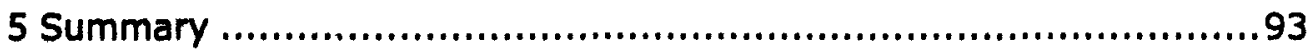

CHAPTER 4: THE CHARACTERISTICS, CIRCUMSTANCES AND ATTITUDES

OF DISTANCE LEARNERS................................................ 95

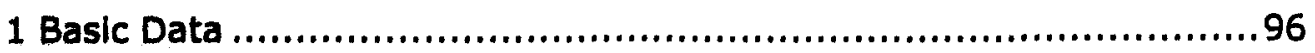

1.1 Gender and Ethnic Distribution of the Sample ......................................................96

1.2 Age Distribution of the Sample ...........................................................................97

1.3 Major Subject Distribution of the Sample ............................................................98

2 The Characteristics of the Sample Learners..................................99

2.1 Marital Status of the Sample Learners......................................................................99

2.2 Employment Status of the Sample Learners ........................................................ 100

2.3 Tuition Fees for Distance Education..................................................................... 101

2.4 Learners' Physlcal Heaith ................................................................................ 102

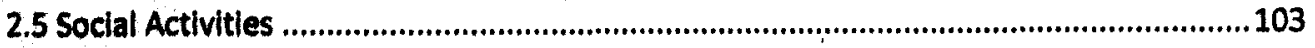

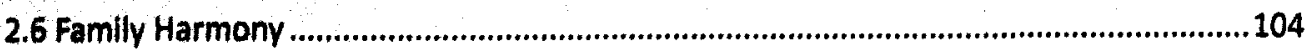


3 Empirical Tests on the Research Hypotheses Concerning Learners'

Characteristics.

3.1 Empirical Tests on the Different Characteristics of Learners Studying Different Major Subjects.

3.2 Comparison of Different Learners' Satisfaction

4 Summary of Learners' Characteristics....

CHAPTER 5: THE BARRIERS TO ONLINE LEARNING FACED BY DISTANCE LEARNERS

1 Learning Barriers facing Distance Learners .............................126

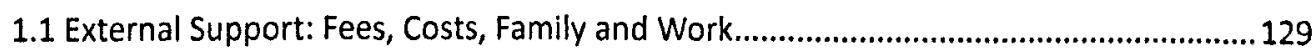

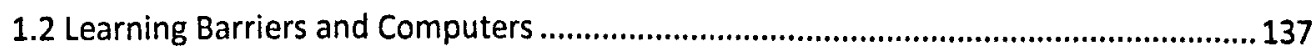

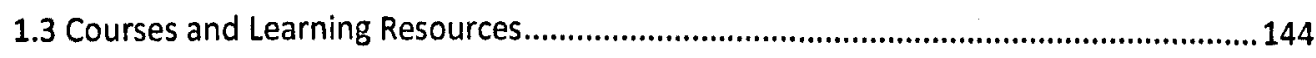

1.4 The Impact of Teachers' Lack of Professional Knowledge ........................................... 149

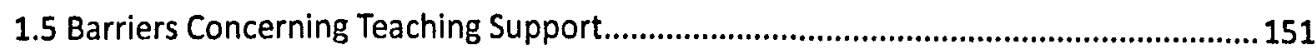

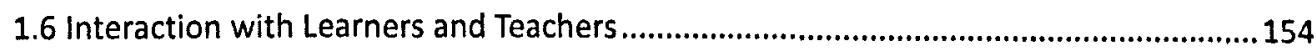

2 The Key and Significant Learning Barriers ............................ 157

3 Differences in Learning Barriers for Different Learners.....................161

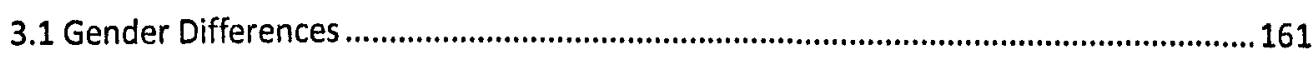

3.2 Differences in Learning Barriers for Learners with Different Fees Payment Circumstances

4 Interaction among the Different Learning Barriers.....................170

4.1 Correlation Analysis of the Various Learning Barriers............................................. 170

4.2 Interaction among Learning Barriers .......................................................................... 173

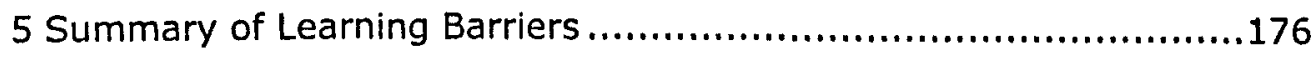

CHAPTER 6: LEARNING BARRIERS, ACADEMIC ACHIEVEMENT AND POSSIBLE REMEDIAL MEASURES ...................................179

1 Learning Barriers and Academic Achievement......................... 180

1.1 Impact from the Financial Costs of Learning and Academic Achievement ..................180

1.2 Teaching Materials and Academic Achievement...........................................................181

1.3 Teaching Support Service Problems and Academic Achievement ..............................184

1.4 Interaction Problems and Academic Achievement .....................................................185

2 Analysing the Impact of Possible Remedial Measures..................188 
3 Variance Analysis of the Effect of Possible Improvement Measures.

3.1 Gender Differences

3.2 Differences in the Expected Effect on Learners with Different Fees-Payment

Circumstances in respect of Different Improvement Measures.

4 Summary 196

CHAPTER 7: COUNTERMEASURES AND THEIR EFFECTS ON OVERCOMING BARRIERS TO ONLINE LEARNING 198

1 Introduction to The O Institution's Services 199

2 Countermeasures on the Barriers in the Area of Communication and Interaction201

2.1 Customer Contact Centre. .201

2.2 Optimizing the Online Course Forum. 204

2.3 Introducing Popular Online Chat Tools .205

2.4 Establishing Learner Communities Online 206

3 Impacts and Effects 207

3.1 Significantly Increasing the On-average Monthly Log-in Rate and Weekly Online Learning Time Length of Learners 207

3.2 Rises in the Continuous Course Registration Rate of Learners .208

3.3 Increasing Visits to The $O$ Institution Website 209

4 Summary

CHAPTER 8: SUMMARY AND CONCLUSION 214

1 Why This Topic?

2 Research Questions and Methods of Inquiry.

3 Research Findings.

3.1 A Brief Summary of the Main Findings

3.2 Have My Research Findings Basically Answered My Research Questions? 221

3.3 Comparing My Main Findings with Those of Other Researchers. 224

4 Further Possible Developments: Suggestions 225

4.1 Suggestions for The $O$ Institution. .227

4.2 Suggestions for Other Chinese Universities Delivering Online Learning ....................... 231

4.3 Suggestions for Administrative Authorities.

5 Some Limitations.

6 Concluding Comments. 
APPENDIX 1: QUESTIONNAIRE ON BARRIERS TO ONLINE LEARNING OF

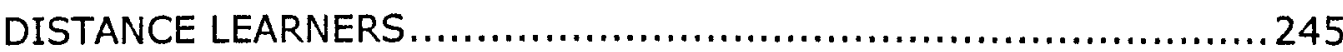

APPENDIX 2: LEARNER INTERVIEW OUTLINE............................253

APPENDIX 3: EXPERT INTERVIEW OUTLINE ...........................25

APPENDIX 4：远程学习者网上学习障碍调查问卷 …….......................2256

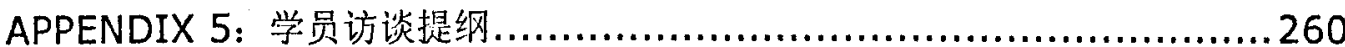

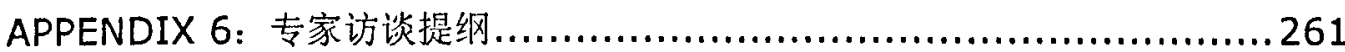

APPENDIX 7: FACTORS AND FACTORS' LOAD OF QUESTIONNAIRE ON

BARRIERS TO ONLINE LEARNING OF DISTANCE LEARNERS ...........262

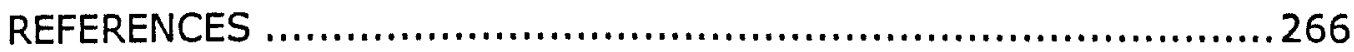

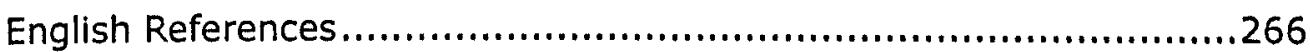

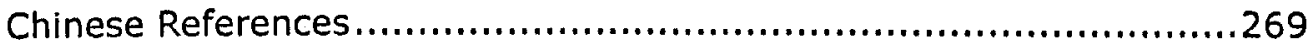




\section{Chapter 1: Introduction}

\section{Research Context}

\subsection{Brief Introduction to the Development of Modern Distance Education $^{1}$ in China}

In the late 1990s, the Chinese Government decided to embark on a vigorous expansion of higher education in the country. As a consequence, the scale of Chinese higher education has been expanded by more than $20 \%$ every year since 1999, and such expansion did not slow down until 2005. Even since 2005, the annual rate of expansion has only gradually decreased to below $20 \%$. Such speed of higher education expansion is rare and has been accompanied by a sharp increase in both the absolute number of students in Chinese higher education, and also in the rate of participation ${ }^{2}$. By 2002, the enrolment level, or participation rate, in Chinese higher education had reached $15 \%$; whereas in 1998 it was merely $9.8 \%$.

According to Trow's analysis of higher education's typical 'stages' of development (Trow, 1973) ${ }^{3}$, within barely five years China had achieved the historic shift from 'elite' higher education to 'mass' higher education, a situation which might normally take countries tens of years to secure. While

\footnotetext{
I In this research, I will not distinguish distance education and online education strictly, although there are substantial differences between them.

2 Usually measured as a proportion of the principal age cohort of higher education students, that is $18-21$ year olds.

Fccording to Trow's view, the nature of a country's higher education will not change until the proportion of the college-age youth provided with opportunities of accessing higher education reaches $15 \%$. When the proportion is below $15 \%$, higher education is defined as being at the stage of 'elite' higher education. Once the proportion reaches 15\%, higher education becomes 'mass' higher education.
} 
higher education in China has been in this phase of enormous expansion, distance education and online learning in China have also been developing quickly, contributing tremendously to the rapid transition from elite higher education to mass higher education in China.

Since 1990 s, with the rapid development and widespread application of Internet technology and satellite communication technology, the main model of distance education in China has also been undergoing an essential change. The previously dominant models of Radio and TV education in China, making use of broadcasting supported by extensive printed materials as well as correspondence education, is now being replaced by a predominantly online model of distance education. Today in China, online distance education, based on computer networks and satellite communication technology, with its distinctive character of two-way interaction, is commonly referred to as 'Modern Distance Education'.

In January 1999, the Ministry of Education issued and began to implement an 'Action Scheme for Invigorating Education Towards the 21st Century', approved by the State Council. The scheme aimed to take full advantage of the various possible applications arising from the rapid development of information technology, especially the speedy popularization of Internet technology, in order to communicate high quality educational resources from universities to urban and rural communities, to enterprises, to families and to individual learners, making it far more possible for a large number of citizens to share the opportunities and rights of using quality education resources and accessing higher education, and helping to bridge the gaps in the standards of education, economics and society between the Eastern and Western Regions of China, and between urban and rural areas of the country. 
In the Action Scheme, the government put forward a 'Modern Distance Education Project', based on developing an 'open education network' and establishing a 'lifelong learning system' for China. The Modern Distance Education Project was also listed as one of the six cross-century national educational projects. In March 1999, in launching the Modern Distance Education Project, the Ministry of Education approved four universities, including Tsinghua University and Zhejiang University, as the first batch of pilot universities to implement the Project. In the same year, the Ministry of Education issued a paper, entitled 'Opinions on Developing Modern Distance Education in China', which elaborated the guidelines, objectives and tasks of developing modern distance education in China, providing the guidelines in terms of its overall planning, demand-driven, extending openness and improving quality.

In ten years, modern distance education has already made an outstanding contribution to the popularization of higher education in China, and has already become the leading approach in the country for adult continuing education, at the same time promoting higher education's equity and popularity, and helping to create a lifelong educational system and learning society in China. According to official statistics, in 2006, undergraduate enrolment in China had reached 25.537 million, of which distance education undergraduate enrolment was 6.528 million, constituting some $25.6 \%$ of higher education enrolments and the enrolment of online undergraduates had reached 2.793 million, or $10.9 \%$ of higher education enrolments. By 2007, undergraduate enrolment in China had reached 27.215 million, among which distance education undergraduate enrolments amounted to 8.366 million and the enrolment of online undergraduates amounted to 3.105 million, with the proportion in higher education rising 
from $10.9 \%$ to $11.4 \%{ }^{4}$. From these data, it can be seen that the recent expansion of distance education and online education in China has been faster than that of traditional higher education, and, as a consequence, this necessarily raises questions about, and challenges for, quality, status and effectiveness of Chinese contemporary distance education and, especially of its rapidly growing online learning, and the ability of people to take full advantage of it as part of the overall expansion and reform of modern China's higher education system.

\subsection{Problems in the Development of Modern Distance Education in China}

There is a general rule, derived from both historical and international comparison that the rapid expansion of higher education enrolment in a short period tends to risk resulting in a reduction in quality (Walters, 2006). Some research suggests that the quality of higher education in China has indeed declined alongside the rapid development of higher education in the last decade or so (Bao, Wel, 2007; Cheng, Gang, 2006; Ma, Wanhua, 2002). An important issue, therefore, for China's modern distance education is whether, increasingly supported by information technology, the decline in quality often associated with large-scale and rapid expansion has indeed occurred and, if so, whether this decline can be halted while still maintaining both economies of scale and its openness to a wide range of participants.

Although there is little systematic published research on the influence of large-scale expansion resulting in a decline of quality, certain research does Indicate that online courses and learning resources that lack appropriate Instructional design usually fall to enable learners to learn effectively (Chen,

\footnotetext{
4 The statistics listed above are for diploma education. Originally, I planned also to collect data for non-diploma education, but, unfortunately, the statistical yearbooks do not contain the data on distance non-diploma education. However, it still can be seen that distance education and online education in China have been in rapid development.
} 
2005). In this research, the researcher found that online learners expected that online courses should be designed to take full advantage of adult learners' existing knowledge structure, experiences and abilities, providing every adult learner with an open online learning system with real choices, as well as with interactive space (Chen, 2005). Without this, it was believed, online learning resources could not be appropriately designed to support effective learning, and it was further suggested that there might also be a quality decline in online education along with the increase in online learner enrolments.

In addition to this apparent weakness, the development of modern distance education in China has been beset with many other challenges, besides the problem that the curriculum resources do not always meet the requirements or interests and abilities of adult learners or online learners. For instance, some researches have shown that learning online is still a kind of learning activity that is in reality practiced frequently by only a minority of distance learners. Thus, only one third of learners in the numerous distance education institutions in China reported that they learned online 'constantly', and more than half said that they only 'occasionally' used the Internet (Zhao, 2002) (according to the learners' own interpretation, 'constantly' means learning online at least one hour per day on average; whilst, 'occasionally' means accessing the Internet no more than one hour per week). A survey on a small scale in the institution that I was working in (hereafter referred to as 'The O Institution') conducted in 2006 showed that the average time spent on learning online of per head per week of the 'top' 50 out of 236 learners ('top' learners mean those spending most time learning online) from a certain learning centre was less than 30 minutes, whilst even the longest time spent online per week for one person was only approximately 2 hours. Given that the expectation was that part-time distance learners would spend at least 14 
hours per week in study, it can be seen that, at the time of the research, reported online study amounted to only a small part of these students' studies. $^{5}$

In model of online distance education, neither effective organization nor the successful delivery of teaching resources can be accomplished without attending to questions of the management and design of the online system. Amongst other considerations, that requires focusing on the form and presentation of teaching content, the design and opportunities for learner interaction in teaching activities, provision of arrangements for discussion of questions in the tutorials and other forums (including online synchronous and asynchronous sessions), the processes for providing feedback, the design and organization of tests and examinations, the tracking and recording the process of students' learning, information processing and the overall support for learners and the management of all online teaching and learning processes. None of this can be successfully accomplished without paying detalled attention to the design and management of online teaching and the learning platform. It is the platform for teaching and learning online that constitutes an essential element of the infrastructure for online education and through which teaching providers are able to conduct most of their teaching and Its corresponding management, and through which learners can subsequently carry out self-directed learning and interact with teachers and other learners, and through which institutions of teaching and learning support can establish systems to provide support for students and other services for teaching and learning. In this sense, ensuring that as far as technically, organisationally and financially possible, the teaching platform and learner management system and their associated online functions, Including the use of the Internet, and other learner support systems are all 
appropriate and accessible for both the tasks in hand and for the sorts of learners, and their skills and predispositions, expected to be recruited. Without such a well-designed platform, it is unlikely that the declared ambitions of the Chinese government and of providers such as The 0 Institution for the successful development of online learning will be successfully achieved.

But getting the 'system' side of the arrangements in order and working effectively is, of course, only part of the story. If we can assume that the technical and system arrangements have been well designed and are appropriate, accessible and useable (all of which are huge assumptions or tasks to be accomplished), then the learners themselves also need to be fully prepared and properly skilled and resourced to be able to engage in rewarding online learning. In this, a consideration of their circumstances, aptitudes and attitudes is vital. It would be not only a great waste of resources but probably also wholly demoralising those responsible for designing, implementing, funding and operating a modern online learning system if, in the event, the students were either unable or unwilling to avail themselves of it.

In fact, the two above-mentioned researches suggest that there exists a distinct gap between the learning behaviour of online learners in reality and in theory. If so, then we need to inquire as to what exactly are the factors that are apparently preventing learners in online education from effective engaging in online learning activities, including frequent use of the Internet, in their distance education studies? Further, we need to discover in what ways, if at all, are the learners' learning behaviour and, especially, their achievements impacted by a relatively low level of online activity? We should explore whether and to what extent there may be 'negative effects' from learners failing to use online resources or the Internet and what those are 
precisely. And we need to consider what appropriate countermeasures could be designed, especially as regards the detail of pedagogy, to encourage and support learners in online education to get them more used to learning online, and, it is to be hoped, to improve their learning experiences and the quality of the learning provided through an online programme.

\section{Research Motivation}

I have been engaged in the management of distance education since the early 1990 s, and now am working as a senior manager in a famous institution in China, which is committed to support for online learners. With a full experience of modern distance education in China, from its commencement through its subsequent development, I have become keenly aware of the tremendous (although often somewhat hidden) potential troubles associated with online teaching and learning, in spite of online teaching institutions' rapid development, as part of the widening along with the expansion of modern distance education in China. As mentioned above, some previous research has suggested that the majority of adult learners in online education tend to spend less time online than that is deemed sufficient to support effective regular online learning, despite the fact that they have actively chosen the online way to learn. Online education is based on the premise that learners should engage in online learning regularly with facilities and resources provided. If a majority of the 3 million Chinese online learners currently enrolled in the universities which are delivering online learning do not regularly and frequently engage in online learning, the vast amount of resources now provided online, the comprehensive online teaching systems and the service and supporting environments that learners have, all invested In and developed by the Chinese government, universities and enterprises, are not really being effectively used by online learners. In such circumstances, 
complex and sophisticated online interactions between learners and teachers cannot be conducted, and both the learning effectiveness and the learning outcomes and hence the overall quality of the online learning will almost certainly be adversely affected. If that is the case, that would represent not just a serious waste of education resources, but also would probably mean that large numbers of Chinese learners would miss out on the opportunities that good online facilities can offer to learn and to succeed. If learners cannot succeed in online learning, after making the active choice and paying a considerable sum of money, the sustained development of online education would also be at risk, especially where the traditional universities and private universities continue to expand enrolment and relax the restrictions on the age of enrolment, with the possible ultimate consequence that the policy support for modern distance education from government might consequently be cut back. So the problem of non-use or under-use of expensive online resources and facilities could easily come to constitute a significant issue in relation to government- or enterprise-provided online education's very existence, value and its potential for sustainable development.

Perhaps surprisingly, the existence of some evidence suggesting that many learners enrolled in online education in China appear neither to like using it nor frequently communicate online as part of their online learning activity has not, to date, attracted close attention of either online education institutions or scholars of distance education. Through a literature review of the reseaich, articles and books on distance education published in China, I discovered that, to date, there has been little systematic research in this field, particularly where the attitudes, orientations, preferences and behaviour of the learners themselves are concerned and of their actual or reported interaction with the online facilities and resources available. Among the few existing researches, with the notable exception of a small number of reports 
of investigations designed for online learners, in which such issues are indeed mentioned, there are only few examples of theoretical analysis and empirical research, especially of quantitative research, on the specific barriers facing online learners in using the Internet to learn, and there are scarcely any publications providing relevant suggestions or measures to overcome such barriers. Such a situation is not conducive to the sustainable development of online education.

The potential barriers to effective engagement in online learning are manifold, as we shall see later. Some will have their origins in the attitudes and behaviour of the learners themselves and of those people, with whom they Interact - family, peers, other learners, employers and so on. Other barriers may have more to do with the online learning environment itself - its design, the ease of access and use of any learning platforms and learner management systems, the software and courseware available. And still others may originate in the quality of learning support provided to online learners - from institutions, from teachers and advisors or from peer learners. The important point is to acknowledge that these barriers may exist and, if they do, they could considerably limit the use and effectiveness of online education and help us to understand why online learners appear to be somewhat reluctant to make use of the online facilities available.

In my view, The O Institution, where I currently work, will be confronted with a serious crisis of funding and even of its very existence in the event of It failing to recognize and tackle the many potential barrlers to the effective use of online resources, which I believe is becoming a defining predicament of modern distance education's development in China. Therefore, I am convinced of the necessity for systematic and comprehensive research on the barrlers confronting online learners, and for research aimed at helping and supporting learners to overcome those barriers and improve their learning 
motivation and outcomes. Only in that way will sustainable development of modern distance education be promoted on a large scale in China and the threatened crisis that The $O$ Institution might be confronted by possibly be overcome.

That is the prime motivation for me to undertake this research, in which both The $O$ Institution and I have invested a considerable amount of time and resources. Besides, The $O$ Institution is now facing fierce competition, triggered by more and more enterprises' and institutions' getting into the operation of modern distance education. A central question, therefore, for The $O$ Institution is how to secure service quality and respect for our brand and reputation in the face of this fierce competition in modern distance education in China. That is another motivation behind my research.

In summary, the main reasons for this research are therefore to help promote the healthy continuous development of the whole Chinese modern distance education (against the background of the rapid expansion of regular higher education in China), and to contribute to the improvement of The 0 Institution's online teaching quality, to enhance online learners' use of the facilities provided and to maintain or improve The $O$ Institution's market competitiveness. I intend to do this through a focus on the barriers learners face in using online learning and ways of counteracting these. The aim will be to attempt to identify the current barriers to utilising online resources and methods of learning amongst learners who are themselves enrolled in online programmes and for countermeasures to be proposed which online teaching institutions might apply in practice, so as to promote online students' active engagement in online learning activities, including greater use of dedicated online resources and of the Internet. I shall do this through a relevant literature review, by the use of a questionnaire survey on a large scale, and through in-depth interviews with key informants. It is hoped that, through 
this research, I can make a modest contribution to improving the use and quality of online learning both in China generally and in The $O$ Institution in particular.

\section{Research Aims}

The aims of this research are to manage to investigate what kind of barriers online learners might face and what we can do to help online learners overcome these barriers.

Based on my years' acquaintance with online education, on an initial literature review and some pre-interviews with some learners, I can now initially outline some possible reasons for an apparent unwillingness or Inability of learners to take advantage of online learning resources and facilities. They are as follows:

(1) Chinese traditional concepts and habits. Traditionally, Chinese education is teacher-centred and teaching oriented, in which, from primary school to university, students learn relatively passively, complying with teachers' plans in most cases. This traditional concept further emphasizes that students' learning outcomes are determined principally by the quality of teachers' teaching. Falling into the habit of passively accepting knowledge, which is promoted in such traditional education, many people are willing neither to explore actively nor to take responsibility for their own learning. Some observers, who hold to the idea of learners' dependence on teachers and who are used to traditional face-to-face teaching, believe that people cannot learn anything without classroom teaching or without face-to-face tutoring; others think that students who have already been used to learning mostly through printed teaching materials and notes, mostly provided by tutors and under thelr direct guldance, cannot develop the habit of learning and discussing with others online. 
(2) Achieving a diploma or degree is usually the prime motive for learning at a higher level in China. There is, in China, a long-established tradition of selecting talents through civil servant examinations, selecting successful candidates from and for all trades and professions through the public examination system. Accordingly, Chinese people have an almost inveterate habit of evaluating a person by his or her academic achievements and especially according to their certification. In Chinese society, having an educational certificate or diploma means being able to achieve a position, a salary or having a chance of getting a good job. Under the pressures of acquiring a certificate, people set out with a predominantly utilitarian attitude, and thus expect to engage in online learning with the primary, maybe even only, intention of acquiring a paper qualification, which can bring promotion, a pay rise and a kind of 'superiority complex', and not because of the specific learning advantages or benefits that online learning might bring. Generally speaking, the learners of such a type are concerned neither for whether they can acquire knowledge and understanding, nor whether they can improve their abilities effectively, through online learning or by participating in online learning actively. Thus, they will not spend time on learning online except insofar as it furthers their principal objective of securing the sought-after qualification. In other words, many online learners' prime motivation for their choice of online learning is seeking certification rather than acquiring knowledge, and their learning motivation is thus reflected in their learning behaviour.

(3) Online learners are also faced with competence barriers and with some technical problems of access. Using the Internet to learn, learners are required to be proficient in using computers and in negotiating and effectively utilizing online learning platforms, accessing and effectively browsing the Internet and sifting the results judiciously, and utilizing various interactive 
environments, materials and resources provided through online teaching platforms. Some elderly learners, who are perhaps suffering from fear of computers and Internet technology, might lack the necessary computer skills and self-confidence; and some learners in remote or rural areas, who seldom have opportunities to use computers and the Internet, might simply lack access to the necessary facilities, as well being in fear of using what are mostly unfamiliar computers and the Internet. Moreover, some other more technical factors, including the availability of computers, the local Internet environment, speed of broadband and relevant charges, might reduce learners' initiative in participating in online learning.

(4) Customized learning strategies and methods are sometimes somewhat lacking in the quality of the design and operation of online learning. Online education is a particular model of education, in which learners Inevitably are required to engage in an element of self-directed learning, with the help of dedicated online teaching resources and an interactive learning environment. Learners are required to understand their own learning preferences, build their own learning strategies and environments, which reflect their learning preferences and characteristics, apply their own learning styles appropriately, and develop their own personalized learning methods. However, a considerable number of learners have neither acquired such capabilities and the self-confidence to deploy them, often not having been properly trained in those aspects of online education and, in many cases, the learning environments and pedagogical methods which are deployed do little to develop and sustain such capabilities. As a consequence, in reality they cannot truly choose appropriate learning methods and strategies in accordance with their own learning styles, nor are they able to utilize the online resources provided and interactive learning environment effectively. As a result, lacking the requisite skills, they lose enthusiasm to participate 
actively in online learning.

(5) Online learning is also faced with conflicts over time. A majority of learners involved in online learning in China are working adults, with many responsibilities, tasks and demands arising from work, family, social interactions, entertainment and personal interests. It is difficult for them to manage their time for online learning properly. If they cannot manage their time for online learning effectively, this necessarily reduces the time that they are able, or willing, to spend actively online. Hence, a considerable number of learners cannot or do not engage in online learning frequently. Moreover, if their learning motivation is primarily on certification, they will not spend their limited time on online learning. Accordingly, learners cannot be expected to spend more time and energy on online learning unless their time management is improved and their learning motivation is changed.

(6) Online learners are also confronted with barriers to interaction. Research in traditional classroom learning indicates that interactions between learners can promote learners' academic achievement, which is known as the 'Peer Effect' (Hanushek, 1995; Zimmer and Toma, 2000). Learners can thus share their learning experiences, problems and methods of tackling issues through interaction with their classmates, and can support and encourage each other when suffering pressures and setbacks, so as to promote their learning efficiency and academic achievement. Indeed, regular interaction between online learners is considered as essential for online education's success by many experts, researchers and practitioners in online education (Muilenburg and Berge, 2001, 2005). Porter and Strum (2006) found that successful adult literacy learners were related to a good relationship with the instructor. Therefore, insufficiency of interaction in present Chinese online education might be an important factor, resulting in learners' reluctance to use the Internet to learn. This lack of interaction, or the existence of barriers 
to effective interaction, may result from a variety of factors, including the teaching and learning model of online education espoused, the particular instructional design deployed and the production quality of Chinese online courses or courseware, the actual availability and attractiveness of online resources, the provision of timely tutoring (or its absence) from teachers online, and the aforementioned lack of training and development for students in self-activated and online learning techniques. Some online education institutions, without the benefit of any relevant research on online education's essential nature and learners' characteristics, mechanically copy the models deployed in face-to-face teaching into their online teaching platforms and practices, attempting simply thus to replace face-to-face teaching with online courses or courseware. In that case, neither the specific forms and functions of online teaching and learning can be realized in the course design nor, importantly, can the particular ways of promoting and encouraging learner-to-learner interaction be achieved. Some institutions directly put out original classroom and lecture-based teaching programmes as so-called 'online' courses or courseware, without being based on any effective or relevant online instructional design. Such programmes are often lengthy and tedious, and so III-suited to an online form, and so learners cannot spare enough time and patience to follow them. On some institutions' online teaching platforms, there is nothing but teacher's courseware, thus learners can hardly approach other learning resources or engage in dialogue with other online learners; some online teaching platforms lack any kind of effective interaction environment, on which almost all learners are limited to a few online chatrooms, where it is hard for learners to find classmates and teachers with whom to discuss ideas and problems, and, in any case, there are no teachers online to give tutoring or respond to questions (Leng, Wang, and Dlao, 2005; Wang, $\mathrm{Ma}$, and $\mathrm{He}, 2007)$. 
Above I have suggested an initial list of some of the main potential barriers that online learners in Chinese online education might be confronted with, which I have deduced from my own working experience and from my preliminary literature review and discussions with learners and others involved in online learning. What is now needed is to enquire into these issues, and others, in a more systematic and scientific way. A whole series of issues, as following, are needed to be researched more systematically than can be deduced from my simple, preliminary list. For instance, if these barriers do exist and can be identified, are they perceived as being a problem and do they matter? Are there some omissions in this summary of the main barriers to participate in online learning? If so, are those missing barriers of particular importance? Do some learners respond differently to the various barriers to online learning? Do the various barriers result in the same sorts of impacts for all learners, or not?

As suggested above, there are likely to be many different factors on the side of the learners leading to learners' willingness or reluctance to make frequent use of the Internet to learn, such as traditional educational concepts and habits, learners' motivation, learning strategy, time management, barriers in interaction and technical barriers. Among these potential factors, of particular interest to me is the whole question of the barriers to interaction amongst students enrolled in online programmes. Given that a majority of current Chinese online learners are employed adults, which is one of their major characteristics, engaging in study with the hope of increasing the skills, aptitudes and knowledge needed in their jobs, I wonder whether the attractions of studying online and of using the Internet for learning might be strengthened by improving the opportunities for effective online interaction between learners. For example, this might satisfy adult learners' apparent needs for a social dimension to their work and study behaviour, helping to 
establish some communities of interest or practice amongst them and overcoming some of the problems of isolation typically experienced by many distance learners. And once the learning communities, including both virtual and physical communities (and it is of importance that emotional learning communities should be developed) are built up as an element of learners' online learning experiences and classmate relationships and even friendships are developed between learners, could learners' enthusiasm for using the Internet to communicate and learn be promoted?

Therefore, summarised in more detail, my research aims are to investigate the following issues:

Firstly, who are the learners involved in online learning? What are their demographical features and learning characteristics? What appear to be their original learning abilities? Are there any differences in the learning characteristics and abilities of learners from different groups?

Secondly, what kind of barriers might online learners confront in online learning? These barriers might include factors in learners' personal lives, home and work circumstances, lack of computer skills, poor quality or fitness of courses and teaching software, shortage of learning support services, insufficiency of a social interaction environment or in the learners' own motivation, attitudes or preferences. All potential barriers described above will be reviewed in this inquiry.

Thirdly, to what extent does the issue of the absence of, or relatively limited opportunities for, social interaction constitute a common problem or barrier for learners enrolled in online programmes? Do different groups or sorts of learners experience this barrier and its impact differently? What, if any, is the relationship between this barrier to interaction and other identified problems or barriers faced by these learners? 
Fourthly, what kind of strategies and countermeasures can be taken to help online learners overcome the difficulties and barriers in online learning? How will it be possible to verify the effectiveness of those strategies and countermeasures?

The thesis will especially seek to discuss whether those learners who have more opportunities of interacting with teachers and classmates can improve their learning outcomes. Also the effect of the countermeasure of improving interaction and that of other measures (for example, offering free accessing to the Internet to learners) will be compared.

Based on the conclusions of my empirical investigation of the issues mentioned above, I will present advice on policy improvement and reforms to the model of online education in China and the advancement and upgrading of The O Institution's online teaching platform and learning support services.

\section{The Framework of the Thesis}

This is the way in which the thesis is organised and my research is reported.

Chapter 2: Literature Review. In this chapter, I survey the current domestic and foreign literatures on the characteristics of learners and the barriers to learning, for both adult learners generally and online learners in particular. This chapter contains four parts as follows: (1) a review of foreign literature on the characteristics of adult learners and online learners; (2) a review of domestic literature on the characteristics of adult learners and online learners; (3) a review of foreign literature on the barriers to learning for adult learners and online learners; (4) a review of domestic literature on barriers to learning for adult learners and online learners.

On the basis of the literature reviews, certain research hypotheses will be 
raised, which can be tested empirically, and which will be developed in Chapter 4 and 5 , and will constitute the basis on which a 'framework' of barriers to learning of The $O$ Institution's online learners will be built up.

Chapter 3: Research Methods. In this study, quantitative research and qualitative research are combined, the former taken as the principal method, supplemented by the latter. The quantitative research is based on data collected through a questionnaire survey, and the qualitative research was collected through interview. The development of the questionnaire, sampling methods, collection of data and the technology applied in data analysis will be described in this chapter, and the development of interview's outline, sampling of interviewees and the principles of using the interview materials will be considered.

The conclusions suggested by the empirical analysis will be laid out in the following three chapters, Chapter 4,5 and 6.

Chapter 4: Empirical Analysis of Online Learners' Characteristics. The picture of the learners sampled will be shown through statistical methods, Including frequency analysis, means comparison and cross-tabulation, so as to give an answer to the question of 'who exactly are the learners involved'.

Chapter 5: Empirical Analysis of the Barriers Confronting Learners in Online Learning. In this chapter, the barriers faced by various learners in online learning will be systematically analyzed through statistical and quantitative methods, such as frequency analysis, means comparison, cross-tabulation and multiple linear regression. In addition, I will address the issue of whether learners of different types are faced by different barriers in learning, and consider what the relations between barriers of different types are. Not only data analysis but also interview materials supporting the outcomes of data analysis will be laid out in this chapter. Based on the data 
analysis and interview materials, certain of the hypotheses suggested in Chapter 2 will be tested in this chapter.

Chapter 6: Learning Barriers, Academic Achievement and Possible Remedial Measures. This chapter consists of empirical analysis of the measures taken to eliminate barriers to learning and to improve learning outcomes. The issue of what measures can be taken to reduce or eliminate barriers in learning and improve learning outcomes will be addressed through statistical and quantitative methods, including frequency analysis, means comparison, cross-tabulations, and so on. The diversity of different measures' effects will also be analyzed. Besides data analysis, interview materials will be laid out in this chapter to support the outcomes of data analysis. Based on data analysis and interview materials, some of the research hypotheses proposed in Chapter 2 will also be tested in this chapter.

Chapter 7: This chapter will examine the countermeasures taken by The O Institution for overcoming the barriers to online learning which the online learners were faced with, as well as providing an analysis of their apparent effects.

Chapter 8: Summary and Conclusion. In this chapter, a summary of my research findings and limitations will be presented, and some suggestions proposed, which might promote the development of modern distance education in China.

Questionnaire and interview outlines in both English and Chinese are attached as appendices. 


\section{Chapter 2:}

\section{A Literature Review: From Learner \\ Characteristics to Barriers to Online Learning}

The main issues, researched through empirical investigation later in this study, are what barriers learners in current online distance education in China are confronted with, and what measures can be taken to weaken, counteract and maybe even eliminate the negative impacts that the various barriers exert on learning effectiveness and outcomes. Before carrying out empirical research, it Is, of course, necessary to systemically review the methods, contribution and conclusions (as well as weaknesses) of existing studies of online learners' learning characteristics, the barriers they face in online learning and the countermeasures (if any) taken to combat them. Moreover, the literature of not only specifically online learners' learning characteristics and the barriers facing them in learning, but also the generality of adult learners' learning characteristics and the particular barriers to learning that they also face, in turn, will be reviewed. Most present learners in the modern distance education system in China are also adults with working experience (mostly currently in paid work) and given this overlap with a principal characteristic of online learners, it might be instructive to understand the barriers they feel that they face.

Throughout this chapter of literature reviews, it should be borne in mind what exactly constitutes my interest in inquiring into what previous research suggests is important about the characteristics or attitudes or behaviour of adult and online learners, or about the context, circumstances or 
environment in which they study, or about the nature and character of learners' interaction with each other and their tutors. All of this only really matters, in the particular context of this thesis, in so far as these various factors either directly constitute or are closely linked to potential barriers to effective online learning amongst learners engaged in online learning programmes of study.

In addition, it will be necessary in this chapter to sort out the literature centred especially on Chinese learners, who are the focus of investigation in this study, and that which draws evidence from studies in other countries. In the review of the relevant literature, I want to explore whether or not the country or world region from which learners are drawn and where they are registered to study is relevant. So, I intend to review separately the literature centred on Chinese studies and that which deals with other countries.

Hence, the review in this chapter falls into four sections: (1) a review of foreign literature on the characteristics of adult learners and online learners; (2) a review of domestic (Chinese) literature on the characteristics of adult learners and online learners; (3) a review of foreign literature on the barriers to learning confronting adult learners and online learners; (4) a review of domestic literature on the barriers to learning confronting adult learners and online learners.

\section{A Review of Foreign Literature on Learners' Characteristics}

Generally speaking, in the existing foreign research on adult learners' and online learners' learning characteristics, analysis is carried out according to the following aspects:

Demography. Under this heading are included certain demographic factors such as gender, race, culture, age, educational background/literacy, 
working conditions, career, marriage, offspring, parents' education and location, answering the question of who are the people involved in adult learning or Web-based learning (Livneh, 1988).

Psychography. Shipp and Mckenzie (1981) examine the psychographic differences between adult learners and non-adult learners, including their orientation towards the future or past, their time sense, their tendency between sense and sensibility, their feelings of freedom and choice, adventure, mental stability, mobile location.

Disease and Health. Walker (1999) makes a special study of diabetic learners' characteristics, pointing out the differences in social and family support that diabetic learners receive in adult learning and the Impact the differences in their knowledge of diabetes and certain living habits exert on their learning.

The huge amount of literature relating to these three types of data collected on adult learners - demography, psychograph and health demonstrate a wide range of variations amongst adult learners. At this stage of my enquiry, it appears that, other than the otherwise very important facts that adult learners (including those studying online) are typically older than 'conventional', campus-based students, mostly study part-time and do so whilst undertaking other responsibilities (paid work, family raising or care), are notably goal-oriented, suffer higher drop-out rates, and often seek to link their learning directly to their chosen 'central life interests' (employment, promotion, career, lelsure, past-times etc), from the literature it appears that adult learners do not seem to demonstrate any significant characteristics under these three headings that might constitute a useful focus of study for research that is specifically concerned with the barriers to online learning encountered by adult learners registered in online programmes. 
By contrast, the evidence that can be organised under the following three headings - entry competency and 'readiness', learning preferences and strategies, and motivation - more immediately suggests promising lines of enquiry in relation to the whole question of 'barriers'.

Learner's entry competency and 'learning readiness'. There are certain factors under this aspect, such as prior educational experience, knowledge, ability, attitude, orientation, beliefs, self-control and external support, all provide an insight into the question of whether these learners are 'ready' or in an appropriate 'frame of mind' to learn or not.

Learner's learning preferences and learning strategies. This research is concerned with the question of what learning methods these adult learners and online learners normally use in their learning, or prefer to use, including whether they are willing to participate in interaction on their own initiative and also whether they seek external help of their own initiative.

Learner's learning motivation. These data centre on the question as to why these adult learners or online learners want to learn and why they choose certain topics or focus for their learning and why they also choose a certain way or mode of learning for their studies.

\subsection{Entry Competency and Learning Readiness}

Existing studies find that learners' entry competency varies widely, with some particular relevance for this study. Diwakar, Ertmer and Nour (2003) found that about $85 \%$ of learners have been using computers for more than three years, nearly $47 \%$ possess excellent computer skills, and the skills of a further $47 \%$ are 'good'. Most students are quite familiar with using email to fulfil common tasks, and they can interact with other learners through post online, in which discussion helps learners acquire professional knowledge better. Atack and Rankin (2002) found that a considerable number of nurses 
involved in Web-based learning suffered from having poor computer skills, which evidently hindered their learning capability.

Although adult learner and online learner as well are quite different from each other in terms of their entry competence, the dropouts - those who give up their studies midway - share certain common characteristics in entry competence and learning readiness. Adult learner 'drop-outs' were investigated in Kearney's research (1985) in which $64 \%$ of respondents were female, $36 \%$ were male, and most were married, having two or more children. The learners sampled in this study were between aged 28 and 68 , with an average age of 44 ; those between aged 30 and 50 were found to be the most 'weak-willed', or the most likely to lose their commitment to learning and most likely to drop out of their studies. The reasons leading to dropout were varied, which can be summarised as inadequate self-preparation, lack of learning skills - including reading, writing, organization, reasoning, interaction, self-training, judgment, curiosity, persistence - financial or health problems, and lack of support from a spouse, family or from the company leadership.

Based on interviewing experts and learners involved in Web-based learning, Schrum and Hong (2002) investigated successful online learners' characteristics in entry competence and learning readiness, and thought the following two characteristics were the major factors in achieving success in online learning.

Firstly, 'tools and technology experience': The more difficulty the student experienced in getting the necessary technical equipment, the easier it was to find reasons to drop the course. Students could also have a significant and additional challenge if they had to learn both to use the technology and to master course content at the same time. Students needed to have a level of 
comfort with using the tools - experience in solving simple problems, checking email, and printing or file management.

Secondly, 'lifestyle factors and support from the external environment': Students needed to be aware of the responsibilities that govern their lives, and need to determine to devote sufficient time to studying in order to succeed in the online learning environment. They also needed to have some flexibility in their learning schedules in order to be able have sufficient time and opportunities to learn.

Another significant factor here was the amount of support learners could count on from family, friends and co-workers as they pursued their studies. Most students who had dropped an online course mentioned a lack of time to devote to studying. Work related travel and childcare responsibilities were also often cited as reasons for non-completion. So, it was deemed important that students have family support.

In this study, I thus decided to investigate the relationship between learners' entry competency or their learning readiness and their learning achievements and the barriers that they report encountering.

\subsection{Learning preferences and strategies}

Learning preferences and strategies are topics which draw the constant attention of researchers in studies of adult learners' and online learners', as paying more attention to the apparent preferences and, more explicitly, strategies that adult learners adopt for interaction and cooperation, which are deemed to be important characteristics of successful learners. Clearly, a distinction needs to be drawn here between what learners either voice as their preference or indicate as a preference by their behaviour, on the one hand, and the more worked out and deliberately planned or conscious action entailed in the rather grander notion of a learner strategy. What preferences 
and strategies have in common is that, first, each indicates the ways in which learners would seek to pursue their learning goals, where they have some sort of a choice and, secondly, that learner preferences about the approach or, more 'grandly', strategy seems to be linked to learners' levels of satisfaction, particularly where the earlier-mentioned issue of scope for interaction was concerned (Litchfield, 2000; Diwakar, Ertmer and Nour, 2003).

Litchfield (2000) found that cooperative learning strategies were used by a variety of online learners, promoting student-student interaction, and thus enhancing students' learning. Schrum and Hong (2002) found that some students had trouble finishing a course because they were concerned about learning alone, without the benefit of contact with other learners. Therefore, these two researchers suggest that students work in a group so that they feel that they are learning in a collaborative and social environment.

Following the studies above, I intend to investigate the learners' apparent or declared preferences or strategies for learning with especial regard to the value placed on opportunities for interaction as a central part of the learning experience, along with the related issues of the risks of drop-out, non-completion or some other adverse effect on learning outcomes.

\subsection{Learning Motivation}

Some researchers think motives for most adult students enrolling in online classes are to obtain accreditation or experience personal enrichment (Loeffler, 2005; Payne and Johnson, 2005; Stewart, 2006). Some researchers (Schrum and Hong, 2002) think there is little similarity among adult learners' learning motivation who otherwise demonstrate similarities with regard to their demographic characteristics and entry competence. Adult learners manifest a whole variety of reasons for seeking educational experience, and these may include a mandatory upgrade of their skills, 
requirement for additional credits to maintain their licensure, a need to change careers, or a simple desire to gain knowledge. At the same time, other researchers think otherwise. For instance, Kearney (1985) finds that, no matter whether pursuing studies for career or for living, most adult learners' motivations to learn are definite and strong. Sharing the same opinion, Collins (2004) emphasizes that adults are goal-oriented, and like to understand clearly how the proposed educational activity will help them reach their goals, and want the course content to be both relevant and practical. Accordingly, Collins (2004) suggests that adult learning should be applicable to the learner's work or other responsibilities, valued by the learner and that all learners should be respected as individuals.

\section{A Review of Domestic Literature on Learners'}

\section{Characteristics}

To date, a considerable amount of research on the learning characteristics of adult learners and online learners has been undertaken in China, including a lot of empirical studies. The research methods generally used include questionnaire surveys, interviews or a combination of both. Mostly, the research scope is comprehensive, covering learners' demographic characteristics, their learning motivation, the learning environment, learners' entry competence, and their learning preferences. In each case, the characteristics described need also to be considered as potential facilitators or barriers to learning for adult learners enrolled on online programmes. The findings from existing relevant studies can be summarized as follows.

\subsection{Most learners are adults in employment}

Wang (2006) investigated 78 students through questionnaires, who enrolled in English college open education or college open education provided 
by Changsha Radio \& TV University in 2002 and 2003, and found all the students were holding down steady jobs. Xu (2006) investigated the students enrolled in Shihezi Radio \& TV University in 2005-2006 through two rounds of questionnaire survey, with 375 valid questionnaires collected, and found that more than $90 \%$ of these students were between aged 21 and 40 , and most of them were unable to take time out to enjoy any holidays, for they were all learning while working. He (2006) spent one and a half year investigating the adult learners of mainland China through questionnaires, and found that only $2.9 \%$ of those learners were jobless or out of work, $2.1 \%$ were job-waiting with an employment history, $2.9 \%$ were retired, and all the others were working either as an employee, leader or were self-employed ${ }^{6}$. However, there were exceptions. Zhang and $\mathrm{Hu}$ (2002) investigated the learners in distance education in Northwest China through questionnaire surveys, and found from 408 valid returns that $20 \%$ of those learners were without any employment history and one of the main barriers in learning they were faced with was this lack of necessary working experience.

\subsection{Marked Difference in Demographic Characteristics}

\section{Gender}

It is shown in the existing research studies that both males and females are active adult learners or online learners and that female learners seem to account for a higher proportion of such learners. Wang (2006) found that females were more predominant than males amongst adult learners engaged in foreign language distance education. Among the 203 adult learners, Investigated by Zhuang and Wang (2006), from 5 different major subjects of an adult school, 88 learners were male and 115 were female. $\mathrm{Li}$ and $\mathrm{Li}$ (2006) Investigated 164 online learners from the Institute of Online Education of the

\footnotetext{
${ }^{6}$ In this research, the researchers did not introduce detailed sample methods or sample location, nor did they explain whether the final findings went through effective statistical tests.
} 
Southwestern University of Finance and Economics, and found that females, similarly, accounted for a higher proportion (56.1\%), than males (43.9\%). However, once again, there are also exceptions to this finding. For instance, Zhang, Li, and Peng (2002), investigated 152 online learners from 7 different major subjects in Chongqing, and found the percentage of males to be $57 \%$.

Although these different levels of enrolment between men and women in different published studies do not constitute a central concern for this research, unless they are also shown to be associated with systematic differences in the experiencing of barriers to (online) learning, it is worth noting in passing that these differences in enrolment may be the result of a variety of factors. For example, it may be simply a reflection of wider and well recognised differential levels of enrolment by men and women in particular subjects or disciplines (differential levels which often also vary over time and between countries or regions). Similarly, it might be speculated that, given that most adult learners studied are in paid employment where, still in China, male wages are higher than those of women, it is possible that the perceived opportunity costs of men studying part-time in addition to working might be commensurately higher than for women and hence connected to the different levels of male and female enrolment. In any case, I will return to this matter in Chapter 4 to see what light, if any, the data I have collected can throw on the matter.

\section{Marriage}

Zhang, Li and Peng (2002) found that $72 \%$ of the online learners sampled in their research were married. $\mathrm{Li}, \mathrm{Yu}$ and $\mathrm{Li}$ (2006) found, too, married online learners constituted more than half overall, accounting for $58.54 \%$ of the learners whom they studied. By contrast, it has been shown in some research that most learners of English in online education schools were 
single females between aged 20 and 29 (Cao, Tang and Wang, 2005). Again, it is possible that the reason for such significant differences of learners' married status found in the research reported above might be related to the major subject being studied or to the different ages or career paths of the learners being studied. This view will be empirically tested in Chapter 4 , but again the important point for this particular study is that, to the extent that there are some significant differences in the reported levels of enrolment of men and women on different courses or programmes, what matters is whether these differences are systematically linked to any perceived or experienced barriers to online learning.

\section{Educational Background}

He (2006) found adult learners' entry educational backgrounds varied largely, the details of which were as follows: $2.1 \%$ had received primary school education only, $5.5 \%$ had received junior middle school education, $14.3 \%$ had received senior high school education, $35.3 \%$ had already received college education, and $34.9 \%$ had received undergraduate education and $8 \%$ postgraduate education. These are significant differences in the prior educational experience and level of attainment amongst adult learners: the pressing question that arises here is - are these different levels of education linked systematically to the experience of barriers to learning amongst online learners? For example, do those learners who completed their studies at a lower level, or with fewer formal qualifications, face different or greater barriers in online learning than those who stayed in education to higher levels or obtained higher qualifications?

Shi (2007) also found that there were significant differences in the entry educational background of the learners in continuing education. By contrast, the online learners sampled in the research reported in my study manifest 
fairly homogeneous entry educational backgrounds, for all of them are enrolling in Web-based college education, for which the government insists on strict requirements concerning the learners' entry educational backgrounds. Such a finding is in accord with what $\mathrm{Li}, \mathrm{Yu}$ and $\mathrm{LI}$ (2006) found in their research, which was that the entry education backgrounds of Web-based education learners are mainly at senior high school education and college education levels.

On the basis of the above, presently, according to the research in mainland China, whilst the entry educational backgrounds of learners of adult education generally manifest quite marked heterogeneity by contrast those of learners in Web-based education are apparently relatively homogeneous.

\subsection{Learning Motivation}

Some researchers think Chinese online learners' learning motivation demonstrate a marked singularity of purpose and stark utilitarianism, namely the learners' main express needs for qualification and professional development, including especially the acquisition of certificates and the advancement of their social status? ${ }^{7}$. For instance, Zhang (2004) was not optimistic about the present state of online learners' learning motivation, in which it was seen that such 'external' learning motivation was stronger than learners' own 'internal' learning motivation and the overall intensity of learners' motivation was low.

The above inference has been verified by a considerable amount of research. For example, $\mathrm{Li}$ (2007) found through a questionnaire survey of 149 online learners in The School of Online Education of South China Normal University that $88.6 \%$ of those learners were learning specifically for a

7 In fact, both professional development and the acquisition of a diploma can be regarded as occupation oriented rather than knowledge-centered 
certificate of higher education and only $9.4 \%$ were to studying meet the requirements of the learner's job. He (2006) came to the conclusion through his research on adult learners nationwide that $49.6 \%$ of those learners were learning for improved workplace competences, $45.4 \%$ were doing so to meet the requirements of their jobs, $18.5 \%$ were studying for more knowledge, $12.2 \%$ were studying simply to acquire a certificate, and $36.1 \%$ were doing so for higher social status. Cao, Wang, and Tang (2005) also found that more than $90 \%$ of the learners were taking Web-based education for better business English or for a certificate.

Wang (2006) found that learners who were learning English through Web-based education held strong diploma/certificate motivations; $95 \%$ of the Interviewees were motivated by a desire to obtain a diploma or certificate and $75 \%$ were learning in preparation for the attainment of a 'professional title' $^{\text {by examination }}{ }^{8}$. It was also found in this research that besides considerations of career, some learners were learning English through Web-based education for certain aspects of living more generally, such as more convenience in travelling abroad, which was taken into consideration by $37 \%$ of the learners, and to able better to help with the tutoring of children in English, but which only $9 \%$ mentioned.

By contrast, Shi (2007) found that, besides those who were learning for career development, a number of learners in Web-based education were also learning for self-fulfilment (accounting for $57 \%$ of those studied). Again, Xu (2006) found that $52 \%$ of learners chose Web-based learning with the purpose of improving their e-learning abilities; $39 \%$ wanted to developing their lifelong learning skills and habits; and $27 \%$ were wanting to enhance their social skills, though half of all were also learning motivated by the

\footnotetext{
- Many vocational promotion examinations contain English examinations. Teachers in college who want to become associate professor from lecturers or professors from associate professors are required to pass certain English examinations
} 
requirements of their jobs or in preparation for new jobs.

Kong (2009) found that many old people were taking Web-based learning as compensation for those hobbies they had to give up because of various reasons in the past, and some others were learning in order to be better placed to support the education of their grandchildren.

It can be seen from the above that, although many Chinese online learners at present are oriented principally to their jobs and professional development, along with the economic development of China, they also manifest a demand for learning beyond the job, such as learning in order to support the education of children, travelling abroad, developing the habits of lifelong learning. Moreover, the learning motivation of Chinese online learners can be expected to be increasingly diversified as more and more old people are coming into Web-based learning.

\subsection{Entry Learning Competence}

Zhang and Chen (2006) investigated 396 freshman and sophomore learners from nine schools of arts or science of Xi'an Jiaotong University, and found there were significant subject differences and grade differences, but no gender differences, in students' entry learning competence in net search skills. Wang and Zhang (2005) carefully investigated online learners' entry competences, through questionnaires returned from 112 students of The School of Online Education of Renmin University of China, The School of Online Education of Shandong University, who were learning in Rizhao City and Qufu City in Shandong Province, and found that the Internet access conditions online learners enjoyed could meet their basic learning demands and, moreover, most online learners had acquired basic Internet skills. Whilst competence in these operational skills no longer constituted 'bottlenecks' in Web-based learning, nevertheless online learners' lack of entry competence 
in other online learning methods were impeding learners from learning efficiently, as Wang and Zhang (2005) had found. It was also found that the online learners sampled in the research showed weaknesses in planning and organizing their learning, with few students making learning plans before starting and few completing their plans successfully, even if they had made some; and students were very different from each other in using any kind of strategy for or competence in self-directed learning, most not being able comfortably to employ advanced or flexible strategies for self-directed learning.

Investigating 254 freshmen and seniors following different major subjects through questionnaire-based research, Zheng and Dong (2002) conducted research on the online learning capacities of undergraduates in conventional institutions of higher education, and found that these students were generally good at operating computers and accessing the Internet and, moreover, many of them knew a lot about the Internet, such as websites for learning resources, chat rooms or BBS. However, it was also found in this research that the simple acquisition of the capacities and knowledge mentioned above did not prevent students from getting lost online, and even the reverse. All the findings in this research were in accord with earlier findings and it can safely be concluded that entry learning competence in operational and basic online skills were no longer a bottleneck in Web-based learning, whereas students still generally suffered from a lack of more refined learning methods and skills, which resulted in them still encountering barriers to their learning development.

At the same time, it has further been found in some research that online learners suffer from a lack of computer skills, shortage of self- management capabilities in learning, and insufficiency of knowledge preparation before enrolment in online learning programmes ( $\mathrm{LI}, \mathrm{Yu}$ and $\mathrm{LI}, 2006$ ). It is possible 
that, $L i, Y u$ and $L i(2006)$ reached a different conclusion from others because the students they researched were from Western China, who might have manifested real differences in their entry learning competence, especially with regard to their entry skills in using computers and accessing the Internet because of the relative situation regarding learning facilities and opportunities generally in that part of China.

Entry learning competences, such as operating computers, accessing the Internet, searching learning resources, making and conducting a learning plan, and utilizing learning methods and skills as well as strategies for self-directed learning and so on, are essential for learners' success in online learning. The above-mentioned studies show varying entry learning competencies. But, some of the studies used only questionnaires to gather data, which might not be a true reflection of the actual situation. It was possible that the respondents were not wishing to appear to fall into either of the 'extreme' points on the scale, leading them to choose the 'safe' options around the mid-point of the scale offered to respondents. If anything, these research findings from the above-mentioned studies are most likely to manifest some variance from the real situations. It suggests that we should employ comprehensive research methods in empirical research, for instance, combining questionnaire survey with interviews and, where possible direct observation of behaviour, instead of depending overmuch on simple questionnaire-based research.

\subsection{Learning preferences}

Most research designed to explore the learning preferences of Chinese online learners at present suggests that a majority of students tend to choose to be taught in traditional face-to-face classes as their learning preference rather than learning mostly or wholly online. Zhang (2003) found that $97 \%$ of 
the online learners studied were eager to be taught face-to-face in class and that the use of printed media, such as teaching materials and supplementary materials, were most popular in student support services, and multimedia discs came second. Jiang, Zhang, and Kuang (2004) investigated 823 students enrolled in college education and the second year of upgrading their education in CCRTVU open education pilots through research methods that combined questionnaire surveys with focus group interviews, finding that the main forms of support these students tended to choose were face-to-face teaching and live broadcast courses; CAI courseware and IP courseware were seldom chosen for preference, and the support styles chosen by the learners of capital cities were notably different from those chosen by the learners in learning centres in districts and counties. Wang (2006) found that $78 \%$ of the online learners studied considered face-to-face teaching to be of most importance, followed by team discussion, question-and-answer on the telephone, discussion in BBS and, last, self-learning alone. Xu (2006) found $63 \%$ of learners preferred traditional face-to-face teaching for the purposes of explanation on the difficulties and key points in course content and tutoring on exams - the former accounting for $51 \%$ of learners and the latter accounting for $45 \%$. He (2006) found in a study of adult learning that the learning preferences the learners expressed, from most to least valued, were: face-to-face teaching supplemented by self-learning, entire self-learning, learning under tutoring, cooperative learning, learning online and correspondence learning. He (2006) also found the learning media and learning materials that adult learners were most likely to choose, from most to least likely, were literature, Web media, TV media and audio \& video recording media. $\mathrm{Li}$ (2007) found $72.5 \%$ of learners preferred face-to-face teaching, while only $20.1 \%$ said that they would like to learn online.

Although online learners or adult learners still prefer to learn through 
traditional face-to-face tuition, it can be seen from the research reported above that there is evidence of some downward tendency in the proportion of the learners favouring wholly face-to-face tuition according to how recently the research has been undertaken. It is shown, additionally, that more and more learners are beginning to get used to communicating in online learning along with the increasing popularity of the Internet in daily life. For instance, She, $\mathrm{Li}$ and Chen (2007) researched 182 students in their first year, second year or third year of every major subject of Hangzhou Normal University through questionnaires, and found that most students have recognized that teaching must combine traditional and Web-based styles in the future and students are increasingly inclined to communicate online through QQ, MSN, BBS and Emails. He (2006) made a special study of interaction amongst adult learners and found that learners are used to interacting with, in order of frequency, first colleagues, followed by friends and teachers; and that the content of their interaction was, again in order of frequency, study problems, followed by learning experience, learning methods and learning materials.

\section{A Review of Foreign Literature on Barriers to Learning}

Barriers to learning are problems or situations that prevent learners from accessing programs, which make it difficult for learners to engage in study or make it hard for learners to concentrate and learn. Barriers to learning faced by learners are diverse and complex, and differ from student to student and even from day to day, which may be emotional, mental and physical health concerns; may be attitudinal, organisational or practical; may be employment and financial issues; may be problems arising from their housing, legal and transportation situations; and may be issues to do with family relationships and social support. Some emotional, mental or attitudinal barriers may be related to learners' characteristics, such as their 
overalls attitudes to learning or online learning, their motivation to learn and so on. This might be why some of the subsequent pieces of literature that I reviewed discussed barriers to learning without distinguishing between characteristics which adversely affect learning achievements and barriers to effective learning.

\subsection{Classification of Learning Barriers}

Much foreign research on the barriers facing adult or online learners places emphasis on the classification of learning barriers. Research indicates that there is a considerable number of barriers influencing learners' learning online, some of which are related to adult learners' attitudes and orientations, such as cultural concepts, their learning motivation, learning strategy, time management; some are related to learners' facility or frequency in their use of the Internet, computer skills and the Internet technology accessed, such as the technological level; some are related to the characteristics of institutes of distance Web-based education, such as course design, the availability and frequency of interaction, and staff training. Different researchers make different classifications from different points of view, and some representative classifications can be briefly examined here.

According to psychological classification, Merrill (1992) thinks that learning barriers can be classified into three groups of issues as follows: ethical issues, legal issues and cultural issues. Garland (1993) classifies the barriers affecting adult learners' persistence in learning into four groups,

including (1) Situational, (2) Institutional, (3) Dispositional; and (4) Epistemological. Epistemological barriers are such problems such as some subjects being difficult to learn, some courses requiring the intensive use of technology and abstraction, and students are short of the necessary entry knowledge or the contents of courses are lacking in interest or relationship 
with students' lives.

Taking students of UK Open University as the subject of research, Castles (2004) studied the factors affecting learners' persistence in distance education and classified them into three groups: (1) social and environmental factors, including available time and space, work style, capability of participation in instruction, support from other important people and adaption to social activities and friendship; (2) traumatic factors, including disease, bereavement, unemployment or lack of support from fellows and adaption to the stress of daily living, such as taking care of children and old people; (3) intrinsic factors, including a student's attitude, motivation, certain qualities like persistence, endurance or processing capability, and learning methods and procedures as well. Castles (2004) also found that the factors mentioned above might interact with each other, in spite of their independence, and that external support is most helpful for learner's persistence in learning.

Rezabek (1999) classified barriers in distance education into three groups: (1) Situational barriers, (2) Institutional barriers, (3) Dispositional barriers. Situational barriers result from an individual's general situation or environment, and include such issues as transportation, age, time constraints, and family responsibilities; institutional barriers are created by an institution's programs, policies, and procedures, and include problems with admissions, registration, scheduling of courses, financial aid, and support services; dispositional barriers result from an individual's personal background, attitude, motivation, learning preferences, and self-confidence. Rezabek's classification is in accord with the first three groups of Garland's (1993) classification.

Through researching the online classroom experiences of the learners 
who drop out of Web-based courses, Schilke (2001) updated and improved Garland's (1993) model. The model was updated to reflect the unique features of learning delivered through the World Wide Web, and divided the learners who suffer attrition from web-based courses through online classroom experiences Into five groups: (1) Situational; (2) Dispositional; (3) Epistemological; (4) Institutional; (5) Technological. It can be seen that Schilke (2001) adds a group of technical factors to Garland's model.

Based on Schilke's (2001) research, Mungania (2004) investigated the learners who had participated in Web-based training delivered 100 percent online. It was suggested that learners' learning barriers can be classified into seven groups as follows: (1) Dispositional; (2) Learning preferences; (3) Instructional; (4) Organizational; (5) Situational; (6) Content-suitability; (7) Technological barriers.

Berge, Muilenburg and Haneghan (2002) explained the factors and framework of learning barriers firstly by enumerating the sixty-four barriers to distance education identified in research and then by doing factor analysis. The factor analysis of the sixty-four barrlers to distance education resulted in ten factors that accounted for $52 \%$ of the overall variance, which were: (1) Administrative structure; (2) Organizational change; (3) Technical expertise; (4) Social interaction and quality; (5) Faculty compensation and time; (6) Technology threats; (7) Legal issues; (8) Evaluation/effectiveness; (9) Access; (10) Student support services.

Based on further research, Muilenburg and Berge (2005) enumerated eight barriers to online learning in order of seriousness, from light to heavy, as follows: (1) Administrative issues; (2) Social interaction; (3) Academic skills; (4) Technical skills; (5) Learner motivation; (6) Time and support for studies; (7) Cost and access to the Internet; (8) Technical problems. Among 
the eight barriers, social interaction, administrative issues, learner motivation and time and support for studies were the four of most importance.

Muilenburg and Berge (2005) attempted to explain the four most important learning barriers mentioned above through eleven independent variables, including: (1) gender; (2) age; (3) self-reported ethnicity; (4) type of learning institution attended; (5) ability and confidence with online learning technology; (6) learning effectiveness in the online environment; (7) learning enjoyment in the online classroom; $(8)$ the number of online courses completed; (9) the number of online courses dropped; (10) the likelihood of taking a future online course; and (11) whether or not students experienced prejudicial treatment in the traditional classroom due to cultural background, disability, or other personal characteristics. Through statistical and quantitative analysis, the researchers found the five independent variables that have the most effect on the above four barriers are: (1) ability and confidence with online learning technology; (2) effectiveness of online learning; (3) online learning enjoyment; (4) online courses completed; and (5) the likelihood of taking a future online course. It was also found in this research that the barrier of social interaction was the most serious one of all, which constituted a strong connection between enjoyment and the effectiveness of online learning, and the likelihood of taking a future online course. Accordingly, it would be possible to counteract some learning barriers by improving social interaction in online learning, which will also bring more enjoyment and effectiveness to online learning.

The various classifications of learning barriers given in the researches summarised above are, of course, different, but they generally share some common factors such as situational, institutional, dispositional and technical factors. 
However, in much of the research summarised above the researchers did not indicate clearly the respect in which learning barriers were classified or what precisely were the standards of the classification; and as a result, existing classifications of learning barriers are at best ambiguous, and rarely sufficiently comprehensive; many do not relate systematically to other studies, whilst some amount to little more than duplications of others.

Meanwhile, some of the classifications cannot, it seems, distinguish between characteristics which adversely affect learning achievement and barriers to effective learning. Some of the barriers stated in certain classifications, such as intrinsic factors, including a student's attitude, motivation and so on, are learner characteristics.

In terms of research methods, some of the research reported was based principally on theoretical analysis, building up a theoretical framework of which constitutes 'learning barriers'. Then empirical researches based on questionnaire surveys became the mainstream form of inquiry, and some research conclusions, supported by quantitative data, began to be drawn from these survey results.

To research learning barriers in distance education more fully and thoroughly, combining with a study of The O Institution's characteristics, this study attempts to make a deeper study of learning barriers in distance education and their classification, and to build a more distinct and rational framework. When the literature review of domestic literature on learning barriers is finished, I attempt to advance a classification or 'framework' of learning barriers in this chapter, so as to direct my research design more effectively.

\subsection{Factors Influencing Learning Barriers}

In my empirical study, I will follow previous studies that threw light on 
the factors influencing learning barriers in China. Synthesizing the researches outlined above (Castles, 2004; Muilenburg and Berge, 2005), I suggest classifying and enumerating the key influencing factors that might lead to learning barriers for adult learners or online learners, as follows:

(1) Learners' demographic variables, including gender, age, ethnicity, marriage, children, entry education level, work pressure, financial burdens, support from family, the number of online courses completed, the number of online courses dropped, and the likelihood of taking a future online course.

(2) Learners' psychological features, including learning motivation, learning preferences, influence of previous education experience, whether or not students experienced prejudicial treatment in the traditional classroom, ability of self-control and self-adjustment, expectation on success, learning effectiveness in the online environment, and learning enjoyment in the online environment.

(3) Learners' learning skills, including the ability in using computers to learn, ability to balance learning requirements with other responsibilities such as household work, accomplishment of successful learning based on the use of resources, ability to understand feedback and dealing with assessment.

(4) External factors, including teachers' instruction and support, the learning environment, availability of a learning support system, whether or not the courses are well designed, appropriately presented and suitable for students' needs and levels, access to learning resources and facilities, including computers, the Internet and World Wide Web.

It is worth emphasizing that these factors might not exist alone, but rather affect each other. And it is even more important that these factors are very likely, interweaving with one another, to lead to learning barriers, rather 
than coming to constitute learning barriers by acting alone.

\subsection{Suggestions for Overcoming Learning Barriers}

Some suggestions of how to overcome learning barriers have been made in many of the above-mentioned researches. Based on the integration of much literature on strategies for overcoming barriers to Web-based learning, Mungania (2004) put forward a relatively comprehensive and systematic, strategic framework, which can be divided roughly into three parts, including learner, courses and teaching, and educational institutions.

\section{Learners}

(1) To better understand and meet learners' characteristics and expectations. The barrier, for example, might be the use of irrelevant course content or materials, which does not meet learners' expectations.

(2) To offer learner opportunities for development. The barriers, for example, might be the result of learners' lack of preparation.

(3) To offer learner technical training and exchange. The barriers, for example, might simply be learners' limited skills or anxiety in using skills.

(4) To enhance learner's self-efficacy (that does not necessarily mean that one is confident about e-learning in spite of his/her success in other endeavours).

\section{Courses and teaching}

(1). In terms of course design, various learning preferences of different learners need to be considered. The barriers might be aversion to other technologies for teaching delivery. Pickett (2009) examined adult learning and ways in which the effective use of technology can foster the learning environment and found that learning style had little to do with online student 
interactivity, rather, an instructional design customized for the specific learning outcomes was found to improve online experiences and course satisfaction. Pickett suggested that a modular course design should be provided to better integrate individualized learning outcomes.

(2) To offer learner abundant e-learning resources. The barriers might be that learners cannot find the resources suitable for online learning.

(3) To avoid information overloaded. The barriers might be caused by learners being overwhelmed by the provision of too much information and discrepancy in their requirements.

(4) To pay attention to tracking learner progress in learning and post-learning. The barriers might be learner's unawareness of his/her status and improvement. Chan and Waugh (2007) investigated the barriers that affected learners' participation in the online learning at the Open University of Hong Kong and found that adding learners' assignment records would improve the participation in the online learning.

(5) To make sure tests and assessments are clear and not confusing. The barriers might be caused by unsuitable assessments or tests that do not add value.

(6) To make sure that course content is easy to obtain or access. The barriers might be caused by unreliable technology and inconsistent access.

(7) To pay attention to course design. The barriers might be curriculum incoherence, illogicality and obscurity or too poor integration of different course elements and the means chosen for their delivery.

(8) To pay attention to course navigation. The barriers might be difficulties in finding one's way through inconsistent and poorly designed programmes or where learners lack organisational skills. 
(9) Teachers need to be competent as facilitators of online courses. The barriers might be caused by teachers' own lack of e-learning knowledge, skills and positive attitudes.

(10) Teaching must be clear and logical. The barriers might be caused by poorly organised or badly structured teaching, resulting in a sense of chaos or confusion.

\section{Educational Institutions}

(1) Educational institutions need to inspire learners. Barriers might be caused by lack of understanding of learner's motivation or failure to engage students' enthusiasm and interests and thus fail to insplre learners. Barriers may also arise because learners themselves are not clear about their reasons for learning. Thus, Chyung (2001) found that an important reason why learners felt lacking in confidence in distance learning was that they did not know exactly what they wanted. Chyung suggested that distance learning environments need to appeal to the goal orientation of distance learners.

(2) Educational institutions should not compromise on quality in order to cater for the learner's need. Barriers will certainly be caused by courses of poor quality, inattention to the maintenance of high standards, low expectations of learners and relaxed requirements.

(3) To offer learners interactive information of course and enrolment. Barriers might be caused by poorly organised or badly communicated information, insufficiency of course information, or by poor interaction with would-be learners.

(4) To enhance employees' self-efficacy. The neglect of inculcating employees' self-efficacy might lead to a reduction of quality of teaching and support services, thus might impact the learners' effectiveness of learning 
and increase potential learning barriers.

(5) To establish or maintain the reputation of e-learning. The barriers might be learners' distrust of e-learning's credibility and the reputation of the providing institution.

In addition, some literature provides suggestions for overcoming potential learning barriers facing adult learners, including:

(1) Educational institutions should promote adult learners' demand for self-assessment, set goals and make plans together with learners, offer suitable learning materials and equipment, both of which are appropriate for adults, and provide adult learners with feedback and tracking selfassessment (Dettmer, 1986).

(2) Educational institutions should help adult learners set their own learning pace, offer learners 'problem-centred' learning materials, provide learners with practical course contents, give interior and external inspiration so as to adapt to learners' various learning preferences and characteristics, and offer timely feedback (Collins, 2004).

(3) Online education systems should provide adult learners with a participation mechanism to make group interaction possible and support interoperation with other tools of online education, for instance, building virtual groups (Pimplapure, 1996; Walker, 1999).

(4) Online education systems should provide a structured, yet flexible classroom environment and establish trusting relationships among learners (Young, 2006).

From the above review of the literature, it appears that there are few research-based suggestions regarding the issues of learning hardware and facilities and the barriers to online learning that these might entail. This 
might be saying that these factors are the easiest to deal with and any associated problems are the easiest to overcome. At the same time, the strategies or suggestions given in existing research that focus on issues where teachers or learners can effectively intervene or improve, are mostly concerned with such matters as the online course design, the provision of technical training, improving learner's learning strategies, methods and skills, increasing interaction between teachers and students. Increasing the interaction of adult learners both online and off-line is taken as the most crucial issue by many researches.

\section{A Review of Domestic Literature on Learning Barriers}

Domestic research on learning barriers can be divided into two groups: one focusing on holistic investigation of all factors influencing distance learning behaviour and outcomes, working towards some sorts of classification or categorization of learning barriers; the other inclined to targeted studies of just certain aspects of learning barriers, concrete studies of just one type or a limited number of learning barriers and giving some corresponding suggestions.

\subsection{Classification of Learning Barriers}

Bai and $\mathrm{Ge}$ (2004) summarize, through their own reading of the literature, the present learning barriers facing Chinese online learners as follows: lack of self-efficacy, psychological barriers(for instance, learning anxiety), poor skills in computer operation and usage of learning tools, low learning motivation and learning control ability, lack of timely help from tutors, frequent loneliness in Web-based learning, poor quality of teaching materials, lack of interaction, and neglect of learner's characteristics.

Jiang (2003) made an overall study on the barriers to Web-based 
learning, similarly through a literature study, and classified these barriers into three groups as follows: Firstly, those originating with learners themselves, for instance, financial problems, lack of learning motivation and learning control ability, psychological problems such as loneliness and loss of sense of belonging and common identity(both of which result from learners' separation from each other), lack of necessary distance learning skills and experience, and lack of necessary training in operational skills. Secondly, those originating with teaching staff, for instance, lack of a valid and necessary concept of Web-based education, lack of knowledge or understanding of learners' needs, lack of essential technology training, and shortages of appropriate professional staff. Thirdly, those originating with the online courses, for instance, insufficiency of course description, poor quality of teaching materials, unsure availability to learning resources, either overabundance or insufficiency of resources, inconvenience of access to resources, lack of technology of assessment for learners.

From a different point of view, Tao (2004) classified the major difficulties learners faced in distance learning into three groups as follows: (1) problems of learning, referring to learning methods and troubles of technology and resources happening during the course of study; (2) problems of communication, referring to difficulties in communication and of information dissemination to learners during their interaction with distance educational institutions in other cities or their representatives and (3) problems of individuals, referring to the problems of learner's family, job, or finance.

Leng, Wang and Diao (2005) believe that successful online distance learning should contain the following factors: successful Web-based learning requires appropriate and adequate motivation on the part of the learners; active interaction between person and computer; learners possessing certain online communication skills; learning environments with the capacity for 
flexible interaction; an emphasis on learners' ability for self-directed learning; high quality information; the provision of learner support services and assistance; and the integration of theoretical knowledge with practice and training.

Besides these literature studies, some Chinese researchers have undertaken empirical research and compiled classifications of learning barriers based, for example, on questionnaire surveys. For instance, Zhang and $\mathrm{Hu}$ (2002) investigated the characteristics of, and the learning barriers encountered by, distance learners in Northwest China through the use of a questionnaire survey. They found that the first three barriers for these learners were insufficiency of learning time, family financial burdens and lack of necessary working experience. The researchers made a further analysis on the causes of the barriers, which are concluded to be as follows: (1) Learners do not have enough time and energy, because, as in-service adult learners, they have to give consideration to working and family as well as learning. (2) Learners might encounter barriers of inadequate learning support and learning motivation, confidence and interest. (3) People's income is low in Northwest China where the research population lived, because of regional economic backwardness and the costs of learning were onerous.

Additionally, Zhang and Huang (2003) found, in an investigation of learners in Shanghai TV University, that the difficulties students faced in online learning can be summarized into five groups. These were, in sequence: time management, expense, technology, methods of teaching and learning, and slow processes on computers. Difficulties in management of learning time came first. Secondly, the expense of studying online restricts the time available for online learning. Difficulties of technology included common problems, for example, computer system breakdown, the online platform not working, lack of familiarity with the terminology used on the online teaching 
platform, and low level of computer operational capability. More than one third of students were unfamiliar with the style of reading instruction and were short of an ability to engage in self-directed learning, and a considerable number of students were suffering from difficulties of typing in communication online.

\subsection{Comments on Domestic Research on Learning Barriers}

Compared with foreign research on learning barriers, current Chinese research on learning barriers is weak, as can be shown by the following two points:

Firstly, research methods. Existing domestic research is inclined to use a single method of enquiry. Desk-based research and literature reviews alone, are used in most researches, while empirical research is seldom adopted. In terms of studies of the literature, existing Chinese literature on learning barriers in distance education is not abundant enough, so such research tends to rely overmuch on personal experience and, consequently, suffers from a lack of scientific perspective, objectivity and hence persuasiveness. Even though some researchers have made use of questionnaire surveys, the generalisability of these studies' conclusions is doubtful, as the range of learning barriers these researches focus upon is too narrow, and the sample for the questionnaire surveys is usually selected from a small group.

Secondly, there is a lack of in-depth analysis of learning barriers. For instance, existing research seldom discusses the following issues, such as which barriers are acting as key factors? What are the other factors connected with these barriers? How deeply or seriously do learning barriers influence learners' learning? Do the various factors or barriers interact in any way?

Accordingly, on the whole, domestic research in this field remains at a 
low level, which is out of line with China's extensive and rapid development of modern distance education. And this is also one of the motivations inspiring me to undertake in-depth research on learning barriers in Chinese online and Web-based learning.

\section{An Initial Conceptual 'Framework' of Learning Barriers}

\section{facing Online Learners}

The international and domestic literature on learning barriers that I have briefly reviewed above involve, or result in the development of, classifications about learning barriers and their influencing factors, and some suggestions for overcoming learning barriers, as well as the characteristics of the sample learners.

Among all of the literature that I reviewed, I think the researches of Rezabek (1999), and Berge, Muilenburg and Haneghan (2002), as well as Muilenburg and Berge (2005), are most influential in guiding my own research, and in helping me to establish my own initial conceptual framework.

Synthesizing international and domestic literature on learning barriers I reviewed, especially based on the researches above-mentioned which have been most helpful and influential, a conceptual framework emerged in my mind in which I classify the factors that might constitute distance learners' online learning barriers into just two broad groups as follows:

(1) Factors originating in learners themselves, including their learning motivation, self-directed learning ability, financial burdens and external support, readily available computer and the Internet facilities, skills for using computer and Internet, and interaction in learning.

(2) Institutional factors in distance education, including the curriculum 
(course contents, course burdens and examinations), the teaching and learning environment (teachers, resources and process) and range and availability of support services (course support services and administrative support services).

My conceptual framework for online learning barriers of distance learners is shown in Figure 2-1.

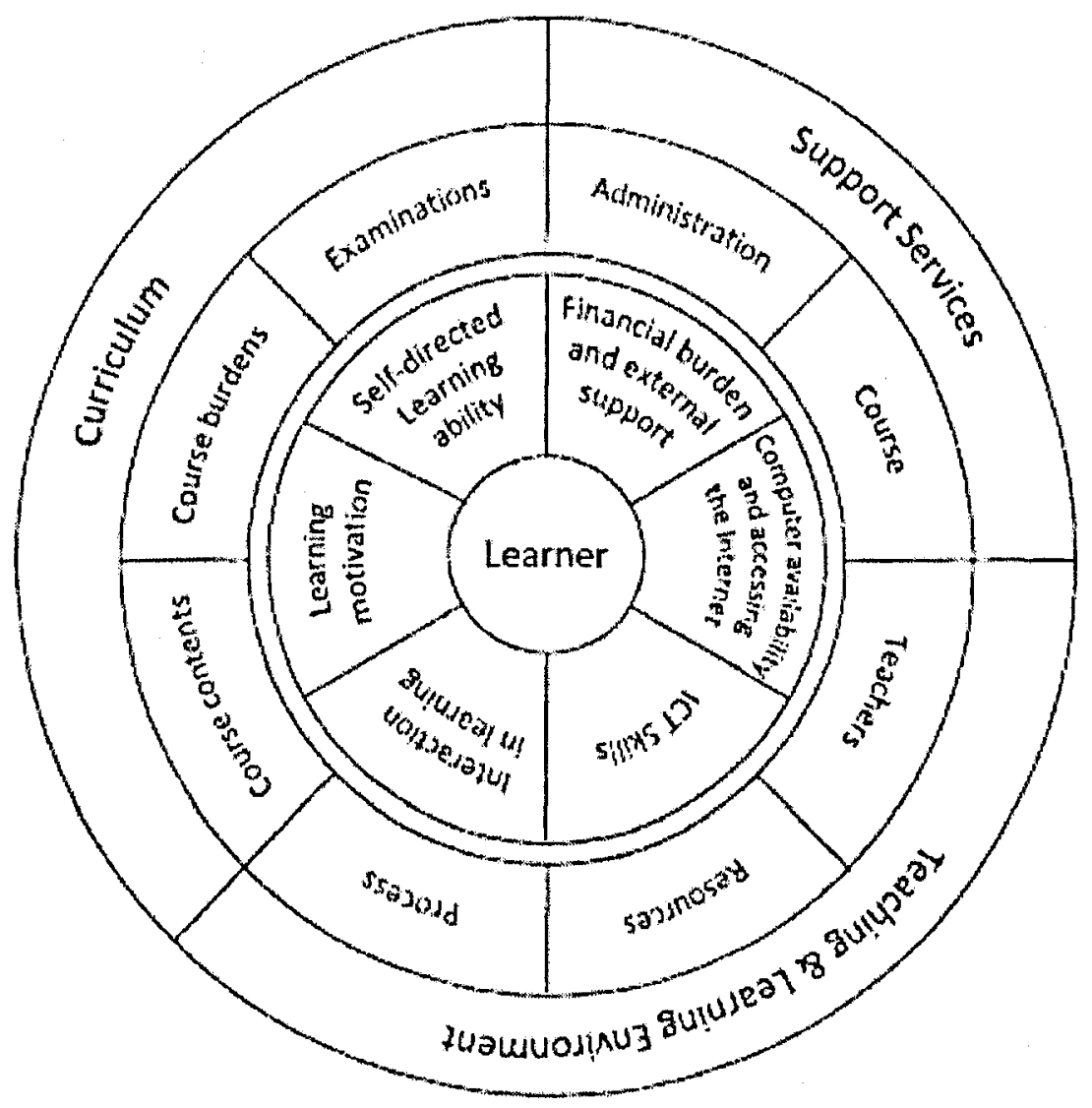

Figure 2-1 Online learning barriers framework of distance learners

Drawing on the research of Berge, Muilenburg and Haneghan (2002) and the research of Muilenburg and Berge (2005), I am seeking to elaborate every aspect summarized in Figure 2-1. The elaboration of each aspect's manifestation and the associated factors are shown in Table 2-1.

Figure 2-1 and Table 2-1 constitute my initial analytical framework for understanding and studying the barriers to learning online faced by online learners in this study, and on which the design of the interview outline and of 
the questionnaire that I used in my empirical inquiry is based.

Table 2-1 Online learning barriers framework of distance learners

\begin{tabular}{|c|c|c|}
\hline & Factors & Manifestation \\
\hline \multirow{6}{*}{$\begin{array}{l}\text { Learners } \\
\text { themselves }\end{array}$} & Learning motivation & $\begin{array}{l}\text { Impetus for promoting learner's learning, including interior } \\
\text { and external learning motivation. }\end{array}$ \\
\hline & $\begin{array}{l}\text { Self-directed } \\
\text { learning ability }\end{array}$ & $\begin{array}{l}\text { Including learner's education background, confidence of } \\
\text { learning, whether or not to develop and carry out learning } \\
\text { plans, whether or not to guarantee enough learning time. }\end{array}$ \\
\hline & $\begin{array}{l}\text { Financial burden } \\
\text { and external support }\end{array}$ & $\begin{array}{l}\text { Financial burdens caused by learning, and support from } \\
\text { family, friends and employers. }\end{array}$ \\
\hline & $\begin{array}{l}\text { Computer } \\
\text { availability and } \\
\text { accessing the } \\
\text { Internet }\end{array}$ & $\begin{array}{l}\text { Whether or not learner owns a personal computer, and } \\
\text { whether or not it is convenient to access the Internet. }\end{array}$ \\
\hline & ICT Skills & $\begin{array}{l}\text { Skills in using computers and the Internet, as well as the } \\
\text { online learning platform. }\end{array}$ \\
\hline & $\begin{array}{l}\text { Interaction in } \\
\text { learning }\end{array}$ & $\begin{array}{l}\text { Experience of distance learning and interaction with } \\
\text { teachers and other learners. }\end{array}$ \\
\hline \multirow{3}{*}{$\begin{array}{l}\text { Universities } \\
\text { and } \\
\text { distance } \\
\text { education } \\
\text { institutions }\end{array}$} & Curriculum & $\begin{array}{l}\text { Whether or not the course contents, teaching materials and } \\
\text { course burdens are suitable to learner's demands; whether } \\
\text { or not the examinations are suitable for adults. }\end{array}$ \\
\hline & $\begin{array}{l}\text { Teaching \& } \\
\text { Learning } \\
\text { Environment }\end{array}$ & $\begin{array}{l}\text { Teachers: teachers' qualification, teaching ability; } \\
\text { Resources: quality, convenience of the usage of courseware, } \\
\text { abundance and suitability of learning resources; Process: the } \\
\text { quality of teaching delivery, interaction between teacher and } \\
\text { student. }\end{array}$ \\
\hline & Support Services & $\begin{array}{l}\text { Administrative support services: the availability and degree } \\
\text { of satisfaction of services online and off-line; Course } \\
\text { services: the availability and quality of the tutorials. }\end{array}$ \\
\hline
\end{tabular}

\section{Research Questions}

Synthesizing my literature review and previous interviews with some web-based distance learners in a learning centre, as well as focused 
conversations and discussions with some researchers, managers and practitioners, and based on the initial conceptual framework that I established, I focused my research questions on the following:

(1) Who precisely are the learners in online education?

A. What are their demographical features and learning characteristics?

B. What are their previous learning abilities and achievements?

C. Are there any differences in the learning characteristics and abilities or achievements of learners from different groups?

(2) What kind of barriers might online learners confront in online learning?

A. What are the main barriers to online learning faced by web-based distance learners in China, as manifested through my own empirical study? Which ones are the most frequently encountered?

B. What factors constitute or contribute to the barriers to online learning faced by web-based distance learners in China, as evidenced by my study?

C. Are there any significant statistical differences in those learning barriers for learners with different characteristics?

D. What, if any, is relationship between different learning barriers? For an individual learner, is there any discernible interaction between these different learning barriers? Will one or more barriers become weakened or eliminated because of the elimination of another?

\section{Research Hypothesis in Need of Empirical Test}

In order to answer the questions above-mentioned in part, I would like to propose some research hypotheses which arise from the literature review and 
next need to be put to empirical test and accordingly reported in the chapters on empirical inquiry in this study.

I hope that, the distinct characteristics of Chinese online learners, as evidenced by the data from my study, and the principal barriers to their online learning could be identified by proving or disproving those hypotheses.

The principal research hypothesis on the characteristics of Chinese online learners is as follow:

There will be significant differences in the characteristics of learners studying different major subjects.

The research hypotheses concerning the principal barriers to online learning are as follows:

(1) The barrier of poor opportunities for interaction online is the key barrier that adult online learners encounter and has significant impacts on the learners' online learning.

(2) The various learning barriers identified are likely to influence each other and to be otherwise related. The elimination of one barrier can lead to the weakening or elimination of another barrier or several other barriers.

\section{Summary: From Learner Characteristics to Learner Barriers}

International and domestic literature on learner characteristics and learner barriers that I reviewed involved the development or application of a varlety of classifications about learning barriers and their influencing factors, and some suggestions for overcoming learning barriers, as well as the characteristics of the sample learners.

In terms of the classifications of learning barriers, they were, of course, different, but they generally shared some common factors such as situational, 
institutional, dispositional and technical factors.

However, in much of the research summarised in this chapter the researchers did not indicate clearly the respect in which learning barriers were classified or what precisely were the standards or criteria of the classification suggested or the relative weight of the different factors identified. Meanwhile, some of the classifications could not distinguish between characteristics which adversely affect learning achievements and barriers to effective learning.

In terms of the influencing factors underlying learning barriers, the key influencing factors that might lead to the presence or emergence learning barriers could be enumerated as follows: demographic and psychological variables, learning skills, external factors and so on.

In terms of the suggestions for overcoming learning barriers, they could be divided into three parts: learner, course and teaching, and educational institution.

In terms of the characteristics of the online or adult learners involved, the analysis was based on the following aspects: demographic, psychological, disease and health, learner's entry competency and learning readiness, learner's learning preference and learning strategy, and learner's learning motivation.

Generally speaking, learner characteristics are various and complex, including cognitive, affective, physiological, social characteristics and specific prior knowledge and so on, affecting learning process which the learner engages in. Different learners may have some general and steady characteristics, but may also reveal various and possibly decisive differences in their characteristics. Some learner characteristics may directly constitute or be closely linked to learner barriers in a certain context, circumstances and 
environment in which learners study. In other words, learner barriers may originate in manifold factors, but many factors may have their origins in some learner characteristics. Especially, some emotional, mental or attitudinal barriers may be related to learners' characteristics. Therefore, in order to investigate learner barriers systematically, we should have to inquire learner characteristics.

I would like to emphasize that although this thesis manages to deal with learner characteristics and learner barriers as two separate categories; both sets of the factors may overlap inevitably when they come to an overall understanding the barriers facing online learners. This might be why some of the above-mentioned literature I reviewed discussed barriers to learning without distinguishing between characteristics which adversely affect learning achievements and barriers to effective learning.

In this thesis, I will report on my data and on my empirical analysis of learner characteristics and learner barriers separately in chapter 4 and chapter 5 . 


\section{Chapter 3: Research Methods}

\section{Choice of Research Methods}

Broadly speaking, research methods can be divided into two types: quantitative and qualitative. Quantitative research uses numerical methods to collect and analyze research data drawn from different sources which can include surveys, collection of statistics, the testing of hypotheses by numerical data, and the application of a range of statistical analytical techniques used to assess theories, to test or develop concepts and, for example, thus to judge the quality of education phenomena, or to discover any underlying laws and to test certain theoretical hypothesis (Chen, 2005). Qualitative research focuses principally on the meanings actors give to their own and others' behaviour and relies on the researcher becoming the main research tool to explore social phenomena through various methods of data-collection such as observation in natural settings, direct participation in events or activities, in-depth interviews, the use of documents, and proceeds by analysis of data by induction on which interpretation and theory are developed. Thus, interpretive understanding of the research object's behaviour and meaning is achieved through interaction between the research object and the researcher himself (Chen, 2000).

From the literature reviews, both domestic and international, it can be seen that a range of research methods have been utilized in empirical studies of learner characteristics and of the factors that inhibit learning or which constitute barriers to learning. Both quantitative and qualitative research methods have been widely used in those studies. In the studies using 
quantitative research methods, the relevant learners' information is mostly obtained through questionnaires, and then the research issues or assumptions are tested through the application of a variety of statistical and measuring methods, including frequency analysis, means comparison, cross-tabulation with tests of significance, showing distribution and discrepancy, correlation analysis, and regression analysis. In the studies using qualitative research methods, methods such as interviews, Delphi expert interviews, observation notes, case studies and 'contrast experiments' are applied.

The inquiry that I report here is based largely on quantitative research, using questionnaires to collect data which I then analyze through the use of a variety of statistical and quantitative techniques. In my study, qualitative methods play a supplementary role, mainly in the design of the questionnaire, including their use to check the questionnaire's validity. I also make use of several, well-targeted 'in-depth' interviews, which provided valuable information and findings and which have also proved of some importance in supporting and explaining the main ideas issuing from the quantitative data analysis.

Thus, in my study, quantitative and qualitative research methods are combined, the former as the principal approach, supplemented by the latter. I decided to do this for the following reasons.

Firstly, the choice of research methods ought to be decided according to the main research questions and issues being addressed. In my case, the research was aimed at exploring the characteristics of online learners in large-scale provision, and the difficulties and barriers they encounter in learning, the influence that these negative factors constitute for their learning, and the measures taken to reduce or remove these negative factors. 
In this study, this research focus has been carried forward through statistical description and the sorting of comparisons, in which quantitative research was more advantageous than qualitative research would have been.

Secondly, in quantitative research, the researcher usually has already made certain theoretical assumptions, or has taken the concepts and theories of other researchers, and has determined to test these assumptions or concepts numerically. In this study, certain verifiable assumptions were sorted out first through the literature review. Even though there was a need for several assumptions yet to be finally formed, the research issues were thus initially clarified to be tested through statistic analysis.

Thirdly, compared with qualitative research, which is particularly well adapted for in-depth analysis of samples on a limited scale, quantitative research, focusing on overall conditions and seeking any underlying laws of relevant phenomena, is more suitable for the analysis of large scale data. In this study, it is viable to carry out a quantitative research because I was able to collect large scale data.

Fourthly, while quantitative research is of particular advantage to the issues being researched in this study, qualitative research is applied in some specifics to enrich and where possible to cross-check, any conclusions or propositions that arise from the statistical analysis. In any case, it needs to be borne in mind, that, however sophisticated the statistical analysis, such quantitative methods are only able to indicate associations between factors or variables (or, of course, the absence of associations): in themselves, they neither 'prove' a causal link between variables, nor do they constitute an explanation or theory in their own right. At the same time, rigorous statistical analysis can be very usefully deployed to explore the relationship between factors or variables, especially if supplemented by qualitative evidence, such 
as might be drawn from a variety of qualitative sources, including observation, in-depth interviews and reflection on personal experience.

Fifthly, of course, quantitative analysis is only as good as the clarity and reliability of the definitions and concepts which give shape to the various factors or variables and their interaction that the statistical analysis seeks to illuminate.

Lastly, the domestic literatures on barriers to online learning are mostly summaries or reflections on experiences and phenomena, mostly lacking sophisticated quantitative research.

Although my study is mainly based on quantitative research, qualitative Interviews playing a significant supplementary role, are applied in the identification of research questions and the design of questionnaire, as well as in verifying, supporting, qualifying and explaining more deeply the main Ideas issuing from the quantitative data analysis, adding to the value and validity of the findings more generally.

\section{The Procedure of Questionnaire Design}

\subsection{Establishing an Analytical Framework}

In chapter 2, I reviewed international and domestic literature on learner barriers and learner characteristics. Different literatures mentioned different learning barriers and their influencing factors, and some suggestions for overcoming learning barriers, as well as the characteristics of the sample learners. In terms of learning barriers, they were, of course, different, but they generally shared some common factors such as situational, institutional, dispositional and technical factors. In terms of learner characteristics, the analysis was carried out according to the following aspects: demographic, 
psychological, disease and health, learner's entry competency and learning readiness, learner's learning preference and learning strategy, learner's learning motivation and so on.

Based on the literature review, I established an analytical framework for my study which was showed in chapter 2 (refer to Figure 2-1 and Table 2-1). In this conceptual framework, I classified the factors might constitute distance learners' online learning barriers into two groups as follows:

(1) Factors originating in learners themselves, including their learning motivation, self-directed learning ability, financial burdens and external support, readily available computer and the Internet facilities, skills for using computer and Internet, and interaction in learning.

(2) Institutional factors in distance education, including the curriculum (course contents, course burdens and examinations), the teaching and learning environment (teachers, resources and process) and support services (course support services and administrative support services).

Furthermore, synthesizing literature review and my years' acquaintance with online education, as well as previous interviews with some web-based distance learners in a learning centre, I sorted out my research questions and hypotheses (also refer to chapter 2).

Based on the analytical framework, taking my research questions and hypotheses into account, I developed an initial questionnaire, including items which I sorted out from the literature review.

\subsection{Preliminary Study: Developing a Draft Questionnaire}

In order to construct the questionnaire items, two group discussions were conducted in order to identify the online learners' barriers and supplementary items. The first group discussion was organised in a learning 
centre based in Beijing, with 9 learners selected by convenience sampling. The second group discussion was organised in The O Institute where I worked, with 5 experts ( 2 professors from The Open University of China, 2 distance education researchers from Beijing Normal University and The 0 Institute respectively, and 1 tutor from a learning centre).

Based on results of literature review and the group discussions, a questionnaire was drafted, including three sections:

The first section consisted of 10 headings with 48 items aimed at collecting learner basic information according to their characteristics variables: demographic, psychological, disease and health, entry competency and learning readiness, learning preference and learning strategy, as well as learning motivation.

The second section centred on the possible learner barriers to online learning, comprised 10 headings with 56 items, involving learner's competence in self-directed learning, the financial burdens they faced and the availability of external support. Questions were also designed to elicit information on students', experience of the computer and network infrastructure, learners' computer skills and facility in network operations, the opportunities for communication and interaction in learning, the provision of courses, learning resources and teaching process, as well as support services for learners.

The third section consisted of 4 headings with 24 items aimed at probing suggestions, possible solutions and the measures of advice to be provided to learners, and intended to challenge the barriers encountered, also some items aimed at probing the effect of these various measures in improving learning efficiency. 


\subsection{Content Validity Analysis}

The content of the draft questionnaire was validated by experts through the method of group discussion. Nine experts were invited and attended the group discussion for content validation of the questionnaire, including 5 distance education researchers from Tshinghua University, Peking University, Beijing Normal University, Capital Normal University, and The Open University of China respectively; 2 Deans from the Schools of Online Education of Renmin University of China and Dongbei University of Finance and Economics; and 2 tutors from 2 learning centres affiliated to The 0 Institute. We discussed the structure and the arrangements of the items of the draft questionnaire. The group's contributions were as follows:

(1) The objectives, structure and items of the questionnaire were reviewed.

(2) Combined some items to improve the degree of structuring.

(3) Improved some items' statements to enable them easily to be understood and to avoid ambiguity.

(4) Simplified and shortened the questionnaire by deleting the items that could be collected from The $O$ Institute's learning platform.

According to the results of questionnaire validation, the revisions were made as follows:

In the first section of the draft questionnaire, we deleted the items related to learner demographic information, their online time recording, and their online academic scores and so on. Because these information can easily be collected from The O Institution's learner database, which is affiliated to its learning platform. Consequently, we got 7 headings with 19 items in this section. 
In the second section of the draft questionnaire, we combined some headings and their items and then got 6 headings with 47 items.

In the third section of the draft questionnaire, we also combined some headings and their items and then got 1 heading with 15 items.

Finishing the revision, we greatly simplified and shortened the draft questionnaire by reducing 10 headings with total 47 items. Furthermore, we discussed and improved the statements of all the headings and their items of the revised draft questionnaire to ensure that they could be easily understood and, as far as possible, to avoid ambiguity. Finally, the members of the group checked the draft questionnaire again and thought it was well structured and would be a valid instrument to use for the survey of learners in exploring the principal research questions.

\subsection{Pilot Study for Suitability Analysis}

I selected 34 students for questionnaire survey as a pilot study from three learning centres based in Beijing, Tianjin and Baoding, using a convenience sampling technique, following by in-depth interviews with 21 participants out of them, in order to gather their respondences and comments on the draft questionnaire as well as the learning barriers that they encountered in online learning. (The data from the interviews was also used for supporting and explaining deeply the main findings sorted out from the quantitative analysis later.)

The participants put forward many questions relating to the draft questionnaire's structure and its headings as well as its individual items. Some participants thought the draft questionnaire a little verbose; some suggested that it would be better for them to respond to the items just by ticking the appropriate choice instead of filling in the blanks somewhere; some felt the statements of certain headings or items were ambiguous. 
In the interviews with the 21 interviewees out of the 34 participants selected with 'convenience sampling', I got much supplementary information and some comprehensive findings referring to the potential barriers to online learning faced by adult learners.

All the outcomes of the pilot study and the interviews helped me greatly in finalizing my questionnaire. The main changes of the draft questionnaire in finalizing were stated in the later section in details (referring to '2.7 Finalizing the Questionnaire').

\subsection{Construct Validity Analysis}

A book named Discovering Statistics Using SPSS written by Andy Field (SAGE Publications, Second Edition, 2005) enlightened me to analyse the construct validity of the questionnaire based on the 34 questionnaires that I had pre-tested. Field (2005, p666) suggested that we could use factor analysis to validate a questionnaire. Meanwhile, a Chinese book named Statistical Data Analysis and Applications of SPSS (Yu and $\mathrm{He}, 2003$ ) also proposed that factor analysis could be a way to validate a questionnaire. Furthermore, Zeng and Huang (2005) argued that, in a paper entitled Analysis on the Reliability and Validity of Questionnaire, which was issued in Statistics and Information Forum, the way in common use to analyse the construct validity of a questionnaire was factor analysis. Moreover, In order to understand how other researchers to validate their questionnaires, I searched in Google with 'SPSS + validity (in Chinese)' and found a lot of Chinese papers using factor analysis to validate questionnaires. So, it seems that factor analysis might be in common use to validate a questionnaire, at least in mainland China.

In order to check whether the 34 data from the pilot questionnaire survey were suitable for doing factor analysis, the value of the Kaiser-Meyer-Olkin 
Measure of sampling adequacy (KMO) was calculated with SPSS (version 13). The results shown that the KMO value was .921 , Bartlett's test is highly significant $(p<.001)$, therefore I concluded that factor analysis is appropriate here, indicating the existence of common factors between items.

(In general, the KMO statistic varies between 0 and 1 . A value of 0 indicates that the sum of partial correlations is large relative to the sum of correlations, indicating diffusion in the pattern of correlations. Hence, factor analysis is likely to be inappropriate. A value close to 1 indicates that patterns of correlations are relatively compact and so factor analysis should yield distinct and reliable factors. KMO values between .5 to .7 are mediocre, values between .7 to .8 are good, values between .8 to .9 are great and values above .9 are superb.)

The results of the KMO and Bartlett's test are shown in Table 3-1.

Table 3-1 KMO and Bartlett's Test

\begin{tabular}{lc|c}
\hline Kaiser-Meyer-Olkin Measure of Sampling Adequacy & .921 \\
Bartlett's Test of Sphericity & Approx. Chi-Square & 101253.130 \\
& df & 2278 \\
& Sig. & .000 \\
\hline
\end{tabular}

The next step was to undertake some factor analysis. In the analysis, items were selected according to the following criteria: (1) each item's load value on factors should be above $.4 ;(2)$ the difference between a certain item's load values on each of two factors should be greater than .05; (3) each factor Included more than two items. (Yu \& He, 2003)

In the first factor analysis, the value of $86 \_4$ was .320, smaller than .4; three factors (B6_2\&B6_3, B1_58B1_6, A7_138A7_12) only included two items. I eliminated these items, and then conducted factor analysis again, the results accorded with the criteria above-mentioned. Thus, it needed no longer do factor analysis again. And then 12 factors remained (where the 
characteristic value was greater than 1 , and the accumulative contribution rate was 65.427\%). Details are shown in Appendix 7.

12 major factors and 61 items, each showing a load value greater than .4, were reached through factor analysis. According to the items contained in each factor, these factors' names, brief explanations and items contained are listed hereinafter.

Factor 1: Teaching \& Resources: B3_9, B3_10, B3_8, B3_12, B3_7, B3_6, B4_1, B4_2.

Factor 3: Skills with Computers and the Internet: B2_6, B2_5, B2_9, B2_4, B2_7, B2_8.

Factor 4: Ability to Engage in Self-directed Learning: A7_7, A7_8, A7_5, A7_9, A7_6, A7_4, B6_1.

Factor 5: Communication and Interaction: B5_4, B5_3, B5_6, B5_2, B5_1, B5_5, A7_10.

Factor 6: Courses: B3_4, B3_2, B3_1, B3_5, B3_3.

Factor 7: Support Services: B4_4, B4_3, B4_5, B4_6, B3_11.

Factor 8: Learners Evaluation of Learning: B6_6, B6_7, B6_8, B6_5.

Factor 9: Computer $\&$ the Internet Conditions: B2_1, B2_2, B2_3.

Factor 10: External Support \& Financial Burdens: B1_3, B1_2, B1_4, B1_1.

Factor 2: Suggestions about Learning Skills: C1_9, C1_10, C1_11, C1_8, C1_12, C1_7.

Factor 11: Suggestions about Hardware: C1_2, C1_3, C1_1.

Factor 12: General Characteristics of Learners: $A 7 \_3, A 7 \_1, A 7 \_2$. 
It can be seen from the results of the factor analysis, except for Factor 2 \& Factor 11 (possible remedial measures), Factor 4 \& Factor 8 (learners' estimating on their own self-directed learning and their likelihood to engage further in online learning) and Factor 12 (learner's characteristics), the other seven factors are all related to the potential barriers to online learning, which represented a good correspondence with the analytical framework of the barriers to online learning faced by web-based distance learners. These results suggested that the items in the questionnaire could be expected to reflect the actual situation of the barriers to online learning faced by web-based distance learners, which suggested to me that questionnaire was valid.

\subsection{Reliability Test}

Reliability just means that a scale should consistently reflect the construct it is measuring. The better method to check the reliability should be test-retest. One way to think of this is that, other things being equal, a person should get the same score on a questionnaire if they complete it at two different points in time (e.g. a month later). But it was too difficult because I found it almost impossible to get the same participants to complete the same questionnaire at two different points in time.

The simplest way to do this in practice is to use split-half reliability. The problem with this method is that there are several ways in which a set of data can be split into two and so the results could be a product of the way in which the data were split. To overcome this problem, Cronbach (1951) came up with a measure that is loosely equivalent to splitting data in two in every possible way and computing the correlation coefficient for each split. The average of these values is equivalent to Cronbach's alpha coefficient, which is the most common measure of scale reliability. So, in my study, the 
Cronbach's alpha coefficient was applied in carrying out a reliability analysis.

Table 3-2 Cronbach's alpha coefficients of the questionnaire and the items included

\begin{tabular}{|l|c|}
\hline \multicolumn{1}{|c|}{ Items } & Cronbach's alpha coefficients \\
\hline Suggestions on Learning Skills & 0.923 \\
\hline Skills of Computer \& The Internet & 0.898 \\
\hline Courses & 0.885 \\
\hline Support Services & 0.881 \\
\hline Teaching \& Resources & 0.879 \\
\hline Communication and Interaction & 0.860 \\
\hline Suggestions on Hardware & 0.836 \\
\hline Computer \& The Internet Conditions & 0.834 \\
\hline Learner's Evaluation on Learning & 0.801 \\
\hline Self-directed Learning Ability & 0.747 \\
\hline External Support \& Financial Burdens & 0.700 \\
\hline General Characteristics of Learners & 0.502 \\
\hline Total & 0.897 \\
\hline
\end{tabular}

All factors' alpha coefficients are listed in Table 3-2, as well as the overall coefficient. As shown in Table 3-2, the alpha coefficients of the most majority of the factors (especially the factors representing barriers to online learning) are above .7, and so is the total one, .897 , except for the factor of 'General Characteristics of Learners' with items A7_3, A7_1, A7_2, .502. That indicates both the whole questionnaire and the most majority of the items included are reliable, but the items A7_3, A7_1, A7_2 should be checked again (referring to '2.7 Finalizing the Questionnaire').

(In general, the alpha coefficient should above .6; above .7 means better, above .8 means very good.)

\subsection{Finalizing the Questionnaire}

Through content and construct validity analysis and pilot study as well as reliability test, the questionnaire's final version was thus refined, enabling it be used for measuring and analyzing the barriers to online learning facing distance learners. 
To finalize the questionnaire, I synthesized all the outcomes of the pilot study and the interviews as well as the analysis of questionnaire's validity and reliability, revised the structure and content of the draft questionnaire again as follows:

(1) Simplified and refined again the statements of the all headings and its items to enable them more easily to be understood and to avoid ambiguity.

(2) Utilized tables to sort out some items to make the questionnaire more terse and convenient to tick the appropriate response choices.

(3) Utilized the response choices sorted out from the pilot study and the interviews with the 21 participants to improve the questions $A 1-A 6$ in the first section of the questionnaire, replacing the pattern of filling in the blanks with the pattern of response choices.

(4) Checked the items $A 7 \_1, A 7 \_2, A 7 \_3$ (respectively relating to the healthy, social activities and family, their Cronbach's alpha coefficients are lower than .6) again, found that their original statements were ambiguity and then amended them.

(5) Added two open-ended questions respectively at the ends of the second section and the third section, enabling the learners to describe other problems in online learning.

The English version and Chinese versions of the final questionnaire are attached in the appendix 1 and 4 respectively, both with a total of 16 headings (with a total of 83 items), of which 6 are basic information questions, 2 are open-ended questions and the rest are in the form of a five-point scale of learners' responses, with a score of 1 representing 'very much in line with'; 2 representing 'relatively in line with'; 3, 'neutral response'; 4, 'not in line 
with'; and 5, 'not in line with at all'.

It might be noticed that some essential demographic information on the learners, such as their gender and age, in the end was not included in the questionnaire. That was not because such data are unimportant; to the contrary, it was because the sample of learner in this study would be taken from amongst the students who were studying in The O Institution, and I was able to obtain this important demographic information direct from the Institution's database. Thus, I was able to save the respondents' time and make it convenient for students to take part in the survey. Thus, the final version of the questionnaire omitted the demographic information.

\section{Sampling and Conducting of the Questionnaire}

\section{Survey}

\subsection{Random Sampling and the Questionnaires' Collection}

As above-mentioned, the sample of learners in this study was taken from amongst the students who were studying in The $O$ Institution.

Up to the end of 2009, The O Institution, the biggest Distance Education Service Providers in China, had contracted with over 40 well-known Chinese universities such as Peking University, Zhejiang University, to establish cooperative partnerships, through about 2,000 learning centres covering the mainland China, offering learning support services for over 400,000 Chinese online learners.

As one of the top managers of The O Institution then, I was able to conduct a large-scale questionnaire survey among the online learners of The O Institution. I decided to select randomly $1 \%$ of the 400,000 online learners as my research sample. 
My sampling and questionnaires' collection procedure was conducted as follows:

Step 1: Establishing a 'sample pool'.

The learner database of The $O$ Institution held more than 400,000 online learners, each with a unique ID number. Permitted with the top management of The $O$ Institution, I asked the database administrator help me draw out randomly 4,000 learners ID number. Using the 4,000 learners ID number, I established a 'sample pool'.

Step 2: Distributing the questionnaires and inviting the respondents.

I embedded my questionnaire into the learning platform of The 0 Institution supported by the programmers and indicated that I would like to invite respondents from the 'sample pool' to complete the questionnaires online. The data-entry would be automatically completed in the back-end of the learning platform of The $O$ Institution while the respondents were answering the questionnaires.

Utilizing the ID number in the 'sample pool', I obtained the 4,000 sample learners' email addresses and telephone numbers. I sent an invitation email to the all 4,000 sample learners by using the email sending system of The 0 Institution, following by phone calls conducting by the Call-Centre of The 0 Institution (to finish the 4,000 phone calls, 5 dedicated and trained persons worked for almost one month), to invite them to $\log$ on to the learning platform to complete the questionnaire anonymously. One month later, I sent the invitation email to the all sample learners again to remind them to complete the questionnaire (somebody might ignore the second email if he or she had completed the questionnaire).

Step 3: Finishing the sampling and questionnaires' collection. 
I spent near two months in collecting the completed questionnaires, supporting by my colleagues with identifying every questionnaire by ID number one by one. Although the respondents completed the questionnaires anonymously, logging on to the learning platform with their ID number, I could obtain their basic demographic information, their online time and learning process records, and academic scores, as well as other data needed by later statistical analysis, from the learner database of The $O$ Institution, with their ID number.

Finally, I got 3,396 completed (returned) questionnaires out of the 4,000 sample learners. The rate of returned questionnaires is $84.9 \%$, very high indeed for this kind of study.

\subsection{Eliminating the Invalid Questionnaires}

In order to avoid distortions to the conclusions that I drew from the responses to the questionnaire that might have been caused by the information provided (for example, through providing deliberately misleading or irresponsible answers), certain 'checking' or 'lie-detecting' questions were also included in my questionnaire. There were two pairs of lie-detecting questions, as seen in Table 3-3.

As can be seen in Table 3-3, questions A7_12 and A7_13 were designed to acts as checks by eliciting answers that were quite opposite. Invalidity was recorded as ' 1 ', if the same answers were given to this pair of questions. Otherwise, the responses were recorded as '0'. Questions B6_4 and B6_5 also contradict each other in meaning. Again, the indication of invalidity was recorded as ' 1 ', if the same answers were given to this pair of questions. Otherwise, the responses were recorded as ' 0 '. Any returned questionnaire with two indications of invalidity was defined as an 'invalid questionnaire' for the purposes of this study. Those with only one indication of invalidity were 
taken as valid.

Table 3-3 Lie-detecting Questions

\begin{tabular}{|r|l|c|c|c|c|c|c|}
\hline No, & \multicolumn{1}{|c|}{ Items } & $\begin{array}{l}\text { Very } \\
\text { much in } \\
\text { line with }\end{array}$ & $\begin{array}{l}\text { Relatively } \\
\text { in line } \\
\text { with }\end{array}$ & $\begin{array}{l}\text { Neutral } \\
\text { response }\end{array}$ & $\begin{array}{l}\text { Not in } \\
\text { line } \\
\text { with }\end{array}$ & $\begin{array}{l}\text { Not in } \\
\text { line with } \\
\text { at all }\end{array}$ & $\begin{array}{l}\text { Label of } \\
\text { Invalidity }\end{array}$ \\
\hline A7_12 & $\begin{array}{l}\text { Compared with paper } \\
\text { medium based learning, } \\
\text { I prefer online learning. }\end{array}$ & 1 & 2 & 3 & 4 & 5 & 1 \\
\hline A7_13 & $\begin{array}{l}\text { Compared with online } \\
\text { learning, I prefer reading } \\
\text { paper materials. }\end{array}$ & 1 & 2 & 3 & 4 & 5 & 1 \\
\hline B6_4 & $\begin{array}{l}\text { I cannot feel my progress } \\
\text { and lack a sense of } \\
\text { accomplishment. }\end{array}$ & 1 & 2 & 3 & 4 & 5 & 1 \\
\hline B6_5 & $\begin{array}{l}\text { Overall, I am very } \\
\text { satisfied with this online } \\
\text { study. }\end{array}$ & 1 & 2 & 3 & 4 & 5 & \\
\hline
\end{tabular}

950 out of 3,396 returned questionnaires showed one indication of invalidity and 465 had two. That means 465 questionnaires were rejected as being invalid, and 2,931 were valid, or $86.3 \%$ of those returned.

\section{Developing the Interview Outline and Conducting}

\section{Interviews}

\subsection{Developing the Interview Outline}

As previously stated, quantitative methods were the principal means of Inquiry in this study, supplemented by some important qualitative data. Qualitative research was undertaken in my study by the way of in-depth interviews, designed to contribute to the development of the questionnaire, as well as to provide in-depth information, cross-check emergent themes and to add richness to the quantitative data.

Two types of people involved in distance education were chosen as 
interviewees in the series of in-depth interviews. One type were distance learners undertaking learning online, as described above, and the others were experts in modern distance education. As the interviews were designed partly to support the development and refinement of the questionnaire, the interview was first constructed with a focus on the content of the questionnaire. Starting from the literature review and the first draft of my questionnaire, two separate interview outlines were drawn up, each targeted at one or other of the two types of persons involved in online learning, as described above. The English version outline of the interview for the online learners is attached as Appendix 2, and its Chinese version is attached as Appendix 5. Whilst, the English version outline of the interview for experts in distance education is attached as Appendix 3, and its Chinese version is attached as Appendix 6.

Interviews were conducted, centring on the question of the barriers, or potential barriers, facing online learning undertaken by distance learners. The interviewees were expected to draw attention to deficiencies in the questionnaire as well as talk about their feelings or the story of their experiences of the barriers in online learning they encountered, in a more detailed and fresh manner during the interviews.

In the second set of interviews, with experts in distance education, I expected to be able to gather a range of expert views, suggestions and help on the research issues and methods, as well as on the substance of barriers to online learning and how to tackle them.

\subsection{Conducting the Interviews}

I carried out the interviews while I conducted the pilot study on my draft questionnaire in three learning centres located respectively in Beijing, Tianjin and Baoding in May and June, 2009. I selected 34 participants with 
'convenience sampling' from the three learning centres to conduct the pilot study and 21 interviewees out of the 34 participants to conduct in-depth interviews, gathering their responses and comments on the draft questionnaire as well as the learning barriers encountered in online learning.

The interviewees put forward many questions relating to the draft questionnaire's structure and its headings as well as its individual items, and provided some supplementary information referring to the potential barriers to online learning faced by adult learners. The outcomes of the pilot study and the interviews helped me greatly in finalizing my questionnaire. Also, the data of interview would use for supporting and explaining deeply the main findings sorted out from the quantitative analysis later.

The 21 interviewees came from the enrolled learners of the three learning centres registered respectively in six universities: Beijing Language and Culture University, Southwest University, China Medical University, Dongbel University of Finance and Economics, Renmin University of China and Xi'an Jiaotong University. These interviewees majored in 10 subjects, including Chinese language \& literature, Japanese, Economics \& Management, Administration Management, Clinical Pharmacy, Nursing, Law, Business Administration, Public Utilities Management and Human Resources Management. The interviewees included not only experienced learners with two or three years' online learning history, but also freshmen newly attending distance education, who enrolled in September 2005, March 2006, September 2006, March 2007, September 2007 and March 2008. Their age distribution was between 20 and 50. Table 3-4 shows the detailed information distribution?.

\footnotetext{
The demographic information of all 34 learners involved in the pilot study could not be collected, for they filled out the questionnaires anonymously as against 21 out of the 34 who participated in the in-depth interviews, which made it possible to collect their demographic information. Thus, the 21 , instead of the 34, are described in the overall information of all the learners involved in the pilot study.
} 
Table 3-4 Sample structure of interview

\begin{tabular}{|l|l|l|l|l|l|l|c|}
\hline $\begin{array}{l}\text { Learning } \\
\text { Centre }\end{array}$ & $\begin{array}{l}\text { Number of } \\
\text { Learners }\end{array}$ & $\begin{array}{l}\text { Home } \\
\text { Location }\end{array}$ & $\begin{array}{l}\text { Number of } \\
\text { Leamers }\end{array}$ & Gender & $\begin{array}{l}\text { Number of } \\
\text { Learners }\end{array}$ & Age & $\begin{array}{l}\text { Number of } \\
\text { Leamers }\end{array}$ \\
\hline Baoding & 12 & Urban & 18 & Male & 9 & $50+$ & 2 \\
\hline Beijing & 4 & Town\&Rural & 3 & Female & 12 & $40-50$ & 5 \\
\hline Tianjin & 5 & & & & & $30-40$ & 7 \\
\hline & & & & & & $20-30$ & 7 \\
\hline Total & 21 & Total & 21 & Total & 21 & Total & 21 \\
\hline
\end{tabular}

\subsection{Principles in Using the Interview Materials}

To keep interviewees' personal information and identities confidential and to avoid any adverse or other influence the data collected in the research might have on certain institutions or individuals, all the names involved in reporting my research are assumed. Moreover, the interview materials collected were not subject to separate, systematic analysis, but only taken as a complement to and further illustration of the statistical analysis.

\section{Summary}

In this chapter I have reported the research methods used in this study of online learners in The $O$ Institution and the barriers, or potential barriers that they face. The study was based principally on quantitative research methods and was supplemented by qualitative research methods. My approach to quantitative research, questionnaire design, tests of validity and reliability, the distribution and collection of questionnaires, the decisions taken on sampling method, the elimination of invalid questionnaires and simple description of samples were all introduced in this chapter. As regards qualitative research, the purpose of the interviews, designed not only to contribute to my questionnaire's development, was also to provide complementary information and further illustration to the data collected from the questionnaire survey and to cross-check emergent themes in my study. I 
also described here my reasons for maintaining the anonymity of both individuals and institutions taking part in my study. 


\section{Chapter 4:}

\section{The Characteristics, Circumstances and Attitudes of Distance Learners}

In this chapter, I report the empirical findings of my research on the learning characteristics, circumstances and attitudes of distance learners in China, based both on the literature review undertaken and on the specific data collected. The aim in the chapter is simply to explore in more detail the nature of the online learners who participated in the study, to throw some light on their personal characteristics and the circumstances of their lives, to examine their attitudes, and to look at their levels of satisfaction. At this stage, I am not yet seeking to understand how, or to what extent exactly, any of the characteristics, personal circumstances or attitudes either constitute in themselves, or contribute to, barriers to their effective or successful engagement with the online facilities available to them. Nevertheless, it will become evident as the chapter unfolds that the personal characteristics and attitudes revealed may indeed represent barriers, and further analysis of their impact will be undertaken in subsequent chapters.

The chapter is divided into the following four parts. Firstly, an introduction to the basic data on the learners collected in my research; secondly, a more comprehensive report on the learners' learning characteristics in my sample; thirdly, an account of specific tests of the hypotheses derived from the earlier literature review and my initial analytical framework; finally, I provide a brief summary of the chapter.

In this Chapter, I begin to test out the extent of negative impact on 
studying experienced by the learners in my sample arising from a number of possible sources, as suggested by the literature, previous studies and my initial analytical framework. Thus, I present a large number of tables that examine the extent of these possible negative impacts, or barriers to learning, according to the experiences of the learners in my sample.

\section{Basic Data}

\subsection{Gender and Ethnic Distribution of the Sample}

Table 4-1 shows the gender and ethnic distribution of the sample of learners studied. The sample includes 1578 males, accounting for $53.8 \%$, slightly higher than the proportion of female learners. As already mentioned in the literature review, by contrast the majority of China's empirical Investigations have found that female learners account for a larger proportion of distance learners. I believe that this is likely to be due largely to the limitations of the various samples, which were often taken from learners majoring in the humanities and social sciences, where there are more female learners registered and this is possibly reflected in the samples studied. I also believe that the sample sex ratio would change once this factor accounting for the major difference is controlled. This chapter will further test this hypothesis in the following sections.

In my study, 2804 cases were Han Chinese, accounting for $95.7 \%$ of the total, ethnic minority learners accounted for only $4.3 \%$. This was only broadly In line with China's overall ethnicity. In 2005, China conducted a nationwide ${ }^{10}$ sample survey of $1 \%$ of the total population and had found that the Han population accounted for $90.56 \%$ of the total. In view of this, the proportion of the Han Chinese learners in my sample was higher than the proportion of

\footnotetext{
10 'Nationwide' here means 32 provinces including Taiwan, but without Hong Kong and Macao Special Administrative Regions.
} 
the Han Chinese in the entire country. The possible reason for this phenomenon, I suggest, is that ethnic minorities are mostly concentrated in the frontier provinces, while the learners in these areas are less active in distance learning, especially online learning, and less likely to enrol in The 0 Institution.

Table 4-1 Gender and Ethnic Distribution

\begin{tabular}{|c|c|c|c|}
\hline \multirow{4}{*}{ Gender } & Male & 1578 & 53.8 \\
\cline { 2 - 4 } & Female & 1353 & 46.2 \\
\cline { 2 - 4 } & Total & 2931 & 100.0 \\
\hline \multirow{4}{*}{ Ethnic } & Han & 2804 & 95.7 \\
\cline { 2 - 4 } & Minority & 127 & 4.3 \\
\cline { 2 - 4 } & Total & 2931 & 100.0 \\
\hline
\end{tabular}

\subsection{Age Distribution of the Sample}

The number of people of different ages and each age group's percentage in the sample can be found in Figure 4-1. Table 4-2 lists the lowest age, the highest age, the mean age and the standard deviation of the age distribution of sampled distance learners. From Figure 4-2 and Table 4-2, it can be seen that the age distribution of the distance learners in my sample is mainly concentrated in the range between aged 20 and 45 , while the other age groups account for smaller proportions. The age of the youngest respondent in my sample was 17 and the oldest was 57 , with the mean age being 28.75 . Thus, it can be noted my sample learners were mainly relatively young adult learners of working-age. 


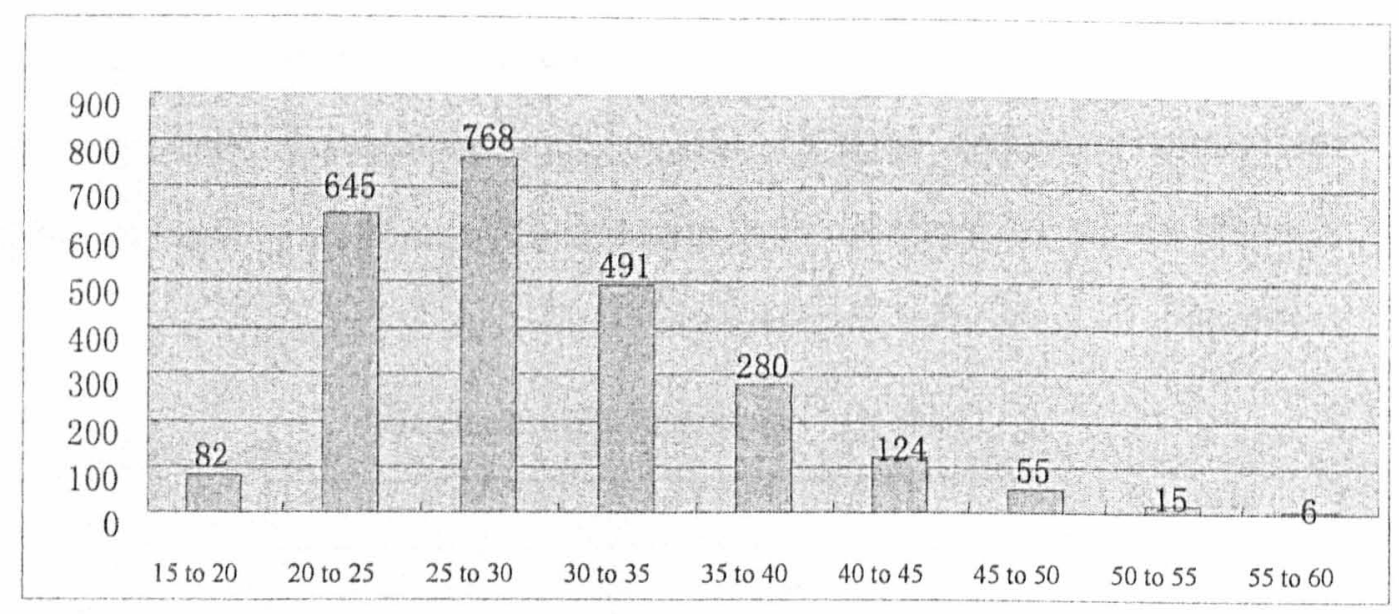

Figure 4-1 Age Distribution of the Sample Learners

Table 4-2 Lowest, Highest and Mean Age

\begin{tabular}{|c|c|c|c|c|c|}
\hline & $\mathrm{N}$ & Minimum & Maximum & Mean & Std. Deviation \\
\hline Age & 2931 & 17 & 57 & 28.75 & 6.801 \\
\hline
\end{tabular}

\subsection{Major Subject Distribution of the Sample}

Table 4-3 lists the distribution of the sample learners in terms of the major subject being studied, from which it can be seen that majors of management, engineering and economics were the most popular while those of agronomy, history and philosophy were less likely to be studied by the distance learners in my study. This is consistent with the current data on the distribution of learners across the major subjects being studied in distance education in China. There are more programmes in economics, engineering and management science delivered through distance education in China, and fewer programmes in history, philosophy and agriculture, possibly because the former ones have a closer relationship with the labour market currently. If this is true, and the study was not specifically designed to test that proposition, it nevertheless suggests that the distance learners in my sample, as in higher education in China more generally, are mainly studying subjects that are likely to be, at least in part, labour market-oriented or labour 
market-focused.

Table 4-3 Major Subject Distribution of the Sample Learners

\begin{tabular}{|l|c|c|}
\hline \multicolumn{1}{|c|}{ Major Subject } & Frequency & Percent \\
\hline Management & 826 & 28.2 \\
\hline Engineering & 794 & 27.1 \\
\hline Economics & 526 & 17.9 \\
\hline Literature & 257 & 8.8 \\
\hline Law & 159 & 5.4 \\
\hline Medical Science & 146 & 5.0 \\
\hline Education & 144 & 4.9 \\
\hline Science & 64 & 2.1 \\
\hline Philosophy & 9 & 0.3 \\
\hline History & 3 & 0.1 \\
\hline Agronomy & 3 & 0.1 \\
\hline Total & 2931 & 100.0 \\
\hline
\end{tabular}

\section{The Characteristics of the Sample Learners}

\subsection{Marital Status of the Sample Learners}

Table 4-4 shows the distribution of the marital status of the sample, in which unmarried and married each accounts for about $50 \%$. As marital status is often a differentiating characteristic amongst adult learners, the possible implications, if any, will be explored, of the learners' marital status for their learning behaviour, and for the learning barriers that they face. The overall learning effects and learning outcomes will be further discussed in the following sections.

Table 4-4 also shows whether learners in the sample have children. The result shows that $49 \%$ of the sample learners already have children, and a further $2.7 \%$ of them are planning to have children. As to whether learners having children would affect their time use and might possibly constitute a pressure on their learning, a barrier to learning and affect. their learning 
outcomes - all possible effects of having children - will be further discussed in later sections of this study. However, due to the possible similarity of the effects of marital status and of having children on study behaviour, it will be necessary to undertake a comprehensive consideration of these two factors later.

Table 4-4 Marital Status and Children

\begin{tabular}{|c|l|c|c|}
\hline \multirow{4}{*}{ Marital Status } & Frequency & Percent \\
\hline & Single & 1482 & 50.6 \\
\cline { 2 - 4 } & Married & 1449 & 49.4 \\
\cline { 2 - 4 } & Total & 2931 & 100.0 \\
\hline \multirow{4}{*}{ Children } & With children & 1436 & 49.0 \\
\cline { 2 - 4 } & About to have children & 80 & 2.7 \\
\cline { 2 - 4 } & Without children & 1415 & 48.3 \\
\hline
\end{tabular}

\subsection{Employment Status of the Sample Learners}

Table 4-5 shows the employment status of the sample. Unemployed learners in the sample account for only $9.1 \%$, while the proportion of employed respondents reaches as high as $90.9 \%$. Being employed is an important feature of the adult learners in my sample, as it often is of all adult learners, not only in China but elsewhere.

Table 4-5 Employment Status and Full-time/Part-time Study

\begin{tabular}{|l|l|c|c|}
\hline \multicolumn{2}{|l|}{} & Frequency & Percent \\
\hline \multirow{3}{*}{$\begin{array}{l}\text { Employment } \\
\text { Status }\end{array}$} & Unemployed & 268 & 9.1 \\
\cline { 2 - 4 } & Employed & 2663 & 90.9 \\
\cline { 2 - 4 } & Total & 2931 & 100.0 \\
\hline \multirow{3}{*}{ Full-time/Part-time } & Full-time & 176 & 6.0 \\
\cline { 2 - 4 } & Part-time & 2755 & 94.0 \\
\cline { 2 - 4 } & Total & 2931 & 100.0 \\
\hline
\end{tabular}

Distance Education Learners can be studying either full-time or part-time.

Table 4-5 also shows the mode of learning - part-time or full-time - of my 
sample of learners, with only $6 \%$ of the learners choosing to be full-time learners, while most were part-time. Comparing this information with the data on the sample's employment status, it can be seen that even some unemployed people choose to study at a distance on a part-time basis. One possible explanation is that although some learners have no jobs, they may have other commitments, so they still do not fully dedicate themselves to distance learning. For example, some women may choose to stay at home, but they are likely responsible for tasks as carers, as full-time housewives or full-time mothers or carers, and distance learning thus constitutes only their part-time commitment. This characteristic of 'part-time' study amongst adult and online learners is clearly of importance in the design of programmes of study for learners, the availability and accessibility of learning facilities, as well as in the types and levels of support offered and the opportunities that they have for contact and communication.

\subsection{Tuition Fees for Distance Education}

In China, higher education is not a part of compulsory education. Since 1997, colleges and universities have begun to implement a comprehensive cost-compensation mechanism, which means that, except for the learners majoring in military and some normal college programmes, the majority of learners need to pay for their higher education. Distance higher education is mainly for adult learners, and learners are charged tuition fees from the very beginning.

Table 4-6 shows the situation regarding the payment of fees by my sample. The overwhelming majority of the learners were paying the total tuition fees at their own expense (95.6\%), while only 25 had obtained complete financial support from their employers (only 0.9\%). Together with the $3.5 \%$ of the learners who share the payment of the fees with their 
employers, only $4.4 \%$ of the learners in my sample received some financial support from their employers. Whether the learners' situation with regard to the payment of fees will constitute learning barrier will be further analyzed in the later sections of this study.

Table 4-6 Payment of Tuition Fees

\begin{tabular}{|l|c|c|}
\hline & Frequency & Percent \\
\hline Payment at learners' own expense & 2803 & 95.6 \\
\hline Total financial support from employers & 25 & 0.9 \\
\hline Shared payment by employers and learners & 103 & 3.5 \\
\hline Total & 2931 & 100.0 \\
\hline
\end{tabular}

\subsection{Learners' Physical Health}

Table 4-7 shows the answers of the sample of learners to the following question: "Please choose the answer based on the extent of your agreement with this statement ' I am physically very healthy': 1 . very much in line with; 2. relatively in line with; 3. neutral response; 4 . not in line with; 5. not in line with at all." ${ }^{\prime 1}$

Table 4-7 Considering Self to be in 'Excellent Health'

\begin{tabular}{|l|c|c|c|}
\hline & & Frequency & Percent \\
\hline Very much in line with & 1 & 1916 & 65.4 \\
\hline Relatively in line with & 2 & 722 & 24.6 \\
\hline Neutral response & 3 & 278 & 9.5 \\
\hline Not in line with & 4 & 13 & 0.4 \\
\hline Not in line with at all & 5 & 2 & 0.1 \\
\hline Total & & 2931 & 100.0 \\
\hline
\end{tabular}

It can be seen from the results in Table 4-7 that $65.4 \%$ of the sample learners consider themselves to be in excellent health; $24.6 \%$ of the sample learners consider themselves relatively healthy: together, these two add up to $90 \%$, which shows that the great majority of the sample learners regard themselves as being in fairly good health. In addition to this, in China,

\footnotetext{
"In the following contents, I will omit the five options.
} 
currently it is thought that distance education represents a convenient and flexible way of learning for healthy, employed adult learners but not for the disabled, mainly due to the reason that people with disability have to deal with many disadvantages in the competitive circumstances of contemporary society, and their lives are mostly supported by their families and society at large, but not specifically in the field of distance education online. Both subjective and objective conditions need to be improved for the disabled to participate fully and on equal terms with able-bodied learners in distance education.

\subsection{Social activities}

Table 4-8 shows the answers of the sample of learners to the question, "Please choose the answer based on the extent of your agreement with this statement 'I have social activities every week'."

Table 4-8 Weekly Participation in Social Activities

\begin{tabular}{|l|c|c|c|}
\hline \multicolumn{2}{|l|}{} & Frequency & Percent \\
\hline Very much in line with & 1 & 657 & 22.4 \\
\hline Relatively in line with & 2 & 716 & 24.4 \\
\hline Neutral response & 3 & 1103 & 37.6 \\
\hline Not in line with & 4 & 408 & 13.9 \\
\hline Not in line with at all & 5 & 47 & 1.6 \\
\hline Total & & 2931 & 100.0 \\
\hline
\end{tabular}

It can be seen from Table 4-8 that just over one fifth $(22.4 \%)$ of the sample reported that they have frequent social activities and a further quarter $(24.4 \%)$ of the sample said that they have relatively frequent social activities. These two add up to $46.8 \%$ of the overall sample, or nearly half of the learners in my study. Only $1.6 \%$ of the sample learners indicated that they have very few, if any, weekly social activities, while $13.9 \%$ reported that they do not engage very frequently in social activities and over one third gave 
a 'neutral' response, which might indicate a range of social activity behaviours and only $15.5 \%$ of the sample learners in this study reported little engagement in social activities. Thus as a whole, it appears that in this sample of learners, the largest group reported either a relatively high level of social activities, or at least regular social activities.

\subsection{Family Harmony}

Table 4-9 shows the answers of the sample of learners to the question, "Please choose the answer based on the extent of your agreement with the following statement 'My family is very harmonious'."

Table 4-9 Reported Family Harmony

\begin{tabular}{|l|c|c|c|}
\hline \multicolumn{2}{|c|}{} & Frequency & Percent \\
\hline Very much in line with & 1 & 1904 & 65.0 \\
\hline Relatively in line with & 2 & 793 & 27.1 \\
\hline Neutral response & 3 & 217 & 7.4 \\
\hline Not in line with & 4 & 15 & 0.5 \\
\hline Not in line with at all & 5 & 2 & 0.07 \\
\hline Total & & 2931 & 100.0 \\
\hline
\end{tabular}

It can be seen from Table 4-9 that $65 \%$ of the sample learners think their families are harmonious and that $27.1 \%$ think their families are relatively harmonious. These two add up to $92.1 \%$, which indicates that the great majority of the learners think, or at least report, that their families live in harmony; less than $0.1 \%$ of the sample learners think that their families are not getting along well and $0.5 \%$ do not consider their families harmonious, which means that less than $1 \%$ of the sample think they have 'unharmonious' families. Thus as a whole, it can be reported that the families of my sample learners are considered by them to be harmonious. 


\subsection{Learning Preferences}

Table 4-10 shows the answers of the sample learners to the question, "Please choose the answer based on the extent of your agreement with this statement, 'Compared with studying alone, I prefer to study following the teachers' guidance'."

Table 4-10 Preference for Following Teachers' Teaching

\begin{tabular}{|l|c|c|c|}
\hline \multicolumn{2}{|l|}{} & Frequency & Percent \\
\hline Very much in line with & 1 & 609 & 20.8 \\
\hline Relatively in line with & 2 & 1099 & 37.5 \\
\hline Neutral response & 3 & 985 & 33.6 \\
\hline Not in line with & 4 & 211 & 7.2 \\
\hline Not in line with at all & 5 & 27 & 0.9 \\
\hline Total & & 2931 & 100.0 \\
\hline
\end{tabular}

From Table 4-10, it can be seen that only one fifth (20.8\%) of the sample learners whom I studied reported that they strongly preferred to follow the teachers' teaching, and a further $37.5 \%$ of them also liked to learn from their teachers, adding up to a total of $58.3 \%$, or more than one half of them all, but by no means an overwhelming majority. Only $0.9 \%$ of the sample learners did not like to follow teachers' teaching at all and $7.2 \%$ did not enjoy learning from teachers. According to these responses, a majority of the adult, online learners who constituted my sample for study still prefer to follow the teachers in their studies. Again, it is notable that one third of all respondents chose the 'neutral' answer to this question of one aspect of their preferred learning style. As may be imagined, this preference raises a whole range of questions regarding the design, organisation, delivery and operations of both distance and online learning programmes, but may also of course have been a product of the question design. 
Table 4-11 Preference for Studying together with Fellow Students

\begin{tabular}{|l|c|c|c|}
\hline \multicolumn{2}{|l|}{} & Frequency & Percent \\
\hline Very much in line with & 1 & 545 & 18.6 \\
\hline Relatively in line with & 2 & 1054 & 36.0 \\
\hline Neutral response & 3 & 1066 & 36.4 \\
\hline Not in line with & 4 & 232 & 7.9 \\
\hline Not in line with at all & 5 & 34 & 1.2 \\
\hline Total & & 2931 & 100.0 \\
\hline
\end{tabular}

Table 4-11 shows the answers to the following question, "Please choose the answer based on the extent of your agreement with this statement, 'Compared with separate study, I prefer to study together with fellow students'."

From Table $4-11$, it can be seen that just $18.6 \%$ of the sample of learners really liked studying together with fellow students a lot, but a further $36.0 \%$ also rather liked to do that, adding up to a total of $54.6 \%$ or a small majority, just over one half of all respondents. Only $1.2 \%$ of the sample said that they did not like to study together with fellow students at all and $7.9 \%$ reported that they did not enjoy learning with classmates together. Again, it is worth noting that one third of the respondents chose the neutral response.

Thus, most of my sample learners preferred to follow the teachers and study together with other learners rather than just study by themselves. However, distance learning, because of the separation of space and time involved, in most cases, may not be able to provide learners with real chance of directly following their teachers' teaching or of studying together with a group of other learners.

In the absence of their ability to learn alone successfully, or by communicating effectively online with other learners or their teachers, this could easily hinder the learning or the achievements of these learners, although for some this might be their preference, but in its absence they 
persevere and even succeed. Moreover, whether or not these 'learning style' preferences also lead to the construction of learning barriers in practice will be further analyzed later in this study.

\subsection{Preferences for Medium of Study}

Table 4-12 shows the answers of the sample learners to the following question, "Please choose the answer based on the extent of your agreement with this statement, 'Compared with online learning, I prefer reading paper materials'."

Table 4-12 Preference for the Medium of Paper

\begin{tabular}{|l|c|c|c|}
\hline \multicolumn{2}{|l|}{} & Frequency & Percent \\
\hline Very much in line with & 1 & 359 & 12.2 \\
\hline Relatively in line with & 2 & 766 & 26.1 \\
\hline Neutral response & 3 & 1273 & 43.4 \\
\hline Not in line with & 4 & 431 & 14.7 \\
\hline Not in line with at all & 5 & 102 & 3.5 \\
\hline Total & & 2931 & 100.0 \\
\hline
\end{tabular}

From Table $4-12$, it can be seen that only $12.2 \%$ of the sample learners express a strong preference for learning based on paper media, compared with learning online, while a further quarter (26.1\%) expressed a relative liking for the medium of paper, adding up to a total of $38.3 \%$, or more than one third of my respondents. On this occasion, the largest single category of response was 'neutral'. This indicates that there is still a considerable number in the sample of learners studied by me either preferring to learn through the traditional medium of paper or who have not yet firmly decided that online learning is the preferred method for them, which might constitute a disadvantage to them as distance learners, depending on the availability and quality of the learning materials provided. Whether the preferred medium will lead to differences between learners in terms of the learning barriers 
encountered will be further analyzed later.

\section{Empirical Tests on the Research Hypotheses Concerning}

\section{Learners' Characteristics}

The various research hypotheses regarding learners' characteristics have already been mentioned in the earlier sections of this paper. Below, I set out again the details of the research hypotheses and the empirical tests I carried out on them.

\subsection{Empirical Tests on the Different Characteristics of Learners} Studying Different Major Subjects

From the literature review I found that most current studies in China have found that female learners constitute the majority of adult learners and online learners (Wang, 2006; Zhuang and Wang, 2006; Li, Yu, LI, 2006). I believe that this may be due to the limitations of the various samples in those studies, which were taken from learners mainly majoring in the humanities and social sciences, where women are in the majority, and where no consideration of this was taken into account in describing the different samples. Therefore, the first hypothesis concerning learners' characteristics is based on this.

Hypothesis 4.1: There are significant gender differences amongst the distance learners studying different major subjects.

Table 4-13 sets out the sex ratio of learners in different major subjects, from which it can be seen that except for philosophy, history and agriculture which have a total of less than 30 , the rest of the eight major subjects have a clear sex ratio difference. These differences are highly statistically significant, with a significance level of $p<0.01$. 
In the science field, the proportion of male learners reached $54 \%$, higher than $46 \%$ of the proportion of female learners; in the engineering field, the gender gap is even more obvious with the proportion of male learners being $80.5 \%$, far exceeding the proportion of female learners. These two major subjects are still in China, as in many other countries, traditionally 'male-dominated' subjects.

In addition to science and engineering, law and management (both of which belong to the social sciences, but are often directly linked to future career or professional intentions) also have a larger proportion of male learners. In terms of law, the proportion of male learners is $66.7 \%$, which might be a reflection of a larger proportion of male workers in the field of law, although this study was not specifically designed to explore that issue. As for management, the phenomenon of having more male learners than female learners may possibly suggest that male learners are more active in accepting management study through distance education either because generally speaking, these are career routes more typically pursued by or particularly attractive to men (and correspondingly 'off-putting' to women), associated with a whole bundle of career and course programme characteristics, or else males might believe that they will have a distinct advantage, and females believe they will be relatively disadvantaged, in seeking management positions. But all of this is largely speculation.

Whatever the explanation for these figures, again it needs to be noted that this question of the relative distribution of men and women between different major subjects of study was not a core issue to be explored in this study: what is of interest in the actual differential distribution in my sample and the possible implications of this will be further explored later.

As for 'female-dominated' major subjects, the proportions of male 
learners in Economics, Education, Literature and Medicine are respectively $31.6 \%, 27.8 \%, 36.2 \%$ and $4.8 \%$, showing that in these four major subjects by contrast, the proportion of male learners is lower than that of female learners. Economics and education belong to social sciences, while Literature belongs to the humanities, which raises the question why apart from some specialist major subjects such as Law or Business Studies, female learners constitute the great majority in major humanities and social science majors. One might speculate that this distribution reflects the different perceived future job opportunities for men and women, or it might be related to the actual or perceived focus of the subjects to be studied, or that these subjects are regarded as inherently more 'female' by students, or else it might simply be a reflection of a long-established tradition (i.e. 'these are the subjects that girls mostly like to study'). The reason why females are so dominant in the study of medicine could again be a reflection of the structure of labour market opportunities in China, or of a 'traditional' division of labour. These thought is strengthened by the fact that my sample learners are all studying for a college degree or undergraduate degree through distance education, which mainly provides learners programmes in nursing and pharmacy. These programmes both relate to traditionally 'female-dominated' occupations.

From the analysis of Table 4-13, it can be seen that indeed there are very obvious gender differences amongst the distance learners studying different major subjects. Overall, in distance education, there are more male learners majoring in Science and Engineering while female learners appear to tending more to major in the Humanities, Social Sciences and health-related Medical programmes.

This pattern of gender distribution is also consistent with that found in standard, campus-based, higher education. 
Table 4-13 Gender Comparisons of Distance Learners Studying Different Major Subjects

\begin{tabular}{|l|c|c|c|c|}
\hline \multirow{2}{*}{ Major Subjects } & \multicolumn{2}{|c|}{ Male } & \multicolumn{2}{c|}{ Female } \\
\cline { 2 - 5 } & Frequency & Percentage & Frequency & Percentage \\
\hline Agriculture & 3 & $100.0 \%$ & 0 & $0 \%$ \\
\hline Engineering & 639 & $80.5 \%$ & 155 & $19.5 \%$ \\
\hline Law & 106 & $66.7 \%$ & 53 & $33.3 \%$ \\
\hline History & 2 & $66.7 \%$ & 1 & $33.3 \%$ \\
\hline Management & 482 & $58.4 \%$ & 344 & $41.6 \%$ \\
\hline Philosophy & 5 & $55.6 \%$ & 4 & $44.4 \%$ \\
\hline Science & 35 & $54.0 \%$ & 29 & $46.0 \%$ \\
\hline Literature & 93 & $36.2 \%$ & 164 & $63.8 \%$ \\
\hline Economics & 166 & $31.6 \%$ & 360 & $68.4 \%$ \\
\hline Education & 40 & $27.8 \%$ & 104 & $72.2 \%$ \\
\hline Medical Science & 7 & $4.8 \%$ & 139 & $95.2 \%$ \\
\hline Total & 1578 & $53.8 \%$ & 1353 & $46.2 \%$ \\
\hline Pearson Chi-Square & & & 565.610 & \\
\hline Likelihood Ratio & & 615.824 & \\
\hline Df & & & & \\
\hline Asymp. Sig. (2-sided) & & & & \\
\hline
\end{tabular}

Fan (2011) investigated 47,000 freshers who enrolled in 175 universities based in 31 cities of mainland China in summer 2007, and found that, there were obvious differences in the propensity for males and females to choose major subjects. Both males and females were apt to choose those major subjects considered as more appropriate for their respective genders, at least according to conventional and traditional views. The statistics revealed that, in 47 undergraduate major subjects investigated, except Mathematics, Chemistry, Basic Medicine, Clinical Medicine and Medical Technology, there were obvious difference in the probability of males and females choosing the remainder of major subjects. Those major subjects chosen by males that were twice as likely to be chosen by males than by females, were Materials Science, Geology, Mining, Mechanical Engineering, Engineering Mechanics, Physics, Science and Technology of Electronic Information, Civil Construction, 
Surveying and Mapping, and so on. Especially in the first 5 major subjects, the probability of being chosen by males was 5 times more than being chosen by females. Obviously, those majors were all typical Engineering or Science subjects, traditionally 'male-dominated'. In contrast, those major subjects whose probability of being chosen by females was twice that of being chosen by males were Linguistics and Languages, Library Science, Archival Science, Nursing Science, Sociology, Education, Journalism and Communications, Arts, Psychology and Statistics. Especially in the foremost 4 major subjects, the probabllity of being chosen by females was 4 or 5 times more than that likely to have been chosen by males. Those majors are all typical Humanities and Social Sciences subjects, traditionally 'female-dominated' in Chinese higher education, as is often the case elsewhere in the modern world.

In the literature review section, I suggested some possible reasons why, overall in online distance education, the proportion of male learners is lower than that of female learners. In addition to the factor of the major subject being studied, there is another possible reason. Most adult learners are paid workers as well as learners. In addition to the matter of finding time to study alongside paid work, there is the fact that male workers in China have higher salaries than do females. Tan (2012) uses the data of 'Survey of Chinese Graduates Applying for Jobs and Their Work Skills' to examine gender salary gaps for college graduates and its distribution characteristics. Quantile decomposition shows that the gender salary gaps are approximately 9 to 20 percent, with males salaries higher than those of females salaries after only six months following their graduation; Cao, Yue (2010) reviewed recent studies on gender salary gaps In Chinese labour market and also found that there was a significant difference in favour of males. The data of a survey conducted in 1999 on the incomes of residents in mainland China also showed that female salaries were lower than the salaries of men in general in 
almost every occupation. Male learners thus have to face potentially higher opportunity costs in order to undertake adult learning, which might act as a disincentive and thus prevent more male workers from engaging in distance education learning. Therefore, this chapter suggest a second research hypothesis as follows:

Hypothesis 4.2: When the factor of major subject being studied is controlled, there will be a notable decrease of the number of male learners in distance education.

In order to test hypothesis 4.2 , then I constructed a binary Logistic regression model, in which the dependent variable is the gender binary dummy variable, with female as the reference group.

The independent variables include binary dummy variables of 10 different major subjects, which are Philosophy, Economics, Law, Education, Literature, History, Science, Agriculture, Medicine and Management. It means that Engineering operates as the reference group. In addition, the independent variables also include the employment status of learners with the unemployed as the reference group. Regression results can be found in Table 4-14.

From Table 4-14 it can be seen that the coefficient of constant is positive and also significant. The significance level is $p<0.01$. This shows that with control of the major subject being studied, there are more male learners because of this. This refutes hypothesis 4.2 . Then why is this? The reason why I came up with hypothesis 4.2 was that this was due to the fact that distance education learners were mostly adult learners and given that male adult learners would have higher incomes than females, this could mean that the opportunity costs faced by male workers were higher and their participation in distance education would possibly be less than that of 
females.

However, the research shows that it is quite the opposite. A possible explanation for this is that males have higher aspirations and expectations of their careers and this requires continuous investment in their human capital, which encourages more males to choose distance learning. This point is also supported by research conducted by Cao and Yue (2010), where they suggested that, compared with females, males might be more apt to invest in human capital, and also might have more opportunities in work for education, training and promotion.

Table 4-14 Regression Analysis on Learners' Gender

\begin{tabular}{|l|c|c|c|c|c|c|}
\hline & B & S.E. & Wald & Df & Sig. & Exp(B) \\
\hline Philosophy & -1.205 & 0.677 & 3.171 & 1 & 0.075 & .300 \\
\hline Economics & -2.184 & 0.131 & 278.756 & 1 & 0.000 & .113 \\
\hline Law & -0.742 & 0.193 & 14.719 & 1 & 0.000 & .476 \\
\hline Education & -2.355 & 0.207 & 129.618 & 1 & 0.000 & .095 \\
\hline Literature & -2.016 & 0.161 & 157.641 & 1 & 0.000 & .133 \\
\hline History & -0.735 & 1.228 & .358 & 1 & 0.549 & .479 \\
\hline Science & -1.269 & 0.268 & 22.363 & 1 & 0.000 & .281 \\
\hline Agriculture & 19.774 & 23205.422 & .000 & 1 & 0.999 & $387,208,895.164$ \\
\hline Medicine & -4.415 & 0.398 & 123.236 & 1 & 0.000 & .012 \\
\hline Management & -1.063 & 0.114 & 86.344 & 1 & 0.000 & .345 \\
\hline Employment & 0.269 & 0.140 & 3.702 & 1 & 0.054 & 1.308 \\
\hline Constant & 1.160 & 0.157 & 54.681 & 1 & 0.000 & 3.189 \\
\hline-2 Log likelihood & & & 3377.519 & \\
\hline Cox \& Snell R Square & & & 0.192 & \\
\hline Nagelkerke R Square & & & \multicolumn{5}{|c|}{0.256} & \\
\hline N & & & & \\
\hline
\end{tabular}

Note: The dependent variable is the binary dummy variable of whether the learners are male.

From Table 4-14 it can be seen that the variable of 'employment' is also significantly positive, indicating that employed male people tend to choose distance education. This can also support the former assertion, that is, 
employment itself may not become a factor hindering learners' investment in distance education, but it is a contributing factor in the investment in distance education for adults.

The assertion has also been supported by data provided from the interviews that I conducted. In Learning Centre B, there was a male learner B. When asked why he chose online learning, he answered:

'I graduated from a college and entered the present enterprise. Now I am a middle-level manager. Many of my team members hold bachelor's degrees, master's degrees even doctor's degrees. This has given me a lot of pressure. Some time ago, a colleague got promoted from middle-level manager to senior manager, whose age and seniority are both lower than me. Then why was it not me who got promoted? In fact, my performance is better than his. So the most likely cause is my lower academic qualification. Then I told myself, I will get a bachelor's degree as soon as possible and will pursue a master's degree.'

In the literature review, I pointed out that the reason why there are great differences in the marital status of adult learners and distance learners is possibly that this reflects a difference in the major subject being studied.

Thus, I would like to put forward hypothesis 4.3: There are significant differences of marital status among distance learners studying different major subjects.

Table 4-15 is the marital status distribution among learners studying different major subjects. It can be seen from Table 4-15 that indeed there is a notable difference in the marital status of learners in the different major subjects. The significance level is $p<0.01$. In particular, where the major subject is Economics, Law, Literature, Engineering and Management, the proportion of unmarried students is obviously higher. 
Table 4-15 Marital status among learners studying different major subjects

\begin{tabular}{|l|c|c|c|c|}
\hline \multirow{2}{*}{ Major Subjects } & \multicolumn{2}{|c|}{ Unmarried } & \multicolumn{2}{c|}{ Married } \\
\cline { 2 - 5 } & Frequency & Percentage & Frequency & Percentage \\
\hline Philosophy & 1 & $11.1 \%$ & 8 & $88.9 \%$ \\
\hline Economics & 296 & $56.3 \%$ & 230 & $43.7 \%$ \\
\hline Law & 86 & $54.1 \%$ & 73 & $45.9 \%$ \\
\hline Education & 59 & $41.0 \%$ & 85 & $59.0 \%$ \\
\hline Hiterature & 127 & $49.4 \%$ & 130 & $50.6 \%$ \\
\hline Science & 0 & $.0 \%$ & 3 & $100.0 \%$ \\
\hline Engineering & 14 & $22.2 \%$ & 50 & $77.8 \%$ \\
\hline Agriculture & 408 & $51.4 \%$ & 386 & $48.6 \%$ \\
\hline Medicine & 0 & $.0 \%$ & 3 & $100.0 \%$ \\
\hline Management & 61 & $41.8 \%$ & 85 & $58.2 \%$ \\
\hline Total & $52.1 \%$ & 396 & $47.9 \%$ \\
\hline Pearson Chi-Square & & $50.6 \%$ & 1449 & $49.4 \%$ \\
\hline Likelihood Ratio & & & 51.552 & \\
\hline Df & & & 11 & \\
\hline Asymp. Sig. (2-sided) & & & 5.000 & \\
\hline
\end{tabular}

\subsection{Comparison of Different Learners' Satisfaction}

The following section of this chapter compares the differences in learners' levels of satisfaction with distance education, so as to suggest some conclusions about of the characteristics of those who are satisfied with distance education.

The information on learners' satisfaction comes from the answers of the learners to the question: 'Overall, I am very satisfied with this online study.'

Table 4-16 shows the distribution of the satisfaction of learners. $17.2 \%$ of learners are very satisfied with their study; $41.2 \%$ of learners are relatively satisfied with their study. If, as usual, we assign values 1-5 to the five degrees of 'very satisfied', 'relatively satisfied', 'neutral response', 
'dissatisfied' and 'very dissatisfied' respectively' ${ }^{12}$, the average satisfaction score would be 2.29 . Thus, overall, learners' satisfaction with their study is at the midpoint with a slight upper position, certainly not a marked inclination towards satisfaction.

Table 4-16 Learners' Satisfaction

\begin{tabular}{|l|c|c|}
\hline \multicolumn{1}{|c|}{ Learning Satisfaction } & Frequency & Percentage \\
\hline Very satisfied & 503 & 17.2 \\
\hline Relatively satisfied & 1209 & 41.2 \\
\hline Neutral response & 1107 & 37.8 \\
\hline Dissatisfied & 101 & 3.4 \\
\hline Very dissatisfied & 11 & 0.4 \\
\hline Total & 2931 & 100.0 \\
\hline
\end{tabular}

\section{Gender and Satisfaction with Online Learning}

Table 4-17 is the cross-tabulation of learners' gender and their level of satisfaction with online learning.

Table 4-17 Gender and Satisfaction with online learning

\begin{tabular}{|l|c|c|c|c|c|l|}
\hline \multicolumn{1}{|c|}{ Gender } & $\begin{array}{l}\text { Very } \\
\text { Satisfied }\end{array}$ & $\begin{array}{l}\text { Relatively } \\
\text { Satisfied }\end{array}$ & $\begin{array}{l}\text { Neutral } \\
\text { response }\end{array}$ & Dissatisfied & $\begin{array}{l}\text { Very } \\
\text { dissatisfied }\end{array}$ & Total \\
\hline Male & $20.1 \%$ & $41.6 \%$ & $34.9 \%$ & $3.0 \%$ & $0.4 \%$ & $100.0 \%$ \\
\hline Female & $13.7 \%$ & $40.9 \%$ & $41.2 \%$ & $3.9 \%$ & $0.3 \%$ & $100.0 \%$ \\
\hline Pearson Chi-Square & \multicolumn{7}{|c|}{26.888} \\
\hline Likelihood Ratio & \multicolumn{7}{|c|}{27.131} \\
\hline Asymp. Sig. (2-sided) & \multicolumn{7}{|c|}{000} \\
\hline
\end{tabular}

From Table 4-17, it can be seen that there is a significant difference in satisfaction levels between females and males, with a significance level of $p<0.01$. The proportion of males choosing 'very satisfied' or 'relatively satisfied' is higher than that of females, and the proportion of males choosing

${ }^{12}$ In the following contents, I will assign values according to the same way. 
'dissatisfied' and 'very dissatisfied' is lower than that of females. Why do female learners show less satisfaction compared with male learners? This might be because males have more interest in information technology than females and they can improve their communication skills through online learning; on the other hand, it may be that females have stricter standards than males, and expect more of their studies. However, this is all speculation and, it deserves further reflection and study on why men are apparently more satisfied with their online learning.

\section{Marriage and Satisfaction with Online Learning}

Table 4-18 is the cross-tabulation of marital status and level of satisfaction with online learning of the learners in my study.

Table 4-18 Marital Status and Satisfaction with online learning

\begin{tabular}{|l|c|c|c|c|c|l|}
\hline \multicolumn{1}{|c|}{ Marital status } & $\begin{array}{l}\text { Very } \\
\text { Satisfied }\end{array}$ & $\begin{array}{l}\text { Relatively } \\
\text { Satisfied }\end{array}$ & $\begin{array}{l}\text { Neutral } \\
\text { response }\end{array}$ & Dissatisfied & $\begin{array}{l}\text { Very } \\
\text { dissatisfied }\end{array}$ & Total \\
\hline Unmarried & $16.5 \%$ & $37.2 \%$ & $41.5 \%$ & $4.3 \%$ & $0.4 \%$ & $100.0 \%$ \\
\hline Married & $17.8 \%$ & $45.3 \%$ & $34.0 \%$ & $2.6 \%$ & $0.3 \%$ & $100.0 \%$ \\
\hline Pearson Chi-Square & \multicolumn{7}{|c|}{30.063} \\
\hline Likelihood Ratio & \multicolumn{7}{|c|}{30.187} \\
\hline Asymp. Sig. (2-sided) & & \multicolumn{7}{|c|}{000} \\
\hline
\end{tabular}

From Table 4-18, it can be seen that there is a significant difference of learning satisfaction in terms of marital status, with a significance level of $p<0.01$. Here, unmarried learners have significantly lower levels of satisfaction.

Some reasons can be speculated from the following interviews conducted with two learners and an expert in distance education.

In Learning Centre D, learner A who was unmarried mentioned in the interview: 
'As I'm very busy usually, I rarely come to the learning centre to learn or review, nor do I make full use of the online learning platform in my spare time. Yet, it is only one week from our examination, so I have to come here to try my best to review what I've learned in order to get a good score... In fact, I think most of the learners coming here today are similar to me.'

Learner $D$ in Learning Centre $T$ who was married said bluntly when being interviewed:

'I do not care about the barriers or difficulties encountered during the learning, I actually just want an easy way to get a certificate and that's exactly why I picked online learning ... As long as I can eventually pass all the examinations, and can finally get a certificate, I am satisfied.'

The Dean of the Online Education College in D University, who is an expert and also a practitioner of distance education, talked about his confusion during the interview:

'We normally use the pass rate and academic achievement of learners to evaluate a learning centre, a teacher or a tutor but found that it was a mistake. The reason is that once the teachers and staff members set stringent requirements for learners, it may become very difficult for many learners to pass the exams and the dropout rate of enrolled learners will become serious. On the contrary, if the teachers require the learners less, the scores would go up but the quality actually goes down.'

Thus, in online education, academic achievement and learning satisfaction may be two completely different evaluation indices, which deserve attention and further research by distance education practitioners and researchers. 


\section{Distance Learning Experience and Learning Satisfaction}

Table 4-19 Distance Learning Experience and Learning Satisfaction

\begin{tabular}{|l|c|c|c|c|l|l|}
\hline $\begin{array}{c}\text { Distance learning } \\
\text { experiences }\end{array}$ & $\begin{array}{l}\text { Very } \\
\text { Satisfied }\end{array}$ & $\begin{array}{l}\text { Relatively } \\
\text { Satisfied }\end{array}$ & $\begin{array}{l}\text { Neutral } \\
\text { response }\end{array}$ & Dissatisfied & $\begin{array}{l}\text { Very } \\
\text { dissatisfied }\end{array}$ & Total \\
\hline With experience & $19.2 \%$ & $43.9 \%$ & $34.0 \%$ & $2.8 \%$ & $0.2 \%$ & $100.0 \%$ \\
\hline Without experience & $15.5 \%$ & $39.2 \%$ & $40.8 \%$ & $4.0 \%$ & $0.5 \%$ & $100.0 \%$ \\
\hline Pearson Chi-Square & \multicolumn{7}{|c|}{24.301} \\
\hline Likelihood Ratio & \multicolumn{7}{|c|}{0.000} \\
\hline Asymp. Sig. (2-sided) & \multicolumn{7}{|c|}{} \\
\hline
\end{tabular}

Table 4-19 is the cross-tabulation of whether learners have had previous experience of distance learning and their levels of satisfaction with their current online learning. From Table 4-19, it can be seen that the proportions choosing 'very satisfied' and 'relatively satisfied' of those who have had previous distance learning experience are, respectively, $19.2 \%$ and $43.9 \%$, which are both notably higher than the corresponding proportions of $15.5 \%$ and $39.2 \%$ amongst those who have had no previous distance learning experience. And the proportions of choosing 'dissatisfied' and 'very dissatisfied' of those who have had distance learning experiences before are respectively $2.8 \%$ and $0.2 \%$, which are both lower than the corresponding proportions of $4.0 \%$ and $0.5 \%$ amongst those who have had no previous distance learning experience. This shows that, generally speaking, whether or not learners have had previous distance learning experience appears significantly associated with their level of satisfaction with online learning. Learners who have had previous distance learning experience are obviously more content with their current mode of study than those without such previous experience.

This conclusion can be further supported by the interview information provided by the distance learners. When asked whether he felt lonely when studying online, Learner A from the Learning Centre B replied: 
"No, not at all. Isn't online learning aimed at learners' self-dependence?

I have already got my college diploma through online learning and am going to get bachelor's degree through this, too. I do not feel lonely at all."

Although what the learner said about the independent study in online learning may not be totally right, it actually reflects the self-positioning of those who are already familiar with distance learning. Of course, this does not mean that the reason why learners feel dissatisfied is just that they have had no previous experiences of distance learning. On the contrary, distance education institutions should pay more attention to those who have had no relevant previous experiences of distance learning so as to improve their levels of satisfaction with online learning.

\section{Having Children and Learning Satisfaction}

Table 4-20 Having Children and Learning Satisfaction

\begin{tabular}{|l|c|c|c|c|c|c|}
\hline \multicolumn{1}{|c|}{$\begin{array}{c}\text { Status of having } \\
\text { children }\end{array}$} & $\begin{array}{l}\text { Very } \\
\text { Satisfied }\end{array}$ & $\begin{array}{l}\text { Relatively } \\
\text { Satisfied }\end{array}$ & $\begin{array}{l}\text { Neutral } \\
\text { response }\end{array}$ & Dissatisfied & $\begin{array}{l}\text { Very } \\
\text { dissatisfied }\end{array}$ & Total \\
\hline With children & $18.8 \%$ & $45.0 \%$ & $33.2 \%$ & $2.8 \%$ & $0.2 \%$ & $100.0 \%$ \\
\hline Without children & $15.5 \%$ & $37.4 \%$ & $42.5 \%$ & $4.1 \%$ & $0.5 \%$ & $100.0 \%$ \\
\hline About to have children & $16.3 \%$ & $42.5 \%$ & $36.3 \%$ & $3.8 \%$ & $1.3 \%$ & $100.0 \%$ \\
\hline Pearson Chi-Square & \multicolumn{7}{|c|}{35.032} \\
\hline Likelihood Ratio & \multicolumn{7}{|c|}{35.210} \\
\hline Asymp. Sig. (2-sided) & \multicolumn{7}{|c|}{000} \\
\hline
\end{tabular}

Table 4-20 is the cross-tabulation of the learners having or not having children and their level of satisfaction with their current learning. From Table 4-20 it can be seen that the proportions choosing 'very satisfied' and 'relatively satisfied' of those who have children, or who are about to have children, are significantly higher than those who have no children, with a significance level of $p<0.01$. This is consistent with the earlier findings in 
terms of the marital status of learners. Here, people with children, or about to have children, show significantly higher levels of satisfaction.

This suggests that, on the one hand, whilst family responsibilities and child-rearing responsibilities can significantly bring down distance learners' learning outcomes, on the other hand this group of learners manifests a significantly higher level of learning satisfaction. According to the results of the previous interviews, I believe that one possible reason why learners with no family responsibilities appear to have lower levels of satisfaction is that because they may be more critical of what is provided and perhaps more sensitive to the quality of online learning, or they might have higher or even unrealistic expectations of what online learning can offer. Whatever the truth Is (and again it requires more in-depth research), this finding indicates that online education providers should improve every aspect of their teaching and management so as to truly improve the quality of online education and the learning experience which provides to all types of online learner, irrespective of their age, marital or family status, gender or prior experience of distance or online learning.

\section{Family Harmony and Learning Satisfaction}

Table 4-21 is the cross-tabulation of learners' feelings about their family harmony or otherwise and their levels of satisfaction with current learning. From Table 4-21, it can be seen that apart from a small number of sample of learners who reported having unharmonious and very unharmonious families, the proportions of learners who choose 'very satisfied' decrease as the extent of family harmony declines from 'very harmonious' to 'relatively harmonious', which are respectively $22.1 \%, 8.1 \%$. And the proportions of choosing 'dissatisfied' and 'very dissatisfied' tend to increase as the degree of family harmony declines from 'very harmonious' to 'relatively harmonious'. The 
difference is statistically significant with a significance level of $p<0.01$. It can be concluded that it appears that family harmony is significantly associated with the learner's level of satisfaction with his or her learning. However, as ever, we do not know if this represents a direct causal relationship between these variables. All we can be absolutely sure of from these data is that there is a statistically significant relationship which in itself is highly suggestive and worthy of further inquiry.

Table 4-21 Family Harmony and Learning Satisfaction

\begin{tabular}{|l|c|c|c|c|c|c|}
\hline \multicolumn{1}{|c|}{$\begin{array}{c}\text { Degree of family } \\
\text { harmony }\end{array}$} & $\begin{array}{l}\text { Very } \\
\text { Satisfied }\end{array}$ & $\begin{array}{l}\text { Relatively } \\
\text { Satisfied }\end{array}$ & $\begin{array}{l}\text { Neutral } \\
\text { response }\end{array}$ & Dissatisfied & $\begin{array}{l}\text { Very } \\
\text { dissatisfied }\end{array}$ & Total \\
\hline Very harmonious & $22.1 \%$ & $41.4 \%$ & $33.4 \%$ & $2.7 \%$ & $0.4 \%$ & $100.0 \%$ \\
\hline Relatively harmonious & $8.1 \%$ & $43.4 \%$ & $44.4 \%$ & $3.9 \%$ & $0.3 \%$ & $100.0 \%$ \\
\hline Neutral response & $7.4 \%$ & $33.2 \%$ & $50.7 \%$ & $8.3 \%$ & $0.5 \%$ & $100.0 \%$ \\
\hline Unharmonious & $6.7 \%$ & $33.3 \%$ & $60.0 \%$ & $0.0 \%$ & $0.0 \%$ & $100.0 \%$ \\
\hline Very unharmonious & $50.0 \%$ & $0.0 \%$ & $50.0 \%$ & $0.0 \%$ & $0.0 \%$ & $100.0 \%$ \\
\hline Pearson Chi-Square & & & 134.980 & & \\
\hline Likelihood Ratio & & & 141.705 \\
\hline Asymp. Sig. (2-sided) & \multicolumn{7}{|c|}{0.000} \\
\hline
\end{tabular}

Summary of characteristics of learners with high levels of satisfaction with their current learning

By comparing different learners' levels of satisfaction with online learning, the following characteristics can be found:

(1) Male learners show significantly higher levels of satisfaction with their online learning.

(2) Family status and learners' learning satisfaction are significantly related. Learners who are unmarried or without children show significantly lower levels of satisfaction with their online learning. And of course, the more harmonious learner's family is, the higher level of satisfaction with their online learning is reported by the learner in this study. 
(3) Learners with previous experience in distance learning show higher level of satisfaction with their current studies.

\section{Summary of Learners' Characteristics}

This chapter has presented a systematic empirical analysis of the characteristics of the sample of learners in my study and the following characteristics can be found:

(1) Most online learners are employed people, accounting for $91.9 \%$. Most learners study part-time, accounting for $94.0 \%$. Most learners meet their tuition fees at their own expense, accounting for $95.6 \%$.

(2) Most learners engage in relatively frequent social activities and report that they have relatively harmonious families.

(3) Although they are currently studying online, there are still large numbers of learners who prefer or strongly prefer their learning materials in a paper medium (38.6\%). In addition, most learners do not like to study alone, but would rather work closely with the teacher and study with other students.

(4) There is a significant gender difference associated with the different major subjects being studied $(P<0.01)$. Overall, science and engineering disciplines have more male distance learners, while the humanities and social sciences disciplines have more female distance learners. This gender distribution pattern is basically consistent with the situation in standard, campus-based higher education.

(5) By controlling the factor of the different major subject being studied by learners, there are significantly $(p<0.01)$ more male than female learners. And also among employed people, more males than females tend to choose distance learning. This finding, as well as the data collected through interview, 
suggests that males perhaps feel that they need to invest continuously in their human capital, maybe due to their higher aspirations and expectations. Therefore, for adult learners, it seems that employment status may not be a barrier to their investment in distance education, but rather a contributing factor in their decision to enrol in such education. Again, this might be one of the reasons why online distance education has such a big potential market.

(6) Whether learners are employed or not is not associated with any significant difference in their levels of satisfaction with online learning.

(7) There are significant correlations between learners' family status and their levels of satisfaction with online learning $(p<0.1)$. Unmarried learners or learners without children have lower levels of satisfaction with online learning. 


\section{Chapter 5: \\ The Barriers to Online Learning Faced by Distance Learners}

In the previous chapter, I presented an empirical analysis of my sample of online learners' personal characteristics, their circumstances, attitudes and levels of satisfaction with online learning. In this chapter, I present a great deal of empirical evidences on the barriers faced by online learners, based on the information obtained from my surveys and interviews. Firstly, this chapter will introduce the various learning barriers systematically and find out which ones are the most frequently encountered and what level of reported impact, if any, they have upon the learners in my sample, according to their own perceptions. Secondly, this chapter will analyze and discover which factors are the key and significant barriers affecting learners' online study, through factor analysis and multiple linear regression. Thirdly, this chapter will analyze and see whether there is any statistical difference in different learners' experiences of learning barriers or obstacles. Finally, this chapter will analyze whether one learning obstacle will have impact on another one or more, in other words, I will explore whether there appears to be any interaction between the different obstacles identified, again using tests of statistical association, to explore this possibility. Thus, when one learning obstacle is eliminated or reduced in impact, will another one, or more, become weakened or even eliminated?

\section{Learning Barriers facing Distance Learners}

In the second chapter of this thesis, I set up an initial analytical framework of online learning barriers, based on the literature review, on my 
own experience in working in online learning, on conversations with distance learning students and experts in the field, as well as on the known characteristics of The $O$ Institution. On the basis of this very simple 'model', I also designed the questionnaire utilised in this study, which, amongst other issues, asked the respondents about their experience of a range of possible barriers and asked them about their perception of the level of impact of these on their studies. In the sections of this chapter which follow, I report those learner responses and perceptions and test the various factors that emerge for their statistical significance.

In my study, as I say, the barriers explored arise from my own earlier analysis, based on the literature survey, in-depth interviews with key and senior informants, my own extensive experience and conversations with online learners. The study that I report here, it is important to remember, consists principally of the students' perceptions and attitudes as reflected in the responses to my questionnaire, supplemented by data collected through the interviews with students that I conducted. As will be seen, and as might be expected, not all of the online learners studied by me have had the same experiences nor do they have the same perception of the impact on their own studies of the various barriers explored: that is perhaps only to be expected. Moreover, even where a considerable level of impact of a particular factor or barrier is reported, even by a large proportion of the learners themselves, this does not of itself mean that there was in practice such an effect or at such a level: what I report in this chapter is students' perceptions and expectations.

In presenting the data set out in this chapter and the various statistical manipulations that I undertake, to test for possible links and statistical associations, it is important to bear in mind a number of necessary limitations and cautions. 
Firstly, the barriers whose impact that I seek to assess, based on students' perceptions, are derived from the analytical framework presented earlier and are not generated directly from the responses to the questionnaires, although many of them are validated by what students said to me both in the formal interviews that I undertook and informally, over the years of my professional practice. Even so, any weaknesses, omissions or confusions in that framework are bound to affect my findings and recommendations.

Secondly, although my framework is cast in terms of 'barriers', in practice these may only constitute possible or putative barriers in that if a student reports that a given barrier has absolutely no impact on his or her study then, at least for the student concerned, the potential barrier is not perceived or experienced as a barrier. Just to make things even more complex, even if a student perceives that a (potential) barrier has no impact, or very little impact, on his or her studies, this does not mean that in reality no such impact occurs: it only indicates that this is the student's reported perception. All of which means that in dealing with the barriers to learning for online learners (or for any learners in practice) it always needs to be clear whose perspective is being reported and how such a perspective was gathered or measured.

Thirdly, in this chapter, as will be self evident from what follows, I am undertaking a largely statistical analysis, supplemented here and there with data and quotations from the interviews with students and others that I undertook. An important part of that process of statistical analysis is the attempt to seek if there are any statistical associations between different variables, or different clusters of variables. Whilst this is a core element of the research at this stage, even where the various statistical tests suggest either positive, negative or neutral levels of association, in themselves these do not 
indicate any causal relationship between the variables under review. As I explain in the chapter, whilst this reservation is both essential and important, it does not render the analysis worthless.

Thus, making use of the earlier framework and of the data collected principally through the completed questionnaires and interviews, the following represents an empirical analysis of learners' views of the possible impact upon their online learning of a range of barriers. I start by looking at their perception of the possible impact on their learning of a number of factors that are 'external' to the programmes of teaching and learning.

\subsection{External Support: Fees, Costs, Family and Work}

\section{Tuition Fees and Internet Costs}

Table 5-1 Impact of Tuition Fees

\begin{tabular}{|c|c|c|}
\hline Impact Level & Frequency & Percent \\
\hline 1 & 303 & 10.3 \\
\hline 2 & 692 & 23.6 \\
\hline 3 & 1445 & 49.3 \\
\hline 4 & 401 & 13.7 \\
\hline 5 & 90 & 3.1 \\
\hline Total & 2931 & 100.0 \\
\hline Mean & \multicolumn{2}{|c|}{2.76} \\
\hline Std. Deviation & \multicolumn{2}{|c|}{0.922} \\
\hline
\end{tabular}

Table 5-1 is a simple statistical description of learners' own reports about impact concerning their tuition fees. This information comes from learners' answers to the question: "Please choose the answer based on the impact on your study brought by the following environmental factor - 'The tuition fees are too high and they have become a serious financial burden to me." Here I also assign values $1-5$ to the different impact levels reported, with 1 indicating the greatest impact from tuition fees and 5 indicating the least. 
From Table $5-1$, it can be seen that $10.3 \%$ of the learners felt that tuition fees impact was really great, and $23.6 \%$ of them felt the fees were a relatively great impact, adding up to a proportion of $33.9 \%$, one third of the whole sample. A further half of the respondents (49.3\%) chose the mid-point (i.e. a value of 3) of the simple five-point scale of possibly experiencing tuition fees as being too high and a burden. By contrast, only $3.1 \%$ of the learners appeared to feel that the fees were too high and constituted a burden, and a further $13.7 \%$ reported only a little impact from their tuition fees. This indicates that tuition fees are experienced as burdensome by a substantial proportion of the learners in my sample, but by no means were they experienced as a great impact by all or even a majority of learners responding to this question. Furthermore, it can be seen that the mean score on this question was 2.76 , lower than the 'neutral' one of 3 , which might be taken to indicate that whilst, on average, these learners did not consider the fees to be especially high and a particularly large burden, nevertheless there is some evidence that such evaluations of fees cannot be entirely disregarded.

Table 5-2. Impact of the Cost of the Internet

\begin{tabular}{|c|c|c|}
\hline Impact Level & Frequency & Percent \\
\hline 1 & 197 & 6.7 \\
\hline 2 & 512 & 17.5 \\
\hline 3 & 1441 & 49.2 \\
\hline 4 & 623 & 21.3 \\
\hline 5 & 158 & 5.4 \\
\hline Total & 2931 & 100.0 \\
\hline Mean & & 3.01 \\
\hline Std. Deviation & \multicolumn{2}{|c|}{0.934} \\
\hline
\end{tabular}

Table $5-2$ is a simple statistical description of learners' reports about their feelings concerning the expense for these learners of using the Internet. This information comes from learners' answers to the question: "Please 
choose the answer based on the impact on your study brought by the following environmental factor - 'The Internet fees are too expensive'."

From Table 5-2, it can be seen that whilst only $6.7 \%$ of the learners felt that the costs of accessing the Internet had a large impact on their studies, a further $17.5 \%$ of the learners felt relatively great impact from these costs, adding up to a proportion of $24.2 \%$ or about one quarter of all respondents. Learners who felt little or almost no impact accounted for $26.7 \%$ of responses to this question and $49.2 \%$ of the learners chose the mid-point on the available scale - again the largest single category. Whilst this certainly suggests that almost half did not consider the costs of using the Internet had a major impact on their studies, they equally certainly did not think that these costs had no, or only little, impact. It can be seen that the mean score on this question is 3.01, indicating that on average the costs of using the Internet are experienced as having some impact on the studies of the learners in my sample, at the same time this potential impact is slightly less serious than the impact experienced from their tuition fees.

We need to explore further why there is a relatively large minority of learners feeling that tuition fees and Internet costs had a burdensome impact on their studies. One important reason for this might be that the direct costs to learners of online learning are higher than the direct costs of face-to-face learning, and this is reflected in the charges that these learners faced. Setting up the network platform, making courseware, constructing online resources, and organizing specialized support services are all very costly undertakings. In addition, tuition fees and other learning costs are mainly paid by the learners themselves: the proportion of learners in my study who paid for their distance education at their own expense was $96 \%$. Learners who got full financial support from employers represented only $1 \%$ while learners who shared the payment with their employers accounted for $3 \%$. 
During the interviews, it was found that learners who live in urban areas generally have computers in their office and at home as well as good Internet access, while those who live in rural areas often have poor Internet access and sometimes they have to obtain computers and Internet access just for distance learning, which costs much more than if they already have these resources or can readily access them.

Although The $\mathrm{O}$ Institution has taken economic differences in different areas of the country into account in its policies and practices and has set different fee standards accordingly, there is still a very big gap of income between cities and rural areas in China. During the interviews, it was found that learners from towns and villages voiced more complaints about economic burdens, while learners living in cities felt better about these but they also hoped the tuition fees will not go any higher.

Learner $C$ from Learning Centre $D$ was interviewed and said:

"The Internet access fees are a little expensive but still affordable. However, the tuition fee was too high. Buying a computer if you do not have one, paying Internet fees, and paying tuition fees will add up to $5000+2000+6000$, which will be more than ten thousand."

This shows that even though some learners can bear each individual fee, when they are all added together, the costs are considerable, and represented for learner $\mathrm{C}$, a civil servant, something of a burden, having a big impact on their studies.

\section{Lack of Support from Employers, Families and Friends}

Table $5-3$ is a simple statistical description of learners' reports about the lack of support from their employers or bosses. From Table 5-3, it can be seen that only $2 \%$ of the learners said that there certainly was a great impact 
on their studies because their bosses did not support their studies, and $4.5 \%$ of the learners felt that such a situation constituted a relatively big impact, adding up to only $6.5 \%$ overall. Learners who felt little impact from this cause constituted $49.9 \%$, half of all the respondents, and those who indicated the lowest level of impact from employers' lack of support accounted for $23 \%$. Furthermore, the mean score in responses to this question is 3.88 , close to the 'little impact' indicator (with a value of 4 ). This shows that as a whole, lack of employers' support appears not to have been perceived as having any impact upon these learners' studies.

Table 5-3 Lack of Employers' Support

\begin{tabular}{|c|c|c|}
\hline Impact Level & Frequency & Percent \\
\hline 1 & 59 & 2.0 \\
\hline 2 & 131 & 4.5 \\
\hline 3 & 602 & 20.5 \\
\hline 4 & 1464 & 49.9 \\
\hline 5 & 675 & 23.0 \\
\hline Total & 2931 & 100.0 \\
\hline Mean & \multicolumn{2}{|c|}{3.88} \\
\hline Std. Deviation & \multicolumn{2}{|c|}{0.883} \\
\hline
\end{tabular}

Table $5-4$ is a simple statistical description of learners' reports concerning some impact on their learning arising from the lack of the support from families and friends. From Table $5-4$, it can be seen that only $2 \%$ of the learners said that there was a great impact on their studies because families and friends did not support their learning, and only $3.3 \%$ of the learners felt there was a relatively large impact, adding up to a very small proportion of $5.3 \%$ overall. Learners who experienced little impact accounted for $49.8 \%$, and those who did not feel there was great impact made up almost one third of the respondents ( $31 \%$ ). Furthermore, the mean score for responses to this question was 4.05, higher than 'not great impact', (again given a value of 4 ). This shows that, as a whole, lack of families' and friends' support was not 
experienced by learners in this study as having an impact and might even suggest the opposite, namely that, on the whole, families and friends have been supportive, although this question did not test that assumption.

Table 5-4 Lack of Support from Families and Friends

\begin{tabular}{|c|c|c|}
\hline Impact Level & Frequency & Percent \\
\hline 1 & 58 & 2.0 \\
\hline 2 & 98 & 3.3 \\
\hline 3 & 407 & 13.9 \\
\hline 4 & 1459 & 49.8 \\
\hline 5 & 909 & 31.0 \\
\hline Total & 2931 & 100.0 \\
\hline Mean & \multicolumn{2}{|c|}{4.05} \\
\hline Std. Deviation & \multicolumn{2}{|c|}{0.871} \\
\hline
\end{tabular}

This finding was supported by data from the interviews. During the Intervlews, a lot of people expressed the view that the bosses, families and friends, no matter whether they were young or old, all encouraged them to study. They even gave them some direct support and help. For example, when it was examination time, the learners were able to request a shift change and even ask for leave. Family members also gave them every possible support in terms of help with housework and finance. Learner B from Learning Centre D said:

"When we apply for senior professional titles, we need to have undergraduate degree. Thus, for sure, my bosses will support me to get this certificate through online study... they can let you study in office, as long as it won't affect my own current job."

In terms of families' and friends' support, the experiences of female learners and male learners suggested significant differences from the material collected in the interviews. Most male learners felt that they had strong support from family members and friends while female learners have 
more complaints. For example, learner B from Learning Centre D was a female learner. Her bosses were very supportive of her study. However, as women in China, as in most countries, still conventionally shoulder more family responsibilities, it is likely that greater impact on study from family life would be encountered. She said:

"Of course, there are difficulties. Guys may not feel this. But for women like us, with children, we have too many things to do. When we want to go online, the kids are just restless... We do not have time to study and have to wait for the kids to go to bed and then do our homework."

\section{Impact of Working and Family Responsibilities}

Table 5-5 Impact of Paid Work/Jobs

\begin{tabular}{|c|c|c|}
\hline \multicolumn{1}{|c|}{ Impact Level } & Frequency & Percent \\
\hline 1 & 361 & 12.3 \\
\hline 2 & 805 & 27.5 \\
\hline 3 & 1121 & 38.2 \\
\hline 4 & 515 & 17.6 \\
\hline 5 & 129 & 4.4 \\
\hline Total & 2931 & 100.0 \\
\hline Mean & \multicolumn{2}{|c|}{2.74} \\
\hline Std. Deviation & \multicolumn{2}{|c|}{1.026} \\
\hline
\end{tabular}

Table 5-5 is a simple statistical description of learners' reports about the impact on their studies of working in a paid job. From Table 5-5, it can be seen that $12.3 \%$ of the learners said that there was a great impact on their studies stemming from working in a job, and $27.5 \%$ of the learners felt a relatively great impact, adding up to two fifths $(39.8 \%)$ of the learners. Learners who felt that having a job had little impact added up to $22 \%$ of the respondents. Furthermore, the mean score for responses to this question was 2.74, lower than 'not so great an impact' (indicated by the value of 3 ). This suggests that, on average, the impact of being busy working in paid 
employment had a relatively little impact on learners' studies.

Table 5-6 is a simple statistical description of learners' reports about the impact upon their studies from their family responsibilities.

Table 5-6 Impact of Family Responsibilities

\begin{tabular}{|c|c|c|}
\hline Impact Level & Frequency & Percent \\
\hline 1 & 210 & 7.2 \\
\hline 2 & 612 & 20.9 \\
\hline 3 & 1268 & 43.3 \\
\hline 4 & 670 & 22.9 \\
\hline 5 & 171 & 5.8 \\
\hline Total & 2931 & 100.0 \\
\hline Mean & & \\
\hline Std. Deviation & \multicolumn{2}{|c|}{0.979} \\
\hline
\end{tabular}

From Table 5-6, it can be seen that $7.2 \%$ of the learners said that there was a great impact on their studies brought about by their family responsibilities (mainly household duties), and $20.9 \%$ of the learners felt relatively great impact, adding up to a proportion just less than $30 \%$ : about the same proportion that reported little impact from family responsibilities. Furthermore, the mean score on this matter was 2.99 , very close to the mid-point of 'not so great an impact', with the value of 3 . This shows that, in their opinion, as a whole, their family responsibilities have represented a certain degree of negative impact on their studies, but not a great one.

By comparing Tables 5-5 and 5-6, it can be observed that working in a job apparently constitutes more impact for learners than do family responsibilities. Of course, this may be due to the fact that there are more male learners, for whom, as things stand, work pressures are rather greater than family responsibilities. During the interviews, it was also noticed that there were more male learners complaining about the impacts of working on their studies. For example, Learner C from Learning Centre D, a civil servant, 
complained:

"Before, my working time was well scheduled but now because of the Olympic Games, I have to work at the weekends too. I feel too exhausted and lazy to do any study... I even interact with teachers much less."

\subsection{Learning Barriers and Computers}

\section{Lack of Computers and Inconvenient Internet Access}

Table 5-7 Impacts from Lack of Computers

\begin{tabular}{|c|c|c|}
\hline Impact Level & Frequency & Percent \\
\hline 1 & 164 & 5.6 \\
\hline 2 & 163 & 5.6 \\
\hline 3 & 209 & 7.1 \\
\hline 4 & 1301 & 44.4 \\
\hline 5 & 1094 & 37.3 \\
\hline Total & 2931 & 100.0 \\
\hline Mean & \multicolumn{2}{|c|}{4.02} \\
\hline Std. Deviation & 1.082 \\
\hline
\end{tabular}

Table 5-7 is a simple statistical description of learners' reports about the impact upon their studies of learners lacking computers.

From Table $5-7$, it can be seen that $5.6 \%$ of the learners said that there was a great impact on their study from their lack of computers, and a further $5.6 \%$ of the learners felt relatively great impact, adding up to a proportion of only just over one tenth of the respondents. Learners who felt there were little impact or did not experience any impact at all made up a proportion of more than $80 \%$. Furthermore, the mean score on this issue was 4.02 , markedly higher than 'not so great impact' number 4 . This shows that as a whole, lacking computers does not appear to constitute a main obstacle for learners in this study, at least from their own perceptions and points of view. 
Again, I need to repeat the caveat: just because this is an accurate reflection of their reported perceptions, this does not mean that learners' studies were not affected by the availability of computers. The same caveat applies to the next element of data examined.

Table 5-8 is a simple statistical description of learners' reports about the impact on their studies of inconvenient Internet access.

From Table $5-8$, it can be seen that $10 \%$ of the learners said that there was a great impact on their studies from inconvenient Internet access, and also a further $10 \%$ of the learners felt relatively great impact, adding up to a proportion of $20 \%$, or one fifth of my respondents, at least a notable minority. Learners who felt little impact or did not report any impact at all made up almost $70 \%$, over two-thirds of the respondents in the study. Furthermore, the mean score on this item was 3.66, higher than 'not so great impact', with a value of 3 . This suggests that, as a whole, inconvenient Internet access was not seen a main obstacle by the learners in this study. Nevertheless, it is worth noting that a substantial minority still reported that problems in accessing the Internet had a fairly big impact on their studies, and this certainly requires improvement.

Table 5-8 Impacts from Inconvenient Internet Access

\begin{tabular}{|c|c|c|}
\hline Impact Level & Frequency & Percent \\
\hline 1 & 294 & 10.0 \\
\hline 2 & 295 & 10.1 \\
\hline 3 & 354 & 12.1 \\
\hline 4 & 1148 & 39.2 \\
\hline 5 & 840 & 28.7 \\
\hline Total & 2931 & 100.0 \\
\hline Mean & & 3.66 \\
\hline Std. Deviation & \multicolumn{2}{|c|}{1.265} \\
\hline
\end{tabular}

From Tables $5-7$ and $5-8$, it can be seen that having the minimum 
necessary hardware and infrastructure conditions, computers and Internet access, do not constitute a main obstacle to online learning, at least to the majority of learners in my study. However, as China is a vast country, there are significant differences between regions, urban and rural areas. Some scholars have named this phenomenon as 'one China, four worlds' (Hu and Xiong, 2000); Thus, although a lack of access to computers and the Internet are not main barriers for learners in economically developed areas, they are still problems faced by people in poor areas, especially in poor rural areas according to previous research that I have undertaken.

\section{Computer and Internet Operational Matters}

Table 5-9 Deficiency with Computer Operation Skills

\begin{tabular}{|c|c|c|}
\hline Impact Level & Frequency & Percent \\
\hline 1 & 84 & 2.9 \\
\hline 2 & 200 & 6.8 \\
\hline 3 & 618 & 21.1 \\
\hline 4 & 1213 & 41.4 \\
\hline 5 & 816 & 27.8 \\
\hline Total & 2931 & 100.0 \\
\hline Mean & \multicolumn{2}{|c|}{3.85} \\
\hline Std. Deviation & \multicolumn{2}{|c|}{0.998} \\
\hline
\end{tabular}

Table 5-9 is a simple statistical description of learners' reports about the impact on their learning represented by problems with computer operations. From Table 5-9, it can be seen that only $2.9 \%$ of the learners said that there was a great impact on their study due to their deficiency in computer operation skills, and also $6.8 \%$ of the learners felt there was a relatively great impact, adding up only less than $10 \%$ in total. Learners who felt little impact or did not felt there was any impact at all made up almost $70 \%$. Furthermore, the mean score on this question was 3.85, near to 'not so great an impact', indicated by the value of 4 . This shows that as a whole, a deficiency with 
computer operation skills was not experienced as a main obstacle for most learners in my study, although it needs to be remembered that, to some extent at least, this is a self-selected sample, which might have biassed the responses: at least, in taking up online distance learning, the learners in my study must have expected to be able to work effectively with computers.

Table 5-10 is a simple statistical description of learners' reports about the impact on their studies of them not being familiar with using the Internet to interact with others. From Table 5-10, it can be seen that only $3 \%$ of the learners said that there was a great impact on their studies from their felt lack of skills for interaction online, and also $6.9 \%$ of the learners felt relatively a great impact from such a lack, again adding up to a proportion of less than $10 \%$. By contrast, there were more than $70 \%$ of the learners who felt that there was no great impact from a deficiency in their skills of interaction online. Furthermore, the mean score on this question was 3.91, close to 'not so great impact', indicated by the value of 4 . This shows that as a whole, not only was insufficient computer operational capability not a main obstacle for most learners in this study, but also that insufficient interaction online did not constitute a main obstacle for the learners in my study. Once again, however, the caveat of them being, to an extent anyway, a self-selected group must be remembered.

Moreover, in reporting these data, again it needs to be remembered that what is being recorded here are the learners' own assessments of their skills and aptitudes in using computers and the Internet. Of course, that may or may not be an accurate measure of their competence and it is always possible that they overestimated their skills and, hence, failed fully to understand the impact of what might have been less developed skills on their studies. That does not mean that these data in themselves are invalid or of no interest, quite the contrary, but it does emphasize that these are only the learners' 
own, self-reported assessments and such assessments may or may not be accurate, or measured by each of them against a common scale of competence measurement. This reservation needs to be borne in mind again with the following tables.

Table 5-10 Deficiency of skills on Interaction Online

\begin{tabular}{|c|c|c|}
\hline Impact Level & Frequency & Percent \\
\hline 1 & 87 & 3.0 \\
\hline 2 & 202 & 6.9 \\
\hline 3 & 512 & 17.5 \\
\hline 4 & 1231 & 42.0 \\
\hline 5 & 899 & 30.7 \\
\hline Total & 2931 & 100.0 \\
\hline Mean & \multicolumn{2}{|c|}{3.91} \\
\hline Std. Deviation & \multicolumn{2}{|c|}{1.008} \\
\hline
\end{tabular}

Table 5-11 is a simple statistical description of learners' reports about the impact on their studies of learners' deficiency of skills in finding learning resources online. From Table 5-11, it can be seen that only $3 \%$ of the learners said that there was a great impact on their studies from their having a deficiency of skills for finding learning resources online, and also $8 \%$ of the learners felt there was a relatively great impact from such a lack, adding up to a proportion of $11 \%$. By contrast, there were almost $70 \%$ of the learners who felt that there was no great impact from this deficiency of skills in finding learning resources online. Furthermore, the mean score on this question was 3.79, again close to 'not so great an impact' level, indicated by the value of 4 . This shows that, as a whole, it was felt by the respondents that a deficiency of skills in finding learning resources online, or believing that they lacked such skills, was also not experienced as a main obstacle for the learners in this study, in so far as their own evaluations of their competence and skills in these aspects of their studies were accurate. If, for example, they were less competent than they judged themselves to be, not only might the reality 
have a greater impact on their studies than they believed, but this perception itself might constitute an unrecognised difficulty or barrier.

Table 5-11 Deficiency of Skills to Find Learning Resources Online

\begin{tabular}{|c|c|c|}
\hline Impact Level & Frequency & Percent \\
\hline 1 & 87 & 3.0 \\
\hline 2 & 235 & 8.0 \\
\hline 3 & 616 & 21.0 \\
\hline 4 & 1251 & 42.7 \\
\hline 5 & 742 & 25.3 \\
\hline Total & 2931 & 100.0 \\
\hline Mean & \multicolumn{2}{|c|}{3.79} \\
\hline Std. Deviation & \multicolumn{2}{|c|}{1.004} \\
\hline
\end{tabular}

From Tables 5-9, 5-10, and 5-11, we can see that learner's abilities with computers and Internet operations were not perceived as having any great impact upon the majority of online learners in this study, and hence it may be suggested do not appear to constitute barriers to their learning or have serious negative effects on their studies. This is wholly consistent with the finding in Chapter 4 that learners in this study considered their initial abilities in these aspects of study to be relatively high.

\section{Online Learning Platform Usage}

Table 5-12 is a simple statistical description of learners' attitudes about their perception of the impact on their studies resulting from their lack of skill in using the online learning platform provided. From Table 5-12, it can be seen that only $2.3 \%$ of the learners said that their lack of skills in using the online learning platform constituted a great impact on their studies, and $5.5 \%$ of the learners felt such a lack of skills constituted a relatively big Impact, adding up to a total of only $7.8 \%$. At the same time, almost $70 \%$ of the learners felt that they had not experienced any great impact on their studies from such a lack of skill. Furthermore, the mean score for responses 
to this question was 3.77 , close to 'not so great an impact' score of 4 . This indicates that, as a whole, a perceived lack of skills amongst learners in using the online learning platform in The $O$ Institution was not a major barrier for them, as far as they perceived matters.

Table 5-12 Lack of Skills in Using the Online Learning Platform

\begin{tabular}{|c|c|c|}
\hline \multicolumn{1}{|c|}{ Impact Level } & Frequency & Percent \\
\hline 1 & 68 & 2.3 \\
\hline 2 & 161 & 5.5 \\
\hline 3 & 741 & 25.3 \\
\hline 4 & 1373 & 46.8 \\
\hline 5 & 588 & 20.1 \\
\hline Total & 2931 & 100.0 \\
\hline Mean & \multicolumn{2}{|c|}{3.77} \\
\hline Std. Deviation & \multicolumn{2}{|c|}{0.910} \\
\hline
\end{tabular}

Although most learners do not think that the current learning platform in The $O$ Institution has constituted for them any great difficulties in their studies, there were still a lot of learners who proposed some improvements as follows. Each of the following points is a summary of students' views and suggestions for improvement.

(1) Normally, learners would use only the functions of Notice, Tutorial Materials, Courseware Browsing, and Assignment. However, these commonly used function 'buttons' are not highlighted or obvious enough. Function modules like 'Assignment' and 'Courseware' can only be opened after several mouse 'clicks'. This has brought a lot of trouble to learners, as they have to spend a lot of time finding and getting used to this.

(2) It would be better to put learners' assignments all together on one page, as learners tend to submit their assignments after finishing one page without looking at other pages.

(3) The course announcement system is currently a bit confusing. 
Announcements from learning centres and universities are not clearly separated, which makes it difficult for learners to identify the most important notices.

In addition, from the interviews, it was also found that many learners generally tended not to visit the home page of The $O$ Institution, but rather directly use their account to access the study module. However, the platform is upgraded often and changes greatly, which requires learners to spend a long time adapting to it. Some learners also expressed the view that whenever it is examination time, the online learning platform is 'very difficult to $\log$ on to, and unbelievably slow'.

\subsection{Courses and Learning Resources}

\section{Problems with Courses}

Table 5-13 Lack of Interest in Courses Provided

\begin{tabular}{|c|c|c|}
\hline Impact Level & Frequency & Percent \\
\hline 1 & 49 & 1.7 \\
\hline 2 & 152 & 5.2 \\
\hline 3 & 982 & 33.5 \\
\hline 4 & 1424 & 48.6 \\
\hline 5 & 324 & 11.1 \\
\hline Total & 2931 & 100.0 \\
\hline Mean & & 3.62 \\
\hline Std. Deviation & \multicolumn{2}{|c|}{0.813} \\
\hline
\end{tabular}

Table $5-13$ is a simple statistical description of learners' reports about the impact on their studies arising from learners' lack of interest in the courses provided. From Table 5-13, it can be seen that only $1.7 \%$ of the learners said that there was a great impact on their studies due to their lack of interest in the courses provided, and $5.2 \%$ of the learners felt there was a relatively great impact, adding up to only a small proportion overall of the sample: just 
$6.9 \%$ in total. There were almost $60 \%$ of the learners who felt no great impact on their studies from their lack of interest in the courses provided. Given that fully one third of the respondents placed themselves in the middle of the scale on this question, accordingly, the mean score on this variable was 3.62 , close to 'not so great an impact' allocated the value of 4 . This shows that as a whole, learners' lack of interest in the courses provided did not represent a main obstacle for these learners.

Table 5-14 Too Much Course Content

\begin{tabular}{|c|c|c|}
\hline Impact Level & Frequency & Percent \\
\hline 1 & 109 & 3.9 \\
\hline 2 & 426 & 15.3 \\
\hline 3 & 1118 & 40.2 \\
\hline 4 & 1021 & 36.7 \\
\hline 5 & 109 & 3.9 \\
\hline Total & 2783 & 100.0 \\
\hline Mean & \multicolumn{2}{|c|}{3.30} \\
\hline Std. Deviation & \multicolumn{2}{|c|}{0.949} \\
\hline
\end{tabular}

Table 5-14 is a simple statistical description of learners' reports about the perceived impact on their studies arising from there being 'too much course content'. From Table 5-14, it can be seen that almost $20 \%$ of the learners said that there was a great impact on their studies because of too much course content; while $40 \%$ of the learners felt no great impact; at the same time, $40 \%$ of the learners placed themselves at the mid-point on the scale of responses.

The mean score on this occasion, in Table 5-14, was 3.30, higher than the 'neutral' score, given a value of 3 . This shows that, overall, although too much course content is not a main obstacle for learners, there is still a substantial minority of learners who felt this was the case. Although only one fifth of the sample reported that they felt there was too much course content, 
still a notable minority, the extent of this negative response is still higher than the negative responses given to many of the other issues so far reviewed as being perceived as potential barriers facing online learners. This should not be overlooked.

From Tables 5-13 and 5-14, it can be seen that 'lack of interest in courses' and 'too much course content' have not apparently constituted too serious learning difficulties for the learners in this study. The factor of 'too much course content' brought more difficulties for learners than the factor of their own lack of interest in courses.

Some reasons for this were provided in the interviews. Many learners were more interested in specialized courses, but showed less interest in public courses such as Politics or English. That is to say, some learners complained about 'too much course content' largely because they felt that there were too many public courses. Learner A from Learning Centre D complained in the interview:

"I do not like English... we do not need any English in daily work. If we are moving toward internationalization, we can learn English through crash courses. But now even in distance education, there is a minimum requirement of passing English level 3. If you cannot pass it, then you can only get a certificate of completion instead of a bachelor's degree certificate."

\section{Learning Resources}

Table $5-15$ is a simple statistical description of learners' reports about the Impact on their learning that they felt caused by inappropriate teaching materials. From Table $5-15$, it can be seen that only $2.0 \%$ of the learners said that there was a great impact on their studies arising from unsuitable 
teaching materials and also only $7.0 \%$ of the learners felt a relatively great impact from this source, adding up to a proportion of less than $10 \%$ of the overall sample; almost $60 \%$ of the learners felt there had not been any great impact. Furthermore, the mean score on this question was 3.59 , notably higher than the 'neutral' score which scored 3 . This shows that, as a whole, the problem of unsuitable teaching materials was not experienced by the great majority of these learners as a main obstacle in this study.

Table 5-15 Unsuitable Teaching Materials

\begin{tabular}{|c|c|c|}
\hline Impact Level & Frequency & Percent \\
\hline 1 & 60 & 2.0 \\
\hline 2 & 206 & 7.0 \\
\hline 3 & 928 & 31.7 \\
\hline 4 & 1424 & 48.6 \\
\hline 5 & 313 & 10.7 \\
\hline Total & 2931 & 100.0 \\
\hline Mean & \multicolumn{2}{|c|}{3.59} \\
\hline Std. Deviation & \multicolumn{2}{|c|}{0.848} \\
\hline
\end{tabular}

Table 5-16 is a simple statistical description of learners' reports about the impact they perceive as arising from an inability to download courseware.

Table 5-16 Inability to Download Courseware

\begin{tabular}{|c|c|c|}
\hline \multicolumn{1}{|c|}{ Impact Level } & Frequency & Percent \\
\hline 1 & 360 & 12.3 \\
\hline 2 & 562 & 19.2 \\
\hline 3 & 925 & 31.6 \\
\hline 4 & 840 & 28.7 \\
\hline 5 & 244 & 8.3 \\
\hline Total & 2931 & 100.0 \\
\hline Mean & \multicolumn{2}{|c|}{3.02} \\
\hline Std. Deviation & \multicolumn{2}{|c|}{1.141} \\
\hline
\end{tabular}

From Table 5-16, it can be seen that the learners divided into three main groups in response to this question. Almost $30 \%$ of the learners said that 
there was great, or very great impact on their studies when they could not download the courseware, but $37.0 \%$ of the learners felt no such great impact, and more than $30 \%$ of the learners placed themselves at the mid-point on the scale of responses. Furthermore, the mean score on this question was 3.02, very close indeed to the 'neutral' response that scored 3 , but that only goes to show that the overall mean score can be very misleading as a presentation either of the respondents as a whole or of the different groups within the sample. In any case, these data suggest that, overall, an inability to download courseware while not a main obstacle for about one third of the respondents, this was nonetheless an obstacle for a substantial minority of the learners that I studied.

In the literature review section, I introduced the research concerning barriers to adult learning in China and mentioned that the problem of unsuitable learning resources has been reported elsewhere as being a significant obstacle for adult learners (Jiang et al, 2003; Tao, 2004). From Tables 5-15 and 5-16, it can be observed that the responses in my study suggest that, for these learners at any rate, the provision of poor learning resources of the sort I inquired about was not a major obstacle to their learning, due no doubt, in part, to the fact that curriculum designers and courseware compilers have recognized the importance of offering suitable teaching materials and courseware to adult online learners. But, even so, how the resources are used or accessed may bring new barriers. A lot of learning resources cannot be downloaded, which hinders learners' ability to study online: when learners cannot access the Internet, they cannot study either.

During the interviews, there were many learners complaining about this. As they had to work and study at the same time, they had relatively fragmented time available and also experienced restricted Internet access 
conditions. This brought learners a lot of inconvenience in that courseware could not be downloaded or even opened at the end of classes. Especially when it came to examination time, many learners were looking for relatively quiet places to study and to review their work, but due to the inability to download learning resources, they just had to give up this idea.

Learner A from Learning Centre D put forth his objections thus and said:

"The current courseware can only be used for one term instead of a lifelong time. This is a rigid time restriction for me. When I cannot remember what I have learned, I cannot review it. The courseware cannot be downloaded as well. If only it can be downloaded to the U disk. However, we were told that our student ID number was available for lifelong. This is quite at odds with the truth."

In fact, the inability of distance online learners to download learning resources has become a big dilemma in distance education in China. On the one hand, in order to protect intellectual property rights, to prevent courseware piracy and transmission, learning resources' providers limit courseware usage offline, as they spend huge sums of money on producing courseware. On the other hand, learners feel this to be an inconvenience as they can only study online with their student account. In order to attract more people to online education, it is important to reconcile the convenience for learners with the commercial interests of providers. The problem of courseware downloading should be settled based on discussions between researchers, online education providers and learners.

\subsection{The Impact of Teachers' Lack of Professional Knowledge}

Table 5-17 is a simple statistical description of learners' reports about the impact to their learning that arose from teachers' perceived lack of professional knowledge. From Table $5-17$, it can be seen that only $2.2 \%$ of 
the learners said that they felt that there had been a great impact on their study due to teachers' perceived insufficient knowledge, and $4.8 \%$ of the learners felt there was a relatively great impact, adding up to a total of $7 \%$.

Table 5-17 Impact of Teachers' Lack of Professional Knowledge

\begin{tabular}{|c|c|c|}
\hline \multicolumn{1}{|c|}{ Impact Level } & Frequency & Percent \\
\hline 1 & 65 & 2.2 \\
\hline 2 & 140 & 4.8 \\
\hline 3 & 1025 & 35.0 \\
\hline 4 & 1351 & 46.1 \\
\hline 5 & 350 & 11.9 \\
\hline Total & 2931 & 100.0 \\
\hline Mean & \multicolumn{2}{|c|}{3.61} \\
\hline Std. Deviation & \multicolumn{2}{|c|}{0.840} \\
\hline
\end{tabular}

However, there were almost $60 \%$ of the learners who felt there had been no great impact because of this matter. Furthermore, the mean score on this question was 3.61, higher than the mid-point 'moderate impact' response, allocated the value of 3 . This shows that as a whole, teachers' lack of knowledge was not seen as a main obstacle for learners in my sample.

Table 5-18 Lack of Teacher-Student Interaction

\begin{tabular}{|c|c|c|}
\hline Impact Level & Frequency & Percent \\
\hline 1 & 346 & 11.8 \\
\hline 2 & 701 & 23.9 \\
\hline 3 & 1128 & 38.5 \\
\hline 4 & 570 & 19.4 \\
\hline 5 & 186 & 6.3 \\
\hline Total & 2931 & 100.0 \\
\hline Mean & & 2.85 \\
\hline Std. Deviation & \multicolumn{3}{|c|}{1.066} \\
\hline
\end{tabular}

Table 5-18 is a simple statistical description of learners' reports about their experience of a lack teacher-student interaction. From Table 5-18, it can be seen that $35.7 \%$ of the learners said that they felt that there had been a 
great, or very great impact on their studies arising from the lack of interaction with teachers, whilst about a quarter of the learners felt that there had been no great impact from this. Almost $40 \%$ of the learners gave a neutral response. Furthermore, the mean score on this issue was 2.85 , close to the 'neutral score', allocated a value of 3 , although, once more, just focussing on the mean score tells us nothing about the distribution of scores, especially the fact that as many as one third of those learners who were surveyed in my study reported a negative effect of the lack of interaction with teachers. A perceived lack of interaction with teachers was indeed a main issue for a substantial proportion of the learners that I studied.

Learner A from Learning Centre $T$ complained about the problem of a perceived lack of teacher-student interaction. He said:

"Some of my classmates asked the teachers for help before. But the teachers' answers were very simple and ambiguous ...So, now I rarely interact with teachers. Whenever I encounter a problem, I always try to solve it by myself. Only when it cannot be solved at all, would I go to the teacher... I do want to have face-to-face interactions with teachers. But basically there is just no such opportunity..."

From Tables 5-17, 5-18, it can be observed that a perception of teachers' professional competence did not constitute a major obstacle for students' learning. But the lack of teacher-student interaction has become perceived as a main learning obstacle for a substantial minority of the learners whom I surveyed.

\subsection{Barriers Concerning Teaching Support}

Table 5-19 is a simple statistical description of learners' reports about the impact of a poor service attitude of learning support staff. . 
Table 5-19 Support Staff's Poor Attitude on Service Provision

\begin{tabular}{|c|c|c|}
\hline Impact Level & Frequency & Percent \\
\hline 1 & 44 & 1.5 \\
\hline 2 & 113 & 3.9 \\
\hline 3 & 765 & 26.1 \\
\hline 4 & 1520 & 51.9 \\
\hline 5 & 489 & 16.7 \\
\hline Total & 2931 & 100.0 \\
\hline Mean & \multicolumn{2}{|c|}{3.78} \\
\hline Std. Deviation & \multicolumn{2}{|c|}{0.819} \\
\hline
\end{tabular}

From Table $5-19$, it can be seen that only $1.5 \%$ of the learners said that there was a great impact on their studies due to learning support staff's poor service attitude, and only $3.9 \%$ of the learners felt a relatively great impact from this, adding up to a proportion of $5.4 \%$. By contrast, almost $70 \%$ of the learners felt no great impact, and just over one quarter of them reported a neutral response. The mean score on responses to this issue was 3.78 , close to the 'not so great impact' number 4 . This, together with the marked views of a majority, suggests that, as a whole, support staff's poor attitudes on service provision were not a main obstacle for learners in this study.

Table 5-20 Tutors' Failure to Provide Timely Answers to Students' Questions

\begin{tabular}{|c|c|c|}
\hline Impact Level & Frequency & Percent \\
\hline 1 & 87 & 3.0 \\
\hline 2 & 238 & 8.1 \\
\hline 3 & 1052 & 35.9 \\
\hline 4 & 1219 & 41.6 \\
\hline 5 & 335 & 11.4 \\
\hline Total & 2931 & 100.0 \\
\hline Mean & \multicolumn{2}{|c|}{3.50} \\
\hline Std. Deviation & \multicolumn{2}{|c|}{0.905} \\
\hline
\end{tabular}

Table $5-20$ is a simple statistical description of learners' reports about the impact that arose from tutors' failure to provide timely answers to students' 
questions. From Table 5-20, it can be seen that there was a great impact on only $3 \%$ of the learners: a further $8.1 \%$ of the learners felt there had been a relatively great impact on their studies from tutors not providing timely answers, adding up to a total of $11.1 \%$ experiencing a negative impact from a lack of timely responses from tutors. By contrast, $53 \%$ of the learners felt there had been no great impact. The mean score on this matter was 3.50 , higher than the median. This shows that as a whole, although tutors' inability to provide timely answer to students' questions was not a main obstacle for learners, it has brought some difficulties to a small minority of learners' learning.

From Tables 5-19 and 5-20, we see that, overall, support staff's attitudes and the service quality they provided have not been perceived as having brought too many difficulties to learners. One important reason for this may be that The $O$ Institution requires support staff to respond to any question from learners within 48 hours. Besides, if any student complains or reports certain people's poor attitudes, The $O$ Institution investigates to see if the complaint is valid. If proven, the relevant people will be punished, according to the severity of the situation.

Although The $O$ Institution requires support staff to serve the learners conscientiously, still there are some learners who felt that they had experienced difficulties in this regard. Learner $E$ from Learning Centre D complained in the interview and said:

"There are only a few counselling teachers, who are just administrators instead of professional teachers. Sometimes, their answers are vague and ambiguous..." 


\subsection{Interaction with Learners and Teachers}

Table $5-21$ is a simple statistical description of learners' report about the impact on their studies of having little chance to study together with fellow students.

Table 5-21 Having little chance to learn with fellow students together

\begin{tabular}{|c|c|c|}
\hline \multicolumn{1}{|c|}{ Impact Level } & Frequency & Percent \\
\hline 1 & 733 & 25.0 \\
\hline 2 & 1277 & 43.6 \\
\hline 3 & 860 & 29.3 \\
\hline 4 & 49 & 1.7 \\
\hline 5 & 12 & 0.4 \\
\hline Total & 2931 & 100.0 \\
\hline Mean & \multicolumn{2}{|c|}{2.09} \\
\hline Std. Deviation & \multicolumn{2}{|c|}{0.800} \\
\hline
\end{tabular}

From Table $5-21$, it can be seen that $25 \%$ of the learners said that there was a great impact on their studies because of having little chance to learn alongside other students, and the proportion of the learners who felt that this represented a relatively great impact was as high as $43.6 \%$, adding up to a total proportion of almost $70 \%$ in my sample. Only $2.1 \%$ of the learners felt no great impact from this factor. Here, the mean score of responses was 2.09, very close to the 'relatively great impact', given the value of 2 . For a large majority of the learners in my study, having little chance to study together with fellow learners was certainly thought by learners to have had an impact on their studles and, hence, according to my analytical framework, was experienced as a main obstacle in their studies.

Table $5-22$ is a simple statistical description of learners' reports about the impact on having little chance to learn under teachers' supervision. From Table $5-22$, it can be seen that $26.2 \%$ of the learners said that there was a great impact on their studies when they have little chance to learn under 
teachers' supervision and the proportion of the learners who felt this had a relatively great impact was as high as $45.3 \%$, adding up to a total of more than $70 \%$. Only $1.5 \%$ of the learners felt that there was no great impact on their studies from this factor. In this instance, the mean score for responses on this matter was 2.04 , very close to the 'relatively great impact' response, allocated the value of 2 . This shows that for many of the learners in my research having little chance to learn under teachers' supervision certainly was perceived by them as having an impact on their studies and, according to my analytical framework, constituted a main obstacle for the learners.

Table 5-22 Having little chance to learn under teachers' supervision

\begin{tabular}{|c|c|c|}
\hline \multicolumn{1}{|c|}{ Impact Level } & Frequency & Percent \\
\hline 1 & 767 & 26.2 \\
\hline 2 & 1329 & 45.3 \\
\hline 3 & 790 & 27.0 \\
\hline 4 & 33 & 1.1 \\
\hline 5 & 12 & 0.4 \\
\hline Total & 2931 & 100.0 \\
\hline Mean & & 2.04 \\
\hline Std. Deviation & \multicolumn{2}{|c|}{0.782} \\
\hline
\end{tabular}

Table $5-23$ is a simple statistical description of learners' reports about the impact of 'feeling lonely' when studying. From Table 5-23, it can be seen that $12 \%$ of the learners said that there was a great impact on their studies from feeling lonely when studying and the proportion of the learners who felt this had a relatively great impact reached $23.3 \%$. Only $2 \%$ of the learners felt no such great impact and $16.4 \%$ of the learners felt little impact from this factor. On this question, the mean score for all respondents was 2.73, lower than the 'neutral response' given the score of 3 . This shows that as a whole, feeling lonely when studying was still experienced by a substantial minority and thus, according to my analytical framework, constituted an obstacle for the online distance learners in my study. 
Table 5-23 Feeling Lonely when Studying

\begin{tabular}{|c|c|c|}
\hline Impact Level & Frequency & Percent \\
\hline 1 & 351 & 12.0 \\
\hline 2 & 683 & 23.3 \\
\hline 3 & 1357 & 46.3 \\
\hline 4 & 482 & 16.4 \\
\hline 5 & 58 & 2.0 \\
\hline Total & 2931 & 100.0 \\
\hline Mean & \multicolumn{2}{|c|}{2.73} \\
\hline Std. Deviation & \multicolumn{2}{|c|}{0.940} \\
\hline
\end{tabular}

From Tables 5-21, 5-22 and 5-23, we can find that each of what might be termed 'interaction factors' - including 'having little chance to study together with fellow students', 'having little chance to learn under teachers' supervision', and 'feeling lonely when studying' - were experienced as having an impact on the studies of many of the learners whom I studied. In this regard, in the interviews, some learners expressed a strong desire to strengthen the interaction elements of their studies. Learner B from Learning Centre B was already a middle-level manager. Apart from gaining knowledge and a diploma, he also wanted to broaden his social networks. He said:

"Now there is too little interaction between students. Even when we happen to interact, it is only about exams and reviews. As adults, we are more than just students. Student identity only accounts for $20 \%$ of our identity and the other $80 \%$ is our consumer and investor identity. Given that I pay such high tuition fees, I expect a valuable service and return on my investment. This is a rule recognized by most people. I strongly wish that we could have more face-to-face interaction, just like in a learning salon. Then we can get to know more friends ..."

In other words as well as, a lack of interaction and loneliness representing substantial learning barriers for the learners studied, these 
experiences also made them miss out on gaining an important by-product of their studies, namely, the development of their social capital (Stanton-Salazar and Dornbusch, 1995; Buerkle, 2002).

\section{The Key and Significant Learning Barriers}

In the previous section, I presented a relatively simple, systematic introduction to the impact on learners' studies, constituting what I have termed learning barriers, arising from reported experiences explored through the questionnaire completed by the online learners whom I studied. The initial analysis above indicates that interaction problems were the key learning barriers experienced by my respondents. This preliminary analysis confirmed the research hypothesis on this matter first mentioned in the literature review section in chapter 2, Hypothesis 5.1, namely that 'communication and interaction problems are the key and significant learning barriers for adult learners in online learning'.

In this section, I will present a further empirical test of this hypothesis. In order to test hypothesis 5.1 , it is necessary to undertake a factor analysis of the items concerning learning barriers as indicated by the answers given by respondents to the questionnaire, to sort out what are the principal barrier factors. Then I will investigate the impacts of these barrier factors on learners' academic achievements through a multiple linear regression so as to find which factors are the key and significant learning barriers facing online learners. Furthermore, I will compare the mean and standard deviation of those principal barrier factors and then conduct a Paired Samples T-Test.

The result of the factor analysis of all responses is basically consistent with the result of the factor analysis of the questionnaire pilot study. Thus, we arrive at seven principal factors constituting learning barriers. Their items are 
as follows.

Factor 1: B3_9, B3_10, B3_8, B3_12, B3_7, B3_6, B4_1, B4_2.

Factor 2: B2_6, B2_5, B2_9, B2_4, B2_7, B2_8.

Factor 3: B5_4, B5_3, B5_6, B5_2, B5_1, B5_5.

Factor 4: B3_4, B3_2, B3_1, B3_5, B3_3.

Factor 5: B4_4, B4_3, B4_5, B4_6, B3_11.

Factor 6: B2_1, B2_2, B2_3.

Factor 7: B1_3, B1_2, B1_4, B1_1.

I have given these seven principal factors the following labels as barriers In the remainder of this analysis.

Barrier Factor 1: Learning Resources;

Barrier Factor 2: Computer and Internet Operation Skills;

Barrier Factor 3: Communication and Interaction;

Barrier Factor 4: Teaching and the Curriculum;

Barrier Factor 5: Teaching Support Services;

Barrier Factor 6: Computers and Internet Access Conditions;

Barrier Factor 7: External Support and Financial Burdens.

Then, I try to run a multiple linear regression to investigate the impacts of different factors on learners' academic achievements by stepwise technique. The dependent variable is learner's academic achievement.

Firstly, I put all the variables including the learners' characteristics, motivation as well as the seven principal factors of learning barriers into the multiple linear regression function. Then, I run the function by stepwise 
technique so that the key and significant variables or factors can be captured and the problem of multi-collinearity can be solved. The table 5-24 shows the regression result by stepwise technique.

Table 5-24 The Results of Impacts on Online Learners' Academic Achievements

\begin{tabular}{|l|c|c|c|}
\hline & $\begin{array}{c}\text { Unstandardized } \\
\text { Coefficients }\end{array}$ & $\begin{array}{c}\text { Standardized } \\
\text { Coefficients }\end{array}$ & $\mathrm{T}$ \\
\hline Constant & $84.38^{* * *}$ & & 104.90 \\
\hline Age & $-2.23^{* * *}$ & -0.093 & -5.44 \\
\hline With children & $-7.75^{*}$ & -0.075 & -1.64 \\
\hline Employed & $12.63^{* * *}$ & 0.108 & 3.03 \\
\hline Continuous learning ability & $6.850^{* *}$ & 0.084 & 2.03 \\
\hline Leaders' requirement & $9.85^{*}$ & 0.085 & 1.86 \\
\hline 'Communication and Interaction' factor & $6.59^{* * *}$ & 0.051 & 3.24 \\
\hline 'Teaching and the Curriculum' factor & $5.85^{* * *}$ & 0.045 & 2.73 \\
\hline 'Teaching Support Services' factor & $4.52^{* *}$ & 0.031 & 3.18 \\
\hline 'Learning Resources' factor & $4.45^{* *}$ & 0.031 & 2.17 \\
\hline 'External Support and Financial Burdens' factor & $4.04^{*}$ & 0.028 & 1.67 \\
\hline Adjusted R Square & & 0.067 & \\
\hline N & & 2931 & \\
\hline
\end{tabular}

From Table 5-24, it can be found that, with other variables controlled, five principal barrier factors have the significant impacts on the learner's academic achievement. They are 'Communication and Interaction' factor, 'Teaching and the Curriculum' factor, 'Teaching Support Services' factor, 'Learning Resources' factor and 'External Support and Financial Burdens' factor. Among these five barrier factors, both unstandardized coefficients and standardized coefficients of the 'Communication and Interaction' factor are the biggest. It means that 'Communication and Interaction' factor is the key and significant factor impacting online learner's academic achievements. This finding is consistent with James Taylor's finding in his empirical research conducted in University of Southern Queensland. In that study, Taylor (2002) studied the interaction activities of online learners and found that the levels of students engaging in interaction activities would impact their academic 
achievements directly. The workers (those engaged in interaction actively) had the highest average scores whilst the shirkers (those engaged in interaction rarely) had the lowest average scores and even failed in the course.

The two barrier factors of 'computer and Internet operation skills' and 'computer and Internet access conditions' do not appear in the results of regression, which suggests that the two barrier factors got in factor analysis might be covered by other barrier factors.

In order to confirm the finding that the factor of 'communication and interaction' is the key and significant learning barriers facing online learners, I try to compare the importance of different factors by scores.

In the book Discovering Statistics Using SPSS (Second Edition), Field (2005) describes the usage of factor analysis and its scores detailedly (Page 625-628). Field argues that the method of score is known as 'a weighted average', and it is the easiest way to explain the relative importance of factors. I calculate the scores by various methods provided by SPSS software, the results are the same substantially.

Table 5-25 Mean Values of Barrier Factors

\begin{tabular}{|l|c|c|}
\hline \multicolumn{1}{|c|}{ Barrier Factors } & Mean & Std. Deviation \\
\hline Communication and Interaction & 2.25 & 0.644 \\
\hline Teaching and the Curriculum & 3.43 & 0.642 \\
\hline Learning Resources & 3.69 & 0.765 \\
\hline Teaching Support Services & 3.71 & 0.697 \\
\hline External Support and Financial Burdens & 3.75 & 0.717 \\
\hline Computer and Internet Operation Skills & 4.04 & 0.778 \\
\hline Computers and Internet Access Conditions & 4.11 & 0.786 \\
\hline $\mathrm{N}$ & & 2931 \\
\hline
\end{tabular}

Table 5-25 shows the mean scores on these seven barrier factors, which are sorted from low to high. From Table 5-25, the following points can be 
observed: The barrier consisting of poor communication and interaction has the lowest mean value of 2.25 with the remaining barrier factors' mean scores all being higher than 3, which suggests that the barrier of poor communication and interaction is the key barrier to their online learning experienced by the learners in this study, according to their responses to the questionnaires that I used. In addition, the standard deviation on this barrier factor is 0.644 , the second lowest among all. This indicates that the learners in this study were highly consistent in the view that poor communication and interaction had constituted for them a very key barrier in their online learning.

Furthermore, a Paired Samples T-Test, between the 'communication and interaction' barrier factor and the other six barrier factors, was undertaken respectively and showed that there was a significant difference between the value of the 'communication and interaction' factor and the values of the other factors with a significance level of $p<0.01$.

At this point, the empirical tests on hypothesis 5.1 are completed. The empirical tests have found that, among all the potential learning barriers reviewed as experienced by the online learners in my research, those constituted by poor communication and a lack of interaction would have key and significant impacts on the learner's online learning.

\section{Differences in Learning Barriers for Different Learners}

\subsection{Gender Differences}

\section{Gender Differences in Barriers in respect of External Support}

In the first section of this chapter, we found from the interviews that gender differences may exist in the experience of barriers in oniine learning in 
respect of external support. The following section comprises empirical tests on the gender differences in barriers concerning external support.

Table 5-26 Mean Values of Male and Female Learners' Experiences of Learning Barriers in respect of External Support

\begin{tabular}{|l|c|c|c|c|}
\hline Barriers concerning external support & Male & Female & F value & Sig. \\
\hline Too busy working & 2.73 & 2.76 & 0.379 & 0.538 \\
\hline Too many family responsibilities & 3.12 & 2.79 & 15.105 & 0.000 \\
\hline Lack of support from bosses & 3.82 & 3.94 & 13.982 & 0.000 \\
\hline Lack of support from family and friends & 4.10 & 4.00 & 10.223 & 0.001 \\
\hline
\end{tabular}

Table 5-26 lists and compares the mean values of male and female learners' experiences of the impact of various aspects of 'external' support on their studies, which, according to the framework outlines earlier can constitute barriers or obstacles. From Table 5-26, it can be seen that for both males and females, being 'too busy working' has the greatest impact and that the difference between men and women is not statistically significant. However, significant gender difference do exist in respect of the impact of each of a 'lack of support from bosses', a 'lack of support from family and friends', as well as having 'too many family responsibilities', with a significance level of $p<0.01$. Male learners experienced more impact from what they saw as a 'lack of support from bosses' while female learners encountered more problems than their male peers because of a 'lack of support from family and friends' and of having 'too many family responsibilities' to attend to. To some extent these results might be thought to be unsurprising given the persistence of a fairly rigid and conventional sexual division of labour that still prevails in China, especially where women's traditional responsibilities around the home and with the family are concerned, however much it might be thought desirable for the balance of responsibilities between males and females should change. In China, there is an old saying: 'Men's work centres around the outside world, women's work 
centres around the home'. Traditionally, this has simply meant that men are primarily oriented towards the world of work and paid employment and can be left to focus on their jobs and their career development, while women are still mainly responsible for family affairs, despite the fact that many women juggle paid work, care responsibilities in the family and at home, and being a good mother, daughter and wife! From this perspective, one challenge for distance education providers should be at least to pay more attention to the challenges each sex faces, as things stand, and offer different and appropriate services to females' and males' studying online.

\section{Gender Differences in Lack of Skills with Computers and Internet Operations}

In the previous chapter, it was found that female learners had lower levels of learning satisfaction than the males in my study. No explanation for these differences are forthcoming from this study but, drawing on my own long experience in The $O$ Institution and from observation more widely, I believe that it is possible that this may well be due to the apparent advantages that male learners often seem to enjoy with regard to technology, as against the position for women, as well as from the fact that many studies and much anecdote report the impression that female students are more assiduous in attending to their studies than are their male counterparts. Females may also set themselves higher standards and more demanding goals and have greater expectations than do their male fellow students. That, perhaps and somewhat paradoxically, is why males show higher levels of learning satisfaction.

But this is mere speculation and anecdote: it could equally well be true that men are more easily satisfied when it comes to learning satisfaction than are women, and that women have more exacting and critical standards on 
this score than do men. In any case, below, I present some empirical tests on gender differences concerning the men's and women's feelings about the possible impact on their studies arising from their skills, or lack of them, in computer and Internet operations.

Table 5-27 Mean Values of Male and Female Learners' Experiences of Learning Barriers in respect of Computer and Internet Operation Skills

\begin{tabular}{|l|c|c|c|c|}
\hline Barriers concerning computer and the Internet operation skills & Male & Female & F value & Sig. \\
\hline Skilfully using the Internet to find suitable learning resources & 3.89 & 3.69 & 29.172 & 0.000 \\
\hline Computer operation skills & 3.93 & 3.74 & 26.243 & 0.000 \\
\hline Skilfully using the Internet to interact with others & 3.99 & 3.81 & 24.345 & 0.000 \\
\hline
\end{tabular}

Table 5-27 lists and compares the mean values of male and female learners' experiences the impact on their learning in respect of computer and Internet operation skills. From Table 5-27, it can be seen that, according to the mean scores of each sex, there is a significant difference with regard to this issue, with a significance level of $p<0.01$. Where these skills and aptitudes are concerned, female learners appear to have faced more difficulties than male learners in my study or, at least, they do not rate their skills in these areas as highly as do their male counterparts.

\section{Gender Differences Concerning Communication and Interaction}

Table 5-28 Mean Values of Male and Female Learners' Experiences of an Impact on their Studies in respect of Communication and Interaction

\begin{tabular}{|l|c|c|c|c|}
\hline \multicolumn{1}{|c|}{ Barriers concerning communication and interaction } & Male & Female & F value & Sig. \\
\hline Having little chance to learn under teachers' supervision & 2.01 & 2.08 & 4.612 & 0.032 \\
\hline Having little chance to learn together with fellow students & 2.04 & 2.15 & 13.632 & 0.000 \\
\hline Feeling lonely when studying & 2.67 & 2.80 & 14.468 & 0.000 \\
\hline
\end{tabular}

Table 5-28 lists and compares the mean values of male and female learners' reported impact on their studies concerning communication and interaction. From Table $5-28$, it can be seen that there were again significant 
gender differences in every aspect of the barriers experienced with regard to communication and interaction, this time with male learners reporting having faced slightly more difficulties than women learners reported as having faced.

Compared with Table 5-27, we can see that, although males had experienced less impact upon their studies as regards 'skilfully using the Internet to interact with others', they appear to have encountered more difficulties than the females in 'having little chance to learn together with fellow students', in 'having little chance to learn under teachers' supervision', and in 'feeling lonely when studying'. Earlier in this chapter, we have already found that, among all the different learning barriers or obstacles encountered in studying, as revealed by my research, problems with communication and interaction had the key and significant impact for learners generally in this study. In respect of this particular obstacle, it appears that male learners have experienced more difficulties than their female counterparts have done.

\subsection{Differences in Learning Barriers for Learners with Different} Fees Payment Circumstances

In chapter 4 , it has already been found that the majority of learners in this study paid full tuition fees at their own expense and only a small proportion of learners obtained full or partial tuition fees support from their employers. Here I will analyze my data to see whether there is any difference in the experience of learning barriers faced by learners with different fees-payment circumstances.

The Impact of the Financial Costs and Expense of Learning for Learners with Different Fees-Payment Circumstances

Table 5-29 lists and compares the mean values of the impact arising from the costs of learning for learners with different fees-payment circumstances. 
From Table 5-29, it can be seen that learners with different fees-payment circumstances reported significantly different levels of difficulty in respect of tuition fees and the costs of the Internet, with a significance level of $p<0.05$ in the obstacle of 'the Internet fees are too expensive', and a significance level of $p<0.01$ in respect of the obstacle of 'the tuition fee is too expensive'.

Furthermore, from Table 5-29, it can also' be seen that the mean values of the impacts perceived increase from 'Payment at one's own expense', through 'Shared payment with the employer' to 'Full payment by the employer'. This means that the learning obstacle that consists of the various expenses of learning decreases along with learners having less responsibility for having to meet the costs of paying fees entirely by themselves.

Table 5-29 Mean Values of the Impact on Their Studies for Learners with Different Fees Payment Circumstances

\begin{tabular}{|l|c|c|c|c|c|}
\hline $\begin{array}{l}\text { Impact Concerning Expense of } \\
\text { Learning }\end{array}$ & $\begin{array}{l}\text { Payment at one's } \\
\text { own expense }\end{array}$ & $\begin{array}{l}\text { Shared payment } \\
\text { with the employer }\end{array}$ & $\begin{array}{l}\text { Full payment } \\
\text { by the employer }\end{array}$ & F value & Sig. \\
\hline Tuition fees are too high & 2.74 & 2.91 & 3.40 & 7.868 & 0.000 \\
\hline The Internet fees are too expensive & 3.00 & 3.13 & 3.40 & 3.046 & 0.048 \\
\hline
\end{tabular}

Naturally, for all students of average means, or who do not come from a wealthy background, the financial burdens of following programmes of study can be considerable, especially when set alongside other financial responsibilitles, such as for the costs of working and raising a family. For online, largely part-time adult learners, studying at a distance, the question of fees and other costs may even have figured in their calculations when thinking about opting to learn and seek qualification through the mode of online, part-time study. In such cases, any help they can get with theses costs will surely be welcomed. Of course, when the fees reach a certain level, some people may not be able to undertake distance online learning or may drop out once started, which will threaten to reduce the human capital 
investment for the whole community, and which will especially affect the adult learners adversely. If this occurs, it will almost certainly cause new injustices and be a possible further source of social stratification in modern China. A viable option to solve this problem might be to draw on the experiences from conventional colleges and universities, studying their student financial assistance policies to establish a student financial assistance system for distance, online learners, with the help of distance education providers, governments and other social parties. For example, tuition fee loans can be provided; fee remission for excellent performers can be offered so as to encourage learners to increase their learning efficiency; hardship grants might be available to help the most hard pressed.

In addition, I also believe that employers should pay a certain amount of money for their employees to engage in distance online learning. Many learners invest in distance online learning mainly in order to obtain a higher education degree as a kind of general training or general improvement of their own human capital and to help become more skilled, more effective or more up-to-date employees and yet many companies seem to think that they have no responsibility to pay for this (Becker, 1964).

However, many studies in companies' training programmes have found that there are more than ten good reasons why companies should provide employees with on-the-job training: $46 \%$ of companies provide training to staff mainly for 'employees' benefits'; $23 \%$ are doing it in order to 'attract new employees'; $57 \%$ of business executives believe that the provision of training is not directly to improve employees' productivity, but to enhance employees' loyalty to companies through training programs, thereby indirectly increasing employees' productivity. They think that various forms of on-the-job training can increase employees' self-esteem, improve their family harmony and their degree of satisfying with their companies. All of 
these factors have helped to extend working hours in companies and to improve their efficiency, thereby further indirectly increasing their productivity (Bassi, 1994). Therefore, in the viewpoint of Bassi (1994), companies or employers should give some financial support for learners so as to reduce the impact of this learning obstacle.

Differences in Experiencing Inadequate Teaching Support as a Barrier for Learners with Different Fees-Payment Circumstances

Table 5-30 lists and compares the mean values of the impact on learners' studies in terms of the teaching support experienced by the learners with different fees-payment circumstances.

Table 5-30 The Impact of Varieties of Teaching Support on Learners with Different Fees Payment Circumstances

\begin{tabular}{|l|c|c|c|c|c|}
\hline $\begin{array}{l}\text { Impact in respect of teaching } \\
\text { support }\end{array}$ & $\begin{array}{l}\text { Payment at one's } \\
\text { own expense }\end{array}$ & $\begin{array}{l}\text { Shard payment } \\
\text { with the employer }\end{array}$ & $\begin{array}{l}\text { Full payment by employer } \\
\text { the em value }\end{array}$ & Sig. \\
\hline $\begin{array}{l}\text { The tutors cannot answer } \\
\text { students' questions in time }\end{array}$ & 3.50 & 3.55 & 3.92 & 2.319 & 0.099 \\
\hline $\begin{array}{l}\text { Teaching support staff have } \\
\text { no enough patience }\end{array}$ & 3.78 & 3.76 & 4.04 & 2.971 & 0.048 \\
\hline
\end{tabular}

From Table 5-30, it can be seen that there is a significant difference in their experience of teaching support, and its impact on their learning, for learners with different payment arrangements for fees. The significance level is $p<0.05$ in respect of the obstacle constituted by 'teaching support staff have not enough patience'; and the significance level is $p<0.1$ in respect of the obstacle of 'the tutors cannot answer students' questions in time'.

Furthermore, in Table 5-30, we also find that the mean values of the impact, or barriers as outlined in my analytical framework, increase from those whose 'payment at one's own expense', through those who 'shared payment with the employer' to those who benefitted from 'full payment by 
the employer', which is to say that as the burden of fees decreases, so the perceived impact and hence obstacle level also decreases. The reason may be that when learners have to pay more, the feeling of operating more like a paying 'customer' or 'consumer' becomes stronger, as was told to me by learner B from Learning Centre B, which also makes learners hope for better teaching support services in the future.

\section{Differences in Experiencing Communication and Interaction as}

\section{Barriers for Learners with Different Fee Payment Circumstances}

Table 5-31 lists and compares the mean values of learning barriers in terms of communication and interaction experienced by the learners with different fees-payment circumstances.

Table 5-31 Differences in Experiencing Communication and Interaction Problems for Learners with Different Fees Payment Circumstances

\begin{tabular}{|l|c|c|c|c|c|}
\hline $\begin{array}{l}\text { Impact in respect of } \\
\text { Communication and interaction }\end{array}$ & $\begin{array}{l}\text { Payment at one's } \\
\text { own expense }\end{array}$ & $\begin{array}{l}\text { Shared payment } \\
\text { with the employer }\end{array}$ & $\begin{array}{l}\text { Full payment by } \\
\text { the employer }\end{array}$ & F value & Sig. \\
\hline $\begin{array}{l}\text { Having little chance to learn } \\
\text { under teachers' supervision }\end{array}$ & 2.04 & 1.76 & 2.14 & 2.370 & 0.094 \\
\hline $\begin{array}{l}\text { Having little chance to learn } \\
\text { together with fellow students }\end{array}$ & 2.09 & 2.00 & 2.13 & 0.267 & 0.766 \\
\hline Feeling lonely when studying & 2.73 & 2.72 & 2.69 & 1.499 & 0.224 \\
\hline
\end{tabular}

From Table 5-31, it can be seen that there are no significant differences in experiencing the two barriers of 'having little chance to learn together with fellow students' and 'feeling lonely when studying' for learners with different fees-payment circumstances. Even as regards the obstacle of 'having little chance to learn under teachers' supervision', the significance level is only close to the edge of significance (sig. $=0.094$ ). This suggests that, on the whole, there is no statistically significant difference in the degree of experiencing communication and interaction problems as obstacles to their learning for learners with different fees-payment circumstances. 
In the course of this inquiry, I have analyzed a variety of learning barriers that I identified earlier to see if there would be a difference for learners with different fees-payment circumstances, but I found that only in respect of learning expenses and teaching support barriers, there were significant differences. This further helps to demonstrate that learners with different characteristics and in different circumstances may face quite different learning barriers. Thus, to help learners to overcome or avoid these different learning barriers, it is important that the assistance should be appropriately targeted.

\section{Interaction among the Different Learning Barriers}

Based on the empirical inquiry and the analysis in the last section, it can be seen that there appear to be significant differences in the experience or impact of different learning obstacles or barriers for learners who manifest different characteristics or who are placed in different circumstances. We can now further analyze, for every individual learner, whether is there any discernible interaction between these different learning barriers. If so, the question arises as to whether one or more of the barriers will be weakened or eliminated because of the elimination of another. This section of this chapter will focus on this matter and attempt to answer these two questions.

\subsection{Correlation Analysis of the Various Learning Barriers}

Table 5-32 lists the Pearson Correlation coefficient and significance level of the various elements that constitute learning barriers, as identified so far in this research.

From Table $5-32$, it can be seen that there is a significant positive correlation relationship between every two of the various learning obstacles. 
In every case, the Pearson Correlation coefficient between 'Computer and Internet operation skills' and 'Internet access conditions', between 'Computer and Internet operation skills' and 'Teaching and the curriculum', between 'Teaching and the curriculum' and 'Learning resources', between 'Teaching and the curriculum' and 'Teaching support services' always reaches to a significance level of more than 0.5 . This suggests that the relationships between these different pairs of learning barriers are all very close, although of course this tells us nothing about either the direction of the links or about the more complex issue of causal relationships.

From the last row of Table $5-32$, it can be seen that the Pearson Correlation coefficients between 'Communication and interaction' and the other learning barriers are always lower than 0.4 , suggesting that the issue of 'Communication and interaction' is operating somewhat independently from the other learning barriers identified. 
Table 5-32 Correlation Analysis of Various Learning Barriers

\begin{tabular}{|c|c|c|c|c|c|c|c|c|}
\hline & & $\begin{array}{l}\text { External } \\
\text { support } \\
\text { and } \\
\text { financial } \\
\text { burden }\end{array}$ & \begin{tabular}{|l} 
Internet \\
access \\
conditions
\end{tabular} & $\begin{array}{l}\text { Computer } \\
\text { and } \\
\text { Internet } \\
\text { operation } \\
\text { skills }\end{array}$ & $\begin{array}{l}\text { Teaching } \\
\text { and the } \\
\text { curriculum }\end{array}$ & $\begin{array}{l}\text { Learning } \\
\text { resources }\end{array}$ & $\begin{array}{l}\text { Teaching } \\
\text { support } \\
\text { services }\end{array}$ & $\begin{array}{l}\text { Communication } \\
\text { and interaction }\end{array}$ \\
\hline \multirow{2}{*}{$\begin{array}{l}\text { External } \\
\text { support and } \\
\text { financial } \\
\text { burden }\end{array}$} & $\begin{array}{c}\text { Pearson } \\
\text { Correlation }\end{array}$ & 1 & 0.366 & 0.392 & 0.414 & 0.342 & 0.365 & 0.230 \\
\hline & $\left|\begin{array}{c}\text { Sig. } \\
\text { (2-tailed) }\end{array}\right|$ & & 0.000 & 0.000 & 0.000 & 0.000 & 0.000 & 0.000 \\
\hline \multirow{2}{*}{$\begin{array}{l}\text { Internet access } \\
\text { Conditions }\end{array}$} & $\begin{array}{c}\text { Pearson } \\
\text { Correlation }\end{array}$ & 0.366 & 1 & 0.525 & 0.284 & 0.232 & 0.264 & 0.152 \\
\hline & $\begin{array}{c}\text { Sig. } \\
\text { (2-tailed) }\end{array}$ & 0.000 & & 0.000 & 0.000 & 0.000 & 0.000 & 0.000 \\
\hline \multirow{2}{*}{$\begin{array}{l}\text { Computer and } \\
\text { Internet } \\
\text { operation skills }\end{array}$} & $\begin{array}{c}\text { Pearson } \\
\text { Comelation }\end{array}$ & 0.392 & 0.525 & 1 & 0.506 & 0.466 & 0.422 & 0.268 \\
\hline & $\begin{array}{c}\text { Sig. } \\
\text { (2-tailed) }\end{array}$ & 0.000 & 0.000 & & 0.000 & 0.000 & 0.000 & 0.000 \\
\hline \multirow{2}{*}{$\begin{array}{l}\text { Teaching and } \\
\text { the curriculum }\end{array}$} & $\begin{array}{l}\text { Pearson } \\
\text { Comrelation }\end{array}$ & 0.414 & 0.284 & 0.506 & 1 & 0.652 & 0.563 & 0.281 \\
\hline & $\begin{array}{c}\text { Sig. } \\
\text { (2-tailed) }\end{array}$ & 0.000 & 0.000 & 0.000 & & 0.000 & 0.000 & 0.000 \\
\hline \multirow{2}{*}{$\begin{array}{l}\text { Learning } \\
\text { Resources }\end{array}$} & $\begin{array}{c}\text { Pearson } \\
\text { Correlation }\end{array}$ & 0.342 & 0.232 & 0.466 & 0.652 & 1 & 0.618 & 0.397 \\
\hline & $\begin{array}{c}\text { Sig. } \\
\text { (2-tailed) }\end{array}$ & 0.000 & 0.000 & 0.000 & 0.000 & & 0.000 & 0.000 \\
\hline \multirow{2}{*}{$\begin{array}{l}\text { Teaching } \\
\text { support } \\
\text { services }\end{array}$} & $\begin{array}{c}\text { Pearson } \\
\text { Correlation }\end{array}$ & 0.365 & 0.264 & 0.422 & 0.563 & 0.618 & 1 & 0.264 \\
\hline & $\begin{array}{c}\text { Sig. } \\
\text { (2-tailed) }\end{array}$ & 0.000 & 0.000 & 0.000 & 0.000 & 0.000 & & 0.000 \\
\hline \multirow{2}{*}{$\begin{array}{l}\text { Communication } \\
\text { and interaction }\end{array}$} & $\begin{array}{c}\text { Pearson } \\
\text { Correlation }\end{array}$ & 0.230 & 0.152 & 0.268 & 0.281 & 0.397 & 0.264 & 1 \\
\hline & $\begin{array}{c}\text { Sig. } \\
\text { (2-tailed) }\end{array}$ & 0.000 & 0.000 & 0.000 & 0.000 & 0.000 & 0.000 & \\
\hline
\end{tabular}




\subsection{Interaction among Learning Barriers}

Since significant correlations exist among different learning barriers, it is likely that, with a control of other factors reducing the degree of difficulty for the learners caused by one obstacle may help to reduce that of other related barriers. In order to verify this conjecture, I propose the following hypothesis.

Hypothesis 5.2: with control of different learners' characteristics, reducing the degree of difficulty caused by the obstacle of 'poor communication and interaction' will help to reduce significantly the problem experienced, or barriers faced, as a consequence of experiencing poor learning resources.

There are two main reasons why I wanted to test hypothesis 5.2. Firstly, amongst all the learning barriers studied, that of 'poor communication and interaction' appears to be the greatest and also represents a principal focus of this research. Secondly, amongst all the learning barriers studied, the barrier of 'poor communication and interaction' showed relatively low correlation values with the other types of learning barriers identified. Therefore, if it can be found that reducing the degree of communication and interaction problems will help to reduce the impact of other barriers, then this approach will also work for a range of learning barriers.

In order to test hypothesis 5.2 , I constructed a multiple linear regression model. The dependent variable was the degree of problems arising from 'courseware cannot be downloaded'. It was a continuous variable from 1-5 with the highest indicating the least problems. The key independent variable was the level of difficulty arising from 'have little chance to learn together with fellow students': it was also a continuous variable from 1-5 with the highest indicating the least difficulties. 
I expected that the variable coefficient of 'having little chance to learn together with fellow students' obstacle would be positive. That is to say, by reducing the degree of difficulty arising from the problem of 'having little chance to learn together with fellow students', would also reduce the degree of difficulty associated with the problem of 'courseware cannot be downloaded'.

Of course, in testing this, it was important to control the factors of age, sex, marriage, working conditions, payment methods, majors being studied and other individual learner characteristics in the regression model. Moreover, as indicated several times already, statistical associations or correlations, however suggestive, are not in themselves indications of a causal link.

(1) Age - Continuous variable.

(2) Sex - Binary dummy variable, with females as the base variable.

(3) Marriage - Binary dummy variable, with unmarried as the base variable.

(4) Working conditions - Binary dummy variable, with employed as a benchmark.

(5) Two binary dummy variables of 'payment methods', with 'full payment at one's own expense' as the benchmark.

(6) Binary dummy variables of ten different disciplines, namely, Philosophy, Economics, Law, Education, Literature, History, Science, Agriculture, Medical Science, and Management, with Engineering as a benchmark.

Table 5-33 shows the results of the regression analysis of the barrier 'having little chance to learn together with fellow students'. 
Table 5-33 Regression Results of the Level of Difficulty Associated with the Obstacle 'courseware cannot be downloaded'

\begin{tabular}{|l|c|c|c|}
\hline & $\mathrm{B}$ & $\mathrm{T}$ & Sig. \\
\hline Constant & 2.712 & 21.682 & 0.000 \\
\hline Age & 0.002 & 0.677 & 0.498 \\
\hline Male & 0.029 & 0.606 & 0.545 \\
\hline Unemployed & 0.067 & 0.900 & 0.368 \\
\hline Full payment by the employer & 0.023 & 0.101 & 0.920 \\
\hline Shared payment with the employer & 0.082 & 0.704 & 0.481 \\
\hline Philosophy & -0.242 & -0.630 & 0.528 \\
\hline Economics & -0.124 & -1.606 & 0.117 \\
\hline Law & 0.146 & 1.445 & 0.149 \\
\hline Education & 0.046 & 0.432 & 0.666 \\
\hline Literature & -0.085 & -0.984 & 0.325 \\
\hline History & -0.700 & -1.061 & 0.289 \\
\hline Science & -0.242 & -1.607 & 0.108 \\
\hline Agriculture & -0.545 & -0.824 & 0.410 \\
\hline Medical science & -0.011 & -0.096 & 0.923 \\
\hline Management & -0.054 & -0.928 & 0.354 \\
\hline The degree of barrier in 'having little chance to & 0.096 & 3.575 & 0.000 \\
\hline learn together with fellow students'. & & & \\
\hline F & & 1.939 & \\
\hline Adjusted R Square & 0.010 & \\
\hline $\mathrm{N}$ & & 2913 & \\
\hline
\end{tabular}

From Table 5-33, it can be seen that the coefficient of the barrier is positive, with a significance level of $p<0.01$. This confirms hypothesis 5.2 : reducing the degree of one learning barrier it appears can help reduce the impact of other learning obstacles. In particular, if the barrier 'having little chance to learn together with fellow students' is reduced, the other barriers will be reduced as well. This finding is equally important for both distance education learners and distance education institutions, which means that, for either learners or learning providers, when facing a variety of complex 
learning obstacles or barriers, they should always seek to identify the principal one to overcome, as it could help to reduce or eliminate other barriers at the same time.

Further observing other variables in Table 5-33, it can be seen that the significance level is not high, which means that to solve the problems associated with the negative experience of 'courseware cannot be download', it would be necessary first to tackle the other barriers. Therefore, detailed follow-up work required is to further explore the relationship between different types of learning barriers.

\section{Summary of Learning Barriers}

This chapter has sought to present a systematic empirical and statistical analysis from various angles of the barriers faced by online distance learners.

Firstly, this chapter analyzed the perceived impact of various aspects of learning experienced by the learners as obstacles or barriers. To do this, I used factor analysis to analyze these learning barriers so as to identify seven types of barriers.

Secondly; this chapter investigated the impacts of these barrier factors on learners' academic achievements through a multiple linear regression and found that the factor of 'communication and interaction' is the key and significant barrier affecting online learner's academic achievements. This finding is consistent with James Taylor's finding in his empirical research conducted in University of Southern Queensland.

I believe that the above-mentioned findings are consistent with what is already known about the characteristics of adult learners in terms of their orientations, motivation and the challenges that they often have to face. On 
the one hand, as one of the main purposes that adult learners choosing distance learning is to meet new people and engage in more social relations; on the other hand, adult learners often find it hard to adjust to a learning situation without what they regard as enough communication and interaction with fellow learners or academic staff in the course of the learning process (after all, they are already used to thinking and acting via communication and interaction in their daily work and lives).

Thirdly, this chapter found that different learners react differently to the same learning barrier. For example, learners with different fees-payment arrangements showed significant differences in their experience of the barrier arising from the problem of expenses arising from learning. This reminds us that when trying to eliminate a certain barrier, it is essential to take learners' characteristics and personal circumstances into consideration; otherwise, it may strengthen another barrier while eliminating this one.

Finally, this chapter analyzed the relationship between different learning barriers and found that there is a significant correlation between them. However, the learning barrier arising out of 'communication and interaction' problems and other types of learning barriers manifested no close relationship in this study, suggesting that not only was the barrier of 'communication and interaction' acting as the key one faced by these learners, but also that it existed as an independent barrier. Fortunately, after further analysis, I found that, when controlling learners' individual characteristics, then, if we could improve the situation for learners in respect of 'communication and interaction', we might also be able to help resolve learners' problems in respect of 'learning resources'.

Therefore, I believe that if interaction and communication in online learning can be improved for adult learners to meet their express desire for 
'sociability', and once they can thus establish their own 'learning communities' and form relatively stable 'student-to-student' relationships, and 'teacher-to-student' relationships, other learning barriers will possibly be reduced as well. 


\section{Chapter 6:}

\section{Learning Barriers, Academic Achievement and Possible Remedial Measures}

This chapter will first analyse the apparent links between a number of different types of learning barrier and learners' academic achievements, in the light of the level of impact reported by the learners themselves. In undertaking this kind of statistical analysis it needs to be understood that no claims can validly be made about and direct causal relationship between the different variables under review. Of course, that does not make such statistical analysis worthless: correlations with a high level of significance are often highly suggestive of possible links and very helpful in pointing towards possible relationships. These can be further explored by both additional statistical manipulation of the numerical data or may be 'triangulated', using further data collected from observation, interviews, documentary evidence and so on.

Secondly, the chapter will review the expected effect of various possible or hypothetical improvement measures that could be introduced with the aim of reducing the barriers to learning faced by the online distance learners in my study.

Finally, the chapter will analyze the effect brought about by the different measures, especially to see whether there is different effect brought by the same measure on learners with different personal characteristics. 


\section{Learning Barriers and Academic Achievement}

\subsection{Impact from the Financial Costs of Learning and Academic Achievement}

Table 6-1 lists and compares the average academic score of learners who had reported varying degrees of impact from their costs and expenses of their learning (according to their answers to the question of 'Tuition fees are too high and this has become a serious financial burden'). It can be seen from Table 6-1 that, with the decrease in degree of reported impact from learning expenses, there is a small but clearly discernible increasingly upward trend in learners' average academic scores and this difference is statistically significant, with a significance level of $p<0.01$. There could be many reasons for this and, again, to repeat, this is not to claim a direct causal link here. Nevertheless, it might be suggested that one reason for this may be that learners who experience greater impact from the costs and expense of learning have, for example, to spend more time in working to earn income and have corresponding less time for learning, or else because of other pressures and responsibilities in their lives are unable to find ways of gaining additional income to meet those expenses. Thus, for example, Learner $E$ from Learning Centre $D$ experienced greater family financial burdens and had to do two jobs. Talking about his time available for learning, he said, 'Other people can use weekends to study but I still have to work. Thus, I am able only to use the night time and stay up late trying to study. Otherwise I would have no time to learn... I am always afraid that I will not be able to finish my homework...'

Once again, these findings support my opinion, drawn from my own long experience in the worlds of distance and online learning, that is, even in the field of distance education, it is very necessary to draw on the experience and 
practices of traditional universities' financial assistance and to provide various forms of financial subsidy for learners who experience greater financial burdens.

Table 6-1 Impacts of Learning Expense and Average Academic Scores

\begin{tabular}{|l|c|c|c|}
\hline $\begin{array}{l}\text { Tuition fees are too high and this has become } \\
\text { a serious financial burden }\end{array}$ & Mean Score & $\mathrm{N}$ & Std. Deviation \\
\hline Very much in line with & 82.49 & 193 & 11.586 \\
\hline Relatively in line with & 85.08 & 497 & 10.944 \\
\hline Neutral response & 85.22 & 1403 & 10.830 \\
\hline Not in line with & 85.94 & 604 & 11.144 \\
\hline Not in line with at all & 85.51 & 153 & 11.117 \\
\hline F & & 3.664 \\
\hline Sig. & & 3.006 \\
\hline
\end{tabular}

\subsection{Teaching Materials and Academic Achievement}

Table 6-2 lists and compares the average academic score of learners who experienced different degrees of problems with the teaching materials perceived by them as not being suitable for adult learning (according to their answers to the question of 'Teaching Materials are not suitable for adult learning'). It can be seen from Table 6-2 that, as the extent of experiencing such problems decreases, there is a little improvement in learners' average academic scores, but the difference this time is not statistically significant. We may reasonably ask why experiencing problems with teaching materials not being suitable for adult learning apparently did not result in any significant difference in learners' academic achievements. At the very least, given the important role played by learning materials or 'courseware' in online learning programmes, it might be expected that poor or inadequate or inappropriate materials would have a damaging effect on learners' studies and, hence, possibly on their academic achievement as measured by their scores. One possible reason is suggested in the data gathered from the 
interviews, namely that the focus of the examinations and the content of the teaching materials are often different from each other, hence the students' scores do not directly reflect the difficulties that they faced with the teaching materials.

According to the current Chinese context, in the field of distance and online education, teaching materials usually include printed text books and other distributed courseware, and are usually provided or published by the universities who deliver distance or online education programmes. However, the teachers who teach the course actually usually provide some further reference materials or supplementary materials themselves, namely so-called 'own' learning materials. Currently, the courses and the corresponding text books used by the distance learners are usually the same as that used by the full-time students, having no special content tailoring and Instructional design to meet the particular characteristics and learning demands of adult distance learners online. The learners reported universally that the content of the teaching materials was both too much and too divorced from practice, and did not meet their learning needs. Also, the courseware was seen by them as being 'too rigid', and did not arouse their interest. Consequently, many of the learners were not willing to spend time on the text books and courseware. However, the examination papers are usually produced by the teachers who teach the courses. So, the focuses of the examinations are often different from the content of the teaching materials, but are in line with the learning materials provided by the teachers themselves. Therefore, the learners prefer to pay a lot of attention to the learning materials provided by their teachers rather than the more generally distributed teaching materials that come out as part of a more general distribution of materials. In other words, where the learners have only to master the learning materials provided by the teachers who teach the 
courses, they may pass the examinations or even get good scores.

Although there is no significant difference in learners' academic achievements arising from the problem of learners feeling that the teaching materials were not suitable for adult learning, this does not mean that the problem will not cause learners any other learning difficulties. For the reasons mentioned above, Chinese distance online learners have a tendency to pay a lot of attention to passing examinations, but seem to care little about the teaching materials and learning processes, or the skills and knowledge that they can obtain through successful and effective learning.

In my view, good and appropriate teaching materials are one of essential elements in distance and online education. In order to facilitate distance learners' learning in general, support the development of their skills and confidence in self-directed learning and, perhaps, improve their academic achievements, the teaching materials need to be tailored in content, design and in their framework according to online adults' learning characteristics and needs and to the tasks that they are expected to complete successfully as part of their course. Also, high quality instructional design is essential in the production of the teaching materials. Unfortunately, that is not always currently the case.

Table 6-2 Teaching Materials Not Suitable for Adult Learning and Average Academic Scores

\begin{tabular}{|l|c|c|c|}
\hline $\begin{array}{l}\text { Teaching materials are not suitable for } \\
\text { adult learning. }\end{array}$ & Mean Score & $\mathrm{N}$ & Std. Deviation \\
\hline Very much in line with & 83.24 & 60 & 84.32 \\
\hline Relatively in line with & 85.25 & 206 & 84.68 \\
\hline Neutral response & 83.24 & 928 & 84.32 \\
\hline Not in line with & 85.25 & 1424 & 84.68 \\
\hline Not in line with at all & 83.24 & 313 & 84.32 \\
\hline F & & 1.173 \\
\hline Sig. & & 0.321 \\
\hline
\end{tabular}




\subsection{Teaching Support Service Problems and Academic Achievement}

Table 6-3 lists and compares the average academic scores of learners experiencing different degrees of problems with teaching support (according to their answers to the question of 'The tutors cannot answer the learners' question in time').

It can be seen from Table 6-3 that, as the extent of experiencing such problem decreases, there is an increase in learners' average academic scores, and the difference is statistically significant with a significance level of $p<0.05$.

Again, here I need to repeat my earlier warning. This finding is, no doubt, interesting; it raises further questions in the researcher's mind; and the finding even adds to a growing impression of the overall impact of a cluster of obstacles or shortcomings on students' online leaning and attainment.

But, it does not of itself establish a direct causal relationship between the degree of tutors' tardiness with answers to students' questions experienced by different learners and the academic achlevement of those learners.

Table 6-3 'Tutors Cannot Answer the Learners' Question in Time' and Average Academic Scores

\begin{tabular}{|l|c|c|c|}
\hline $\begin{array}{l}\text { The tutors cannot answer the learners' } \\
\text { question in time. }\end{array}$ & Mean Score & $\mathrm{N}$ & Std. Deviation \\
\hline Very much in line with & 81.54 & 84 & 81.54 \\
\hline Relatively in line with & 82.40 & 232 & 85.40 \\
\hline Neutral response & 84.28 & 1025 & 85.28 \\
\hline Not in line with & 85.27 & 1183 & 85.27 \\
\hline Not in line with at all & 85.29 & 326 & 85.29 \\
\hline F & & 2.377 \\
\hline Sig. & & 0.050 \\
\hline
\end{tabular}

Once more, a whole host of possible reasons can be found in the findings from the interviews. In Chapter 5, I introduced learner $E$ in Learning Centre D. 
During the interview, he had complained that, 'There are only a few counselling teachers, who are just administrators instead of professional teachers. Sometimes, their answers are vague and ambiguous...' He also mentioned that, 'I rarely communicate with these teachers. But when the examinations are near, I would often take the initiative to ask them, because they might be able to provide some examination outline, or even help us to analyze some important and difficult points for the exams...'

From this, once again some of the problems of China's distance online education can be clearly seen. Learners care too much about the examination itself and whether they will be able to get the diplomas, rather than the knowledge and the skills that they can acquire, although given the importance still in contemporary China of formal qualifications for employment, promotion, reputation, 'face' and status, this is hardly surprising. Even so, it is essential that inevitably narrowing trend should be challenged in order to ensure not just the sustainable development of distance education and to secure real and long lasting achievements for distance learners in China, but also the development of a cadre of genuine lifelong learners, increasingly able to take charge of their own self-directed learning in a fast changing world. This, it should be remembered, is also one of the main ambitions of the Chinese government in rapidly expanding higher education generally in China, but also in its specific support of online learning opportunities for men and women already in the labour market or who may also have family responsibilities that prevent them from studying full-time or through a conventional face-to-face course.

\subsection{Interaction Problems and Academic Achievement}

Table 6-4 lists and compares the average academic scores of learners experiencing different degrees of the problem of having little chance to learn 
together with fellow students.

Table 6-4 'Having Little Chance to Learn Together with Fellow Students' and Average Academic Scores

\begin{tabular}{|l|c|c|c|}
\hline $\begin{array}{l}\text { It has a great impact on my studies that I } \\
\text { have little chance to learn together with } \\
\text { fellow students. }\end{array}$ & Mean Score & $\mathrm{N}$ & Std. Deviation \\
\hline Very much in line with & 82.81 & 704 & 11.327 \\
\hline Relatively in line with & 84.39 & 1243 & 10.767 \\
\hline Neutral response & 85.20 & 842 & 11.086 \\
\hline Not in line with & 85.42 & 49 & 10.753 \\
\hline Not in line with at all & 85.62 & 12 & 10.646 \\
\hline F & & 2.464 \\
\hline Sig. & & 0.043 \\
\hline
\end{tabular}

It can be seen from Table 6-4 that, as the extent of experiencing the problem of 'having little chance to learn together with fellow students' decreases, there is an increase in learners' average academic scores, and the difference is statistically significant with a significance level of $p<0.05$.

Table 6-5 'Having Little Chance to Learn Under Teachers' Supervision' and Average Academic Scores

\begin{tabular}{|l|c|c|c|}
\hline $\begin{array}{l}\text { It has a great impact to my study that I have little } \\
\text { chance to learn under teachers' supervision. }\end{array}$ & Mean Scores & $\mathrm{N}$ & Std. Deviation \\
\hline Very much in line with & 84.22 & 735 & 11.552 \\
\hline Relatively in line with & 85.67 & 1294 & 10.798 \\
\hline Neutral response & 85.25 & 776 & 10.818 \\
\hline Not in line with & 86.62 & 33 & 9.705 \\
\hline Not in line with at all & 81.87 & 12 & 11.528 \\
\hline F & & 1.550 \\
\hline Sig. & \multicolumn{3}{|c|}{0.185} \\
\hline
\end{tabular}

Table 6-5 lists and compares the average academic scores of learners experiencing different degrees of the problem with having little chance to learn under their teachers' supervision. From Table 6-5, it can be seen that, as the extent of experiencing the problem of 'having little chance to learn under teachers' supervision' decreases, there is no clear pattern in the trend 
of learners' average academic scores, and the difference is not statistically significant.

These two problems are both part of the difficulties or barriers that might be encountered in opportunities for interaction. So, why is the problem of 'having little chance to learn under the teachers' supervision' apparently not systematically associated with online learners' average academic scores whilst the problem of 'having little chance to learn together with fellow students' is apparently so?

There are many possible explanations to this. This result might simply reflect the fact that the learners in my study rated opportunities for interacting with their peers as much more interesting, valuable or likely. On the other hand, once more, I believe that this lack of an association between academic scores and a lack of interaction with teachers is due to the characteristics of China's current distance education. Usually, the universities employ professors to deliver the online programmes and produce examinations, while they employ other 'sessional' teachers or postgraduates to give tutorials and interact with the students. In general, almost all the distance learners have little chance to have tutorials from their professors and interact directly with them. So, the problem of 'having little chance to learn under the teachers' supervision' does not, in my view, mean no student interaction with this army of post-graduate, part-time or 'sessional' teachers, it means (realistically) little chance of interaction with the full-time academic staff and professors, hence the result that there is apparently little or significant association with this experience (however much impact it is judged by student to have) and their average academic scores.

In any case, many learners prefer to get help and information about learning and examinations by interacting with fellow students or senior students, rather than with academic or support staff, as I have reported early. 
Therefore, the greater the degree of experiencing the problem of 'having little chance to learn together with fellow students', the more significant disadvantages the learners will experience and this may well be manifest in their academic achievements and scores. This further supports the importance of the so-called 'Peer Effect' (Hanushek, 1995; Zimmer and Toma, 2000) mentioned in earlier sections of this thesis. Namely, studying together with fellow students enables learners to share their learning experiences and methods, and support and encourage each other when suffering impacts and setbacks, so as to promote their learning effectiveness and subsequent academic achievements.

Therefore, it should be noted that, in distance and online education, facilitating interaction between students does not only help learners to get more social resources, enjoy a better social life, but it might also help them to improve their academic achievements.

\section{Analysing the Impact of Possible Remedial Measures}

We already know that encountering learning barriers may constitute difficulties for learners and that such barriers can also be statistically associated with differences in learners' academic achlevements. In the following section, I will analyse what measures might be expected to reduce or eliminate learning barriers and also try to explore what impact these measures might have on learners' academic achievements.

In the last part of the questionnaire given to the students in my study, I had proposed 15 possible and specific remedial measures to the possible barriers that online learners might encounter in the course of their studies based on the interviews with experts and learners in distance education that I had undertaken.

I then asked the sample learners to respond to the possible remedial 
measures, by asking them 'To what extent do you think the following measures will help you to further enhance your learning?' (Learners were asked to choose one of five options: 'Very effective', 'Relatively effective', 'Uncertain effect', 'Limited effect', 'Have no effect'). Of course, the 'effect' measured by these results are only hypothetical: they are not, in any sense, the real effect of such possible changes, but, usefully, they are those subjectively estimated by the learners in my sample as likely to occur ${ }^{13}$. Thus, if it is not specially described, the 'effect' or the 'impact' of improvement initiatives considered in this section means the changes which learners subjectively believe would occur if the measure in question were to be introduced.

Table 6-6 shows the distribution of learners' evaluations on the possible effect of these 15 putative improvement measures.

From Table 6-6, it can be seen that, among all the improvement measures, 6 measures secured the result of more than $25 \%$ of learners selecting the 'Very effective' response.

They are as follows sorting by from the highest to the lowest score:

(1) To have more interaction with fellow students.

(2) To have more practical opportunities or internships.

(3) To have clearer course description and guidance.

(4) To receive more learning resources.

(5) To have more interaction with teachers.

(6) To have timely feedback from supporting staff.

Among these 6 measures, there was only one measure where more than $30 \%$ of the learners chose the 'Very effective' response, that was, 'To have more interaction with fellow students'.

${ }^{13}$ For the future, $I$ intend to implement measures in The $O$ Institution and evaluate their real effect. 
Table 6-6 Effect Distribution of Various Improvement Measures (\%)

\begin{tabular}{|l|c|c|c|c|c|c|}
\hline \multicolumn{1}{|c|}{ Improvement Measures } & $\begin{array}{l}\text { Very } \\
\text { effective }\end{array}$ & $\begin{array}{l}\text { Relatively } \\
\text { effective }\end{array}$ & $\begin{array}{l}\text { Uncertain } \\
\text { effect }\end{array}$ & $\begin{array}{l}\text { Limited } \\
\text { effect }\end{array}$ & $\begin{array}{l}\text { Have no } \\
\text { effect }\end{array}$ & Total \\
\hline $\begin{array}{l}\text { To have more interaction with fellow } \\
\text { students. }\end{array}$ & 30.4 & 44.5 & 22.6 & 2.1 & 0.4 & 100 \\
\hline $\begin{array}{l}\text { To have more practical opportunities or } \\
\text { internships. }\end{array}$ & 27.9 & 38.4 & 30.0 & 2.9 & 0.7 & 100 \\
\hline $\begin{array}{l}\text { To have clearer course description and } \\
\text { guidance. }\end{array}$ & 27.4 & 42.7 & 26.9 & 2.4 & 0.6 & 100 \\
\hline To receive more learning resources. & 25.8 & 42.5 & 29.2 & 2.1 & 0.4 & 100 \\
\hline To have more interaction with teachers. & 25.7 & 42.3 & 29.6 & 2.0 & 0.5 & 100 \\
\hline $\begin{array}{l}\text { To have timely feedback from supporting } \\
\text { staff. }\end{array}$ & 25.2 & 42.9 & 28.8 & 2.5 & 0.5 & 100 \\
\hline To have timely feedback from teachers. & 24.8 & 42.9 & 28.9 & 2.9 & 0.6 & 100 \\
\hline $\begin{array}{l}\text { To receive more support from family and } \\
\text { friends. }\end{array}$ & 24.7 & 37.1 & 33.3 & 3.6 & 1.3 & 100 \\
\hline $\begin{array}{l}\text { To receive training in time management } \\
\text { skills. }\end{array}$ & 23.6 & 37.5 & 33.2 & 4.9 & 0.9 & 100 \\
\hline To have more Q \& A time with teachers. & 21.2 & 37.9 & 36.6 & 3.6 & 0.7 & 100 \\
\hline To get more support from the boss. & 20.6 & 33.5 & 39.5 & 4.9 & 1.5 & 100 \\
\hline $\begin{array}{l}\text { To receive some free accessing Internet } \\
\text { hours. }\end{array}$ & 20.5 & 28.4 & 37.6 & 10.8 & 2.7 & 100 \\
\hline To receive the Internet usage training. & 19.5 & 33.5 & 35.1 & 9.7 & 2.2 & 100 \\
\hline $\begin{array}{l}\text { To receive computer operation skills } \\
\text { training. }\end{array}$ & 17.3 & 27.3 & 39.1 & 13.4 & 2.8 & 100 \\
\hline To improve the standard of teachers and \\
teaching. & 16.8 & 30.5 & 44.8 & 6.8 & 1.2 & 100 \\
\hline
\end{tabular}

In setting out the results of this line of questioning, I have assigned a value of $1-5$ for the five degrees of effect chosen by the sample students in response to the hypothetical improvements proposed. A lower score means a greater expected effect of the possible improvement measure, while a higher score means that the learners expected a lesser effect.

Table 6-7 shows the mean scores of learners' evaluations of the possible effect of the 15 proposed possible improvement measures. Sorting these different possible improvement measures according to their expected effect, 
gives the following results, in descending order of expected beneficial impact, according to the learners' evaluations:

(1) To have more interaction with fellow students.

(2) To have clearer course description and guidance.

(3) To have more interaction with teachers.

(4) To receive more learning resources.

(5) To have more practical opportunities or internships.

(6) To have timely feedback from supporting staff.

Table 6-7 Mean Scores of Various Possible Improvement Measures' Expected Effect

\begin{tabular}{|l|c|c|c|c|}
\hline \multicolumn{1}{|c|}{ Improvement Measures } & $\begin{array}{c}\text { Mean } \\
\text { Scores }\end{array}$ & Std. Deviation & T value & $\begin{array}{c}\text { Sig. } \\
\text { (2-tailed) }\end{array}$ \\
\hline To have more interaction with fellow students. & 1.98 & 0.808 & - & - \\
\hline To have clearer course description and guidance. & 2.06 & 0.830 & 17.659 & 0.000 \\
\hline To have more interaction with teachers. & 2.09 & 0.817 & 7.960 & 0.000 \\
\hline To receive more learning resources. & 2.09 & 0.817 & 7.739 & 0.000 \\
\hline To have more practical opportunities or internships. & 2.10 & 0.867 & 8.181 & 0.000 \\
\hline To have timely feedback from supporting staff. & 2.10 & 0.825 & 8.567 & 0.000 \\
\hline To have timely feedback from teachers. & 2.12 & 0.831 & 9.171 & 0.000 \\
\hline To receive more support from family and friends. & 2.20 & 0.895 & 13.023 & 0.000 \\
\hline To receive training in time management skills. & 2.22 & 0.890 & 28.952 & 0.000 \\
\hline To have more Q \& A time with teachers. & 2.25 & 0.850 & 10.172 & 0.000 \\
\hline To get more support from the boss. & 2.33 & 0.905 & 20.801 & 0.000 \\
\hline To receive the Internet usage training. & 2.42 & 0.978 & 27.205 & 0.000 \\
\hline To improve the standard of teachers and teaching. & 2.45 & 0.888 & 18.333 & 0.000 \\
\hline To receive some free accessing Internet hours. & 2.47 & 1.019 & 26.012 & 0.000 \\
\hline To receive computer operation skills training. & 2.57 & 1.015 & 33.002 & 0.000 \\
\hline
\end{tabular}

As may be seen From Tables 6-6 and 6-7, 'To have more interaction with fellow students' is ranked as the first one in the possible improvement measures, no matter whether they are sorted by the proportion of those choosing 'Very effective' or by assigning a value to all of the responses given by the learners in my sample. 
To have more interaction with fellow students and teachers are each included in the lists of six 'top' possible improvement measures, according to these learners' responses. Moreover, the hypothetical improvement measure, 'To have more interaction with fellow students', ranked first in both rankings. This suggests that problems of peer interaction and interaction with teachers are the biggest obstacles facing online learners and, if eliminated or at least substantially reduced, this would in all likelihood be associated with the biggest improvement in learners' learning effectiveness and pleasure in learning online, according to the learners' own evaluations.

Table 6-7 also shows the results of Paired Samples T-Test between the Improvement measure of 'To have more interaction with fellow students' and the other 14 possible improvement measures. From Table 6-7, it can be seen that there is a statistically significant difference in comparing the effect of the measure with 'To have more interaction with fellow students' and the other Improvement measures, with a significance level of $p<0.01$.

In addition to the measure of Increasing opportunities for interaction, that could have obvious benefits, the possible measures of having more learning resources, of having clearer course descriptions and guidance as well as having timely feedback from supporting staff, would all also be associated with an Improvement in learners' learning, according to these evaluations. Moreover, some learners majoring in practical programmes thought that 'having more practical opportunities or internships' would be likely to enhance their learning effectiveness and achievements. For example, learner B in Learning Centre T, who was majoring in Nursing, pointed out in the interview, that 'I very much hope that learning centres could provide more opportunities for internships. There are a lot of things that you cannot learn from text books or courseware. In terms of the characteristics of Medical Science, clinical competence cannot just come from text books, 
right?'

According to some distance education experts, the lack of internships or 'placements' is also an important matter that is in now urgent need of remedy. In the interview, Professor $\mathrm{H}$, who is the Dean of the College of Online Learning in University $P$, mentioned that:

'A lot of learners and teaching staff have appealed to add internships sessions. If so, the effect of learning would surely be improved. However, it would increase the teaching cost by a large margin... In fact, currently, traditional higher education is also faced with this dilemma. If there is no money, very few enterprises will be willing to accept students for internships, not to mention accepting adult learners...'

\section{Variance Analysis of the Effect of Possible Improvement}

\section{Measures}

\subsection{Gender Differences}

In chapter 4, I found that male learners in my sample achieved significantly lower academic scores than did females, and in chapter 5, I found that male learners reported having more problems with communication and interaction than females. I earlier suggested that problems of communication and interaction may be an obstacle that was associated with lower male learners' academic scores. I therefore examined whether there were any significant gender differences if there were a reduction of communication and interaction problems, in order to enhance learners' learning effectiveness and achievements.

Table 6-8 lists and compares the mean scores of the expected effect of improvement measures in respect of interaction for men and women in my sample. In Table 6-8, it can be seen that gender differences in the expected 
effect of improvement measures regarding interaction are not statistically significant. The results reported in this table certainly suggest, at least statistically speaking, that there are no major differences between men and women in my sample in aspiring for more interaction with fellow students or teachers.

Table 6-8 Gender Differences in the Expected Effect of Improvement Measures Regarding Interaction

\begin{tabular}{|l|c|c|c|c|}
\hline \multicolumn{1}{|c|}{ Improvement Measures } & Male & Female & F value & Sig. \\
\hline To have more interaction with fellow students. & 1.98 & 1.97 & 0.217 & 0.642 \\
\hline To have more interaction with teachers. & 2.11 & 2.07 & 2.100 & 0.147 \\
\hline
\end{tabular}

Table 6-9 lists and compares the mean scores of the expected effect of improvement measures regarding operation skills on computers and the Internet for men and women in my sample. From Table 6-9, it can be seen that no matter whether the possible improvement measure is to have some training in computer operations, or in the Internet usage, there is greater anticipated impact on female learners than on males, with a significance level of $p<0.01$, suggests we should provide female learners more training of computer operation and Internet usage skills in order to remedy the situation.

Table 6-9 Gender Differences in the Expected Effect of Improvement Measures Regarding ICT Skills

\begin{tabular}{|l|c|c|c|c|}
\hline \multicolumn{1}{|c|}{ Improvement Measures } & Male & Female & F value & Sig. \\
\hline To receive computer operation skills training. & 2.63 & 2.50 & 13.577 & 0.000 \\
\hline To receive Internet usage training. & 2.47 & 2.35 & 11.608 & 0.001 \\
\hline
\end{tabular}

In chapter 5, I found that female learners reported having more problems with computer operations and Internet usage. Here again, the results reported in Table 6-9 suggest that it would be likely to be associated with improvements in the learning of female learners significantly if they could receive more training on computer operations and Internet usage. This 
suggests that online education providers should benefit learners by providing them with some additional ICT training, especially targeted at female distance learners.

3.2 Differences in the Expected Effect on Learners with Different Fees-Payment Circumstances in respect of Different Improvement Measures

Table 6-10 lists and compares the mean scores of the expected effect on learners with different fees payment circumstances in respect of different improvement measures. From Table 6-10, it can be seen that, apart from the possible improvement measure of receiving 'more support from family and friends', whose difference in the expected effect on learners with different fees-payment circumstances is statistically significant, with a marginal significance level of $p<0.1$; other possible improvement measures' expected effect on learners with different fees payment circumstance result in no statistically significant differences.

In particular, the possible improvement measure of 'To receive some free hours accessing the Internet' does not appear to be expected to have a significantly different effect for learners with different fees payment circumstances. However, in Chapter 5, it was found that learners with 'Payment at one's own expense' experienced more impacts or barriers from the expenses associated with learning as compared with students with different arrangements for meeting the costs of their learning. This suggests that, perhaps, it is necessary for us to find ways to help distance learners deal with the impacts they experience arising from learning expenses in order to improve their learning experiences and outcomes. Therefore, I stress here, again, that it is essential to establish some sort of financial assistance system in distance education, such as the policy of loans, fee remission or 
scholarships, to support distance learners who are suffering from financial burdens, with consequent negative effect on their learning.

Table 6-10 Differences in the Expected Effect on Learners with Different Fees Payment Circumstances in respect of Different Possible Improvement Measures

\begin{tabular}{|c|c|c|c|c|c|}
\hline Improvement Measures & $\begin{array}{l}\text { Payment at } \\
\text { one's own } \\
\text { expense }\end{array}$ & $\begin{array}{l}\text { Full payment } \\
\text { by the } \\
\text { employer }\end{array}$ & $\begin{array}{l}\text { Shared } \\
\text { payment with } \\
\text { the employer }\end{array}$ & F value & Sig. \\
\hline $\begin{array}{l}\text { To receive more support from family and } \\
\text { friends. }\end{array}$ & 2.19 & 2.56 & 2.15 & 2.341 & 0.100 \\
\hline To get more support from the boss. & 2.33 & 2.40 & 2.17 & 1.632 & 0.196 \\
\hline To receive more learning resources. & 2.09 & 2.04 & 2.11 & 1.489 & 0.226 \\
\hline $\begin{array}{l}\text { To have clearer course descriptions and } \\
\text { guidance. }\end{array}$ & 2.06 & 1.88 & 1.99 & 0.981 & 0.375 \\
\hline $\begin{array}{l}\text { To have more practical opportunities or } \\
\text { internships. }\end{array}$ & 2.10 & 2.32 & 2.11 & 0.812 & 0.444 \\
\hline To have timely feedback from teachers. & 2.11 & 2.28 & 2.17 & 0.781 & 0.458 \\
\hline $\begin{array}{l}\text { To receive computer operation skills } \\
\text { training. }\end{array}$ & 2.58 & 2.52 & 2.46 & 0.720 & 0.487 \\
\hline To have more interaction with teachers. & 2.09 & 2.08 & 2.17 & 0.526 & 0.591 \\
\hline To have more $Q \& A$ time with teachers. & 2.24 & 2.40 & 2.27 & 0.459 & 0.632 \\
\hline $\begin{array}{l}\text { To improve the standard of teachers and } \\
\text { teaching. }\end{array}$ & 2.45 & 2.60 & 2.46 & 0.355 & 0.701 \\
\hline $\begin{array}{l}\text { To have timely feedback from supporting } \\
\text { staff. }\end{array}$ & 2.10 & 2.20 & 2.15 & 0.322 & 0.725 \\
\hline $\begin{array}{l}\text { To receive some free hours accessing the } \\
\text { Internet. }\end{array}$ & 2.47 & 2.48 & 2.40 & 0.260 & 0.771 \\
\hline $\begin{array}{l}\text { To receive training in time management } \\
\text { skills. }\end{array}$ & 2.22 & 2.12 & 2.19 & 0.196 & 0.822 \\
\hline $\begin{array}{l}\text { To have more interaction with fellow } \\
\text { students. }\end{array}$ & 1.98 & 2.04 & 1.84 & 0.068 & 0.934 \\
\hline To receive the Internet usage training. & 2.42 & 2.36 & 2.41 & 0.044 & 0.957 \\
\hline
\end{tabular}

\section{Summary}

This chapter has sought to analyse the relationship between learning barriers and academic achievement amongst the learners studied in this 
thesis, including by positing some possible improvement measures for learners to evaluate the expected effect on reducing the barriers to learning faced by the distance learners whom I studied. It has been found that the degree of experiencing learning problems, or barriers to online learning, and learners' academic performance, as indicated by their scores in examinations, demonstrate significant negative statistical relationships, meaning that the lower the degree of experiencing particular learning barriers, the higher learners' academic scores. For example, experiencing greater impact from the financial expenses of learning will be statistically related to lower academic scores, and that fewer problems in interacting with other students will be related to higher academic scores. From these results, I believe that it is necessary to consider establishing some sort of financial assistance system so as to help learners experiencing money problems to be able to study better. From these findings, I also believe that online education providers should encourage and help to build more opportunities for interaction between learners through a variety of measures.

This chapter also analyzed the subjectively estimated effect of different possible improvement measures and found that the following six measures were expected by learners to have the greatest effect: To have more interaction with fellow students; To have clearer course descriptions and guidance; To have more interaction with teachers; To have more learning resources; To have more practical opportunities or internships; To have prompt feedback from supporting staff. This once again confirms my conjecture that facilitating interaction between distance learners would represent an important breakthrough in tackling learning barriers faced by distance learners and helping to improve their academic achievements. 


\section{Chapter 7:}

\section{Countermeasures and Their Effects on Overcoming Barriers to Online Learning}

The previous chapters (Chapter 4-6) have displayed the empirical research outcomes of both my quantitative and qualitative analyses, derived respectively from questionnaires and interviews, supplemented by my own experiences and observation and by informal discussions with colleagues experts and some online learners. These researches have served the aim of revealing the perceived impact of learning barriers as experienced by online learners at The $O$ Institution. The findings of the empirical research include:

(1) From the research I conducted, seen from the learners' own assessment on the level of impact on their studies, the learners' key and significant barrier in their online learning experience is the lack of sufficient opportunities for communication and interaction.

(2) Although there are some significant correlations between the different barriers listed above, the correlation coefficients between the barrier concerning 'communication and interaction' and other barriers are relatively not so significant. This means that 'communication and interaction' is not only apparently the key and significant barrier faced by the online learners, but also it seems to operate independently from the other barriers to a great extent. I also found that if the learners' personal characteristics are controlled for, the improvement in respect of the barrier in the area of 'communication and interaction' - that is, its reduction - can also significantly lead to some improvement in respect of the impact of barriers experienced or encountered in the other areas, such as the area of 'learning resources',

(3) Most online learners regarded the following six possible 
improvement measures as likely to be very effective for improving their online learning. The rank order of perceived effect is ranked from the most helpful to the least: to have more interaction with fellow learners; to have clearer course descriptions and guidance; to have more interaction with teachers; to receive more learning resources; to have more practical opportunities or internships; to have timely feedback from teachers.

Based on the above findings, the most urgent matter seems to be to facilitate communication and interaction amongst the online learners themselves, as well as between learners and teachers. Therefore, The 0 Institution has already been taking action to attempt to increase learner-learner and learner-tutor communications and interactions, beginning in 2009. The following are the actual measures that The 0 Institution has implemented and their resulting effect.

\section{Introduction of The O Institution's Services}

In order to reflect what actual measures The $O$ Institution has implemented and what kinds of effect the measures have resulted in, I would like to introduce the services which The O Institution could provide in general.

The $O$ Institution's main business is to play a professional role for distance education service providers in China, building a digital environment dedicated to distance teaching and learning as well as the associated process management and services. It aims to do this by developing a distance education learning and teaching management system, and building a public support services system of distance education and by setting up franchised learning centres across the country in both urban and rural communities or in enterprises, industry, and government agencies, as well as providing online education support services for universities, colleges and students. This includes enrolment support, transmission of teaching and counselling 
support, student learning support, teaching management support, student affairs management and support, and course examinations management and support. The $\mathrm{O}$ Institution provides a 'one-stop' service with professional quality and personnel, standardization procedure, and innovative idea and skills, to ensure the 'reintegration' of teaching and learning in distance education as well as the smooth operation of information, logistics and capital operations.

Table 7-1 The O Institution's service relevant to the learning of online learners

\begin{tabular}{|c|c|c|}
\hline Teachin & Learner Administration & Learner Support Services \\
\hline $\begin{array}{l}\text { Teaching Notice } \\
\text { Self-learning with Printed Materials } \\
\text { Learning Courseware } \\
\text { Teacher's Tutoring and } \\
\text { Answering Questions Online } \\
\text { Face-to-face Teaching } \\
\text { Section of Experiment and } \\
\text { Practical } \\
\text { Online Discussion } \\
\text { Online Homework } \\
\text { Online Test } \\
\text { Unified Subject Exam } \\
\text { Dissertation } \\
\text { Tracking Statistics of Leaming }\end{array}$ & $\begin{array}{l}\text { Enrolment, Registration, Payment } \\
\text { Administration of Student's } \\
\text { Enrolment Status } \\
\text { Enrolment on Courses } \\
\text { Textbook Orders } \\
\text { Homework Management } \\
\text { Score Management } \\
\text { Archives Management } \\
\text { Scholarship Appraisal } \\
\text { Graduate Tracking and Feedback }\end{array}$ & $\begin{array}{l}\text { Freshman Guidance (Policy, } \\
\text { Teaching Plan, Examination } \\
\text { Arrangements, Instruction in } \\
\text { Computer use \& the Internet) } \\
\text { Call-centre } \\
\text { Short Message Service } \\
\text { E-mail Service } \\
\text { Student Forum Online } \\
\text { Online Interaction and Student } \\
\text { Activity }\end{array}$ \\
\hline
\end{tabular}

Up to the end of 2009, The O Institution contracted with Peking University, Zhejiang University, and a further 40 well-known Chinese universities to establish comprehensive cooperative partnerships, through the coverage of mainland China in about 2,000 local learning centres, offering learning support for nearly 400 thousand Chinese online learners. Currently, the 40 
universities in cooperation with The O Institution offer online courses in 180 major subjects in 9 disciplines, including economics, law, education, literature, science, engineering, agriculture, management, medical science (mainly nursing, pharmacy and Chinese Medicine). In addition, The 0 Institution also provides non-diploma education projects, such as vocational education and training.

\section{Countermeasures on the Barriers in the Area of}

\section{Communication and Interaction}

Since 2009, The 0 Institution has also been optimizing the platform's application functions and its users' experiences so as to seek to improve the learner-learner and learner-tutor communications and interactions in a varied way. Today, The O Institution's Learning Management System (LMS) has multiple functions as follows:

(1) Learning resources storage and transmission;

(2) Tracking, managing and service for teaching and learning processes;

(3) Enabling teachers from universities to deliver teaching, assigning and (re)marking assignments as well as tutoring online;

(4) Enabling learners to register online, obtain learning resources, submit assignments, take tests online, as well as participate in online discussion and community activities.

\subsection{Customer Contact Centre}

In the year 2002, The 0 Institution established the first educational services call-centre in China, providing direct and free services for online learners, and has been developing this into the Customer Contact Centre in recent years. In 2005, The O Institution implemented the IS09001 standard 
in the Centre.

Since 2009, The $O$ Institution has invested a large amount of human and capital resources to improve the service standard and efficiency of the Centre, including embedding the Centre services into the Learning Management System so that the online learners can get immediate access to online counselling via a web call, a free $800 / 400$ dial-up, email, text messages and voice mail. In October 2009, the Centre acquired the country's quality system certification for learning support services and, a year later, the $A N A B^{14}$ accreditation. In December 2009, The O Institution's Customer Contact Centre won the 2009 Asia-Pacific Best Call Centre Prize ${ }^{15}$, rated as outstanding by all its peers in the educational service industry in China.

Currently the Centre has developed further its customer services by combining manual and automatic services. The details are as follows:

(1) Telephone counselling, taking the lead in providing ' 800 ' and ' 400 ' free dial-up and problem-solving in the educational service industry in China.

(2) Email services. Every enrolled student receives a life-long effective email address, with abundant data storage room online. Such an email system provides more convenience for communications between teachers and learners as well as between learners and the management side. It can also be used as a means of publishing and distributing formal notices and crucial information and a facility where the students can hand in their assignments and other written work.

(3) Free text message reminding services that also ensure efficient delivery of crucial information and help in the process of supervising and urging the learners' progress.

\footnotetext{
$14 \mathrm{ANAB}$ is an identification accredited by the American National Standards Institute and ASQ National Accreditation Board.

15 The Prize is awarded once a year by China Call-Center \& CRM Association, Asia Pacific Contact Center Association Leaders.
} 
(4) Web counselling, where agents can provide immediate solutions through the medium of online chat.

(5) The online academic advisory service. This is based on an originally developed advisory system with artificial intelligence, based on a knowledge base, whereby online learners receive automatic suggestions on academic help, such as matters concerning learning methods and other supplementary information services.

All the above services are now available for every online learner, so as to ensure their immediate access to helpful information through their preferred means. The services at the Centre are not limited to learning support. Others such as 'pressure release' and psychological counselling can also be provided according to learners' needs. The Customer Contact Centre of The 0 Institution is now fully engaged throughout the customer's whole learning experience.

There are three hundred agent seats here at The O Institution's Customer Contact Centre, providing $7 \times 24$ ( 7 days a week, 24 hours a day) services for the more than four hundred thousand learners registered in the collaborating universities. In recent years, service efficiency and customer satisfaction rates have been rising with every effort invested. The successful connection rate of the telephone counselling service is now more than $94 \%$; more than $90 \%$ of the questions are resolved with only one call; $80 \%$ plus calls are connected within the first fifteen seconds; web enquiries are responded to within sixty seconds, and learners' emails are replied to within four hours. Besides, the complaint and feedback system also handles learners' complaints within four hours of their being filed, with the one-time solution rate being above $80 \%$ and the customer satisfaction rate above $95 \%$.

Thus, through optimizing its customer services, The 0 Institution has already successfully achieved the expected frequency and quality of 
interaction and communication between the learners, the teachers and the management staff. However, as we shall see later, there still remains a number of problem or barriers to be tackled, in the fields of communication and interaction.

\subsection{Optimizing the Online Course Forum}

One of the most important facilities provided by The O Institution's LMS is its course discussion panels. Course discussion has been serving as a key solution for tutors seeking to respond to learners' academic problems. However, the discussion panels of each university used to be managed by local teachers, whose frequency and speed of successfully answering learners' queries was not satisfactory and did not meet the learners' requirements, which resulted in learners' reluctance to post questions onto the panel. In seeking to deal with the above situation, The $O$ Institution has been offering the following three improvement measures since the year 2009. Firstly, agreement has been reached by all the online education institutions from the collaborative universities as regards the unified standards to be provided in managing each course discussion panel, such as the standardization of management and service evaluation. For example, now the tutors required to reply to learners' questions within 48 hours. Secondly, The $O$ Institution has also established an evaluation system so as to enable there to be a continuous supervision of every related panel, the results of which are immediately reported to the related university authorities. Thirdly, the new management standards require tutors to design out-of-class study activities, such as discussion topics or case studies in order to stimulate learners' own initiative and to enable them employ what they learned in solving practical problems.

With the above efforts, the average reply-rate within the first 48 hours of 
learners' posting questions has been kept at a level above $90 \%$. The course discussion panel is now the most heated place for learner-learner and learner-tutor communications and interactions.

\subsection{Introducing Popular Online Chat Tools}

The web-based Video Conference System was launched at the beginning of the year 2009 also in order to satisfy some learners' requests for more 'face-to-face' communication. By settling the time of meeting and the discussion topic, tutors are now able to hold 'summarizing sessions', based on teaching progress, further to analyse or illustrate the key points or difficult points of learning content, instruct the learners with skills of problem-solving or self-directed learning, as well as carrying out other tutoring activities such as $Q$ \& A. This virtual face-to-face interaction is now largely welcomed by online learners for both its convenience and its similarity with the traditional class.

In 2009, The 0 Institution also reached a cooperation agreement with Tencent ${ }^{16}$ Corporation with the latter providing specific QQ Groups for The O Institution's online learners. QQ Groups (or Tencent Instant Messenger Groups) can be established based on the course name, intake of enrolment, university of registration, or on any other distinguishing characteristics of the gathering. Usually, each $\mathrm{QQ}$ Group is established by the tutor of relevant course, who acts automatically as the group manager granting each learner's application to join the group. The characteristics of user-friendliness, flexibility, instantaneity and high efficiency for interaction have made $Q Q$ Groups gain a warm welcome from online learners. The QQ Groups usually hit

\footnotetext{
${ }^{16}$ Tencent Corporation is the world's third largest Internet Company who developed the Tencent Instant Messenger, also called TIM or Tencent QQ in February, 1999. The widget realized free contacts among cell phones, PCs and MIDs (Mobile Internet Device). It is recorded that Tencent QQ boasts a user population of more than 600 million composed mainly of younger generations and students and is the largest registered online group in China.
} 
the maximum member numbers during exam weeks. Now QQ Groups have become the most frequently and commonly used interaction tool and have been playing an effective role in helping to eliminate the barriers of communication and interaction faced by the online learners. In addition, $Q Q$ Groups are liable to make the interpersonal relations between learners and tutors close, and make for coming into being new social circles so as to satisfy adult learners' need for social communication.

\subsection{Establishing Learner Communities Online}

In order to make up for the perceived lack of social communication, The O Institution has also been working on establishing certain kinds of online learning and contact communities, encouraging learners to exchange and share their learning and social experiences with other online learners. The communities include:

(1) Open Talk. This is an online interview programme created in May, 2009. Every month, a registered online learner will be interviewed by the host face-to-face to share his or her learning and life experiences, as well as other Insights. Viewers can find links to the interviews on the website's homepage, and join the related online discussion.

(2) Electronic Newsletter. This is edited by learners with the help from The $O$ Institution in planning and technological support. Each newsletter focuses on several newsworthy topics, in addition to including special columns on learning skills, examinations, career experiences, industry updates, fashion and entertainment, attracting learners to participate in discussion and share.

(3) Online Seminar. This is schemed and organized by The O Institution, inviting industry senior experts to deliver presentations on specific topics, attracting learners to interact with the experts in-depth. 
(4) Online Class Space. This is independently run by the students. They can create contact lists, alumni records, or online circles and societies based on their own interests. The space can also be used to show personal photos and students' other personal stuff.

(5) Blog. The blog is a cyber space for teachers and students to express their own ideas and to present their original work.

(6) Online Games \& Contests. This includes student activities such as beauty pageants, writing and karaoke contests which are all scheduled to introduce more fun into the students' out-of-class time.

\section{Impacts and Effects}

The impact of the above actions has already been somewhat evident in certain sorts of improvement achieved in tackling communication and interaction barriers. To illustrate, the following part of this chapter is dedicated to analysing the effect of these changes as measured by four elements: the learners' average log-in rate per month, average online learning time per week, continuous course registration rate by the registered students as well as the Alexa ${ }^{17}$ ranking statistics of the website.

\subsection{Significantly Increasing the On-average Monthly Log-in Rate and Weekly Online Learning Time Length of Learners}

The monthly log-in rate by the registered learners refers to the proportion of the number of learners who log-in the online platform to the number of all the registered students in a specific month. The average monthly log-in rates from 2008 to 2010 is displayed in Table 7-2. It can be

17 The statistics here are provided by The $O$ Institution's online platform. The 2010 data are a half-year conclusion. 
seen from Table 7-2 that, there is a marked increase in average monthly log-in rates. Especially, the average monthly log-in rate of the year 2010, compared with that of the year 2008 , has added more than 31 percentage points, or almost $80 \%$; compared with that of the year 2009,2010 has added almost 24 percentage points, or a more than $51 \%$ increase.

Table 7-2 Average Monthly Log-in Rates from 2008 to 2010

\begin{tabular}{c|c|c|}
\hline 2008 & 2009 & 2010 \\
\hline $39.20 \%$ & $46.50 \%$ & $70.40 \%$ \\
\hline
\end{tabular}

The average weekly online learning length of time of the registered learners refers to the mean length of time that each registered learner spends on online learning in each week during one year. The statistics of the years from 2008 to 2010 are shown in Table 7-3.

Table 7-3 Average Weekly Online Learning Time Length from 2008 to 2010

\begin{tabular}{|c|c|c|}
\hline 2008 & 2009 & 2010 \\
\hline $5 \min$ & $12 \min$ & $39 \min$ \\
\hline
\end{tabular}

As can be seen from Table 7-3, there has been a large increase in the average weekly online learning time of the registered learners. Especially of note, the average weekly online learning length of time learning online of the registered learners in the year 2010, compared with that of the year 2008, adds up to an additional 34 minutes, or an increase of almost 7 times. Compared with the time spent learning online in 2009, the average for 2010 has added 27 minutes, or a 2.25 times increase.

\subsection{Rises in the Continuous Course Registration Rate of Learners}

The continuous course registration rate refers to the proportion of learners who have registered in an online learning programme for longer than one semester and who come back at the next semester to continue with their 
course registration. The statistics of the years from 2008 to 2010 are shown in Table 7-4. The continuous course registration rate, according to Table 7-4, is relatively stable at $95 \%$. This is already very high and, with the exception of the autumn semester in 2009 , the rate is showing a small rise over the period 2008 to 2010 , and this has been achieved despite a significant expansion of the student body. Such a situation suggests that, with the measures already taken by The $O$ Institution to tackle communication and interaction barriers, online learners' levels of overall satisfaction with the Institution should also be expected to be on the rise.

Table 7-4 Continuous Course Registration Rates from 2008 to 2010

\begin{tabular}{|l|c|c|c|c|}
\hline \multirow{2}{*}{ Semester } & Autumn & Spring & Autumn & Spring \\
& 2008 & 2009 & 2009 & 2010 \\
\hline Total No. of Student & 222320 & 269946 & 302259 & 326594 \\
\hline Continuous Course Registration Rate & $94.84 \%$ & $95.14 \%$ & $94.79 \%$ & $95.95 \%$ \\
\hline
\end{tabular}

\subsection{Increasing Visits to The O Institution Website}

The Alexa ranking of a website is an index of its number of visits and its ranking among all the websites in the world. Updated every three months, the Alexa ranking is based on the geometric mean of website three-month accumulation by the number of Users Reach and Page Views.

Figures $7-1$ to $7-3$ shows respectively the movement of visitor numbers to The O Institution website from three aspects, namely, the Daily Traffic Rank Trend, independent IP (Internet Protocol) address, and Page Views.

It can be seen from Figure 7-1 that, the Alexa ranking of The $O$ Institution website among all the websites in the world, rose to 24,354 th place in the first half of 2010 from the 50,000 th place at the beginning of 2009 . In addition, during the same period, the Alexa ranking of The $O$ Institution website among all the websites in China rose to 2,493 th place in the first half 
of 2010 from the 15,000th place at the beginning of 2009 .

Figure 7-1 Daily Traffic Rank Trend of The O Institution's Website in the First Half of 2010

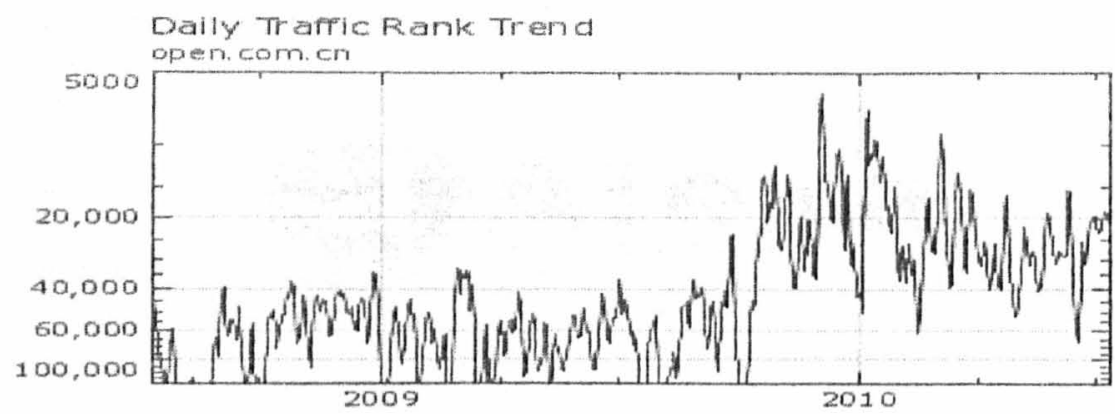

As can be seen from Figure 7-2, the number of independent IP address visited the website in the first half of 2010 has also soared by more than 500 thousand comparing with that in 2008 and 2009.

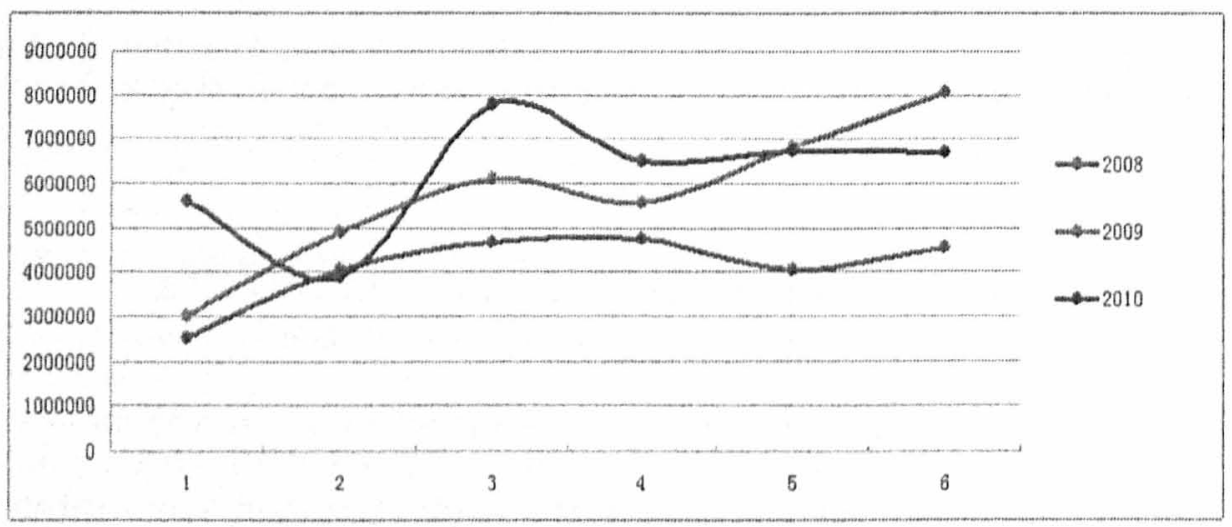

Figure 7-2 The Number of Independent IP Addresses Visiting The O Institution's website

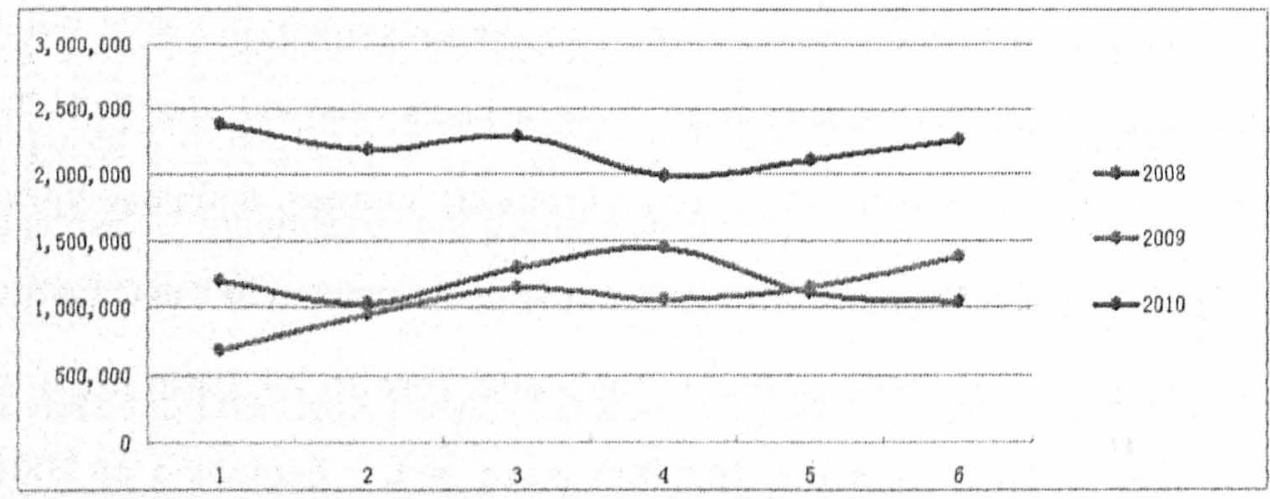

Figure 7-3 The Number of Page Views of The O Institution's Website

Meanwhile, Figure 7-3 shows that the number of Page Views of the 
website in the first half of 2010 have outnumbered those recorded in 2008 and 2009 by more than one million.

From these impressively increasing numbers we may suggest that, at least with the successful handling these aspects of the potential barriers to communication and interaction in online learning, The 0 Institution is beginning to tackle the barrier identified in previous chapters and thereby, it is to be hoped, becoming more and more appealing, or at least of interest, to potential online learners.

However, that is not the whole of the story. Firstly, the whole question of timescale is undoubtedly a complicating factor, in that the introduction of these changes and the increased numbers and other improvements noted above, coincided with my fieldwork and the distribution of my questionnaires amongst The O Institution's online learners. Nevertheless, it is still noticeable that even as these apparent improvements, or rather increases in certain aspects of communication and interaction, were taking place, the online learners' responses to the questionnaire indicated a continuing concern amongst them about the level of impact on their studies of poor or limited opportunities for communication and interaction as part of their online learning programmes. Even if this continuing concern simply suggests rising standards or increased expectations on the students' behalf in this aspect of their studies, that is to say that they want even more improvements, the barrier still has to be tackled, if at all possible.

Secondly, the increased numbers reported in this chapter mostly do not deal with learners wanting improved interaction to feature as an integral aspect of their online studies, which figures prominently in the students' perceived impact on their studies of deficiencies in this aspect of their online learning experience.

Thirdly, and most importantly, the figures indicating improvements or 
increased numbers reported in this chapter apparently resulting from changes implemented by The $O$ Institution are all at best what might be termed 'indirect' measurements of improvement in the immediate learning circumstances or experiences of the students. Of themselves, they do not really measure the improved impact of these changes on the learners' studies or their achievements as, for example, instantiated by improved academic scores.

Fourthly, welcome though the changes and improvements reported in this chapter undoubtedly are, they really only represent a series of individual or somewhat ad hoc changes and certainly do not add up to a fully coherent package aimed at ameliorating this aspect of online learners' experiences whilst enrolled in The $O$ Institution. In that sense, they have not, so far, been Introduced as part of an overall, coherent strategy, designed to put improved opportunities for better communication and interaction at the heart of the whole system of learning provided by The $O$ Institution, and in all aspects of its learning design and delivery. I will return to this matter in the next chapter.

\section{Summary}

In response to the empirical research results presented in the previous chapters, The $O$ Institution has already implemented some improvement measures in respect of communication and interaction that includes establishing the Customer Contact Centre, optimizing course discussion panels, introducing popular online chatting tools, and forming various learner communities-all so as to Increase the system's efficiency and the satisfaction of its online learners'.

Although, so far, there are insufficiently direct, robust measurements or indicators that can definitively demonstrate that these various initiatives 
have resulted in actual, positive accomplishments for the Institution and its online adult learners, nevertheless by comparing the average monthly log-in rates and the continuous course registration rates, examining the data on average weekly online learning time, as well as noting the Alexa ranking of The $O$ Institution website, we are still able to get some indirect idea of the trends that are associated with the introduction of these initiatives taken to tackle some of the main barriers to online learning faced by online learners, as revealed in this study. Further research is now required to evaluate systematically the effects of these intended improvements on learners' experiences, levels of satisfaction and achievements. 


\section{Chapter 8:}

\section{Summary and Conclusion}

\section{Why This Topic?}

In the past ten years, web-based distance education developed very quickly in the mainland of China. Before the year of 2000, the enrolled web-based distance learners were no more than 500 thousand. But by the end of the year 2007 , the recorded amount reached the peak, was more than 8 million.

The expansion of distance education was just an epitome of the expansion of higher education in China in the past ten years. Some research suggested that the quality of higher education in China had indeed declined (Bao, 2007; Cheng, 2006). People also started to query the quality of web-based distance education. Although there were little published researches on the influence of large-scale expansion resulting in a decline of quality of the distance education in China, certain research did indicate that online course and learning resources lacking of appropriate instructional design usually failed to enable learners to learn online effectively (Chen, 2005). Another research indicated that only one third of the sample learners learned online 'constantly', and more than half of them just 'occasionally' accessed to the online learning platform (Zhao, 2002). (According to the learners' own interpretation, 'constantly' means learning online at least one hour per day on average; whilst, 'occasionally' means accessing to the Internet no more than one hour per week). A survey on a small scale conducted by me and my colleagues in 2006 in a learning centre attached to The $O$ Institution showed that the average time spent on learning online of 
per head per week of the 'top' 50 out of 236 learners ('top' learners mean those spending most time on learning online) was less than 30 minutes, whilst even the longest time spent online per week for one person was only 2 approximately hours. Given that the expectation was that part-time distance learners would spend at least 14 hours per week in study, it can be seen that, at the time of the research, reported online study amounted to only a small part of these students' studies.

One of the essential factors to guarantee the quality of online learning should be to enable learners to learn online frequently or regularly. But the above-mentioned researches indicated a distinct phenomenon. Also, one of above-mentioned research argued that the online learning should be learner-centred and based on self-directed learning; distance education institutes should provide learners with well and appropriately designed online learning resources, should take full advantage of adult learners' existing knowledge structure, experiences and abilities, and should provide learners with an open and interactive online learning environment. But actually, in that time, only few of the distance education institutes were aware of this and try to tailor and design study units for online learners. Learners involved in web-based distance education faced different barriers of access to online learning. In that case, some researchers, managers and practitioners of this field asked: 'Does the online learning happen indeed?'

From my working experience, I had also noted that, although the distance learners enrolled in The $O$ Institution had chosen to study through the medium of online courses, it seemed to me that they often had not allocated adequate study time for the Internet, let alone be over-concerned with the quality of the provision and the level of academic achievement they attained in these online study programs. So, I was also puzzled: what exactly was it that was preventing our online learners from spending enough time on 
their studies and from achieving at the highest possible levels?

As author of this thesis, I had been working with the senior management position at The $O$ Institution and therefore had also become very concerned about these issues: the related matters of the effectiveness and, especially, quality of online learning, and, within this, had wanted to centre increasingly on improving the experiences of the online learners themselves.

It was with the above broad queries and concerns in mind, that I started out on this research. I would like to survey what kind of factors prevent learners in web-based distance education from learning online, in what ways are the learners' learning behaviours and achievements impacted, what could we do to facilitate the learners to learn online and improve their academic achievements. Through extensive literature review, and on the basis of Informal discussions with colleagues in the field and with learners, I came to realise that the whole issue of 'barriers', or obstacles, encountered in online learning, appears to be an important factor that is probably affecting both the effectiveness and quality of online learning.

After reviewing the domestic and international literatures, I found that few literatures systematically examined the barriers to online learning, especially used learners in mainland China as sample. At the same time, as a senior manager in The $O$ Institution, I had become aware that it was one of the main responsibilities of distance education provider to help learners overcome these problems, which, in turn would enable further development of the provider's own business. Therefore, with The 0 Institution as an empirical example, I decided to undertake a serious inquiry, in the form of an academic thesis, with a focus on analysing the learning barriers that exist for adults in distance education and to explore some possible ways through which to improve the quality of online education by overcoming, or at least by 
reducing the impact, of these barriers.

\section{Research Questions and Methods of Inquiry}

My key research questions for the inquiry which provides the basis for this thesis were threefold, as follows.

Firstly, who were the learners engaged in online learning with The 0 Institution? What were their key demographic features and were there any notable differences in these features amongst learners from different groups?

Secondly, what kind of barriers or obstacles might online learners confront in online learning and what might be their perceived impact?

Thirdly, what kind of strategies and countermeasures might be taken to help online learners overcome the difficulties and barriers identified in online learning?

To find out the characteristics of online learners and the learning barriers they typically encounter, my research employed, principally, questionnaires distributed to online learners in The $O$ Institution in order to obtain some statistical data on the backgrounds, experiences and attitudes of largely part-time, adult, online learners. This became my principal research instrument and was then supplemented by qualitative data drawn from interviews with learners themselves, from colleagues and experts in the field of online learning and from documentary analysis.

\section{Research Findings}

\subsection{A Brief Summary of the Main Findings}

Despite these necessary caveats about my study, nevertheless, from a systematic review of all of the various data that I had-collected, and 
especially from the questionnaire responses and interviews with online learners themselves, in summary terms, through the research reported in this thesis, I discovered that problems with 'communication and interaction' were the key issues encountered by online learners amongst the whole range of barriers to online learning.

The majority of my sample learners are employed adults (accounting for $91.9 \%$ ) and part-time studying (accounting for $94.0 \%$ ) who engage in relatively frequent social activities and prefer group study with the teacher and with fellow students instead of studying all on their own. Chapter 4 described the characteristics of the sample of learners: (1) their ages ranged from 20 to $45 ;(2)$ Just over one fifth $(22.4 \%)$ of the sample regarded their social activities as highly frequent, and $24.4 \%$ as quite frequent, indicating that near half of the learners in the sample actively participated in social activities. On the other hand, only $1.6 \%$ of the sample learners said that they rarely engage in social activities and $13.9 \%$ did so not very frequently. Thus, only $15.5 \%$ of the sample learners did not have busy social lives. (3) Among the sample of learners, those who preferred not to study together with the teacher accounted for only $8 \%$ while $58.3 \%$ of the students expressed a preference the other way around; while $9 \%$ of the sample learners preferred not to study with fellow learners, $54.6 \%$ chose the opposite.

Problems of communication and interaction appeared to be the principal barriers to online learning faced by my sample of learners. Thus, in Chapter 5 of this thesis, I reviewed the perceived impact of the barriers that I had identified in the analytical framework devised, as these various impacts were reported through the questionnaires, which were then subject to factor analysis. The barriers explored in this part of the thesis included: learning resources-related barriers; technical barriers such as operating the computer or surfing or searching the Internet; barriers of communication and 
interaction; problems with teaching and courses; learning support services; equipment and internet conditions; and financial and economic problems. After a series of empirical test, it can be found that communication and interaction is the key and significant barrier to learner's online learning.

In this part of my research, I further found that the barrier of 'communication and interaction' was not only acting as the key and significant barrier faced by the online learners, but also appeared to exist as a markedly independent one: most importantly, the problem of 'communication and interaction' was not only the most urgent for the learners, but was also the most independent factor from the rest of the items on the list. I reached this conclusion by a statistical analysis of the relation of each barrier to the others, which showed that while the other six barriers received respectively a Pearson Correlation coefficient higher than 0.5 , the Pearson Correlation coefficients between 'communication and interaction' and the other learning barriers were always below 0.4 , indicating that to a great extent, 'communication and interaction' was likely to relatively independent from the other learning barriers identified.

Also, it appeared that improvements in 'communication and interaction' were the most effective in overcoming the other barriers and also contributed to increasing the learners' learning efficiency and effectiveness.

In addition, still in Chapter 5, I found that, when controlling for learners' individual characteristics, if we can improve the situation for learners in respect of 'communication and interaction', we can also help to resolve learners' problems in respect of 'learning resources'. This suggests that, for either online learners or online learning providers, when facing a variety of complex learning obstacles or barriers, it is always important to identify the most important one to overcome, as tackling it could help to reduce or eliminate other barriers at the same time. 
In Chapter 6, I then went on to analyse the different effect achieved by different means of overcoming the barriers and discovered that 'more interaction with fellow learners' was the most effective and 'more interaction with teachers' was the third most effective among all the possible optimizing measures. This lead to the perception that working on 'communication and interaction' is very likely to be the best starting point for tackling barriers to online learning.

As reported in the chapter, my research (and, indeed, my experience) suggested that, if the situation of 'communication and interaction' in online learning can be improved for online learners so as to meet their desire for 'sociability', that other possibilities and benefits could occur. For example, once online learners can thus establish their own 'learning communities' and form relatively stable 'student-to-student' relationships, and 'student-to-teacher' relationships, other learning barriers faced by these learners will be reduced as well.

In other words, from this necessarily limited inquiry, and returning to my original research questions, I believe that a key barrier or obstacle standing in the way of successful and engaging learning for part-time, adult, online learners in The $O$ Institution is the lack of opportunities for effective communication and interaction as a fully integral and coherent element of online learning. Further, improvement of 'communication and interaction' opportunities as an aspect of the overall design and operation of the online learning schemes provided is precisely where to start to bring down or reduce the barriers that adult learners face in online learning. By tackling the problems associated with poor opportunities for communication and interaction, learning providers can help establish a 'learning community' on the online learning platform so that the 'sociability' needs of adult learners can be better met with a relatively stable 'classmate' relationship and 
teacher-student relationship.

\subsection{Have My Research Findings Basically Answered My Research Questions?}

Firstly, what I presented in chapter 4 with a systematic empirical analysis of the characteristics of the sample of learners have basically answered the question of 'who were the learners engaged in online learning with The 0 Institution'.

My research found that the majority (above 90\%) of the sample learners were employed adults, studying part-time, paid their tuition fees at their own expense, and near half of them engaged in quite frequent social activities. These features of the sample learners are consistent with my acquaintance of learners enrolled in The O Institution.

There is a significant gender difference associated with the different major subjects being studied $(P<0.01)$. Overall, science and engineering disciplines have more male distance learners, while the humanities and social sciences disciplines have more female distance learners. This gender distribution pattern is basically consistent with the situation in standard, campus-based higher education. By controlling the factor of the different major subject being studied by learners, there are significantly $(p<0.01)$ more male than female learners. And also among employed people, more males than females tend to choose distance learning.

Whether learners are employed or not is not associated with any significant difference in their levels of satisfaction with online learning. However, there are significant correlations between learners' family status and their levels of satisfaction with online learning $(p<0.1)$. Unmarried learners or learners without children, have lower levels of satisfaction with 
online learning.

Secondly, what I presented in chapter 5 with a systematic empirical and statistical analysis from various angles of the barriers faced by online distance learners have basically answered the question of 'what kind of barriers or obstacles might online learners confront in online learning and what might be their perceived impact'.

I identified seven types of learning barriers might online learners confront in online learning, which were sorted as follows: communication and interaction; teaching and the curriculum; learning resources; teaching support services; external support and financial burdens; computer and network operation skills; and Internet access conditions. It was seen that the key and significant barrier for learners' online learning was the barrier of 'communication and interaction'.

Furthermore, I found in this chapter that different learners react differently to the same learning barrier. For example, learners with different fees-payment circumstances showed significant differences in their experience of the barrier arising from the problem of expenses arising from learning.

Also, I analyzed and found that there is a significant correlation between different learning barriers. However, the learning barrier arising out of 'communication and interaction' problems and other types of learning barriers manifested no close relationship in this study, suggesting that not only was the barrier of 'communication and interaction' acting as the key one faced by these learners, but also that it existed as an independent barrier. Fortunately, after further analysis, I found that, when controlling learners' individual characteristics, then, if we could improve the situation for learners in respect of 'communication and interaction', we might also be able to help 
resolve learners' problems in respect of 'learning resources'.

Thirdly, what I presented in chapter 6 with a systematic empirical and statistical analysis of the relationship between learning barriers and academic achievement amongst the learners studied in this thesis have basically answered the question of 'what kind of strategies and countermeasures might be taken to help online learners overcome the difficulties and barriers identified in online learning?'.

I found that the degree of experiencing learning problems, or barriers to online learning, and learners' academic performance, as indicated by their scores in examinations, demonstrate significant negative statistical relationships, meaning that the lower the degree of experiencing particular learning barriers, the higher learners' academic scores. For example, experiencing greater impact from the financial burdens of learning will be statistically related to lower academic scores, and that fewer problems in interacting with other students will be related to higher academic scores.

In this chapter, I also analyzed the subjectively estimated effect of different possible improvement measures and found that the following six measures were expected by learners to have the greatest effect: To have more interaction with fellow students; To have clearer course descriptions and guidance; To have more interaction with teachers; To have more learning resources; To have more practical opportunities or internships; To have prompt feedback from supporting staff. This once again confirms my conjecture that facilitating interaction between distance learners would represent an important breakthrough in tackling learning barriers faced by distance learners and helping to improve their academic achievements. 


\subsection{Comparing My Main Findings with Those of Other Researchers}

My main findings are basically consistent with some research results of the literature that I reviewed. For example, Muilenburg and Berge (2005) found the most important or serious learning barrier faced online learners was social interactions, related closely with the enjoyment and effectiveness of online learning as well as the likelihood of taking a future online course. Tao (2004) mentioned that problem of communication and interaction with distance educational institutions was one of the three major difficulties facing distance learners.

However, these researchers did not do further research to verify if the problem of communication and interaction existing as a markedly independent barrier from others; in addition, these researchers did not mention if the improvement in 'communication and interaction' would be the most effective in overcoming other barriers, and if the improvement in 'communication and interaction' would contribute to increasing the learners' learning efficiency and effectiveness.

Furthermore, few of the literature which I reviewed had conducted a large sample empirical study on the barriers to online learning, or had especially used Chinese web-based distance learners as their research sample. At this point, my research might enrich the international and domestic literature concerning barriers to online learning. At least, my research findings might make a practical contribution to the knowledge of the barriers to online learning facing Chinese web-based distance learners, as well as to the practice of reducing the impact of barriers to online learning. For example, $I$ have managed to apply my main findings to The $O$ Institution to facilitate the 'interaction' between learner-learner, learner-tutor and learner-environment. Also, based on my research results, I would like to put 
forward some suggestions respectively to The $O$ Institution, the universities delivering online programmes and the administrative authorities.

\section{Further Possible Developments: Suggestions}

I now turn to applying my research findings to promote the further possible developments in reducing the impact of barriers to online learning. I would like to put forward some suggestions or innovations which may help, or have already been implemented to help, further reduce and even eliminate the barriers to online learning faced by distance learners.

First of all, and reflecting critically on this study and its various findings and suggestions, it needs to be stressed that, I believe that any major consideration of the barriers facing online learners in modern China cannot exclude the impact of those important factors that necessarily operate at a macro-level in China (and maybe in education generally elsewhere in the world), such as the traditional ideas about education and the means of conducting, the current education system and its associated organisational and administrative mechanisms, as well as the associated policy and arrangements for funding and quality review in the field of distance and online education. These are very big issues and, necessarily, outside the scope of a limited inquiry such as the study reported here and certainly are beyond the immediate influence of The $O$ Institution, although its example in seeking to make changes and improvements could be more generally instructive.

Hence, as practitioners of online distance education, it is my belief that we should continue to focus principally on those factors in micro-level that may constitute barriers to and in online learning faced by distance learners, especially adults where we can make the most immediate impact. We should take initiatives to help the distance learners tackle the barriers that may be 
encountered by them in their learning process and all of its associated elements that are, to some extent, under our potential control. Eventually, the findings of my research might provide a framework on which we could manage to find ways to reduce and even eliminate the barriers to and in online learning currently faced by adult distance learners not just in China but, maybe, elsewhere as well.

From the analysis reported in this thesis, I would first argue that we should always pay attention to make good, effective 'communication and Interaction' opportunities occur as a normal part of the learning process and routine experience of online learners. I recommend this principle with all my heart. That means we should consider this 'interaction' matter not only in the delivery process of teaching and tutoring as well as in all learning activities, but also in the production of teaching materials and in the provision of learning materials, as well as in the building of online learning environments. In a word, it is necessary to put the matter of 'interaction' at the very core of instructional design system for the whole process of online learning thus enabling learners to be more likely to interact with the whole array of text books, courseware, learning materials, and the whole learning environment in which they can become involved, as well as with fellow students, teachers, tutors and support staff.

The following part contains my further suggestions derived from reflection about the results set out in this thesis and my everyday working experience. These ideas concern or are directed respectively at The 0 Institution, the universities delivering online learning, and the concerned administrative authorities for distance education. I hope that these observations and suggestions might provide them with a point of reference and help to solve the problems of online learning revealed in my research. 


\subsection{Suggestions for The O Institution}

As we have seen, because of the separation of space-time, the lack of communication and interaction becomes one of the most important barriers to online learning. As a learning support services provider, one of the primary responsibilities of The $O$ Institution is to make the 'communication and interaction' occur naturally and effectively during the learning process of the distance learners. Hence, The O Institution has already been taking a series of measures to facilitate communication and interaction of learner-learner, learner-teacher and learner-institution, and some evident impact or effect have been seen (refer to chapter 7 for details). However, those measures have, so far, just provided the learners with a variety of interaction channels, but have not yet built a mechanism to arouse or stimulate learners' initiatives in matters of communication and interaction. In fact, I found the learners were still not active enough in interacting with each other or with the teachers, and did not make the most of these interaction channels. I think the solution for this problem might be that we should identify the different learning needs of different learners and provide them with individual and value-added learning support services. Therefore, $m y$ further suggestions to The 0 Institution are as follows.

\subsubsection{Provide learners with individual learning support services.}

The survey found that learners had showed a great desire to interact with fellow students and teachers. But, in fact, the learners in The $O$ Institution are not active enough in interacting with other learners or teachers. Why? I think the reasons stem from the learning support services provided by The 0 Institution which do not yet fit the individual needs of the learners. The empirical research reported in chapter 5 found that learners with different characteristics manifested significant differences in the various learning 
barriers encountered by them. For example, in computer and network operation skills, there was a significant gender difference.

Therefore, The $O$ Institution should provide the learners with individualised or 'personalised' learning support services, based on their different characteristics (such as educational background, learning preference, learning styles, learning skills, and others) and learning needs, in order to reduce and even eliminate their barriers of communication and interaction. That is, The $O$ Institution should build a mechanism to evaluate and identify the individual needs of the learners, then customize and promote learning support services that are fitting for them. Fortunately, The 0 Institution is going to introduce some innovations in its learning support services mode, including but not limited to customizing learners individual learning pathways, building them an individual knowledge management space or portfolio, assigning them micro learning activities, monitoring their learning progress, and facilitating the communication and interaction between learner-learner as well as learner-teacher or learner-counsellors. The 0 Institution will employ the counsellors to evaluate and identify the learners' individual needs and help them customize their learning pathways. The $O$ Institution has already integrated these innovations into a pilot project-'National e-Learning Cloud'-which is based on 'Cloud Computing' and aims to facilitate the integration of ICT into distance learning in-depth and to enable people access to the 'National e-Learning Cloud', anywhere at anytime via a variety of display terminals such as PCs, TVs, Mobile Phones as well as other Mobile Internet Devices. The impact and effectiveness of these various developments now need to be rigorously assessed.

4.1.2 Introduce the mode of Social Network Services (SNS) to enable online learning to be more enjoyable and become more value-added. 
The $O$ Institution has provided learners with a variety of interaction channels, such as online course forums and online communities, as well as online chatting tools, but the learners are still not active enough in interacting with others because the current contents or topics do not always attract them. Hence, I suggest that The O Institution should introduce the mode of Socia! Network Services (SNS) to enable the learners to establish their own 'learning communities' and collaborative learning environments, as well as form relatively stable 'student-to-student' and 'student-to-teacher' relationships, share their mutual knowledge and experience, as well as insights. The mode of SNS is propitious to meet the desire for 'sociability' of the adult learners, to make their learning more enjoyable and value-added (for example, to achieve more interpersonal relations, social identities and self-fulfilment). In fact, the mode of SNS is directly in line with the innovation direction of The O Institution's learning platform.

4.1.3 Strengthen the skills training for learners in interaction and platform usage.

Above I suggested that The $O$ Institution should provide online learners with individual learning support services and introduce the mode of Social Network Services (SNS). These two new measures are both involved in developing or enhancing the learners' (and teachers) skills of interaction and platform usage. I believe that these new measures would further reduce the barriers of communication and interaction. In order to enable the learners to apply these new measures effectively to facilitate their online learning, The $O$ Institution should strengthen the skills training for learners and others in the system in interaction and platform usage.

4.1.4 Improve staff recruitment and training in online programme design and operations. 
Amongst other possible changes and improvements that could be tackled at the level of The $O$ Institution is the recruitment, training and supervision of the professional and other staff engaged in designing, providing and supporting online learning so that their practices accord with the found findings and suggestions arising from this study. Above all, it needs to be stressed that the very ways in which online learning is conceived, designed and implemented can either exacerbate or even 'build in' potential barriers and obstacles that stand in the way of online learners, or else they can be acknowledged and 'designed out', or tackled through good, appropriate professional practice.

These suggestions are deliberately focused on the question of instructional system design, calling for joint efforts to be made by the providers of online education and learning support services. In fact, well designed instructional systems may not work without associated effective operational arrangements. So, in regard to this matter of operation, we still need to secure improvements in every detailed element in order to make sure that the whole instructional system goes well.

4.1.5 Understand better the experiences, orientations and attitudes of online learners.

In line with the previous suggestions, it needs also to become part of the routine work with online learners in The $O$ Institution to enquire into the experiences and attitudes of online learners and to respond to these accordingly. That does not exclude the possible need for some additional training in appropriate online learning habits and techniques for the online learners themselves, including the matter of their own orientations to, and skills in, studying online. 


\subsection{Suggestions for Other Chinese Universities Delivering Online Learning}

Currently in field of the Chinese distance education, the courses and their corresponding teaching materials (principally text books and courseware) used by distance learners in most Chinese universities are still usually the same as those used by 'conventional', full-time students studying face-to-face on campus, having no special content tailoring and instructional design according to the characteristics and learning needs and demands of adult distance and online learners. The learners in this study reported universally that the content of the teaching materials was excessive and too divorced from practice, and did not meet their learning needs. Also, the delivery of teaching content is still mainly courseware-based, but the majority of the courseware is lecture-based, which has no special associated instructional design, is usually too rigid and does not attract the learners.

In terms of the assessment of the learning outcomes, the examinations usually focus too much on memory, instead of constituting challenging applications of knowledge and skills (including analytical and critical skills), and are too often different from the content of the teaching materials. Consequently, many of the learners are not willing to spend time on the online courses and their corresponding teaching materials, and are also not willing to communicate and interact in the course forums, instead paying a lot of attention simply on how to pass the examinations quickly. Therefore, my suggestions for the universities who are delivering online programmes are as follows.

4.2.1 Provide the learners with competence-orientated courses and well and appropriately designed teaching materials.

As reported in the chapter 4 , the majority of the online learners are 
employed (91.9\%), studying part-time (94.0\%) and paying the tuition fees at their own expense (95.6\%). In addition to the diplomas, they also aim to advance their professional knowledge and competence. They are eager to employ what they have learned to solve problems or to add their social value. So, what they want are those courses that keep up with the market demand and developments in industry or technology, whose content keeps updating constantly. That means the universities should provide online distance learners with competence-orientated courses to develop their professional competences, skills, and values.

In order to do this, a new approach to curriculum development is needed, and the content of the curriculum and teaching now calls for reform. In order to meet the needs of development of the social, economic and human resources, curriculum design and content tailoring should focus more on learners' professional competences and be designed to meet their desires for better career development. Industry, enterprises and other employers are encouraged to participate in the formulation of better talent training programmes. Specialists, senior practitioners and academic experts in Industries and enterprises should be invited to participate in curriculum development for a better match between professional development goals and vocational qualification standards, with the content of curriculum and teaching more focused and practical so that a 'talent cultivation' model that not only balances knowledge and capacity, but also combines professional education and vocational education, could be established.

In addition to professional knowledge, skills and values, learners' competence in critical thinking, problem solving, communication, information utilization and team collaboration should also be developed. The teaching materials of the courses should be well organized, appropriately designed and developed according to the learning characteristics, needs and demands 
of the adult distance learners. This is very crucial in promoting learner's learning outcomes and helping them to better apply their knowledge to practice and achieve career success. So long as the curriculum and teaching is valuable for learners' career development, learners will be more likely to link their working experience with the current study, thus increasing interest in learning and taking the initiative to communicate, interact and share with others.

4.2.2 Arouse or stimulate learning initiatives on the part of the learners by attempting to introduce more experiential learning in adult online learning programme design and learning processes.

David Kolb (1984) provided one of the most useful (but contestable) descriptive models available of the adult learning process, inspired by the work of Kurt Lewin (1890-1947), the so-called The Experiential Learning Cycle. The model suggests that there are four stages in learning which follow from each other: Concrete Experience is followed by Reflection on that experience on a personal basis. This may then be followed by the derivation of general rules describing the experience, or the application of known theories to it (Abstract Conceptualisation), and hence to the construction of ways of modifying the next occurrence of the experience (Active Experimentation), leading in turn to the next Concrete Experience. All this may happen in a flash, or over days, weeks or months, depending on the topic, and there may be a 'wheels within wheels' process at the same time.

The ideas of Kolb's learning cycle have been adopted and adapted to almost all kinds of learning situation, but it should be noted that they refer to learning from experience or discovery (such as situated learning) rather than to taught (or 'reception' learning, 'transmission' or rote learning). However, this model has been widely applied to design and develop learning activities 
for adult learners. The most direct application of the model is to use it to ensure that teaching and tutoring activities give full value to each stage of the process. This may mean that for the teachers or tutors, the major tasks should be to 'chase' the learner round the cycle, enable the learners to connect their experiences to their current learning, and share or enlighten each other. This may facilitate the communication and interaction between learner-learner and learner-teacher, may be propitious to build an environment of collaborative learning, and arouse the learning initiative of the learners.

\subsubsection{Improve the assessment system of learning outcomes.}

Examinations are currently the primary or most well-regarded means for assessing the learning outcomes of online learners in China (as, mostly, elsewhere), and also for judging and monitoring the quality or effect of the teaching. The feedback information obtained from the examinations should be used to evaluate the gap between teaching effectiveness and teaching objectives, so as to improve the learning outcomes of learners. This paper, however, has found that learners' family status and their academic performance and learning satisfaction are significantly correlated. Learners, who are unmarried and are without children, have significantly higher academic scores but significantly lower levels of learning satisfaction. This might suggest that examinations do not truly reflect the full range of learning outcomes for learners, in which case the enthusiasm of learners will be affected adversely.

Two aspects should be noticed if we want to find out the reasons. One aspect is that the examinations usually focus too much on mere memory and rote learning, instead of on applications of the knowledge and skills gained through learning, which is not really suitable for adult learners (if for any). 
The other aspect is that the content of examinations may often be different from the content of the teaching materials. Therefore, it is very necessary to improve the assessment system of learning outcomes. I suggest that the universities should try the assessment mode of using learners' 'portfolios' (which can be most effectively built up and captured online) to ensure the assessment reflects fully the students' learning achievements and outcomes and encourages more learning initiative of the learners themselves.

\subsubsection{Reform teacher systems.}

A reform in the team composition of teachers is also necessary. Experts with extensive practical experience and theoretical knowledge in industry and enterprises should be invited to be part-time professors, by participating in curriculum design, teaching materials development and teaching activities as speakers or counselling teachers; thus, the team of teachers can be enriched. These teachers would have a clear understanding of the practical needs of society. With their updated theory and application of technology, they could take their industry knowledge and experience into the 'classroom' (virtual as well as concrete) to ensure that teaching content is keeping up with market demand. In teaching practice, such a team of teachers, characterized by team operations in curriculum design and offering learning support services, can provide comprehensive, personalized services for distance learning so that a bridge between learning and practical application for learners can be built. Teachers, as designers and facilitators of learning activities, should guide learners to understand course content and better develop their knowledge and skills, and urge learners to actively participate in the learning process, promote learners' learning through interaction, reflection and sharing. 


\subsection{Suggestions for Administrative Authorities}

Currently in China, the development of distance education is driven by both policy and market demand. In a sense, the policy may have greater impact on its development. Here, I put forward two policy suggestions to the concerned authorities with responsibility for administration.

4.3.1 Establish a system to facilitate that online learning outcomes are recognized and transferred between diploma and non-diploma education at the same level.

'The National Planning Outline of Education Reform and Development for 2010-2020' (issued by the State Council of China in July 2010) put forward the strategic objective of 'by 2020 , achieving modernization of education basically, coming into being learning society basically, getting into the nations queue of powerful human resources'. Distance education was regarded as an important approach for expanding continuing education and constructing a 'learning society' in China, as well as for improving the competency of human resources. But currently, the learning outcomes cannot be recognized and transferred between diploma and non-diploma education even at the same level, which hinders the learning initiative of people engaged in study. The elimination of this obstacle would stimulate the learning initiative of distance learners and further expand the online education.

4.3.2 Establish a financial assistance system in distance education.

In chapter 5, I found that learners with different fees-payment circumstances reported significantly different levels of difficulty in respect of tuition fees and the costs of the Internet. The learning obstacle caused by the 
expense of learning increased significantly along with learners paying more of the expenses of learning.

In the interviews, some learners told me that they had to work in two jobs, as they had family financial burdens and also had to meet the costs of high tuition fees. They have to 'often stay up late to learn' and are 'afraid that they cannot finish homework'. I believe that once the expense of distance education reach a certain level, a lot of people who would otherwise want to pursue distance education may have to give up because of the costs, especially if they have to meet them all at their own expense. This inhibits the investment in human capital for the whole community, especially adult learners, which will certainly constitute an instance of a new injustice and additional aspect of social stratification.

Therefore, I suggest that in the field of distance higher education, a viable option to solve this problem would be to draw on the experiences of colleges and universities and study their student financial assistance policies to establish a student financial assistance system for distance, online learners, with the help of distance education providers, governments and other social parties. For examples, tuition fees loans could be provided, and fees remission for excellent performers can be offered so as to encourage learners to increase their learning efficiency.

\section{Some Limitations}

I need now to point out some of my study's limitations and drawbacks.

Firstly, the study appears to be not in sufficient depth. As an EdD thesis rather than a PhD dissertation, limited by the length, my thesis has no enough scope for further and more deeply discussions on the reasons behind every finding. Some data which I gathered at the interview sessions should have better explanatory value to some certain findings, but I did not always 
discuss them further and more deeply. In addition, it needs to be stressed that this is a study based only on a sample of online learners in The 0 Institution: it cannot be assumed that the findings can easily be generalised to all learners enrolled by the Institution, let alone to all online learners in China or even beyond. In that respect, the conclusions suggested by this inevitably limited inquiry are mostly suggestive and most certainly call for further studies, not only to test out my conclusions and recommendations, but also to explore the extent to which the context and circumstances of online varies the experience of encountering or overcoming of barriers.

Secondly, in proposing a framework for understanding the potential 'barriers' facing online learners, it should be noted that these barriers were constructed from a detailed study of relevant literature, from discussions with colleagues, from experts in the field and from informal discussions with online learners. In other words, they did not emerge from the learners' responses to the formal questionnaire that I designed: on the contrary, they helped shape the questionnaire's content. To that extent, it might be objected that the barriers reviewed in this thesis are ones that principally concern the author himself and others who have written on the subject or who are so-called experts in the field. To this argument I reply that, first of all, my informal discussions with online students also raised the issues termed 'barriers' or obstacles in this study. Moreover, the recognition of these barriers was confirmed in the interviews with students reported above and by the numbers of respondents to the various questions who indicated a high or even very high impact on their studies of the various issues identified in the framework as 'barriers'. However, it still appears to be inadequacy that the study mainly relles on a questionnaire method to collect all data, including the measures to tackle the barriers, for analysis; deriving the learning barriers only from learners' reports without triangulation to check if the results concur. 
Thirdly, even if the respondents perceived no impact on their studies of the different obstacles or barriers, that does not of itself mean that, in practice, there was no such impact. (This, by the way is always a challenge for research that is principally attitudinal). In my study, at least, I was able to explore the links, if any between the level of perceived impact of different possible barriers and learner's academic achievements in terms of their scores in tests and examinations - these latter data not being matters of learners' attitude or perception but of record.

Fourthly, the statistical analysis itself, whilst carried out strictly in accordance with necessary rigour, even where it suggests close associations or links between different variables, does not enable one to draw conclusions about causal relationships between the variables under review, let alone the direction of any causal link. The value of these (fairly exhaustive, if relatively simple) statistical analyses reported in this thesis is that they clearly suggest likely links and influences, and their relative strength, and certainly prompt further inquiry. The statistical analysis also points to the probable differentially perceived or experienced 'impact' of different putative 'barriers' to online learning by different groups of online learners. They also allow the researcher better to understand that not all learners respond in the same ways to issues identified as 'barriers' in the study.

Fifthly, as I commented on further above, the improvement strategies to learner support that I have recommended to The $O$ Institution and some of which have already been implemented need to be further studied with some rigour, to discover whether, and, if so, to what measurable extent, these intended improvements have resulted in better learner experiences and improved levels of academic performance by online learners in The 0 Institution. As I have already reported and refer to again above, there are some clearly indications of positive progress in this regard, but more needs to 
be done to verify the effectiveness of those strategies and measure fully the improvements in learning or the changes and benefits secured.

Finally, the fundamental purpose of conducting this research on online learning barriers was to make a contribution to improving the quality of China's online distance education, by examining and suggesting remedies for, the barriers that are faced by adult learner engaged in online distance education. Despite using others' research findings in order to develop my own framework and research design, I recognise that too little is yet known and understood about the whole range of challenges that adult learners face, especially online. So far, this work constitutes only a modest beginning: my hope is that my own research has added some modest improvement on that situation.

Similarly, I am aware that my own suggestions set out above for improvement need to be systematically tested, and added from other research and examples of good practice. I know, too, that some of the issues addressed, at least in passing, in this thesis, operate at a 'macro' or 'system' level and are less amenable to change at the level of individual providers, such as The $O$ Institution, or individual learners, although all of these levels obviously impact upon each other.

As for the vexed and controversial question of how accurately to measure the quality of a particular kind of education, such as online distance learning in this instance, this thesis is unable to provide any definitive answer, as my efforts at attempting to relate the evaluation of education with course grades and learners' satisfaction turns out to have left much to be desired. This also explains the lack of systematic statistical analysis in Chapters 6 and 7, where the effect analysis relles simply on some modelled or indirect numbers. I would wish to carry future research on the method of measurement for the quality of distance education, and hope that it will help push China's distance 
education industry a further step forward.

\section{Concluding Comments}

This research, prompted initially by my own experiences and observations as a senior manager in an institution devoted to online learning, has concerned itself with the barriers facing online learners in carrying out their studies. In particular, the research reported in this study had a twofold purpose: to discover the perceived impact on their studies of a range of potential barriers, from the point of view of the learners themselves; and to consider ways in which these barriers might be tackled, reduced or even eliminated. In order to pursue these twin objectives, I first undertook a review of the relevant literature with a view to constructing a simple 'framework' or model of the various potential barriers to effective online learning suggested by the literature and through conversations and discussions with online learners themselves, with colleagues in The 0 Institution where I was employed, and by reflecting on my experiences there as a senior manager.

One of the possible implications of the research that I wanted to conduct, and of the research questions that I set myself and of the methods of data collection and analysis that I chose, was that the barriers which I identified and included in my simple framework to test against learners' own experiences would not be recognised as barriers by the learners themselves, or that they might not even acknowledge or even understand the impact of such barriers, even if they accepted their existence.

To some extent, that possibility still exists, although I believe that much of the data collected through my research confirms both students' recognition of the barriers and their willingness to assess the perceived impact of them on their own studies. The problem that remains, of course, is 
the situation where learners, and possibly also the other key players in the provision of online learning, either fail to recognise the existence of such potential barriers, or of their impact upon both the learners and the learning accomplished, or fail to introduce or make use of changes that are intended to help tackle the barriers.

In that sense, in addition to the limitations of my study that I have already reported, the focus of this inquiry still entails much 'unfinished business': there is still much work to be done, both in researching further the Issues raised by this study and in carrying forward what I believe to be much needed reforms. Especially, it is worth to be further researched that how the matter of 'interaction' would impact learning behaviour and academic achievements of online distance learners and how could we apply it to guide our instructional system design and learning materials development.

Furthermore, some follow-up researches could be conducted to further inquire how and to what extent the different learning barriers impact on learners' academic achievements, and how these impacts might be counteracted, how we can do to verify and measure the potential effects of the possible remedial measures which might be expected to reduce or eliminate the impacts of the different learning barriers identified in this study. For example, as I mentioned in the limitations section above, the improvement strategles to learner support that I have recommended to The O Institution and some of which have already been implemented need to be further studied with some rigour, to discover whether, and, if so, to what measurable extent, these intended improvements have resulted in better learner experiences and improved levels of academic performance by online learners.

Last but not least, I feel that I have learned a great deal myself from undertaking this study. 
Firstly, and above all, I have shared with the adult, part-time distance learners the challenges of trying to juggle the varying demands of a very busy professional life at work, with the pleasures and responsibilities of marriage and a growing family at the same time as attempting to study and carry out a serious and rigorous piece of research.

Secondly, I have learned much about the complex matter of designing a research project and just how difficult it is to tailor the design in such a way as to attempt to provide defendable answers to research questions. In this I have come especially to appreciate that nuances in the meaning given to particular words, whether in questions or in answers, can have a huge impact upon the interpretation that can be given to the data collected.

Thirdly, I appreciate much more now not only the strengths of numerical and statistical analysis, but also its limitations and weaknesses, especially as regards the tricky matter of trying to seek out causal relationships and the 'direction' of causes or influence when two or more variables appear to be linked.

Fourthly, and related to the previous point, I understand better now that data collected from a variety of means - so-called 'triangulation' - can be used not only to supplement statistical data, but can also be deployed to cross-check it or to plumb its meaning in greater depth.

Fifthly, I realise now, and to some extent, I believe that I already understood this, that making changes intended for improvement needs action on many fronts and, above all, time to bring about discernible effects. In any case, even well meant and apparently successful improvements may also entail some unintended consequences, not all of which might be benign. Some of these might only manifest themselves after a considerable period of time.

Finally, and this needs to be understood by all concerned with trying to 
improve the lot of part-time, adult, online learners - practitioners, senior managers, policy makers, governments and their advisors, and academic researchers, it is more than ever now clear to me that if real changes and improvements are to be successfully accomplished, it is essential that the learners themselves become active agents in both endorsing the objectives of such intended changes and in helping them to be realised in practice. 


\section{Appendix 1}

\section{Questionnaire on Barriers to Online Learning of Distance Learners}

Dear students,

Thank you for your participation in online learning! In order to understand your learning status and learning barriers, I organized this survey. Your participation in this survey will help us to improve our work and also provide valuable reference for better service for the students in the future. We sincerely hope that you could actively participate in this!

This survey will only be used for statistical analysis and the outcomes will only be used in this study.

\section{Part I: Basic Information}

A1 What are the reasons that you participate in continuous learning? (Multiple choice)

1. Interested in learning

3. Abilities need to be improved

5. Leaders' requirement

7. Self-esteem

9. To make life occupied
2. Want to have better jobs

4. Title Assessment Requirement

6. To be acknowledged by others

8. To contribute to society

10. To win glory for families

11. To set an example for children

12. See other people learn, so want to give a try

13. Others: 

1. Flexible learning time
2. Easy to enrol in
3. Simple tasks, easy to graduate
4. Cheap
5. Just want to do something
6. Others

A3 Are you doing full-time job or part-time job?
1. Full-time
2. Part-time

A4 Do you have children now?
1. Yes
2. No
3. About to have

A5 Have you participated in any of these forms of education before? (Multiple-choice)
1. Correspondence Education
2. Radio and TV Education
3. CD-ROM based Education
4. Web-based Education
5. None of the above

A6 Who pays the tuition fees for you?

1. Payment at my own expense 2. Full payment by the employer

3. Shared payment with the employer

A7 Please indicate the choice that matches your actual situation the most, based on the extent of your agreement of these statements. (Tick" $\vee^{\prime \prime}$ ) 


\begin{tabular}{|c|c|c|c|c|c|}
\hline Items & $\begin{array}{l}\text { Very much } \\
\text { in line with }\end{array}$ & $\begin{array}{l}\text { Relatively } \\
\text { in line with }\end{array}$ & $\begin{array}{l}\text { Neutral } \\
\text { response }\end{array}$ & $\begin{array}{l}\text { Not in } \\
\text { line with }\end{array}$ & $\begin{array}{l}\text { Not in line } \\
\text { with at all }\end{array}$ \\
\hline 1. I am physically very healthy. & & & & & \\
\hline $\begin{array}{l}\text { 2. I have social activities every } \\
\text { week. }\end{array}$ & & & & & \\
\hline 3. My family is very harmonious. & & & & & \\
\hline $\begin{array}{l}\text { 4. My educational background } \\
\text { enables me to deal with my } \\
\text { present studies. }\end{array}$ & & & & & \\
\hline $\begin{array}{l}\text { 5. I can develop a learning plan } \\
\text { and carry it out accordingly. }\end{array}$ & & & & & \\
\hline $\begin{array}{l}\text { 6. I am very confident in } \\
\text { learning. }\end{array}$ & & & & & \\
\hline $\begin{array}{l}\text { 7. I study more than two hours } \\
\text { per day. }\end{array}$ & & & & & \\
\hline $\begin{array}{l}\text { 8. I guarantee to get enough } \\
\text { learning time every week. }\end{array}$ & & & & & \\
\hline $\begin{array}{l}\text { 9. If not disturbed, I am able to } \\
\text { study continuously for more } \\
\text { than three hours. }\end{array}$ & & & & & \\
\hline $\begin{array}{l}\text { 10. Compared with studying } \\
\text { alone, I prefer to study } \\
\text { following the teachers' } \\
\text { guidance. }\end{array}$ & & & & & \\
\hline $\begin{array}{l}\text { 11. Compared with separate } \\
\text { study, I prefer to study } \\
\text { together with fellow students. }\end{array}$ & & & & & \\
\hline $\begin{array}{l}\text { 12. Compared with paper } \\
\text { medium-based learning, I } \\
\text { prefer online learning. }\end{array}$ & & & & & \\
\hline $\begin{array}{l}\text { 13. Compared with online } \\
\text { learning, I prefer reading } \\
\text { paper materials. }\end{array}$ & & & & & \\
\hline
\end{tabular}




\section{Part II: Learning Status}

B1 Please answer questions about the impact on your studies of the

following environmental factors. (Tick" ${ }^{\prime \prime}$ )

\begin{tabular}{|l|l|l|l|l|l|}
\hline \multicolumn{1}{|c|}{ Items } & $\begin{array}{l}\text { Very much } \\
\text { in line with }\end{array}$ & $\begin{array}{l}\text { Relatively } \\
\text { in line with }\end{array}$ & $\begin{array}{l}\text { Neutral } \\
\text { response }\end{array}$ & $\begin{array}{l}\text { Not in line } \\
\text { with }\end{array}$ & $\begin{array}{l}\text { Not in line } \\
\text { with at all }\end{array}$ \\
\hline $\begin{array}{l}\text { 1. The tuition fees are too high and } \\
\text { they have become a serious } \\
\text { financial burden to me. }\end{array}$ & & & & & \\
\hline $\begin{array}{l}\text { 2. The Internet fees are too } \\
\text { expensive. }\end{array}$ & & & & & \\
\hline $\begin{array}{l}\text { 3. My boss/employer does not } \\
\text { support my studies. }\end{array}$ & & & & & \\
\hline $\begin{array}{l}\text { 4. My family and friends do not } \\
\text { support my studies. }\end{array}$ & & & & & \\
\hline $\begin{array}{l}\text { 5. I do not have enough time to } \\
\text { study due to my busy work. }\end{array}$ & & & & & \\
\hline $\begin{array}{l}\text { 6. I do not have enough time to } \\
\text { study due to too many family } \\
\text { responsibilities. }\end{array}$ & & & & & \\
\hline
\end{tabular}

B2 Please answer the questions about the impact on your studies of different aspects of using computers to study. (Tick" $\left.{ }^{\prime \prime}\right)$

\begin{tabular}{|l|l|l|l|l|l|}
\hline \multicolumn{1}{|c|}{ Items } & $\begin{array}{l}\text { Very much } \\
\text { in line with }\end{array}$ & $\begin{array}{l}\text { Relatively } \\
\text { in line with }\end{array}$ & $\begin{array}{l}\text { Neutral } \\
\text { response }\end{array}$ & $\begin{array}{l}\text { Not in line } \\
\text { with }\end{array}$ & $\begin{array}{l}\text { Not in line } \\
\text { with at all }\end{array}$ \\
\hline $\begin{array}{l}\text { 1. I do not have a computer. } \\
\text { I do not have a computer, } \\
\text { making it very inconvenient for } \\
\text { my study. }\end{array}$ & & & & & \\
\hline $\begin{array}{l}\text { 3. I cannot access the Internet } \\
\text { conveniently. }\end{array}$ & & & & & \\
\hline $\begin{array}{l}\text { 4. My computer operation skills } \\
\text { are insufficient. }\end{array}$ & & & & & \\
\hline $\begin{array}{l}\text { 5. I am not familiar with the use of } \\
\text { the Internet to interact with } \\
\text { others. }\end{array}$ & & & & & \\
\hline $\begin{array}{l}\text { 6. I cannot use the Internet to find } \\
\text { suitable learning resources. }\end{array}$ & & & & & \\
\hline
\end{tabular}




\begin{tabular}{|l|l|l|l|l|l|}
\hline $\begin{array}{l}\text { 7. The learning platform } \\
\text { navigation is not clear enough. }\end{array}$ & & & & & \\
\hline $\begin{array}{l}\text { 8. It is troublesome to use the } \\
\text { learning platform. }\end{array}$ & & & & & \\
\hline $\begin{array}{l}\text { 9. I cannot skilfully use the } \\
\text { learning platform. }\end{array}$ & & & & & \\
\hline
\end{tabular}

B3 Please answer the questions about the impact on your studies of different elements of courses and teaching. (Tick" $v^{\prime \prime}$ )

\begin{tabular}{|c|c|c|c|c|c|}
\hline Items & $\begin{array}{l}\text { Very much } \\
\text { in line with }\end{array}$ & $\begin{array}{l}\text { Relatively } \\
\text { in line with }\end{array}$ & $\begin{array}{l}\text { Neutral } \\
\text { response }\end{array}$ & $\begin{array}{l}\text { Not in line } \\
\text { with }\end{array}$ & $\begin{array}{l}\text { Not in line } \\
\text { with at all }\end{array}$ \\
\hline $\begin{array}{l}\text { 1. The learning content does no } \\
\text { meet my needs. }\end{array}$ & & & & & \\
\hline $\begin{array}{l}\text { 2. I am not interested in the } \\
\text { courses that are offered. }\end{array}$ & & & & & \\
\hline $\begin{array}{l}\text { 3. Course content is too much } \\
\text { and becomes a burden for } \\
\text { me. }\end{array}$ & & & & & \\
\hline $\begin{array}{l}\text { 4. Teaching materials are not } \\
\text { suitable for adult learning. }\end{array}$ & & & & & \\
\hline $\begin{array}{l}\text { 5. Examinations are not suitabl } \\
\text { for adult learners. }\end{array}$ & & & & & \\
\hline $\begin{array}{l}\text { 6. Some of the content in } \\
\text { examinations cannot be } \\
\text { found in teaching materials. }\end{array}$ & & & & & \\
\hline $\begin{array}{l}\text { 7. Online courseware is too } \\
\text { rigid. }\end{array}$ & & & & & \\
\hline $\begin{array}{l}\text { 8. Courseware cannot be } \\
\text { downloaded, resulting in less } \\
\text { convenience for learning. }\end{array}$ & & & & & \\
\hline $\begin{array}{l}\text { 9. There are not enough } \\
\text { learning resources on the } \\
\text { platform. }\end{array}$ & & & & & \\
\hline $\begin{array}{l}\text { 10. The instructors do not } \\
\text { understand the psychological } \\
\text { and learning characteristics } \\
\text { of students. }\end{array}$ & & & & & \\
\hline $\begin{array}{l}\text { 11. The instructors lack } \\
\text { professional knowledge. }\end{array}$ & & & & & \\
\hline $\begin{array}{l}\text { 12. There is little interaction } \\
\text { between teachers and } \\
\text { students with rare students' } \\
\text { participation. }\end{array}$ & & & & & \\
\hline
\end{tabular}


B4 Please answer the questions about the impact on your studies of the following different elements of learning support services. (Tick" ${ }^{\prime \prime}$ )

\begin{tabular}{|l|l|l|l|l|l|}
\hline \multicolumn{1}{|c|}{ Items } & $\begin{array}{l}\text { Very much } \\
\text { in line with }\end{array}$ & $\begin{array}{l}\text { Relatively } \\
\text { in line with }\end{array}$ & $\begin{array}{l}\text { Neutral } \\
\text { response }\end{array}$ & $\begin{array}{l}\text { Not in line } \\
\text { with }\end{array}$ & $\begin{array}{l}\text { Not in line } \\
\text { with at all }\end{array}$ \\
\hline $\begin{array}{l}\text { 1. I do not know how to get } \\
\text { help from teachers when I } \\
\text { come up against difficulties } \\
\text { in learning. }\end{array}$ & & & & & \\
\hline $\begin{array}{l}\text { 2. I seldom ask questions in the } \\
\text { BBS. }\end{array}$ & & & & & \\
\hline $\begin{array}{l}\text { 3. The teachers in learning } \\
\text { centres are impatient. }\end{array}$ & & & & & \\
\hline $\begin{array}{l}\text { 4. I am not satisfied with the } \\
\text { services provided by the } \\
\text { learning centres. }\end{array}$ & & & & & \\
\hline $\begin{array}{l}\text { 5. The tutors cannot answer the } \\
\text { learners' questions in time. }\end{array}$ & & & & & \\
\hline $\begin{array}{l}\text { 6. The tutors' answers to the } \\
\text { learners' questions are not } \\
\text { profound. }\end{array}$ & & & & & \\
\hline
\end{tabular}

\section{B5 Please answer the questions about the impact on your studies of} different sorts of interaction. (Tick" ${ }^{\prime \prime \prime}$ )

\begin{tabular}{|l|l|l|l|l|l|}
\hline \multicolumn{1}{|c|}{ Items } & $\begin{array}{l}\text { Very much } \\
\text { in line with }\end{array}$ & $\begin{array}{l}\text { Relatively } \\
\text { in line with }\end{array}$ & $\begin{array}{l}\text { Neutral } \\
\text { response }\end{array}$ & $\begin{array}{l}\text { Not in line } \\
\text { with }\end{array}$ & $\begin{array}{l}\text { Not in line } \\
\text { with at all }\end{array}$ \\
\hline $\begin{array}{c}\text { 1. It has a great impact on my } \\
\text { study that I have little chance } \\
\text { to learn together with fellow } \\
\text { students. }\end{array}$ & & & & & \\
\hline $\begin{array}{l}\text { 2.It has a great impact on my } \\
\text { study that I have little chance } \\
\text { to learn under teachers' } \\
\text { supervision. }\end{array}$ & & & & & \\
\hline 3. I feel at a loss when I study. & & & & & \\
\hline 4.I feel lonely when I study. & & & & & \\
\hline
\end{tabular}




\begin{tabular}{|c|l|l|l|l|l|}
\hline $\begin{array}{c}\text { 5. I am very keen to have more } \\
\text { interaction with fellow } \\
\text { students. }\end{array}$ & & & & & \\
\hline $\begin{array}{c}\text { 6. I am very keen to have more } \\
\text { interaction with teachers. }\end{array}$ & & & & & \\
\hline
\end{tabular}

B6 Please answer the questions about the impact on your studies of the following different elements of evaluation of your studies. (Tick" $\vee^{\prime \prime}$ )

\begin{tabular}{|c|l|l|l|l|l|}
\hline \multicolumn{1}{|c|}{ Items } & $\begin{array}{l}\text { Very much } \\
\text { in line with }\end{array}$ & $\begin{array}{l}\text { Relatively } \\
\text { in line with }\end{array}$ & $\begin{array}{l}\text { Neutral } \\
\text { response }\end{array}$ & $\begin{array}{l}\text { Not in line } \\
\text { with }\end{array}$ & $\begin{array}{l}\text { Not in line } \\
\text { with at all }\end{array}$ \\
\hline $\begin{array}{c}\text { 1. I often do self-analysis and } \\
\text { reflection in my study. }\end{array}$ & & & & & \\
\hline $\begin{array}{c}\text { 2. My major subjects are very } \\
\text { closely related to my current } \\
\text { job. }\end{array}$ & & & & & \\
\hline $\begin{array}{c}\text { 3. What I have learned is very } \\
\text { useful for my work. }\end{array}$ & & & & & \\
\hline $\begin{array}{c}\text { 4. I cannot feel my progress and } \\
\text { lack a sense of } \\
\text { accomplishment. }\end{array}$ & & & & & \\
\hline $\begin{array}{c}\text { 5.Overall, I am very satisfied } \\
\text { with this online study. }\end{array}$ & & & & & \\
\hline $\begin{array}{c}\text { 6. I expect to be promoted in a } \\
\text { near future. }\end{array}$ & & & & & \\
\hline $\begin{array}{c}\text { 7. My promotion would have a } \\
\text { close relationship with my } \\
\text { current online learning. }\end{array}$ & & & & & \\
\hline $\begin{array}{c}\text { 8.If necessary, I will participate } \\
\text { future. }\end{array}$ & & & & & \\
\hline
\end{tabular}

B7 Do you have any other questions or comments for online learning? 


\section{Part III: Recommendations and Measures}

C1 To what extent do you think the following measures will help you to further enhance your learning efficiency? (Tick" $\left.\vee^{\prime \prime}\right)$

\begin{tabular}{|c|c|c|c|c|c|}
\hline Improvement Measures & $\begin{array}{l}\text { Very } \\
\text { effective }\end{array}$ & $\begin{array}{l}\text { Relatively } \\
\text { effective }\end{array}$ & $\begin{array}{l}\text { Uncertain } \\
\text { effect }\end{array}$ & Limited & $\begin{array}{l}\text { Have no } \\
\text { effect }\end{array}$ \\
\hline $\begin{array}{l}\text { 1. To receive some free access hours for the } \\
\text { Internet. }\end{array}$ & & & & & \\
\hline 2. To receive computer operation skills training. & & & & & \\
\hline 3. To receive Internet usage training. & & & & & \\
\hline 4. To receive more learning resources. & & & & & \\
\hline $\begin{array}{l}\text { 5. To have clearer course description and } \\
\text { guidance. }\end{array}$ & & & & & \\
\hline 6. To receive training in time management skills & & & & & \\
\hline $\begin{array}{l}\text { 7. To improve the standard of teachers and } \\
\text { teaching. }\end{array}$ & & & & & \\
\hline 8. To have more $\mathrm{Q} \& \mathrm{~A}$ time with teachers. & & & & & \\
\hline 9. To have timely feedback from teachers. & & & & & \\
\hline $\begin{array}{l}\text { 10. To have timely feedback from supporting } \\
\text { staff. }\end{array}$ & & & & & \\
\hline 11. To have more interaction with teachers. & & & & & \\
\hline $\begin{array}{l}\text { 12. To have more interaction with fellow } \\
\text { students. }\end{array}$ & & & & & \\
\hline $\begin{array}{l}\text { 13. To get more support from the } \\
\text { boss/employer. }\end{array}$ & & & & & \\
\hline $\begin{array}{l}\text { 14. To receive more support from family and } \\
\text { friends. }\end{array}$ & & & & & \\
\hline $\begin{array}{l}\text { 15. To have more practical opportunities or } \\
\text { internships. }\end{array}$ & & & & & \\
\hline
\end{tabular}

C2 Please tell us your suggestions for further improvement.

This is the end of the questionnaire. Thank you for your time and patience. 


\section{Appendix 2}

\section{Learner Interview Outline}

Dear Student,

I am doing a research on barriers to online learning of distance learners. Besides the questionnaire survey I need to further interview you so as to obtain more information. Thank you for your cooperation!

I promise that all the information from the interview will only be used for this research, which will not disclose your privacy or bring any adverse impacts to you personally.

1. What are the reasons that you participate in continuing learning? Why did you choose online learning? In your opinion, what are the common reasons for students to choose online learning? How do you think about the social recognition of online education degree?

2. Are you used to online learning? Can your education background enable you to cope with current learning?

3. How long do you usually study every week? Among which, How long do you spend on online learning?

4. Do you feel a financial burden from the online learning costs?

5. What do you think of your computer skills?

6. Do you feel lonely in the study? How often do you interact with teachers and students? Do you often post messages on the coursa forum? 
7. How do you deal with a problem? Do the teachers respond to your problems timely? Are you satisfied with that?

8. Do curriculum, teaching materials, online courses and resources meet your needs?

9. How is the courseware quality? Can you get other learning resources easily?

10. Do you think of your study as being useful?

11. Are there any other factors that hinder your learning efficiency online?

12. If necessary, will you participate in online learning in the future?

13. Compared with other distance learning institutions, what are the advantages and disadvantages of The $O$ Institution? In what area do you want to get help? 


\section{Appendix 3}

\section{Expert Interview Outline}

\section{Dear Sir or Madam!}

I am now doing a research on barriers to online learning of distance learners. I have reviewed a lot of literatures and interviewed some learners in order to producing a questionnaire. However, I still need some guidance on this research. I would like to have an opportunity to interview you. I believe your professional experience and insight would help me advance my research quality. Thank you!

1. How do you think about the social recognition of online education degree? In your opinion, what are the common reasons for students to choose online learning?

2. What do you specially refer to, when you talk about "learning barriers"? How should we define them?

3. What do you think are the main barriers for learners' online learning? How do you classify them? How many categories will there be? Which ones do you think are the most important?

4. What is the impact of learners' characteristics to learning barriers, or what is the relationship between them? What do demographic variables and psychological variables include?

5. Do you have any suggestions for reducing barriers?

6. Do you have any further suggestions for my research?

7. How do you think I can make a breakthrough in research methods? How can this research be creative? 


\section{Appendix 4：远程学习者网上学习障碍调查问卷}

同学您好!

感谢您参加网上学习。为了解您的网上学习情况和遇到的困难, 我进行这次调 查。您的参与将对我们改进工作、为同学们提供更好的服务有重要的参考价值, 感 谢您的积极参与!

本调查只用于统计分析, 其分析结果也仅为本研究所用。

\section{第一部分：基本信息}

A1 您参加继续学习的原因是什么?（可多选）
1. 对学习感兴趣
2. 想换更好的工作
3. 想提升工作能力
4. 评职称的需要
5. 领导的要求
6. 获得他人认可
7. 提高自身价值
8. 为杜会做贡献
9. 使自己生活更充实

10. 为家人争光

11. 为孩子作榜样

12. 看见身边的人在学习, 所以也来学习

13. 其他

A2 您选择网络学习方式最主要的原因是什么?（可多选）
1. 学习时间灵活
2. 入学容易
3. 学习要求不高, 好毕业
4. 价格便宜
5. 没事干，找点事做
6. 其他

A3 您现在的工作是全职还是兼职?
1. 全职
2. 兼职

A4 您现在有孩子吗?
1. 有
2. 没有
3. 将要有

A5 您以前接受过下列哪种形式的教育? (可多选)
1. 函授教育
2. 广播电视教育
3. 基于光盘的教育
4. 网络教育
5. 无

A6 您的学费是谁支付的?
1. 自己全额支付
2. 单位全额支付
3. 单位和自己分担支付

A7 请根据实际情况填写您对下列说法的同意程度。(请在每题后面的选项下划り)

\begin{tabular}{|c|c|c|c|c|c|}
\hline 目 & $\begin{array}{l}\text { 非常 } \\
\text { 符合 }\end{array}$ & $\begin{array}{l}\text { 比较 } \\
\text { 符合 }\end{array}$ & 中立 & $\begin{array}{l}\text { 不符 } \\
\text { 合 }\end{array}$ & $\begin{array}{c}\text { 非常不 } \\
\text { 符合 }\end{array}$ \\
\hline （1）我身体非常健康。 & & & & & \\
\hline (2) 平均我每周都有社交活动。 & & & & & \\
\hline (3) 我的家庭很和睦。 & & & & & \\
\hline （4）我的学习基础足以应对现在的学习。 & & & & & \\
\hline (5) 我能制定学习计划并认真执行。 & & & & 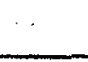 & \\
\hline （6）我对学习非常有信心。 & & & & & \\
\hline (7) 我平均每天学习两个小时以上。 & & & & & \\
\hline （8）我保证了悔周的学习时间。 & & & & & \\
\hline (9) 如果不被打扰, 我能连续学习三个小时以上。 & & & & & \\
\hline
\end{tabular}


（10）与单独学习相比, 我更喜欢跟着老师学习。

(11) 与单独学习相比,我更嘉欢与同学一起学习。

(12) 与纸质材料相比, 我更喜欢在网上学习。

(13) 与网上学习相比, 我更喜欢看纸质材料。

\section{第二部分：学习状况}

B1 请回答下列环境因素对您学习的影响。(请在每题后面的选项下划心)

\begin{tabular}{|c|c|c|c|c|c|}
\hline 题 目 & $\begin{array}{l}\text { 非常 } \\
\text { 符合 }\end{array}$ & $\begin{array}{l}\text { 比较 } \\
\text { 符合 }\end{array}$ & 中立 & 不符合 & $\begin{array}{c}\text { 非常不 } \\
\text { 符合 }\end{array}$ \\
\hline (1) 学费太高, 对我造成了严重的经济负担 & & & & & \\
\hline (2) 网费太贵。 & & & & & \\
\hline (3) 领导不支持我参加学习。 & & & & & \\
\hline (4) 家人朋友不支持我参加学习。 & & & & & \\
\hline （5）工作太忙，没有充足的时间学习。 & & & & & \\
\hline （6）家里事情太多，没有充足的时间学习。 & & & & & \\
\hline
\end{tabular}

B2 请回答下列计算机因素对您学习的影响。(请在每题后面的选项下划々)

\begin{tabular}{|l|l|l|l|l|l|}
\hline \multicolumn{1}{|c|}{ 目蜎 } & $\begin{array}{c}\text { 非常 } \\
\text { 符合 }\end{array}$ & $\begin{array}{c}\text { 比较 } \\
\text { 符合 }\end{array}$ & 中立 & $\begin{array}{c}\text { 不符 } \\
\text { 合 }\end{array}$ & $\begin{array}{c}\text { 非常不 } \\
\text { 符合 }\end{array}$ \\
\hline (1) 我没有电脑。 & & & & & \\
\hline (2) 没有电脑使我学习很不方便。 & & & & & \\
\hline (4) 我上网不方便。 & & & & & \\
\hline (5) 我不能利用因特网熟练地与别人交流。 & & & & & \\
\hline (6) 我不能利用因特网找到合适的学习资源。 & & & & & \\
\hline (7) 学习平台导航不清楚。 & & & & & \\
\hline (8) 学习平台使用比较麻烦。 & & & & & \\
\hline (9) 我不能熟练使用学习平台。 & & & & & \\
\hline
\end{tabular}

B3 请回答下列课程和教学因素对您学习的影响。(请在每题后面的选项下划々)

\begin{tabular}{|l|l|l|l|l|l|}
\hline 题 目 & $\begin{array}{c}\text { 非常 } \\
\text { 符合 }\end{array}$ & $\begin{array}{c}\text { 比较 } \\
\text { 符合 }\end{array}$ & 中立 & $\begin{array}{c}\text { 不符 } \\
\text { 合 }\end{array}$ & $\begin{array}{c}\text { 非常不 } \\
\text { 符合 }\end{array}$ \\
\hline (1) 学习内容不适合我的需要。 & & & & & \\
\hline (2) 我对开设的课程不感兴趣。 & & & & & \\
\hline (3) 婇程内容太䒚, 对我造成了负担。 & & & & & \\
\hline (4) 教材不适合成人学习。 & & & & & \\
\hline (5) 考试形式不适合成人。 & & & & & \\
\hline (6) 有的考试内容在教材上找不到。 & & & & & \\
\hline (7) 网上的课件太死板。 & & & & & \\
\hline
\end{tabular}




\begin{tabular}{|l|l|l|l|l|l|}
\hline (8) 课件不能下载, 不方便学习。 & & & & & \\
\hline (9) 平台上的学习资源不多。 & & & & & \\
\hline $\begin{array}{l}\text { (10) 授课教师不了解学生的心理和学习特 } \\
\text { 点。 }\end{array}$ & & & & & \\
\hline $\begin{array}{l}\text { (11) 授课教师的专业知识不足。 } \\
\text { 少。 }\end{array}$
\end{tabular}

B4 请回答下列支持服务因素对您学习的影响。(请在每题后面的选项下划以)

\begin{tabular}{|c|c|c|c|c|c|}
\hline 题 & 目非常 & $\begin{array}{c}\text { 比较 } \\
\text { 符合 }\end{array}$ & 中立合 & $\begin{array}{c}\text { 不符 } \\
\text { 合 }\end{array}$ & $\begin{array}{c}\text { 非常不 } \\
\text { 符合 }\end{array}$ \\
\hline $\begin{array}{c}\text { (1) 学习遇到问题时不知道怎样得到老师的 } \\
\text { (2) 我很少在论坛上提问。 }\end{array}$ & & & & \\
\hline (3) 学习中心老师的态度不好。 & & & & & \\
\hline (4) 我对学习中心老师的服务不满意。 & & & & & \\
\hline (5) 课程辅导教师对学生的提问回答不及时。 & & & & & \\
\hline (6) 课程辅导教师的回答不深入。 & & & & & \\
\hline
\end{tabular}

B5 请回答下列交流方面的因素对您学习的影响。(请在每题后面的选项下划凹)

\begin{tabular}{|c|c|c|c|c|c|c|}
\hline 题 目 & $\begin{array}{c}\text { 非常 } \\
\text { 符合 }\end{array}$ & $\begin{array}{c}\text { 比较 } \\
\text { 符合 }\end{array}$ & $\begin{array}{c}\text { 中 } \\
\text { 立 }\end{array}$ & $\begin{array}{c}\text { 不符 } \\
\text { 合 }\end{array}$ & $\begin{array}{c}\text { 非常不 } \\
\text { 符合 }\end{array}$ \\
\hline $\begin{array}{c}\text { (1) 不能与同学一起学习对我的学习有很大影 } \\
\text { 响。 }\end{array}$ & & & & & \\
\hline (2) 不能跟着老师学习对我的学习有很大影响。 & & & & & \\
\hline (3) 学习时我感觉到无所适从。 & & & & & \\
\hline (4) 学习时我感到很孤独。 & & & & & \\
\hline (5) 我非常渴望与同学有更多的交流。 & & & & & \\
\hline (6) 我非常渴望与老师有更多的交流。 & & & & & \\
\hline
\end{tabular}

B6 请回答下列学习评价因素对您学习的影响。(请在每题后面的选项下划々)

\begin{tabular}{|c|c|c|c|c|c|}
\hline 题 目 & $\begin{array}{l}\text { 非常 } \\
\text { 符合 } \\
\end{array}$ & $\begin{array}{l}\text { 比较 } \\
\text { 符合 } \\
\end{array}$ & $\begin{array}{l}\text { 中 } \\
\text { 立 }\end{array}$ & $\begin{array}{c}\text { 不符 } \\
\text { 合 } \\
\end{array}$ & $\begin{array}{c}\text { 非常不 } \\
\text { 符合 } \\
\end{array}$ \\
\hline （1）学习时我经常自我分析和反思。 & & & & & \\
\hline (2) 所学的专业与目前工作关系很密切。 & & & & & \\
\hline (3) 所学知识对我的工作非常有用。 & & & & & \\
\hline （4）感觉不到进步，没有成就感。 & & & & & . \\
\hline (5) 总体而言，我对正在接受的网络学习很满意。 & & & & & \\
\hline （6）预计在不久的将来, 我的事业会有升迁。 & & & & & \\
\hline (7) 升迁与䇝现在的网络课程学习关系紧密。 & & & & & \\
\hline (8) 如果需要，我将来还会参加网络学习。 & & & & & \\
\hline
\end{tabular}


B7 您在网络学习中还有哪些问题或意见?

\section{第三部分：建议与方案}

C1 您觉得下列措施在多大程度上会有助于您进一步提高学习效率?

\begin{tabular}{|c|c|c|c|c|c|c|}
\hline \multicolumn{2}{|r|}{ 改进措施 } & $\begin{array}{l}\text { 非常 } \\
\text { 有效 }\end{array}$ & $\begin{array}{l}\text { 比较 } \\
\text { 右效 }\end{array}$ & $\begin{array}{c}\text { 不确 } \\
\text { 定 }\end{array}$ & $\begin{array}{l}\text { 效果 } \\
\text { 有阳 }\end{array}$ & 没效果 \\
\hline (1) & 得到一定的免费机时与上网时间 & & & & & \\
\hline (2) & 得到操作计算机的培训 & & & & & \\
\hline (3) & 得到利用网络的培训 & & & & & \\
\hline$(4)$ & 得到更多的学习资源 & & & & & \\
\hline (5) & 课程导航更加明确 & & & & & \\
\hline$(6)$ & 得到时间管理技能的培训 & & & & & \\
\hline$(7)$ & 提高老师的教学水平 & & & & & \\
\hline$(8)$ & 增加老师的答疑时间 & & & & & \\
\hline$(9)$ & 得到老师的及时反馈 & & & & & \\
\hline$(10)$ & 得到教辅人员的及时反馈 & & & & & \\
\hline (11) & 增加与老师交流的时间 & & & & & \\
\hline$(12)$ & 有机会和同学更芕交流 & & & & & \\
\hline$(13)$ & 得到领导更多的支持 & & & & & \\
\hline (14) & 得到家人和朋友更多的支持 & & & & & \\
\hline (15) & 有更多的实验或者实习机会 & & & & & \\
\hline
\end{tabular}

$\mathrm{C} 2$ 请提出您希望进一步改进的建议。

问卷结束，谢谢您的宝贵时间与意见！ 


\section{Appendix 5: 学员访谈提纲}

亲爱的同学:

您好!

我正在做远程学习者网上学习障碍的研究。除了问卷调查外, 我需要做进一步 的访谈, 以便获取更多的研究信息。谢谢您的配合。我保证访谈所获信息只用于本 研究, 不会泄露您的隐私, 故不会对您个人造成任何不良影响。

1. 您参加继续学习的原因有哪些? 您选择网络教育的原因是什么? 您认为大多数 学生选择网络教育的原因是什么? 您认为网络教育文凭的社会认可度如何?

2. 倊习惯在网上学习吗? 您的学习基础和教育背景可以应对现在的学习吗?

3. 您每周大概学习多长时间? 其中上网学习多长时间?

4. 您感觉网络学习费用的支出对您构成经济负担吗?

5. 您的计算机应用技能如何?

6. 您在学习中感到孤独吗? 您经常与教师和同学交流吗? 您经常在课程论坛上发 帖吗?

7. 您遇到问题怎么办? 老师的回复及时吗? 您满意吗?

8. 课程设罟、教材、网络课程、网络资源是否符合您的需要?

9. 教学课件质量如何? 其他学习资源的可获得性?

10. 您感觉现在的学习对您有用吗?

11. 还有哪些因素导致您不能在网上高效地学习?

12. 如果需要, 您将来还会参加网络课程的学习吗?

13. 与其他远程教育机构相比，您认为 $\mathrm{O}$ 远程教育机构有哪些优势和不足? 您希望 得到哪些方面的帮助? 


\section{Appendix 6: 专家访谈提纲}

您好:

我现在正在做远程学习者网上学习障碍的研究, 前期已经做了大量的文献调研, 并结合学生访谈设计了一份远程学习者网上学习障碍的调查问卷初稿。不过, 我还 希望得到您的指导和帮助。我希望有机会访谈您。我相信您的专业经验和洞见会帮 我提高这个研究的质量。谢谢!

1. 您认为网络教育得到社会的认可度如何? 您认为大多数学生选择网络教育的原 因是什么?

2. 您认为的 “学习哖碍” 指哪些方面？我们应该怎么界定?

3. 您认为目前网络教育中阻碍学生学习的主要障碍有哪些? 您怎样对这些障碍进 行分类? 可分为哪几类? 您认为哪些最重要?

4. 学习者特征对学习障碍的影响或二者的关系?人口统计学变量、心理学变㽢应 该包括哪些?

5. 您对减少障碍有什么建议?

6. 您对我的这个研究还有什么建议?

7. 您认为本研究的研究方法应该怎样突破? 本砳究怎样才能有创新? 


\section{Appendix 7}

Factors and Factors' Load of Questionnaire on Barriers to Online Learning of Distance Learners

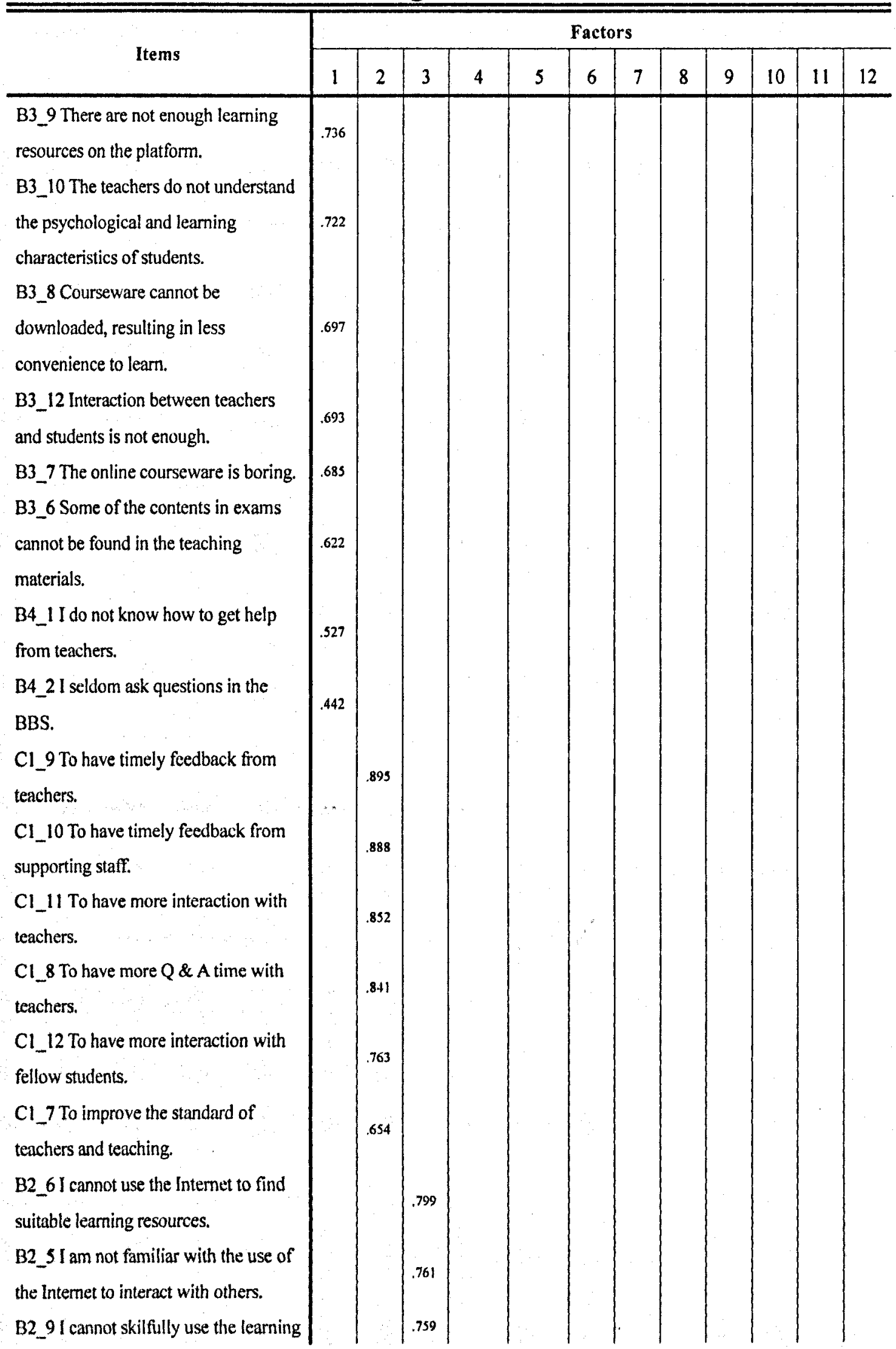


platform.

B2_4 My computer operation skills are insufficient.

B2_ 7 The learning platform navigation is not clear enough.

B2_8 It is troublesome to use the learning platform.

A7_7 I study more than two hours per day.

A7_8 I guarantee to get enough learning time every week.

A7_5 I can develop a learning plan and carry it out accordingly.

A7_9 I am able to study continuously for more than three hours.

A7_6I am very confident in learning. A7_4 My education background enables me to cope with my present studies.

B6_1 I often do self-analysis and reflection in my study.

B5 4 I feel lonely when I study.

B5_3 I feel at a loss when I study. B5_6 I am very keen to have more interaction with teachers.

B5_2 It has a great impact to my study that I have little chance to learn under teachers' supervision.

B5_1 It has a great impact to my study that I have little chance to learn with fellow students together.

B5_5 I am very keen to have more interaction with fellow students. A7_10 I prefer to study following the teachers' guidance.

B3_4 Teaching Materials are not suitable for adult leaming.

B3_2 I am not interested in the courses that are offered.

B3_1 Leaming content does not meet my needs.

B3 5 Examinations are not suitable for

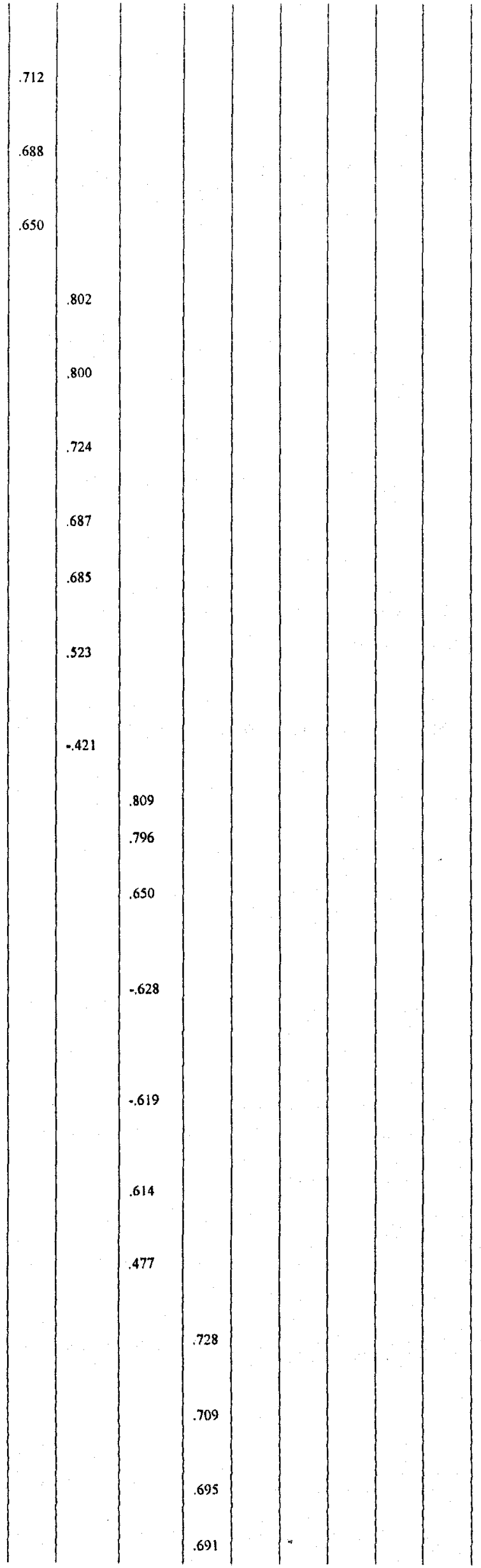


adult learners.

B3_3 Course content is too much and becomes a burden for me.

B4_ 4 I am not satisfied with the services provided by the learning centres.

B4_3 The teachers in learning centres are impatient.

B4 5 The tutors cannot answer the leamers' questions in time.

B4 6 The tutors' answers to the learners' questions are not profound. B3_11 The instructors lack professional knowledge.

B6_6 I expect to be promoted in a near future.

B6_7 My promotion would have a close relationship with my current online learning.

B6_8 If necessary, I will participate in online learning again in the future.

B6_ 5 I am very satisfied with this online form of study.

B2_I I do not have a computer. B2_2 I do not have a computer, making it very inconvenient for my studies.

B2_ 3 I cannot access the Internet corveniently.

B1_3 My boss does not support my studies.

B1_2 The Intemet fees are too expensive.

Bl_ $4 \mathrm{My}$ family and friends do not support my study.

B1_ I The tuition fee is too high and it has become a serious financial burden to me. Cl_2 To receive computer operation skills training.

Cl_ 3 To receive the Internet usage training.

Cl 1 To receive some free access 
Internet hours.

A7_3 My family is very harmonious.

A7_1 I am in good health.

A7_2 I have social activities every week.

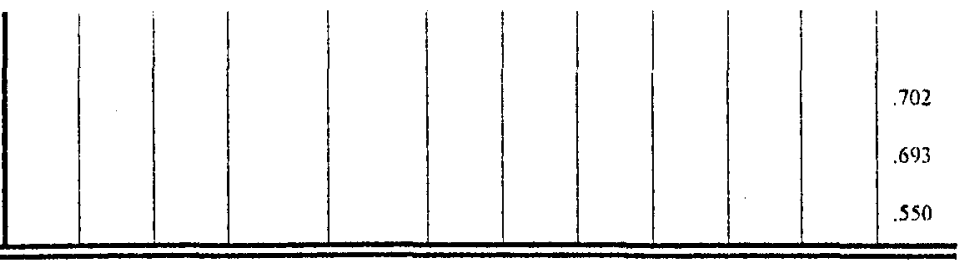

Note: In consideration of layout, not all the items are listed in the chart. Please find the details of questionnaire in Appendix 1. 


\section{References}

\section{English References}

1. Andy, Field, (2005). Discovering Statistics Using SPSS, second edition. SAGE Publications.

2. Atack, L., and Rankin, J. (2002). A Descriptive Study of Registered Nurses' Experiences with Web-based Learning. Journal of Advanced Nursing. 40(4):457-465.

3. Bassi, L. (1994). Workplace Education for Hourly Workers. Journal of Policy Analysis and Management. 13 (1): 55-75.

4. Becker, G. S. (1964). Human Capital: A Theoretical and Empirical Analysis, with Special Reference to Education. New York: Columbia University Press.

5. Berge, Z. L., Muilenburg, L. Y., and Haneghan V. J. (2002). Barriers to Distance Education and Training: Survey Results. Quarterly Review of Distance Education. 3(4): 409-418.

6. Bemard, R. L. (2001). Enhancing Interaction in Web-based Courses: Instructional Strategies. University of Wyoming, Ed.D thesis.

7. Buerkle, K. (2002). What Do You Know, Who Do You Know? School as a Site for the Production of Social Capital and Its Effects on Income Attainment in Poland and the Czech Republic. American Journal of Economics and Sociology. 61(3): 657-80.

8. Carnoy, M. (1995). Joint Production of Education. In Carnoy, M. (Ed.), International Encyclopedia of Economics of Education (Second edition). Oxford: Pergamon Press and Elsevier Science. 297-302.

9. Castles, J. (2004). Persistence and the Adult Learner: Factors Affecting Persistence in Open University Students. Active Learning in Higher Education. 5(2): 166-179.

10. Cegles, K. A. (1998). Emerging Issues Affecting Distance Education Research and Practice in Higher Education: A Global Futures Perspective. Pennsylvania State University, Ed.D thesis.

11. Chan, M. and Waugh. R. (2007) Factors Affecting Student Participation in the Online Learning Environment at the Open University of Hong Kong. Journal of Distance Education 21(3): 23-38

12. Chyung Y (2001). Systemic and Systematic Approaches to Reducing Attrition Rates in Online Higher Education. American Journal of Distance Education. 15(3): 36-49.

13. Collins, J. (2004). Educational Techniques for Lifelong Learning, Principles of Adult Learning. Radio Graphics. 24:1483-1489.

14. Dettmer, P. (1986). Characteristics and Needs of Adult Learners in Gifted Program, In-service and Staff Development. Gifted Child Quarterly. 30(3): 131-134.

15. Diwakar, V., Ertmer, P. A., Nour Y. M. (2003). Developing Interactive Course Web Sites for Distance Education and Characteristics of Students Enrolled in Distance Learning Courses. Information and Technology Approaches to Veterinary Education. 30(4): 351- 
357.

16. Eccles J. S., Adler T, and Meece, J. L (1984). Sex Differences in Achievement: A Test of Alternate Theories. Journal of Personality and Social Psychology. 46: 26-43

17. Morris L. V., Wu S S and Finnegan C. L. (2005). Predicting Retention in Online General Education Courses. American Journal of Distance Education. 19(1): 23-36.

18. Gronau, R. (1977). Leisure, Home Production and Work--The Theory of the Allocation of Time Revisited. Journal of Public Economics. 85(6): 1099-1124.

19. Hanushek, E. A. (1995). Education Production Functions. In: Carnoy, M. (Ed.), International Encyclopedia of Economics of Education (Second edition). Oxford: Pergamon Press and Elsevier Science. 277-281.

20. Garland, M. R. (1993). Student Perception of the Situational, Institutional, Dispositional and Epistemological Barriers to Persistence. Distance Education. 14(2): 181-198.

21. Hammersley, M. (1992). What's Wrong with Ethnography, Methodological Exploration? London: Routledge.

22. Kearney, K. E (1985). Bachelor of Independent Studies, External Degree Program, University of South Florida 1969-84: Learner Characteristics and Outcomes. Innovative Higher Education. 10(1): 66-76.

23. Leibowitz, A. (1974). Home Investments in Children. Journal of Political Economy. 82(2): S111-S131.

24. Leibowitz, A. (1977), Parental Inputs and Children's Achievement. Journal of Human Resources. 12: 242-251.

25. Litchfield, R. E. (2000). Implementation and Evaluation of Interactive Online Instruction in the Dietetic Internship. Iowa State University, PhD thesis.

26. Livneh, C. (1988). Characteristics of Lifelong Learners in the Human Service Professions. Adult Education Quarterly. 38: 149-159.

27. Loeffler, C. A. (2005). The Relationship of Adult Learning Styles and Perceived Factors involved in Online Graduate Education Leadership Programs. Sam Houston State University, Doctoral dissertation.

28. Merrill, P.F., Hammons, I S., Tolman, M. N., Christensen, L., Vincent, B.R., and Reynolds, P. L. (1992). Computers in Education, 2nd ed. Needham Heights: MA, Allyn and Bacon.

29. Muilenburg, L., and Berge, Z L. (2001). Barriers to Distance Education: A Factor-Analytic Study. American Journal of Distance Education. 15(2): 7-22.

30. Muilenburg, L., and Berge, Z L. (2005). Student Barriers to Online Learning: A factor analytic study. Distance Education. 26(1): 29-48.

31. Mungania, P. (2004). Employees' Perceptions of Barriers in E-learning: The Relationship among Barriers, Demographics, and E-learning Self-efficacy. University of Louisville, Ph.D. dissertation.

32. Payne, D. A., and Johnson, J. M. (2005). Succeeding in Graduate School Online: Tips from successful students. College Student Journal, 39(1), 117-128.

33. Porter, P., and Strum, M. (2006). Crossing the Great Divides: Distance Delivery and Flexible Delivery in Adult Basic Education. Available at http://www.distance.alphaplus.ca/pdfs/CrossingTheGreatDividesFullRpt.pdf

34. Rezabek, R. (1999). Barriers to Distance Education Enrollment. Presented at 
Tele-Learning Conference. October. Austin, TX.

35. Robles, R. (2006). Learner Characteristic, Interaction and Support Service Variables as Predictors of Satisfaction in Web-based Distance Education. The University of New Mexico, PhD Dissertation.

36. Pickett, M. C. (2009) Overcoming Technology Barriers In Adult Online Learning Environments With Modular Instructional Design. ASBBS Annual Conference: Las Vegas.

37. Pimplapure, A. (1996). Virtual Groups: A Web-Based Electronic Conferencing System for Online Education. Simon Fraser University, M.Sc. Thesis.

38. Schilke, R. A., (2001). A Case Study of Attrition in Web-Based Instruction for Adults: Updating Garland's Model of Barriers to Persistence in Distance Education. Northern Illinois University, EdD dissertation.

39. Stanton-Salazar, R., and Dornbusch, S. (1996). Social Capital and the Reproduction of Inequality: Information Networks among Mexican-Origin High School Students. Sociology of Education. 68(2):116-135.

40. Schrum, L., and Hong, S. J. (2002) .From the Field: Characteristics of Successful Tertiary Online Students and Strategies of Experienced Online Educators. Education and Information Technologies. 7(1): 5-16.

41. Shipp T., and Mckenzie, L. R. (1981). Adult Learners and Non- Learners Demographic Characteristics as an Indicator. Adult Education. 31(4): 187-198.

42. Stewart, C. K. (2006). The Influence of Learning Style on Student Satisfaction in Online Versus Traditional Learning Environments. University of Louisville, Doctoral dissertation.

43. Trow, M. (1973) Problems in the Transition from Elite to Mass Higher Education. In OECD Policies for Higher Education: 51-104.

44. Vogel, S. A. (1990). Gender Differences In Intelligence, Language, Visual-Motor Abilities, And Academic Achievement In Students With Learning Disabilities: A Review Of The Literature. Journal of Learning Disabilities. 23(11): 44-52.

45. Walker, E A. (1999). Characteristics of the Adult Learner. The Diabetes Educator. 25: 16-24.

46. Walters P B. (2006). The Limits of Growth: School Expansion and School Reform in Historical Perspective. In: Hallinan, T. M. (ed.). Handbook of the Sociology of Education. Sottcover, 241-261.

47. Young S. (2006). Student Views of Effective Online Teaching in Higher Education. American Journal of Distance Education, 20(2), 65-77.

48. Zimmer, R. W., and Toma, E. F. (2000). Peer Effects In Private And Public Schools Across Countries. Journal of Policy Analysis and Management. 19: 75-92.

49. Kolb, D. A. (1984). Experiential Learning: Experience as the Source of Learning and Development. New Jersey: Prentice-Hall. 


\section{Chinese References}

1. Bai, J., and Ge, S. F. (2004). The Analysis about Barriers of Web-Learning. Modern Educational Technology. 14(6): 25-27.

2. Bao, W. (2007). The Fund-Raising Mechanism of Higher Education in China after the Rapid Expansion. Education Development Research, 2007(Z1):63-68.

3. Chen, G. (2005). Research on the University Students' learning characteristics of the network capacity-building strategy" project report. Beijing Jiaotong University.

4. Cao, W., Wang, T., and Tang, J. L. (2005). An Investigation Report on English Major Students in E-learning of China's Higher Education Institutions. China Distance Education. 2005(12): 39-44.

5. Cao, X., Yue, C. J. (2010). Literature Review of Gender Gap in Chinese College Graduates' Employment. Educational Academic Journals. Issue 2, 2010.

6. Chen, X. M. (2000). Qualitative Research Methods and Social Science Research. Beijing: Educational Science Press.

7. Chen, X. M. (2005). How to Use a Qualitative Approach in Educational Action Research. Basic Education Curriculum. 2005 (4): 25-30.

8. Cheng, G. (2006). A Review on the Studies of Scale and Scope Economies of Higher Education. Journal of Technology College Education. 25(5): 5-10.

9. Du, C. Q. (2004). Gender and the Relationship between Academic and Study of English. Social Sciences Review. 19(1): 127-128.

10. Fan, M. C. (2011). Gender Differences in Choosing Major of Today's Chinese Undergraduates. Changchun: Modern Educational Science (Higher Education Research). Issue 2, p56-60.

11. Hu, A. G, Xiong, Y. Z. (2000). An Analysis of Area Gaps in China's Knowledge development: their Characteristics, Roots thereof, and our Policies. Management World. 2000(3): 5-17

12. Jiang, C. F., Wei, Z. H., and Shi, S.E. (2004). Barriers to e-Learning: Literature Review and Analysis. China Distance Education. 2003(11): 32-35.

13. Jiang, G. Z., Zhang, W. Y., and Kuang, G. Q. (2004). Investigation and Analysis on the Support for Remote Learning Methods: Case Study of Radio and Television University. E-education Research. 2004(5): 54-58.

14. Kong, L. (2009). Online Learning Barriers of Old Adults: A Qualitative Case Study. Beijing Normal University, Master thesis.

15. Leng, P, Wang, R. R., and Diao, Y. F (2005). Analysis of Learning Success Factors. China Edu Info. 2005(3): 63-64

16. Li, P., Yu, H., and Li, Q. (2006). Modern Distance Education Mode Characteristics of Adult Learning. Journal of Yibin University. 2006(12): 3-6

17. Li, W. G. (2007). The Survey and Analysis of Adult Network of Guangdong Higher Education. Journal of Higher Correspondence Education (Philosophy and Social Sciences). 2007(1): 43-46

18. Liu, B. Y. (2003). The Related Research on Sex-Role Identity and Academic Performance 
of Junior High School Students. Liaoning Normal University, Master thesis.

19. Ma, W. H. (2002). Analysis on Teaching Quality of Institutions of Higher Learning after Enrollment Expansion. Journal of Higher Education. 23(5):69-74.

20. She, C. J., Li, W. L, and Chen, B. (2007). The Survey Analysis of Hangzhou Normal College Student Learning. Vocational Higher Education Research. 2007(14): 20-23.

21. Shi, Y. (2007). An Analysis of Adult Education Learners Needs. China's Vocational and Technical Education. 2007(9):13-14.

22. Tan, Y. F. (2012). Distribution Characteristics of Gender Wage Gap for Graduates in China: 'Glass Ceiling Effect' or 'Sticky Floor Effect'? POPULATION JOURNAL, No. 6, 2012 ( Tot. No. 196), p51-63.

23. Tao, F. X. (2004). The Major Difficulties and Countermeasures of Distance Learners. Modern Distance Education. 2004(5): 26-28.

24. Wang, H. J. and Zhang, H. Y. (2005). A Survey Report on Self-regulated Learning ability of Web-based Learners. Modern Educational Technology. 2005(1): 33-36.

25. Wang, J. J., Ma, X. R., He, J. F. (2007). The Investigation and Research of Lack of the Emotional Issue in the Modern Distance Education. Research on Private Higher Education. 4(1): 12-14

26. Wang, P. (2006). Language Learning Strategies of Distance Learners. Open Education Research. 2006(1): 88-91

27. Wang, X. M. (2006). Investigations on the Open Education Adult Learner English learning motivation types. Journal of Higher Education Research. 2006(9): 90-93.

28. Wu, L. (2002). Gender differences in academic high school students and educational countermeasures. Southwest China Normal University, Master thesis.

29. Xu, L. L. (2004). The Investigation and Analysis of Learners Needs in Shihezi RTVU. Journal of Xinjiang RTVU. 2006(4): 16-21

30. Yu Jianying, He Xuhong, (2003). Statistical Data Analysis and Applications of SPSS. Posts and Telecom Press.

31. Zeng Wuyi and Huang Bingyi, (2005). Analysis on the Reliability and Validity of Questionnaire. Statistics and Information Forum, Vol. 20, No. 6, Nov., 2005, p11-15.

32. Zhang, D. M. (2004). A Strategy Research on the Motivation in Network Learning. Shanxi Normal University, Master thesis.

33. Zhang, S. B. (2003). The Investigation Report of the Main Conditions for Learning of Open Education Study. China Distance Education. 2003(7): 38-41.

34. Zhang, W. Y., Li, J. P., and Peng, X. J. (2002). Survey and Analysis of Undergraduate students in open education e-learning. China Distance Education. 2002(9): 41-45.

35. Zhang, W. Y., and Hu, J. (2002). A Survey Report on Characteristics and Obstacles of Distance Learners In the Northwest Areas. China Distance Education. 2002(4): 10-14.

36. Zhang, W. Y., and Huang, H. X. (2003). Barriers and Preference of Online Learning: Student Perception in Shanghai. Open Education Research. 2003(2):30-33.

37. Zhang, X. L, and Chen, L. (2006). Information Seeking Behaviour on the Internet of College Students. Journal of Mudanjiang College of Education. 2006(6): 102-103.

38. Zhao, P. Y. (2002). An Analysis of the Factors Affecting Students' Distance Learning. China Distance Education. 2002(8): 50-52 
39. Zheng, X. Q., and Dong, D. J. (2002). Phenomenon of Getting Lost in Networks within University Students. Journal of Beijing University of Aeronautics and Astronautics (Social Sciences Edition). 15(3): 46-50.

40. National Bureau of Statistics of China. (2007). China Statistical Yearbook. Beijing: China Statistics Press.

41. National Bureau of Statistics of China. (2008). China Statistical Yearbook. Beijing: China Statistics Press.

42. Zhuang, R. X., and Wang, Y. (2006). Consideration on Learning Adaptation for Adult Learners in Distance Learning. Distance Education in China. 2006(5): 16-19.

43. James C Taylor (2002). Teaching and Learning Online: The Workers, The Lurkers and Shirkers. Distance Education in China, No. 9, 2002, p31-37. 